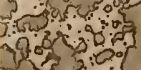

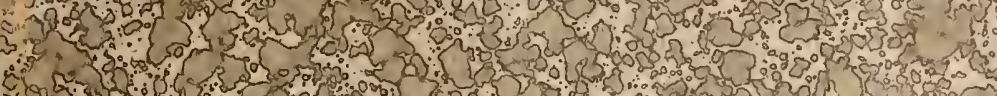

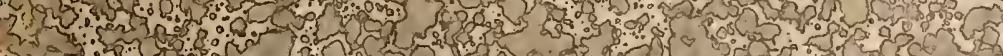

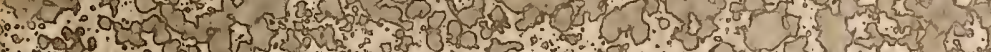

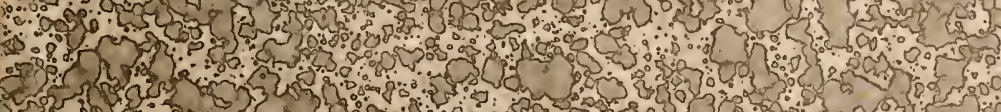
J3

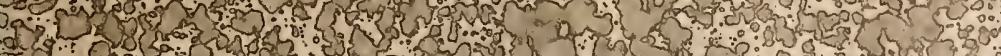

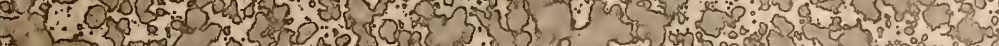

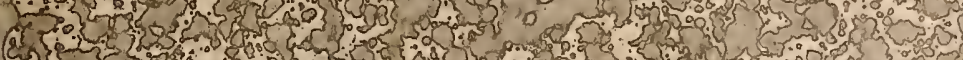

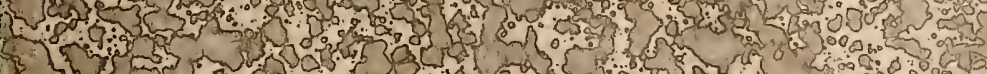

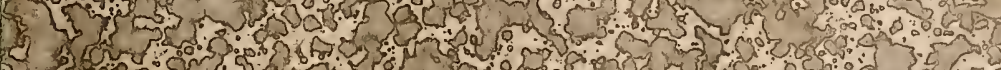
2. if 3 (5)

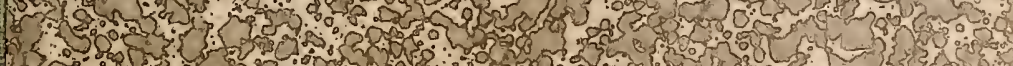

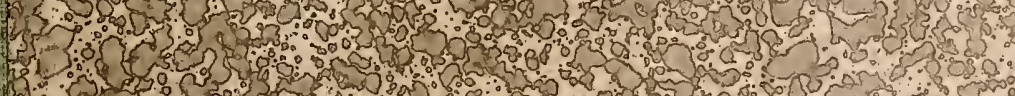

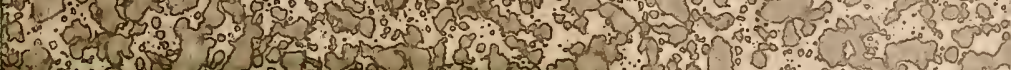

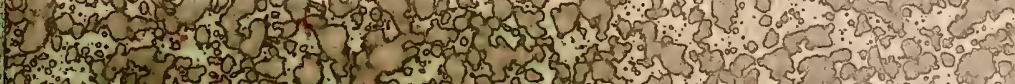
1 (5)

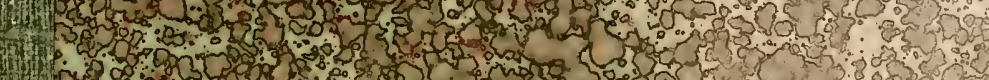

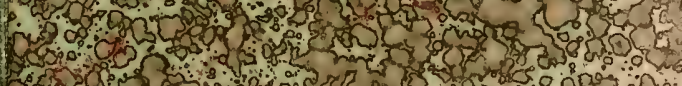

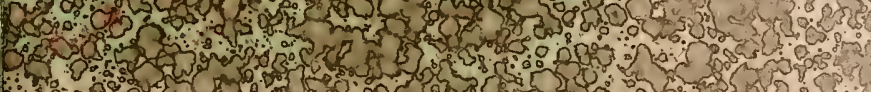

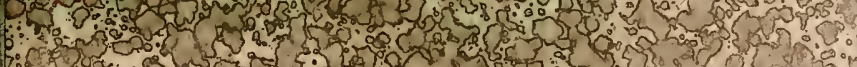
$7:$.

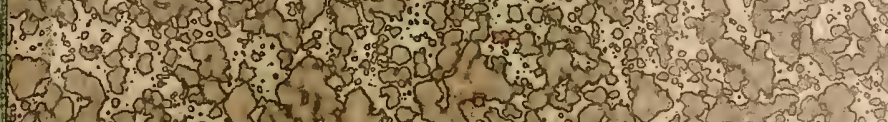

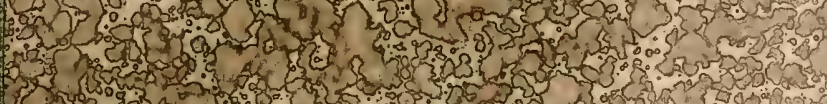

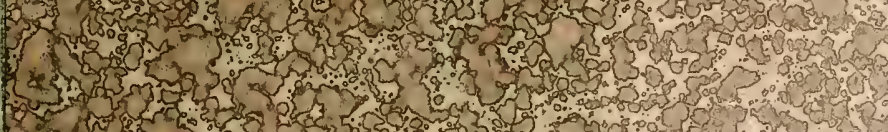

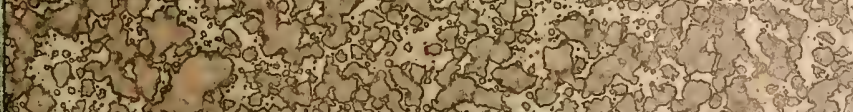

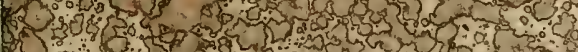

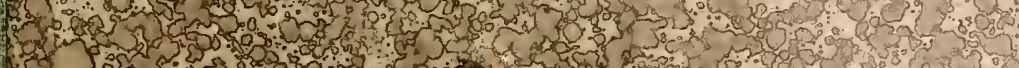

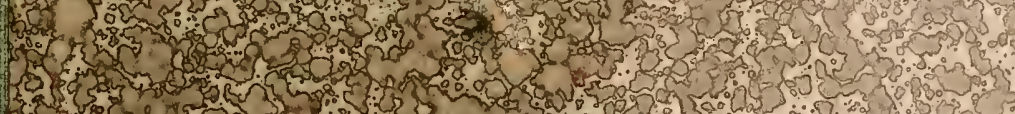

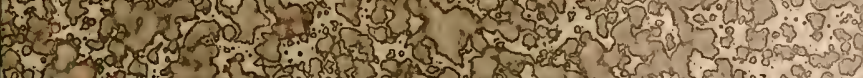

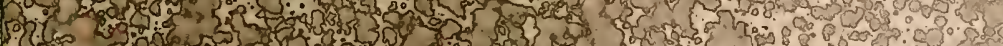
3.

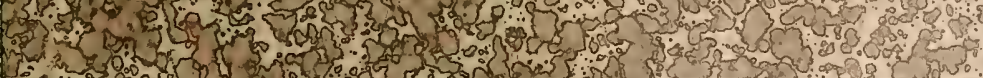
10.

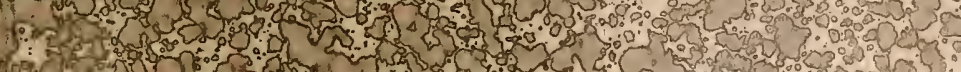

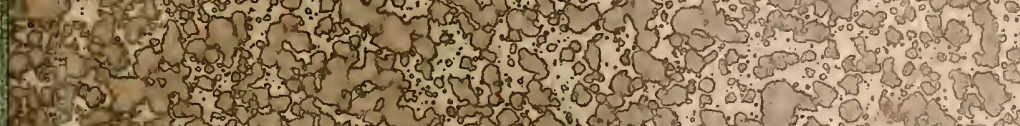
450 . 320 स 


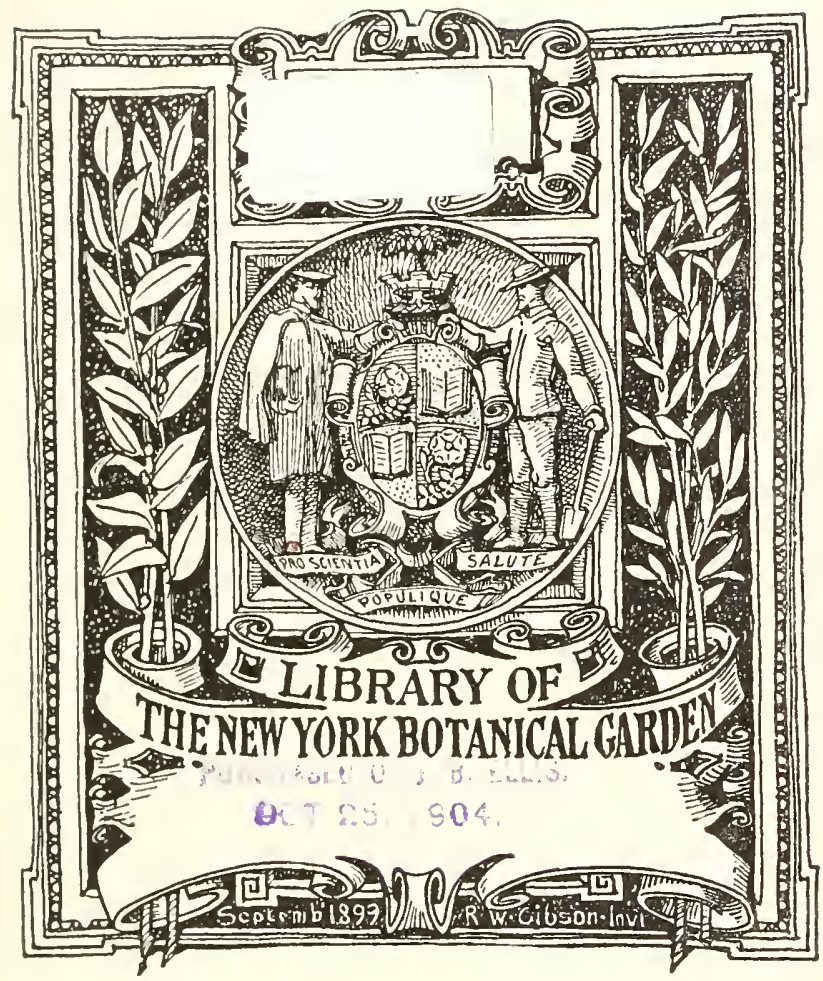







$$
\text { - }
$$




\title{
DIE
}

\section{PILZE DES WEINSTOCKES.}

\author{
MONOGRAPHISCHE BEARBEITUNG
}

DER SIIMITLICHEN BISHER BEKANNTEN, AUF DEN ARTEN

DER GATTUNG VITIS LIN. VORKOMMENDEN

PILZE.

$\operatorname{VON}$

\section{FELIX vON,THÜMEN}

K. K. ADJUNCT DER CHEMISCH-PHYSIOLOGISCHEN VERSUCHSSTATION ZU KLOSTERNEUBURG BET WIEN, VIELER GELEIIRTEN GESELLSCHAFTEN DES IN- UND AUSLANDES MITGLIED.

MIT 5 LITHOGRAPHIRTEN TAFELN.

\section{LIBRARY NEW YORK BOTANKAL GARDEN}

\section{WIEN, 1878.}

W I L H E L M B R A U M Ü L L, E R 
Alle Reclite vorbehalten. 
SEINER EXCELLENZ

LIBRARY

NEW YORK

DEM HOCHGEBORNEN HERRN BOTANKAL

GARDEN

\section{HIERONYMUS GRAFEN ZU MANNSFELI)}

K. K. ACKERBAUMINISTER

EIIRERBIE'IGS'T GENIHME'

VOM

VERFASSER. 

..... le mienx est l'ennemi du hien. Voltaire (La Bégueule).

Das Studium der Mykologie auf streng wissenschaftlicher Basis ist noch verhältnissmässig jung. Zu Anfang museres Jahrhunderts noch beschränkte man sich darauf, die Pilze lediglich nach ihren äusseren, makroskopiseh wahrnehmbaren, Kennzeichen zu beschreiben und zu classificiren, und erst in den Zwranziger Jahren begannen Elias Fries und Link auch auf die, mit dem damals noch äusserst unvollkommenen Mikroskope erkennbaren, Merkmale gegrïudet einer mehr wissensehaftlichen Behandlung des Materials Bahn zu brechen. Das Studium der grossen Pilze, der eigentlichen "Schwämme" par excellence, zu deren morphologischer und systematischer Untersuchung in den meisten Fïllen die Loupe geniigt, und wo das Mikroskop keine so grosse Rolle spielt, war denn auch bald, namentlich Dank dem unermïdlichen Fleisse und der hohen Begabung Fries' demjenigen der niederen Formen weit rorausgeeilt, so dass beispielsweise die Capitel in der 1844 erschienenen "Deutschlands Kryptogamen-Flora" von L. Rabenhorst, welehe die Hymenomyceten behandeln, noch heute ihren hohen Werth besitzen, während die iibrigen $\mathrm{Ab}$ sehnitte, die niederen Formen enthaltend, für den jetzigen Standpunkt der Wissensehaft absolut werthlos und unbrauchbar geworden sind.

Da war es abermals Fries, dieser Heros der Mykologie, welcher in seiner, im Jahre 1849 herausgegebenen "Summa vegetabilium Scandinaviae" zuerst für alle Ordnungen des Pilz- 
reiches ein, auf wissenschaftlich mikroskopische Grundlagen aufgebautes System schuf, und dieses System ist heutigen Tages noch, wenn auch natiirlich mit mancherlei Abänderungen und Verbesserungen, das allgemein giltige. Ton dem Erscheinen dieses Werkes an, das ist also circa ein Viertel-Jahrhundert, datirt das neueste Stadium der mykologischen Forschung, das Stadium der bedingungslosen Ierrschaft des Mikroskopes. Der anatomische Bau, die morphologischen Verhältnisse und vor allen der Bau und die Entwickelung der Frucht, das sind die massgebenden Factoren, und damit ist denn die Mykologie endlich auch da angelangt, wo die anderen Zweige der Botanik schon lange stehen, und den man mit dem Apostel Matthäus bezeichnen könnte, als „an ihren Frïchten sollt ihr sie erkennen!“"

Auf dem, von Altvater Fries (welchem das hohe Gliick beschieden war, wie vor ilım noch Kicinem, am sechzigsten Jahrestage des Erscheinens seines ersten mykologischen Werkes in ungeschwächter Geisteskraft sein grösstes und wichtigstes Werk, die "Hymenomycetes europaei" abzuschliessen) begonnenen Pfade ward nun riistig fortgeschritten und die Namen De Bary, De Notaris, Berkeley, Tulasne und Anderer glänzen als hellleuchtende Sterne an Himmel unserer Wissenschaft!

Wenn nun also die Mykologie selbst, wie aus Vorstehendem ersichtlich ist, im streng wissenschaftlichen Sime so jungen Datums ist, um wie viel mehr muss diess der Fall sein bei der angewandten Mykologie, bei der Kenntniss und Erkenntniss des Einflusses, welchen die Pilze auf die übrige organische Natur ausiiben. Fast alle Entrleckungen auf diesem Gobiete sind neuen und nenesten Datums und doch sind uns ganz sicherlich nur erst Bruchstiicke von den gewaltigen Wirkungen bekannt, welche die Pilze geradezu in jeder Bezichung auf Menschen, Thiere und Pflanzen ausïben. Unzählige Krankheiten der organischen Wesen hat die Pathologie bereits auf Pilze zurïckzuführen vermocht und tïglich, kïnnte man sagen, werden neue, ïberraschende Entdeckungen auf diesem Gebicte zu 'lage gefördert. 
Die Krankheiten der Phanzen, insofern dieselben durch pilzliche Organismen verursacht werden, lenkten sehon seit langer Zeit die Aufmerksamkeit von Forschern und Laien auf sich, es ist aber nur zu erklairlich, wie die Resultate bei dem niederen Standpunkte der Wissenschaft im Allgemeinen gerade hier nur die allerdiurftigsten sein konnten. Erst seit dem Erwachen des strengen Studiums iiberhaupt, wurden auch auf diesem Gebiete erfolgreiche Untersuchungen angestellt und hier war es $\mathrm{K}$ iihn, welcher in seinen "Kranklieiten der Culturgewäichse", welche 1859 erschienen, als epochemachender Bahnbrecher auftrat. $\mathrm{Zu}$ allererst stellte dieser Forscher aus dem Wust von einzehnen Untersuchungen und Beobachtungen ein abgerundetes Ganzes her, welches die pilzlichen Krankheiten der Pflanzen nach allen Seiten hin belenchtete, ihre tiefeingreifende Wirkung anf das Wohl und Wehe unserer wichtigsten Cnlturgewächse darlegte und eine solehe Fiille von nenen Erfahrungen brachte, dass man mit Fug und Recht den Tag des Erscheinens dieses Werkes als den eigentlichen Geburtstag der Pflanzen-Pathologie betrachten kann.

Achtzehn Jahre aber sind seitdem verstrichen, achtzehn Jahre des regsten Forschens anf diesem, wie auf allen anderen Feldern der menschlichen Geistesarbeit, und das Material, welehes Kähn in seinem lierrlichen Werke bearbeitete, hat eine solehe Ausdehnung, eine solche Vermehrung erfahren, dass es schon kaum mehr möglich ist, dasselbe vollständig zu beherrschen, Beweis dessen, dass sich noch Niemand wieder den Muth zugetraut hat, ein ähnliches Werk, wie das Kühn'sche zu bearbeiten, denn die kaum bewältigbaren Schwierigkeiten müssen Jeden zuriickschrecken; ist doeh der einzige, in dieser Hinsicht unternommene Versuch nichts weniger wie als gelungen zu bezeichnen!

Wir leben jetzt im Zeitalter der Theilung der Arbeit, das "Divide et impera" ist das allgemeine Motto und wie anf allen anderen Gebieten, so diirfte es sich auch auf dem Gebiete.der 
Pflanzen-Pathologie bewähren. Diese Ansicht war die maassgebende bei Abfassung rorliegenden Werkes. Es ist der erste Versuch, welcher unternommen wird, die pilzlichen Feinde einer einzelnen unserer Culturpflanzen erschöpfend zu bearbeiten und eben aus diesem Grunde besonders, wird er, wie ja alles menschliche Wissen und Können, nur Stückwerk sein.

Kein Zweig der Botanik, ja der beschreibenden Naturwissensehaften überhaupt, ist so sehwierig zu beherrschen, als die Mykologie, nirgends ist die Literatur eine so zerstreute wie hier, nirgends macht das Fehlen eines, das Gesammtgebiet umfassenden Werkes sich so fühlbar wie in diesem Falle. Aus hunderten von Büchern und Brochuren, von einzelnen Abhandlungen und JournalArtikeln muss mit grösstem Zeit- und Miihe-Aufwand das Nöthige zusammengesucht werden. Es ist aus diesem Grunde also nicht nur wahrscheinlich, sondern wohl gewiss, dass das Fine oder das Andere ïbersehen und ausgelassen ward - trotz aller aufgewendeten Mïhe ist nichts Vollkommenes gesehaffen worden. Das an der Spitze gegebene Motto aber "das Bessere ist des Guten Feind", gibt mir den Muth, vor die Oeffentlichkeit zu treten und getrost mein Werk dem Publicum zn ubergeben.

Was num den Plan für das Unternehmen anbelangt, so galt es vor Allem nach zwei Richtungen hin etwas abgeschlossen Ganzes zu bieten, zwei sehr verschiedene Classen von Lesern zufrieden zu stellen. Einmal musste der streng wissenschaftliehe Zweek des Buches im Auge behalten werden, weleher dem Gelehrten, dem Mykologen von Fach eine möglichst vollständige Uebersicht aller pilzlichen Organismen, welche auf den Arten der Gattumg Vitis bisher beobachtet wurden, ermögliehte. Es mussten dem Herkommen gemäss und auch besonders $u m$ das Buch anderen Nationen ebenfalls nutzbar zu machen, die Diagnosen sämmtlicher Arten in lateiniseher Sprache vorangeselickt werden und musste ferner eine, wenn auch nicht erschöpfende, so doch reiche, ansgewählte und genügende Angabe der einschlägigen literatur bei jeder Species erfolgen. 
Andererseits aber war es wieder nothwendig, anch fiir den Nichtfachmann, für den Laien eine möglichst genane und detaillirte Beschreibung alles Arten in gomeinverständlicher Sprache zu liefern, eine Beschreibung, welehe genigen muss, die Arten mit Zuhilfenahme des Mikroskops zu erkennen. Ohne ein solehes Instrument allerdings wird es niemals gelingen, einen Pilz sicher zu bestimmen und die, von den verschiedensten, Seiten aufgestellte Forderung, dass das Mikroskop nicht nur ein Hausgeräith des Landwirthes, sondern iiberhanpt eines jeden Gebildeten sein miisse, ist eine nur zu gerechtfertigte. Die Handhabung eines solchen Instruments fuir den täglichen Gebranch wird aber jetzt anch wohl sehon ausnahmslos auf allen Fachsehulen den jungen Lenten gelehrt and die Erkenntniss seiner Unentbehrlichkeit bricht sich immer allgemeiner Bahn, und so glaube ich denn zuversichtlich hoffen zu können, dass anch dieses Werkehen seinen Zweck erfüllen wird, und ein Jeder, welcher sich für die Krankheiten des Weinstockes interessirt, mit seiner Hilfe und mit dem Mikroskop in der Hand, in das verborgene Leben dieser kleinen (1rganismen eindringen wird. 'Zu leichterer und sicherer Orientirung sind anch auf den beigegebenen 'Tafeh die Fructificationsorgane der meisten behandelten Arten abgebildet, so dass mit Beschreibung und Abbildung zusammen, kaum leicht ein Irrthum wird entstehen können. *)

Mit Ausnahme einiger kurzer Andeutungen iiber den, dureh die einzehnen Arten verursachten Schaden, habe ich es vermieden, auf die praktische Bedeutung, respective Verderblichkeit der Pilze mich einzulassen. Ich bezwecke gar nichts Anderes, als einen Leitfaden zu geben, nach welchem diese s'chädlinge erkannt werden können. Diese sichere Erkenntniss halte ich jetzt noch für das Wichtigste. Mögen auch einzelne verrannte Praktiker

*) Alle neu aufgestellten Species, sowie auch die meisten iibrigen, sind von mir mit 360facher Vergrösserung selbst gezeiclınet, nur einige wenige sind Copien aus dén Werken der angefïhrten Autoren. 
noch immer sagen: „es ist uns ganz gleichgiltig, wie dieser oder jener Pilz, wie dieses oder jenes Insect vou den Gelehrten genannt wird, wir geben ilım unseren Namen, es macht den und den Schaden, das genïgt vollkommen für uns Praktiker". Zum Gliick sind Lente mit solchen und ähnlichen Ansichten so ziemlich im Aussterben begriffen, die Erkenntniss des innigen Zusammenhanges von Wissenschaft und Praxis breitet sich immer mehr ans, gewinnt immer neue Anhïinger.

Wenn in spaiterer Zeit für eine grössere Reihe von Schädlingen erst die geeigneten Mittel zu ihrer Bekämpfung werden aufgefunden sein, dann wird es sich empfehlen, dieselben zusammengefasst, allgemeinverständlich, dem interessirten Publicum zu ïbergeben, fiir jetzt sind wir noch nicht so weit; sichere Mittel für diese oder jene Krankheit sind nur erst wenige bekamnt, und ich habe sie daher nicht ausfülılich behandelt. Mein Werkchen erhebt nicht den Anspruch ein Heilmittelbuch zu sein, es begnïgt sich damit, eine Beschreibung der Krankheiten zu liefern!

Theils 110 möglichst vollstiudig zu sein, theils aus dem Grunde, weil viele Pilze als Parasiten oder Bewohner lebender Pflanzentheile ihr Dasein beginnen und dasselbe als Saprophyten oder Bewohner todter Organe beschliessen, theils endlich weil viele, auf abgestorbenen Reben und Blättern anftretende Species besonders in die Augen fallen, sind in vorliegender Aufziihlung auch alle, mir irgend bekannt gewordenen Saprophyten der Vitis. Arten mit aufgenommen worden.

Dagegen habe ich mit Vorbedacht alle diejenigen Pilze ausgeschlossen, welche nur auf oder in Producten des Weinstockes vegetiren, also alle Gährungspilze, Bacterien 11. s. w. Das Stıdium dieser Pilze, das Verhältniss der einzelnen Arten zu einander, ist noch nicht vorgesehritten genug, $11 \mathrm{~m}$ etwas Abgesehlossenes zu bieten, ein Fortlassen derselben aus dieser Arbeit wird also gewiss nur gebilligt werden können.

Bei der Anordnung des reiehen, von mir bearbeiteten Materials, habe ich mich lediglich von praktischen Erwägungen leiten 
lassen, ich wollte es dem Nichtfachmanne erleichtern, die eine oder die andere Art, welche er gefunden hat und zu bestimmen wïnscht, aufzufinden. Aus diesem Grunde sind sämmtliche behandelte Arten, 220 an der Zahıl, zunächst in vier grosse Gruppen getleilt, nämlich die Pilze der 'T'rauben, des Stammes und der Rauken, der Blätter und endlich der Wuzehn. Jede dieser Gruppen bringt in ihrem ersten Abschnitte die Arten, welche auf lebenden, im zweiten Abschnitte diejenigen, welche auf todten Individuen auftreten. Kommt eine Species anf Organen vor, welehe in verschiedenen Gruppen untergebracht sind, so findet sich stets ein darauf beziiglicher Hinweis.

Die Pilze der, jetzt allerdings wohl nicht zum Nutzen der europäischen Weincultur, so vielfach angepriesenen amerikanischen Titis-Arten, sind, neben denen unseres gemeinen Weinstockes, ebenfalls in möglichster Vollstiindigkeit aufgefiihrt.

Die gewiss bedeutende Anzahl von 220 Species, welche hier, als auf den Arten der Gattung Titis vorkommend, aufgefiilurt werden, diurfte Viele iiberasehen. Sie liefert uns abermals einen Beweis der unendlichen Mannigfaltigkeit der uns umgebenden organisehen Natur, sie zeigt aber auch, von weleher Unzahl von Feinden unsere Culturen bedrolit werden. Wenn es mir gelang, das Auftreten von 220 Pilzarten auf den Titis-Arten nachzuweisen, so steht es fest, dass unsere anderen Cultupflanzen, deren Verbreitungsbezirk ja grösstentheils vicl bedentender ist, als der des Weinstockes, im Verhiiltniss gewiss ebenso viele beherbergen werden, von denen wir jetzt kaum einen Bruchtheil kennen. Um aber eine solche Kenntniss, deren Wichtigkeit in die Augen springt, nach Möglichkeit zu fördern, dazu bedarf es eines Zusammenwirkens Aller, und wird ein solches, wenigstens in Etwas gefördert, durch diese Blätter, so ist meine Arbeit eine tausendfach belohnte!

Zum Schluss endlich eribrigt mir nur noch die angenelume Pflicht, allen jenen Herren und Collegen, welche mich bei dieser schwierigen und mïhevollen Arbeit unterstiitzten, den herzlichsten 
und verbindlichsten Dank abzustatten. In allererster linie bin ich Herru Professor Cavaliere (t. Passerini, Director des königlichen botanischen Gartens zu Parma, verpflichtet, welcher nicht nur mir eine grosse Reihe von seltenen und theilweise auch neuen Arten mittheilte, sondern auch in schwierigen Fällen mich mit grösster Freundlichkeit durch Ratl und That unterstiitzte. Ferner den Herren C. Spegazzini zu Conegliano in Venetien, Professor P. A. Saccardo zu Padova, C. H. Peck, StateBotanist in Albany N. Y., J. B. Ellis in Newfield, N. J. und H. W. Ravenel in Aiken S. C., alle drei in Nord-Amerika, meinen aufrichtigen Dank für ihre Freundschaft und trene Collegialitait.

Klosterneuburg bei Wien, Mitte September 1877.

\section{Der Verfasser.}

\section{Nachschrift}

Als der Druck dieses Werkes bereits begonnen hatte, erhicht ich von Hern Dr. Romualdo Pirotta zu Pavia sein Werkchen: "I funghi parassiti dei Vitigni" zugesendet. Ich kam nunmehr also nicht, wie vorher gesagt, den Ruhm für mich in Anspruch nehmen, der Erste zu sein, welcher eine Monographie der Pilze einer bestimmten Culturpflanze verfasste. - Was jedoch den Inhalt der Pirotta'schen Publication anbelangt, so bringt dieselbe kaum den dritten Theil der von mir anfgeführten Species, ist also nichts weniger als vollständig. Soweit der vorschreitende Druck es gestattete, habe ich überall auch nachtrïglich noch auf Pirotta's Buch Rücksicht genommen, iibrigens enthielt dasselbe mu drei Species, welche in meinem Manuscript nicht enthalten waren! Auch habe ich selbstverstiindlich alle von mir bereits gegebenen Namen, sofern Pirotta diese Arten schon benannt hatte, wieder cassirt und die seinigen dafuir substituirt. 


\section{VERZEICHNISS DER ARTEN.}

(Nach dem System geordnet.)

\section{Peronosporei.}

1. Peronospora viticola De by.

\section{Mucorinei.}

1. Mucor stolonifer Ehrbg.

\section{Hyphomycetes.}

1. Acrostalagmus eimabarinus Cta.

$\therefore$ Arthobotryum atrum Berk. et Br.

3. Aspergillus glauens Lk.

4. Botrytis acinorum Pers.

5. , cinerea Pers.

6. Chaetostroma pedicellatum l'renss.

7. Chalara fusidioides Cda.

8. Cicinnobolus Cesatii De By.

9. Cireinotrichum maculaeforme $\mathrm{N}$. a. E.

10. Cladosporium ampelinum Pass.

11.,$\quad$ fasciculatum Cia.

12. " Fumago Ik,

13. , lierbarum Lk.

14., Roesleri Catt.

15. Dendryphium Passeriniannm Thüm.

16. Epochnium monilioides Lk.

17. Gonytrichum caesinm N. a. E

18. Gyrocerns Ammonis Cda.

19. Haplotrichum epiphyllum Rabh.
20. Helminthosporium decacuninatum Thiim. et l'ass.

21. Helminthosporinm siliqnosum Berk. et Curt.

22. Macrosporimm uvarum Thïm.

23. Oidium Tuckeri Berk.

24. Phymatostroma fusarioides Cda.

25. Pyrenotrichum Vitis Schnlzer.

26. Septocylindrium dissiliens Sace.

27. virens Sace.

28. Septosporium Fuckelii Thüm.

29. Spicnlaria Icterus Fuck.

30. Sporodum conopleoides Cdi.

31. Sporotrichum ahtacenm Schwz.

32. " ampelinum Thïm, et lass.

$33 . \quad, \quad$ aureum Fr.

34. $\quad$ viticolum schwz.

35. Trichothecinm candidum Wall.

$36 . \quad$ rosenm Lk.

\section{Gymnomycetes.}

1. Coryneum microstictum Berk. et Br.

2. Exosporium Badhami Awd.

3. Fusarium Cesatii Thüm.

4. n pampini Thüm, et Pass.

5..$\quad$ Roesleri Thüm.
6. Fusarium tortuosum Thiim. et Pass.

7. r viticolum Thüm.

8. Fusisporium Biasolettianum sace.

$9 . \quad$ Zaviaumm Sace.

10. Fusoma Vitis Schulzer 
11. Gloeosporium ampelophagum Sace. 12. sarmentitium Mntg.

13. Graphium cinerellum Spegaz.

14. r elavisporum Berk. et Curt.

15. Leptostroma sphaeroides Fr.

16. Periconia elılorocephala Fres.
17. Sporocybe byssoides Fr.

18. Tubercularia ampelophila Sace.

19. $"$ sarmentorum Fr.

20. " $"$ subdiaphana Sehwz.

21. Volutella pennicillata Schwz.

\section{Uredinei.}

1. Uredo Vitis Thiim.

\section{Tremellini.}

1. Dacryomyees viticola Schwz.

2. Ditiola sulcata Fr.

\section{Hymenomycetes.}

1. Agarieus hyemalis Osb.

2. " mellens Valıl.

3. " proteus Kalchl.

4. Auricularia mesenterica Pers.

5. Corticium albido-carneum Thiim.

6. $\rightarrow$ armeniacum Thü̈.

7. $n \quad$ calceum Fr.

8. $"$ crocicreas Berk. et Curt.

9. " hypopyrrhinum Berk. et Curt.

10. $"$ lactescens Berk.

11. " viticola $\mathrm{Fr}$.

12. Cyphella albo-violascens Karst.

13. " villosa Karst.
14. Lenzites atropurprurea Sace.

15. Marasmius calopus Fr.

16. $"$ candidus Fr.

17., epiphyllus Fr. var. sarmentorum 'T'liuim.

18. " viticola Berk. et Curt.

19. Merulius corium Fr.

20. Polyporus vaporarius Fr.var. papyraceus Schwz.

21. $"$ viticola Fr.

22. Stereum cristatum Berk. et Curt.

23.,$\quad L e v e i l l e ́ a n u m$ Berk. et Curt.

24. Xerotus viticola Berk. et Curt.

\section{Gasteromycetes.}

1. Lycoperdon giganteum Batsch.

\section{Discomycetes.}

1. Calloria vinosa Fr.

2. Cenangium viticolum Fuck.

3. Helotium hyalopes Fuck.

4. " pullatun Ger.

5. " sarmentorum De Not.

6. $"$ vitigenum De Not.

7. Hypoderma commune Duby.

8. $\rightarrow \quad$ Rubi De Not.

9. IJysterium australe Duby.

10. " Curtisii Duby.
11. Hysterographium flexuosum Rehm. 12. viticolum Rehm.

13. Lachnella macrochaeta spegaz.

14. Patellaria atro-fusca Berk. et Curt.

15. Peziza ascoboloidea Schwz.

16. " cinereo-fusca Scliwz.

17. " pennicillata Schwz.

18. " pruinata Schwz.

19. " tumida l'ers.

20. " viticola Pers. 
21. Peziza Vitis Schwz.

22. Pyrenopeziza Vitis Relim.

23. Propolis prominula Thün.

24. Rliytisma monogramme Berk. et Curt. 25. " Vitis Schwz.
26. Roesleria hypogaea Thiim. et I'ass. 27. Selerotinia Fuckeliana Fuck. 28. Stictis Saccardoi Rehm. 29. " uberrima Mutg.

\section{Pyrenomycetes.}

1. Acrospermum compressum Tode.

$2 . \quad " \quad$ Ravenelii Berk et Curt.

3. Amplisphaeria sylvana sace. et Spegaz.

4. Anthostomella limitata Sace.

5. Bertia Vitis Schlzr.

6. Botryosphaeria cyanogena Niessl.

7. Calosphaeria minima Tul.

8. Ceratostoma Schulzeri Pirotta.

9. $n \quad$ Vitis Fuck.

10. Cryptovalsa ampelina Fuck.

11. $\rightarrow$ Rabenhorstii Sace.

12. Cucurbitaria Vitis Schulzer.

13. Diaporthe viticola Nke.

14. Diatrype Vitis Berk.

15. Didymosphaeria bacchans Pass.

16. Dothidea myriococca Mntg.

17. " picea Berk, et Curt.

18. $"$ viticola Scliwz.

19. Erysiphe necator Schwz.

20. Eurotium herbariorum Lk.

21. Eutypa ludibunda Thïm.

22. Excipula viticola Schwz.

23. Gibbera Vitis Schlzr.

24. Leptosphaeria Cookei Pirotta.

25 .

Gibelliana Pirotta.

26.

n vinealis Pass.

27. appendiculata Pirotta.
28. Leptosphaeria Vitis Pirotta.

29. Lophiostona angustatum Fuck.

30. $"$ Hederae Fuck.

31. " sexnucleatum Cooke.

32. $"$ Thümenianum Spegazz.

33. Nectria cinnabarina Fr.

34. " viticola Berk. et Curt.

35. Pleospora coronata Niessl.

36. " phaeocomes Ces. et De Not.

37. Rebentischia appendiculosa Sacc.

38. Rhaphidospora sarmenti Pass.

39. Rosellinia lıorida HaszI.

40. Sphaerella fumaginia Catt.

41. " pampini Thïm.

42. $n$ sarmentorum Pirotta.

43. $n$ sentina Fuck.

44. " Vitis Fuck.

45. Sphaeria ampelos Schwz.

46.,$\quad$ pruina Schwz.

47. $"$ stubasciculata Schwz.

48. " viticola Schwz.

49. Teichospora Mesascium Sacc.

50. Uncinula spiralis Berk. et Curt.

51. " "var.racemorum Thüm.

52. Valsa vitigena Cooke.

53. , Vitis Berk. et Curt.

54. Valsaria insitiva Ces. et De Not.

\section{Pyrenomycetes spurii.}

1. Ascochyta Ellisii Thüm.

2. Cheilaria Vitis Schulzer.

3. Cryptosporium ampelinum Thïm.

4. Cryptostictis hysteriojdes Fuck.

5. Cytispora chrysosperma Fr.

$6 . \quad n \quad$ coryneoides Berk. et Curt.

7. $r$ incerta Thiim.

8. $"$ Vitis Mntg:

9. Diplodia Bacchi Pass, et Thuim.
10. Diplodia fabaeformis Pass. et Thüm.

11. " interrogativa Thüm.et l'ass.

12. " viticola Desm.

13. Discosia Vitis Schulzer.

14. Hendersonia ampelina Thiun.

15. longipes Berk. et Curt.

16. " sarmentorum IVestd.

17. $"$ viticola Thüm.

18. Hormococeus olivacens Sace. 
19. Leptothyrinm longisporum Thim. et Pass.

20. Passerinii Thüm.

21. " perpnsillnm Pass. et Thiim.

22. Myrothecim convexum Berk, ef Curt.

23. Vitis Bon.

24. Pestalozria pezizoides De Not.

25. " Thïmenii Spegaz.

26. " " uvicola Spegaz.

27. Phoma ampelinum Berk. et Curt.

28. " baccae Catt.

29. " confluens Berk, et Curt.

30. "Cookei Pirotta.

31. " Negrianmm Thiim.

32. " pallens Berk. et Curt.

33. „ nstulatum Berk, et Curt.
34. Phoma uvicolum Berk, et Curt.

35. " "var. Labruscae Thüm.

36. " Vitis Bon.

37. Phyllosticta Labruscae Thüm.

38.,$\quad$ viticola Thüm.

39. Polynema Vitis Schulzer.

40. Septoria ampelina Berk. et Curt.

41. " fill Berk. et Curt.

42. " Müggenburgii Pirotta.

43. " Vitis Lév.

44. Sphaceloma ampelinum De By.

45. Sphaeronaema viticolum Berk. et Curt.

46. Sphacropsis Peckiana Thüm.

47. uvarum Berk. et Curt.

48. Vermicularia compacta Cooke et Ellis.

\section{Mycelia sterilia.}

1. Ozonium auricomum Lk.

2. Sclerotium echinatum Fuck.

3. " sarmenticolum Thüm.
4. Sclerotium semen Tode.

$5 . \quad, \quad$ uvae Desm.

$6 . \quad$ Vitis Peyl. 


\title{
VERZETCHNISS DER ARTEN.
}

\author{
(Nach den Nïhpflanzen geordnet.)
}

\section{Vitis vinifera Lin.}

1. Acrostalagmus einnabarinus Cila.

2. Agaricus hyemalis usbeck.

3. " melleus Valil.

4. " protens Kalehb.

5. Amphisphacria sylvana sace. et Spegaz.

6. Anthostomella limitata Sace.

7. Arthobotrynm atrum Berk. et Br.

8. Aspergillus glancus Lk.

9. Auricularia mesenterica Pers.

10. Bertia Vitis Schulz.

11. Botrytis acinorum Pers.

12. $"$ cinerea Pers.

13. Botryosphaeria cyanogena Niessl.

14. Calosphaeria minima Tul.

15. Cenangium riticolum Fuck.

16. Ceratostoma Schulzeri Pirotta.

17.

Vitis Fuck.

18. Chatostroma pedicellatum Preuss.

19. Chalara fusidioides Cda.

20. Cheilaria Vitis Schulzer.

21. Cicinnobolus Cesatii De By.

22. Circinotrichum maculacforme N.a.E.

23. Cladosporium ampelinum Pass.

24. $"$ fasciculatim Cda.

25. " Fumago Lk.

26. " herbarum Lk.

27. $"$ Roesleri Pirotta.

28. Corticium lactescens Berk.

29. Coryneum microstictum Berk. et Br.

30. Cryptosporium ampelinum Thïm.

31. Cryptostictis hysterioides Fuck.
32. Cryptovalsa ampelina Fuck.

$33 . \quad$ Rabenhorstii Sace.

34. Cucurbitaria Vitis schulzer.

35. Cyphella albo-violascens Karst.

$36 . \quad$ villosa Karst.

37. Cytispora chrysosperma Fr.

38.,$\quad$ incerta Thiim.

39. $" \quad$ Vitis Intg.

40. Dendryphinm Passerinianum Thüm.

41. Diaporthe ritienla Nke.

42. Didymosphaeria hacehans Pass.

43. Discosia Vitis Selulzer.

44. Diplodia Bacchi Pass. et Thüm.

45. " fabaeformis Pass. ot Thïm.

46. ” interrogativa Thiim. et Pass.

47. $"$ viticola Desm.

48. Dothidea myriococer Intg.

49. Eurotium herbariorum Lk.

50. Eutypa ludibunda Thïm. -

51. Exosporium Badhami Awd.

52. Fusarium Cesatii Thiim.

$53 . \quad " \quad$ pampini Thiim. et Pass.

54. $"$ Roeslerianum Thüm.

55. $"$ tortuosum Thïm. et Pass.

56. $"$ viticolum Thïm.

57. Fusisporinm Biasolettianum Sacc.

58. " Zavianum Sacc.

59. Fusoma Vitis schulzer.

60. Gibbera Vitis Schulzer.

61. Gloeosporium ampelophagum Sacc. 62. " sarmentitium Mntg.

62. Gonytrichum caesium N. a. E. 
64. Graphium cinerellum Spegaz.

65. Gyrocerus Ammonis Cda.

66. Haplotrichum epiphyllum Rabh.

67. Helminthosporium decacuminatum Thüm, et Pass.

68. Helotium hyalopes Fuck.

69. $"$ sarmentorum De Not.

70., vitigenum De Not.

71. Hendersonia sarmentorum Westd.

72. Hormococens olivaceus Sace.

73. Hysterographium viticolum Rehm.

74. Lachnella macrochaeta Spegaz.

75. Lenzites atropurpurea Sace.

76. Leptosphaeria appendiculataPirotta

77.

78.

79.

80.

\section{"}

Cookei Pirotta.

Gibelliana Pirotta.

\section{vinealis Pass.}

81. Leptothyrium longisporum Thüm. et l'ass.

82. "
83.
$\quad$ passerinii T'hüm.

$\quad$ Thüm.

84. Lophiostoma angustatum Fuck.

85. $"$ Hederae Fnck.

86. . . Thümenianum Spegaz.

87. Lycoperdon giganteum Patsch.

Ss. Macrosporimm uvarum Thïm.

89. Marasmius calopus Fr.

90. $"$ canditus Fr.

$91 . \quad " \quad$ epiphyllus Fr. var. sarmentorum Thim.

92. Mncor stolonifer Ehrbg.

93. Myrothecium Vitis Bon.

94. Nectria cinnabarina $\mathrm{Fr}$.

95. " viticola Berk. et Curt.

96. Oidium Tuckeri Berk.

97. Ozonium auricomum Lk.

98. Periconia chlorocephala Fres.

99. Pestalozzia pezizoides De Not.

100. " Thuimenii Spegaz.

101. . uvicola Spegaz.

102. Peziza tumida Pers.

103. " viticola Pers.

104. Phoma ampelinum Berk. et Curt.

105. " baccae Catt.

106.,$\quad$ Cookei l'irotta.
107. Phoma Negrianum Thüm.

108. " Vitis Bon.

109. Phymatostroma fusarioides Cda.

110. Polynema Vitis Schulzer.

111. Pleospora coronata Niessl.

112., phaeocomes Ces. et De Not.

113. Pyrenopeziza Vitis Rehm.

114. Pyrenotrichum Vitis Schulzer.

115. Rebentischia appendiculosa Sacc.

116. Rhaphidospora sarmenti Pass.

117. Roesleria hypogaea Thüm. et Pass.

118. Rosellinia horrida Haszl.

119. Sclerotinia Fuckeliana Fuck.

120. Sclerotium echinatum Frok.

121.,$\quad$ sarmenticolum Thüm.

122. " Semen Tode.

123. " uvac Desm.

124. " Vitis Peyl.

125. Septocylindrium dissiliens Sace.

$126 . \quad$ virens Sace.

127. Septosporium Fuckelii Thüm.

128. Septoria Müggenburgii Pirotta

129. " Vitis Lév.

130. Sphaceloma ampelinum De By.

131. Sphaerella fumaginia Catt.

132. " pampini Thüm.

133. " sarmentorum l'irotta.

134. " Vitis Fuck.

135. Spicularia leterus Fuck.

136. Sporodum conopleoides Cda.

137. Sporotrichum ampelinum Thüm. et Pass.

138. " aurenm Fr.

139. Stictis Saccardoi Rehm.

140. r uberrima Mntg.

141. Teichospora Mesascium Sacc.

142. Trichothecium candidum Wallr.

$143 . \quad \% \quad$ roseum Lk.

144. Tubercularia ampelophila Sace.

145. " $"$ sarmentorum Fr.

146. Uredo Vitis Thüm.

147. Valsa vitigena Cooke.

148. " " Vitis Berk. et Curt.

149. Valsaria insitiva Ces, et De Not.

150. Vermicularia compacta Cooke et Ellis. 


\section{Vitis Labrusca Lin.}

1. Acrospermum compressum Tode

2 . $"$ liavenelii Berk. et Curt.

3. Ascochyta Ellisii Thüm.

4. Botrytis acinorum Pers.

5. Calloria vinosa $\mathrm{Fr}$.

6. Cenangium viticolum Fuck.

7. Cladosporium ampelinum Pass.

8. Corticium albido-carneum Thïm.

9. Cyphella villosa Karst.

10. Cytispora coryneoides lserk. et Curt.

11. Dacryomyces viticola Schwz.

12. Diatrype Vitis Berk.

13. Diplodia viticola Desm.

14. Ditiola suleata Fr.

15. Dothidea viticola Schwz.

16. Epochnium monilioides Lk.

17. Erysiphe necator Schwz.

18. Gonytrichum caesinm N. a. E.

19. Graphinm clavisporum Berk. et Curt.

20. Helotium pullatum Ger.

21. Hypoderma commune Duby.

22. $"$ Rubi De Not.

23. Hysterium anstrale Duby.

24. Hysterographium viticolnm Rehm.

25. Leptostroma sphaeroides Fr.

26. Lophiostoma sexnucleatum Cooke.

27. Marasmins viticola Berk, et Curt.

28. Merulius corium Fr.

29. Myrothecium convexum Berk.et Curt.
30. Peronospora viticola De By.

31. Pestalozzia pezizoides De Not.

32. Peziza ascoboloidea Schwz.

33. , pennicillata Schwz.

34. " pruinata Seliwz.

35., viticola Pers.

36. " Vitis Schwt.

37. Phoma ampelinum Berk. et Curt.

38. " nvicolum Berk, et Curt. var. Labruscae Thiim.

39. Phyllosticta Labruscae Thiim.

40. Polyporus vaporarius Fr. var. papyracens Schwz.

41.,$\quad$ viticola $F r$.

42. Propolis prominula Thüm.

43. Sphaerella sentina Fuck.

44. Sphaeria ampelos Schivz.

45. $\quad$ subfasciculata Sehwz.

46. Sphaeropsis Peckiana Thïm.

47. Sporotrichum alntaceum Schwz.

48. $"$ viticohm Schwz.

49. Tuberenlaria subdiaphana Sehwz.

50. Uncinula spiralis Berk. et Curt.

51. $" \quad$ var. racemorum Thiim.

52. Valsa Vitis Berk. et Curt.

53. Valsaria insitiva Ces. et De Not.

54. Volntella ciliata Fr.

\section{Vitis aestivalis Mchx.}

1. Corticium armeniacum Thïm.

2. Diplodia viticola Desm.

3. Dothidea picea Berk. et Curt.

4. Excipula viticola Schwz.

5. Hendersonia ampelina Thüm.

6. Oidium Tuckeri Berk.

7. Peronospora viticola De By.
8. Phoma ustulatum Berk. et Curt.

9. " uvicolum Berk. et Curt.

10. Rhytisma monogramme Berk.et Curt.

11. $\rightarrow$ Vitis Schwz.

12. Roesleria hypogaea 'Thiim.

13. Sphaeria pruinosa Schwz.

\section{Vitis vulpina Lin.}

1. Helminthosporium siliquosum Berk. et Curt.

2. Patellaria atro-fusca Berk. et Curt.

3. Peronospora viticola De By.
4. Peziza cinereo-fusca Schwz.

5. Phyllosticta viticola Thïm.

6. Septoria ampelina Berk. et Curt.

7. Xerotus viticola Berk. et Curt. 


\section{Vitis riparia $\operatorname{Mch} \mathrm{x}$.}

1. Hysterographium flexuosum Rehm. 3. Pestalozzia pezizoides De Not.

2. Oidium Tuckeri Berk.

\section{Vitis cordifolia Mchx.}

1. Gonytrichum caesium N. a. E.

3. Uncinula spiralis Berk. et Curt.

2. Peronospora viticola De By.

\section{Vitis rotundifolia Mchx.}

1. Sphaeria viticola Schwz.

2. Sphaeropsis urarum Berk. ef Curt.

\section{Vitis candicans Engelm.}

1. Oidium Tuckeri Berk.

IX. Vitis sylvestris Gmel.
1. Hendersonia viticola Thüm.
2. Pyrenopeziza Vitis Rehm. 


\section{Die Pilze der Trauben.}

\section{Oidium 'Tuckeri Berk.}

Berkeley in "Moniteur belge" 1850 IX. p. 2383. - Journal of Hortienltural society 1853. VIII. p. 235. - Id. 1854. IX. p. 69. - Fresenius, Beiträge z. Mykologie p. 76, Tah. IX. fig. 14, 15. - Mohl in Botan, Zeitung 1853. Tab. 11. Id. in Botan. Zeitung 1854 p. 137 Tab. 6. - Willkomm, Wunder der Mikroskopie p. 89, fig. 42. - Regel in Gartenflora 1852. Tab. 21, fig. 1-6. - Cooke, Handbook of British Fungi p. 605. - Fuckel, Symbolae mycol. p. 79. - Pirotta, fungli parassiti dei Vitigni p. S5. - Erysiphe Tuckeri Trevis. Spighe e paglie I. no. 3. - Sphaerotheca Castagnei Lév. Fungus conidiophorus. Fuckel, Symb. mye. p. 79. - Kïhn, Krankheiten der Culturgewächse p. 220.

O. caespitibus dense gregariis, saepe confluentibus et placas magnas albicantes formans, plus minusve arachnoideis, subalbidis, detergibilibus, postremo subfuscidulis; hy phis tenuissimis, ramosis, septatis, septis longis, ad septas non constrictis, achrois; sporis ellipticis vel oblongis, apicalibus, interdum submoniliformibus, $8 \mathrm{~mm}$. long., $5 \mathrm{~mm}$. erass., hyalinis.

Ad folia uvaque viva Vitis riniferae Lin. Ubique. Aestate autumno. In foliis junioribus Vitis aestivalis Mehx. Vitis ripariae Mehx. et Vitis candicantis Engelm. Klosterneuburg.

Es hiesse wahrlich Eulen nach Athen tragen, wollte ich an dieser Stclle mich des Breiteren iiber die "Traubenkrankheit" aussprcehen. Die Zahl der selbstständigen Schriften und der Journal-Artikel über diesen Pilz ist Legion und nur eine Auswahl der wichtigsten derselben konnte ieh oben anführen. Es ist hier weder der Ort, über die Entstehung, Ausbreitung und darauf folgende Bekämpfung der Weinkrankheit zu spreehen, noch 
wïrde ich auch in der Lage sein, irgend ein resentliches nenes Moment zu bringen. Demzufolge beschränke ich mich auf eine Beschreibung der Krankheit vom botanischen Standpunkte aus, den Gesichtspunkt, welcher bei Abfassung dieser Monographie allein massgebend war, streng wahrend. - Einige Zeit nach der Bliithe der Weinstöcke, und zwar je nach der klimatischen Lage, im Nai bis Juli, zeigen sich auf den jüngeren Blättern zuerst spinnwebenartige, weissliche Ueberziige, welche sich rasch vergrössern und immer mehr und mehr ausbreiten, bald auch die jungen, noch saftigen Ranken bedecken und auch auf die älteren Blätter übergehen. Zu Anfang ist nicht gerade eine besonders schädliche Wirkung des Pilzes auf die Vegetations-Fähigkeit der Rebstöcke zu bemerken, scheinbar tritt auch nicht die geringste Störung derselben ein. Abgeselıen ron dem, ja äusserst dünnen, weisslichen Oidium-Anflug zeigen die Blätter kaum hie und da eine etwas krause Form und selbst im Herbst beim Abfallen der Blätter ist keine ungewöhnliche trscheinung bemerkbar. Umgekehrt jedoch verhält es sich mit den Frïchten der befallenen Weinstöcke, ihr. Wachstlum wird im allergrössten Grade beeinträchtigt und nur selten erreichen stark befallene Beeren die Grösse von Lrbsen; bemerkenswerth ist anch das höchst ungleiche Wachsthum der einzelnen Beeren einer Traube. Während eine, allerdings verschwindend kleine Minorität normal sich entwickelt, bleiben, wie schon oben angedeutet, die meisten winzig klein. Die Cuticula der kranken Beeren ist mit mehr oder weniger grossen bräunlichen Punkten und Flecken übersäet, welche späterhin zusammenHiessen, es sind diess die zuerst befallenen, ron der Anheftungsstelle des Pilzes aus erkrankten Stellen. Die Epidermis der Beeren ist sehr hart, kann aber auf die Daner der Zeit dem Druck des wachsenden Parenchyms nicht mehr widerstehen und es entsteht ein, Anfang's sehr feiner, bald aber weitklaffender Riss. Höchst auffallend ist die Beobachtung, dass Beeren, welche nur an einer Stelle vom Pilze befallen sind, hier die beschriebenen Erscheinungen zeigen, an der andern Seite jedoch, wo sie ganz gesund sind, fröhlich fortwachsen und sich ausbilden. So bekommen die Beeren eine völlig unregehmässige, oft ganz eigenthiimliche Gestalt. Das verhinderte Wachsthum der Beeren und die Krankheit überhaupt hat merkwürdigerweise fast gar keinen Einfluss auf die Samenkerne, welche weder in Gestalt noch Form 
und Farbe von anderen, aus normalen Beeren gewomnenen, zu unterseheiden sind. $O b$ sie jodoeh auch keimfähig sind, darïber sind, meines Wissens, Untersuchungen bisher nicht angestellt worden. Bleiben die Beeren, dureh den Einfluss des Pilzes, ganz klein, etwa von Sehrotkorugrösse, so vertroeknen sie ganz einfach, erreichen sie aber doch eine Erbsengrösse, oder etwa die Hälfte der normalen, so tritt dennoch, wemn auch spät, eine Reifung derselben ein, sie färben sich sehwaeh röthlieh, erweiehen etwas und zeigen einen sehwach süssliehen Geschmack; ein irgend brauchbarer Wein kamn aber daraus nicht hergestellt werden. Dureh die Untersuelungen 'Tulasne's, Mohl's, Berenger's, Berkeley's, Anici's u. A. ist evident naehgewiesen, dass das Oidium. Tuckeri eine Conidien-, eine Vorform einer Erysiphee, eines Mehlthan-Pilzes ist. Doch ist das Auftreten des Schlanehpilzes, eben der höchsten Fruehtform, nur ein äusserst seltenes. Fuekel a. a. O. zieht das Oidium zu Syleaerothece Castagnei Lév. - Au den Blättern, grïnen Ranken und Früehten von Vitis vinifera Lin. Ueberall wo Wein gebaut wird. Im Herbste 1877 von mil auch auf jungen Pflanzen von Vitis aestivalis Mehx., Titis riparia Mchx. und Titis candicans Engehm. in Klosternenburg, NiederOesterreich, aufgefunden. (Tab. III tig. 1.)

\section{Macrosporinm urartm Th $\mathrm{T}$ m. nor. spec.}

M. acervulis parvis, gregariis vel etiam confluentibus, subvelutinis e atro grisco-viridibus; myeelio repente, temu; hyphis eurvulato-ereetis, brevibus, simplieibus, eximie brevi artieulatis, subflexuosis, subinaequalibus, olivaeeis, tenuibus; sporis diversissimis, aut bieellularibus, medio eonstrictis, aut longe ellipsoideis, utrinque truneato-rotundatis, quinque- vel sexseptatis, aut multicellularibus plus minusve globoso-clavatis, vertice rotundatis, ad septas minime constrietis, $12-24 \mathrm{~mm}$. long., $6-9 \mathrm{~mm}$. crass. eoloris hypharum.

Ad Vitis viniferae I in. acinos maturos vel submaturos quos exurit. Gorizia, Istriae in antumno legit Bolle.

Die hier anfgestellte neue Speeies der vielgestaltigen Gattung Macrosporium bildet auf der Sehale von fast oder ganz reifen Beeren kleine, zeitweilig zusammenfliessende Räschen, denen man kaum das Prädieat sammtartig beilegen kam, da sie dazu viel 
zu dünn sind, ihre Farbe ist ein in das Schwärzliche übergehendes Graugrün. Das, unter der Cuticula kriechende, Mycel ist sehr wenig ausgebreitet und besteht aus dünnen Fäden aus welchen sich die wenig zahlreichen Hyphen erheben; diese sind hin und her gebogen aufrecht, sehr dïnn und ganz ansnehmend kurz gegliedert, ihre Farbe ist wie die der Sporen ein mattes Olivenbraun. Die an der Spitze dieser Hyphen sich bildenden Sporen sind wie alle Macrosporium-Arten äusserst vielgestaltig; ein Theil, unzweifelhaft die jüngsten sind zweizellig, rund, in der Mitte stark eingeschniurt, andere sind lang elliptisch, fast genau an Helminthosporium erimernd, oben abgestumpft, rundlich und in der Quere fünf- bis sechsmal getheilt, die dritte Art von Sporen, und zwar die röllig ausgebildeten, reifen sind mehr oder weniger aus dem Kugeligen in das Kenlenförmige ïbergehend, am Scheitel abgerundet, gegen die Basis schwach verschmälert und vielfach sowohl der Länge als der Breite nach getheilt, an diesen Theilungsstellen nur wenig eingeschnïnt. Die Crösse der Sporen variirt von $12-24 \mathrm{~mm}$. in der Länge und ron 6-9 $\mathrm{mm}$. in der Breite. - $\mathrm{Ob}$ und welchen Schaden die Beeren durch diesen Parasiten erleiden, das ist noch nicht ermittelt worden, ich erhiclt ihn erst cin cinziges Mal ans dem österreichischen Küstenlande, wo er von Bolle in October 1876 bei Görz auf den Beeren ron Titis viniferae Lin. gesammelt wurde. (T'ab. I. fig. 2.)

\section{Aspergillus glancus $\mathrm{L} / \mathrm{k}$.}

Link in Linné, spec. plant. c. Willdenow VI. 1. p. 67. - Fries, Syst. mycoI. III. p. 385. - Corda in Sturn, Deutschlands Flora III. p. 13, Tal. 7. -Fresenius, Beiträge zur Mykologie p. 82, Tab. X. fig. 13-15. - Corda, Anleitung z. Studium der Mykologie Tab. C. 21, fig. 7, 8. - Bischof, Terminologie fig. 3810. De Bary in Botanische Zeitung 1854 Tab. 11. - Cooke, Handb. of British Fungi p. 588. - Fuckel, Symbolae mycologicae 1. 90. - Saccardo, Mycologia veneta p. 184. - Berkeley, Notices of North American Fungi in Grevillea III. p. 107. Monilia glanca Pers. Syn. fung. p. 691. - Mucor glaucus Lin. Spec. plant. p. 1020.

A. hyphasmate tenui; floccis sterilibus, effusis, albis, fertilibus simplicibus, apice capitatis, sporidiis laxis, glancescentibus. Mycelium plus minus evidens, in junioribus et sterile praecipue luxuriat. Flocei fertiles aggregati, capitulo jam lente simplici granuloso crassiusculo terminate. Stature mere variat. Fries 1. c. 
Id acinos siccos, subputridos Vitis viniferce Lin. Hieme, Flitsch, Istriae (G. Bolle).

Dieser gemeinste aller Schimmel, welehen wir nicht nur an allen möglichen Pflanzentheilen in der freien Natur, sondern auch auf allen unseren Speisen und sogar Geräthen, Kleidern, Papier u. s. w. antreffen, warum sollte el grerade die Weinbeeren verschonen? und er thut es auch nicht, obgleich gerade sein Vorkommen anf denselben mir nur von zwei Standorten bekannt ist und auch in der Literatur dariiber fast nichts zu finden ist. Das Letztere hat aber jedenfalls seinen Grund eben in der allgemeinen Verbreitung unseres Schimmelpilzes, welcher immer als „anf Vegetabilien aller Art vorkommend" angegeben wird. Unser Aspergillus lebt gesellig und bildet dichte, weiche graugrüne Räischen von circa $1 \mathrm{~mm}$. Höhe; er besitzt ein Mycelium, welches aus sehr dümnen, verworrenen, hin und her kriechenden Fäden gebildet und meist nicht sehr verbreitet, stets aber sichtbar ist. Aus diesem erheben sich nun gerade und steif aufrecht die Fadenträger, die Hyphen, welche grau von Farbe, ziemlich dïnn und in kurze Glieder abgetheilt sind. An ihrem Ende tragen sie die Sporenkäpfehen von mehr oder, minder regelmässiger Kugelgestalt. Auf dem inneren festen Kern dieses Köpfchens, welcher mit der Substanz des 'Trägers fest zusammenhängt, betinden sich kurze, steif aufrechte, oben abgestumpfte Sterigmen und am Ende rlieser werden die Sporen gebildet. Diese letzteren sind fast immer zu rosenkranzförmigen Schnïren oder Ketten verbunden, kugelig oder elliptisch kugelig, einfach, ungetheilt, durchsehemend, bläulich gran und ung'ehener zahlreich; manchmal ballen sie sich auch etwas zusammen und wieder sind sie zu Zeiten ganz einzeln. Von Fresenius werden a. a. O. einige merkwürdige Missbildungen der Sterigmen abgebildet. - Ueber den, von de Bary a. a. O. ausfïhrlich dargethanen Zusammenhang des Aspergillus glaucus mit dem Eurotium herbariorum Lk., worauf ich bei letzterem Pilze hinweisen werde, ist hier der Ort nicht, näher einzugehen. Von Herm G. Bolle wurden meine Exemplare auf diurren, halbverfaulten Beeren von Vitis vinifera Lin. unweit Flitsch in Istrien im December 1876 gesammelt, Berkeley a. a. O. gibt den Pilz auch aus Nord-Amerika an. (Tab. II. fig. 8.) 


\section{Botrytis acinorum Pers.}

Persoon, Mycologia europaea I. p. 38. - Fresenius, Beiträge zur Mykologie p. 15, Tab. II. fig. 15-21. - Fuckel, Symbolae mycologicae p. 359. - Fries, Systema mycol. III. p. 400. - Saccardo, Mycologia veneta p. 185. - Pirotta, fungli parassiti dei Vitigni p. 84.

B. floccis ex albo glaucis, fertilibus fasciculatis, simplieibus apice trifidis, sporidiis globosis, albido-glaucis. - Flocei ex albo cinerascentes, steriles tenelli, evanescentes; fertiles in fasciculum connexi, stricti, nitidi, apice trifidi. Sporidia inspersa, primo for'san tandum terminalia. Siccam rite explorare non lieuit. - Fries 1. e.

In acinis uvae Titis viniferae Lim. et Titis Labruscae Lin. marcescentibus. Ubique, frequens.

Auf faulen Weinbeeren ist diese Art äusserst gemein, sie bildet kleine, bald zusammenfliessende und schliesslich die ganze Beere bedeckende Räschen von weisslich-grüngrauer Farbe; das IIyeel durchwuchert mit einem dichten verworrenen Fadengeflecht die ganze Schale der Beeren, daraus erheben sich dann zweierlei Arten von Hyphen. Die einen, die sterilen, sind schlank, einfach, ohne Querwände, sehr dünn und zart und bald vergänglich; die anderen, die fruchttragenden, sind etwas dicker, steif aufgerichtet und mit mehrfacher Quertheilung. An der Spitze tragen diese letzteren eine Anzahl kurzer Aeste, welche sich manchmal wiederum theilen und die zusammen eine Art lockeres Köpfehen bilden. An den Enden dieser Aestchen bilden sich die zahlreichen Sporen, welche oblong-rundlich, weisslich und in ziemlich dichte Bündel vereinigt sind. Als besonders eharakteristisches Merkmal für diese Species sind die verdickten, meist wieder etwas gespaltenen Enden der Aeste anzusehen, an ihnen befinden sich die kurzen Stielchen oder Sterigmen, woran die Sporen hängen und die nach dem Abfallen der letzteren stehen bleiben. - Dieser Pilz dürfte iiberall, wo Wein gebant wird, häufig sein; wem er, wie es zuweilen vorkommt, in manchen Jahren in Menge auftritt, so ist der durch ihn verursachte Schaden an der Ernte ein bedentender. Soviel mir bekannt ist, entwickelt sich die Botrytis nur ausschliesslicli auf reifen Beeren, und zwar meist auf solchen, welche noch am Stocke hängen, doch erscheint er auch auf jenen, welche behufs Conservirung aufbewahrt wurden. In einzelnen weinbautreibenden Gegenden des Rheinufers ist man, im Gegentheil zu anderen, erfreut, wemn 
die Botrytis sich massenhaft cinstellt, man lässt dort die 'T'rauben bis in den Winter, December, am Stocke hängen und nennt den Pilz ,die Edelfänle". Die Beeren schrumpfen selbstverständlich bei diesel Behandlungsweise ganz wie Rosinen und Cibeben ein und der sie bedeckende Pilz soll die Zuckerbildung in der Beere ungemein befördern, so dass der darans gewonnene Wein zwar, was Quautität anbelaugt, sehr gering, desto hesser aber an Qualität wird. Ob und welchen Einfluss auf die Zuckerbildung in der Beere wirklich der Pilz hat, dariiber sind wissenschaftliche Untersuchungen noch gar nicht angestellt worden. - Ich fand die Botrytis ausser auf den reifen Beeren von Vitis vinifera Lin., auch auf solchen von Vitis Labrusca Iin. in Nieder-Oesterreich. (Tab. I. tig. 15.)

\section{Epochnimm monilioides Lk.}

Link, Observationes mycologicae I, p. 16, fig. 28. - Id. in Linné, Spec. plant. cura Willdenow VI. 1, P. 32. - Nees ab Esenbeck, System der Pilze 1. 45, fig. 40. - Martius, Flora Erlang. p. 338. - Fries, Systema mycolog. III. 1. 448. - Schweinitz, Synopsis of North American Fungi p. 275 no. 2573. Monilia fructigene Schum. Fl. Saell. II. 1. 339. - Fusisporimm monilioides Duby, Bot. Gall. II. p. 925. - Sporotrichum monilioules Spr. Syst. reget. IV. p. 548.

E. Hoccis tenerrimis, albis, sporidiis nigris. - Flocei ramosi, septati, telac arancac instar expansi, albi. Acervi sporidiorum matrici firmiter adnati. Sporidia singula basi constricta in apiculun tenuissimun. - Fr. 1. c. - Sporae 3-5 mm. long., 2 mm. crass., subpedicellatac.

Ad acinos uvalum Vitis Labruscae Lin. Passim. Bethlehem, Pemnsylvaia, America septentrionalis, leg. Schweinitz.

Ieh kemne allerding's diese Species genan, denn sie ist in Europa nicht selten, kommt hier aber nur auf halbfaulen Aepfelu und Birnen, namentlich wie Link angibt, anf der Varietät der letzteren, welche den Namen "beuré blanc" fiihrt, vor"; auf Weintrauben habe ich den Pilz noch nicht geschen. Viclfach wird das Epochnimm mit anderen, auf halbfaulendem Kernobst vegetirenden Pilzen ver'wechselt und die meisten Exemplare, welche ich unter diesem Namen erhielt, waren falsch bestimmt, fast immer war es Torula fructigena Pers. - Oidium fructigenum Hk. - Torliegender Pilz bildet ziemlich kleine, wollige, halbkugelige Räischen von grauröthlicher Färbung, die Hyphen sind sehr zart and schlank, wasserhell, mit Querwänden versehen 
und sind eng unter einander verfilzt oder verflochten. Die zahIreichen Sporen haben eine eigenthïmliche Form, sie sind nämlich lang elliptisch oder cylindrisch-elliptisch, an beiden Enden verschmälert zugespitzt, einfach, schwarzgrau; an einem Ende, dem untersten, haben sie eine Art von Stiel, welcher seln schlank, ziemlich kurz, farblos und entweder gerade oder gebogen ist; in welch letzterem Falle er lebhaft an die Wimpern oder Geisseln einiger Bacterien-Formen erinnert, die Länge beträgt $3-5 \mathrm{~mm}$, die Breite $2 \mathrm{~mm}$. - Ton Schweinitz ward dieser Pilz häufig auf Beeren von Vitis Labrusca Lin. in Pennsylvanien gefunden. (Tab. II. fig. 11.)

\section{T'ubercularia ampelophila Sace.}

Saccardo in "Rivista di Viticoltura ed enologia italiana" 1877. p. 494.

T. acervulis minntis, erumpenti-superficialibus, dense gregariis confluentibusque, pallide roseis; basidiis fasciculatis, simplicibus ramosisque, septatis, mubilose hyalinis, apice coniclia (catenulata?) globosa vel ellipsoidea, $6-7 \mathrm{~mm}$. long., $6 \mathrm{~mm}$. crass, mubilosa, e hyalino dilutissime rosea gerentibus. - Sace. l. c.

Ad acinos immaturos uvarum Titis viniferce Lin. var Lugliaticae, in Gloeospor $\ddot{u}$ ampelophagi Sace. pustulis parasitans Venetia (Saccardo).

Ein Parasit auf einem anderen Parasiten! Gewiss ein hochinteressantes Factum. Prof. Saccardo publicirte erst in der allerjünsten Zeit die Beschreibung dieses nenen Pilzes und bin ich noch nicht im Besitz der mil rom Autor gütigst zngesagten Exemplare. Ich beschränke mich hier also darauf, eine Uebersetzung seiner Diagnose zu geben. Die Tubercularia bildet kleine, oberfï̈chlich aufsitzende, kaum hervorbrechend zu nemnende Häufchen, welche dicht gedrängt stehen, zuweilen auch zusammenfliessen und hellrosa gefärbt sind. Die Basidien sind zu Bïndeln vereinigt, entweder einfach oder verzweigt, septirt, wolkig-farblos, an ihrer Spitze schnüren sie die kugeligen oder elliptischen, wolkigen, hellrosa gefärbten Conidien oder Sporen $\mathrm{ab}$, die eine Länge von $6--7 \mathrm{~mm}$., eine Breite von $6 \mathrm{~mm}$. haben; ob diese Sporen zu Schnüren oder Kettchen verbunden sind, ist nicht mit Sicherheit auszunehmen. Der Pilz schmarotzt auf den Häufchen des Gloeosporium ampelophagum Sacc. auf den unreifen 
Beeren der Varietät Lugluetica von Vitis vinifere Lin.; er ward in Venetien von Saccardo entdeckt.

\section{Gloeosporium ampelophagum Sace.}

Saccardo in "Rivista di Viticoltura ed Enologia italiana" 1877, p. 494. - Fictmulariu ampelophaya Pass. La Nebbia del Moseatello ed una nuova crittogama delle Viti 1876. - Rabenhorst, Fungi europaei no. 2266. - Pirotta, funghi parassiti dei Vitigni p. 89. - Phome uirolem Areang. in "Nuovo Giornale botanico italiano" IX. 1) 74 c. icon. (non Berkl. et Curt.!)

Maculae amphigenae, fusco-rufescentes, subdiscoideae, tandem confluentes, medio furfuraceo-griseae; sporae minutae, ellipticae, hyalinae, simplices, ad polos nucleatae, hyphis brevissimis fultae. - Pass. l. e.

Macula seu pustulis (frueticolis) subcircularibus, saepe conHuentibus baccarum epidermiden strataque corticalia occupantibus et arescendo indurantibus atque rufo-vel fuligineo-nigrificantibus, ad centrum (e sporis exsilientibus) griseo- vel roseo-pruinosis: acervulis sub epidermide nidulantibus, minutis, dense gregariis, strato proligero pulvinato minute parenchymatico, hyalino vel dilute fumoso, cellulis superficialibus vertice breve apiculato sporigeris; sporis (conidiis) ex oblougo-ellipsoideis vel ovoideis, כ-6 mm. long., $25-35 \mathrm{~mm}$. crass., biguttulatis, hyalinis, mox acervatim erumpentibus pustulaeque superficiem conspergentibus. - Sace. 1. c.

In Titis viniferae Lin. var. Lugliaticate et aliorum foliis, ramulis, cirrhis, baccisque vivis. - Italia: Toscana, Pedemontium, Venetia, Parma.

Zwei Jahre ist es her, dass dieser neue, äusserst gefährliche Schädiger des Weinstockes zuerst beobachtet ward, und zwar wie aus dem angegebenen Werkchen Passerinis hervorgeht, bei Casale Monferrato in Piemont, durch den Advocaten F. Negri. Später ward der Pilz auch bei Parma von Passerini selbst aufgefunden und von diesem letzteren Standorte sowohl in den Rabenhorst'schen Fungi curopaei ausgegeben als auch mir in sehr zahlreichen Exemplaren mitgetheilt. Das Auftreten des Schmarotzers sowohl auf den lebenden Blättern, als den Ranken und den Beeren nöthigt mich, auch die Beschreibung für jedes der drei befallenen Organe besonder's zu geben. Was nun in 
erster Linie die Blätter anbelangt, so bildet unser Pilz auf denselben unzählige, mehr oder minder grosse, fast kreisrunde Flecken von hellröthlieh branner Färbung; dieselben treten etwas vor der übrigen Blattsulsstanz hervor und man kamn sie füglich fast als scheibenfürmig bezeiehnen, der Rand ist durch eine dunklere Tinie fest ungrenzt, die Mitte der Flecken, und bei jüngeren in vollster Entwickelung stehenden Exemplaren fast der ganze Fleck selbst, ist grauweisslich bestäubt. Auf der Unterseite der Blïtter sind die Flecken rothbram nnd dem oberseitigen scheibenfümigen Hervortreten entsprechend, concav-verticft, ebenfalls mit einer schmalen dunklen Linic umsïumt. Die Sporen sind elliptisch oder kurz-oblong, ungetheilt, an beiden Enden mit einem, meistens nur ganz undentlichem Nucleus versehen, wasserhell, durchsichtig, $5-6 \mathrm{~mm}$. lang und $2.5-35 \mathrm{~mm}$. breit. Wemn der Pilz auf den Ranken vorkommt, was bei den vom Sclimarotzer befallenen Stz̈eken fast regelmäissig der Fall scheint, so bildet er sehr grosse, entweder einzeln stehende oder, was fast als Regel betrachtet werden kamn, zusammenfliessende Flecken. Die Form ist eine mnregelmässige, mohr oder weniger kreisrunde; der Fleck bildet eine schwach hervortretende Scheibe mit einem, durch die emporgezogene Rinden-Cuticula gebildeten, wulstigen dunkelbraunen Rande, im Centrum ist die Farbe gelblich weiss, fast mehlartig; an Blattstielen, Wickelranken und ganz juugen Reben, welche der Pilz gleichfills heimsueht, umschliessen oft die Flecken ringförmig das ganze Organ, welches dadurch ein knotiges Ansehen erhält. - Auf den Beeren bildet sich der Pilz im Anfang Juli ans, es entstehen erst kleinere, dann immer grössere Fleeken auf denselben, welche zu Anfang dunkel-purpurroth sind, später aber dieselbe Färbung annehmen, wie die Flecken auf den Ranken sie zeigen. Das scheibenförmige Hervortreten des ganzen Fleckes ist auf den Beeren ebenfalls bemerklich, wenn anch nicht in solcheni Grade wie bei Blättern und Ranken. Zumeist ist auf einer Beere nur ein Fleck, doch zählte ich auch zwei und drei auf ein und derselben. Die Substanz der Beeren trocknet, sowic der Pilz sie attaquirt hat, mit vehementer Geschwindigkeit zusammen und wenn sic auch nicht abfallen, so kommen sie doch ebensowenig zur Reife. - Bisher ward dieser Schädling schon auf zahlreichen Varietäten von Titis vinifera Lin. beobachtet, besonders auf dem Lugliatica, einer rothen, und dem Moscatello, 
einer weissen Sorte. In Piemont fand ihn Advoeat F. Negri bei Casale Monferrate, bei Parma Profusser G. Passerini und in Venetien Prof. Saccardo. Letzterer hatte bei Abfassung seiner Diagnose und der oben citirten Abhandlung nur die Form auf den Beeren vor sich, aus welchem Grunde ich auch die erste Diagnose Passerini's mit publicire. (Tab. III. fig. 24.)

\section{Erysiphe necator Sehwz.}

Schweinitz, Synopsis of North American Fungi p. 270, nr. 2495.

E. hyphasma tenuissimum, albidum, floccis valde tenuibus, orbiculatum, non constringens. Sporangiolis minutissimis, raris, fusco-nigris, globosis. - Ubi omnino evoluta, etiam haec species destruit uvas. - Schwz. I. e.

In uvis Vitis Labruscae lin, varietatibus cultis in vincis, Raro. - America septentrionalis: Pennsylvania leg. Schweinit\%.

Wie es seheint hat kriner der neneren Mykologen diese Erysiphe wieder gefunden, wenigstens wird sie von Berkeley gar nicht erwähnt, von Cooke aber in seiner vortrefflichen kleinen Arbeit: "The Erysiphei of the United States" nur mit Namen nnter den ".species dubiac" anfgefuihrt. Höchst auffallend ist diess allerdings, da Schreinitz a. a. O. sagt, dass der Pilz, wenn er gehörig entwickelt ist, die Weintrauben zerstirt; wir haben es also hier mit cinem directen Schädling der Trauben zu thun und merkwiirdig genug, hat ihn Niemand wieder gefunden und untersucht! Es ist ein dringendes Desiderium, dass die so fleissigen Mykologen NordAmerikas sich die allergrösste Mïhe gäben, die Schweinitz'sche Art wieder aufzutinden und genau zu untersuchen! - Beschrieben wird der Pilz folgendermassen: Das Geflecht oder Mycelium ist sehr düm und zart, weisslich, die Fäden äusserst zart, kreisrund gestellt, nicht zusammengezogen. Die Sporidiolen (jedenfalls sind unter diesem Namen die Perithecien gemeint) äusserst klein, nur wenige vorhanden, kugelig, schwarzbraun. - Auf Beeren der cultivirten Varietäten von Vitis Labrusca Iin. in den Weinbergen Pennsylvaniens (Schweinitz). 
Uncinula spiralis Berk. et Curt. nor. rar. racemorum Thïm.

Differt a forma normali, mycelio arachnoideo, stabiliore, peritheciis subgregariis, minoribus; ascis, sporidiaque quadrant.

In Vitis Labruscae Lin. racemis languidis aridisque. America septentr. pr. Newtield, New-Jersey, Ant. 1877 (J. B. Ellis).

Von der Hauptform, mit welcher diese Tarietait sonst in ihren mikroskopischen Kennzeichen, was sowohl die Schläuche, als dic Sporen anbelangt, völlig itbereinstimmt, unterscheidet sie sich durch das Mycelium, welches etwas danerhafter ist und längere Zeit spinnervebenartig auf den Kimmen der Trauben verbleibt nud durch die gedringter stehenden, ein wenig kleineren Perithecien. - Soviel ich bisher erfahren konnte, thut dieser Pilz, welcher bisher nu anf den Kämmen von reifen Trauben der Vitis Labrusca Lin. im nordamerikanischen Staate New-Tersey bei Newticld von J. B. Ellis gefunden ward, den Trauben, respective deren Beeren, keinen bedentenden Schaden.

\section{Sphaeropsis urarum Berk. et C'urt.}

Berkeley, Notices of North American Fungi in Grevillea III. p. 1. no. 417. Pirotta, fnnghi parassiti dei Vitigni p. 58.

S. peritheciis innumeris, hyalinis, centro nigris; sporis breviter cymbaeformibus. - Berk. l. c.

Ad acinos subvivos Titis rotundifolice Mchx. America septentrionalis, Carolina septentrionalis, legit Curtis.

Die Beeren erscheinen, wenn sie von diesem Pilze befallen werden, auf den ersten Blick, als seien sie mit einer chemischen Efflorescenz bedeckt, zwischen und auf diesem Ueberzuge finden sich die unzähligen, kleinen, wasserhellen, im Centrum schwarzen Perithecien, welche zusammengedrïckt erscheinen und von der dümnhäutigen Cuticula rund umgeben sind, die Sporen, 3 bis $4 \mathrm{~mm}$. lang und $2 \mathrm{~mm}$. breit, haben eine kurze Kahnform und sind zuweilen ein wenig gekriimmt. - Dr. Curtis entdeckte diesen merkwïrdigen Pilz anf der Culturform Scuppernong von Vitis rotundifolia Mchx. im nordamerikanischen Staate Nord-Carolina. 


\section{Pestalozzia uricola Spegaz. nor. spec.}

P. acervalis e globoso-lenticularibus, quandorque conoideis, atris, subepidermicis, errumpentibus et epidermide lacerata circum circa parum dealbicanta cinctis, circa $300-400 \mathrm{~mm}$. diam., sporis (conidiis) fusiformibus, quinquelocularibus, loculis tribus mediis dilute olivaceo-fiscis, quandoque guttulatis, duo exteriis hyalinis, $35 \mathrm{~mm}$. long., 8-10 mm. crass., inferiore pedunculum conidium tutequanti gerenti, $25-30 \mathrm{~mm}$. long., $1 \mathrm{~mm}$. crass., superiore tribus rostelli vel cilii donato, $8-10 \mathrm{~mm}$. long., $1 \mathrm{~mm}$. crass.

In baccis maturis Titis viniferce Lin. Venetia prope Conegliano, Ant. 1877 leg. et com. C. Spegazzini.

Dem unermuidlichen Fleisse des Ferrn Spegazzini zu Conegliano verdanken wir die Entdeckung dieses nenen Schädlings der reifen Beeren. Da jedoch erst zwei Wochen seit dem ersten Auffinden des Pilzes rerflossen sind, so liegen selbstverstindlich noch gar keine Details über lie Lebensweise, den verursachten schaden und dergleichen vor, und ich muss mich darauf beschr:inken, eine recht genane Beschreibung nach den mir vom Entdecker freundlichst überlasseneu Original-Exemplaren zu geben. Anf den ganz normal entwickelten und auch gefäribten, von Saft strotzenden Beeren finden sich schwärzliche, mehr oder weniger kreisrunde, gehärtete Flecken von $0.5-0.8$ Centimeter Durchmesser. Auf diesem, verhältnissmëissig sehr grossen Flecken, stehen in bedeutender Anzahl die Häufchen des Pilzes, welche eine zwischen halbkugelig und linsenförmig die Mitte haltende Form haben, vereinzelt kommen anch vollkommen kegelförmige Perithecien vor, alle sind schwarz, aus der Epideruis hervorbrechend und von derselben mit einem weisslichen, zerschlitzten Rande rund umgeben, ilı. Durchmesser beträgt ungefïhr 300 bis $400 \mathrm{~mm}$. Die Sporen oder Conidien sind fast spindelförmig, fünfzellig, die drei dicksten mittleren Zellen sind hell olivenbräinnlich, an den Theilungsstellen schwach eingeschnürt und meistentheils mit Guttulis versehen, die beilen Endzellen dagegen sind wie bei vielen anderen Pestalozzia-Arten ungefärbt, mehr oder weniger conisch, die Länge der ganzen Spore ist $35 \mathrm{~mm}$., die Breite 8-10 $\mathrm{mm}$. Am unteren Ende ist der gekrümmte, farblose, gleich dicke, 25-30 mm. lange und nur $1 \mathrm{~mm}$. breite Stiel, während sich am oberen Ende die drei charakteristischen Haare oder 
Schnäbelehen befinden, letztere sind farblos und messen $8-10 \mathrm{~mm}$. in der Länge und $1 \mathrm{~mm}$. in der Dicke. - Auf Tranben der Verdisa-Sorte von Vitis vinifera Lin. im September 1877 von C. Spegazzini bei Conegliano in Venetien entdeckt und mir mitgetheilt.

\section{Pestalozzia Thimenii Spegaz. nor. spec.}

P. acervulis oblongo-depressis, primo epidermidem tumefacentibus, dein longitudinaliter erumpentibus, $300-350 \mathrm{~mm}$. long., $60-90 \mathrm{~mm}$. crass.; sporidiis (conidiis) cuneiformibus, deorsum attenuatis, ex hyphis repentibus, fuligineis, septulatis, 3-4 mm. crass. oriundis, quinquelocularibus, dilute olivaceis, loculi duo extimis vix pallidioribus, omnibus plus vel minus guttulatis $35 \mathrm{~mm}$. long., $6 \mathrm{~mm}$. crass., pedicello versiforme ac varia longitudine, $5-10 \mathrm{~mm}$. long., 2-2.5 $\mathrm{mm}$. crass. hyphis suffultis; loculo supremo inaequilaterali cimbiformi, duo rostellis crassiusculis, hyalinis, $15 \mathrm{~mm}$. long., $1.3 \mathrm{~mm}$. crass. donato, $11 n$ e vertice, alio e latere orientibus.

Ad acinos maturos Vitis viniferce Lin. Venetia: Conegliano, Sept. 1877 detexit et com. C. Spegazzini.

Noch ein neuer Schädiger der reifen Beeren, welcher ebenfalls von Herrn C. Spegazzini zu Conegliano entdeckt ward. Er gehört derselben Gattung an wie die vorige Art, ist aber von derselben, wic aus der Beschreibung ersichtlich, himmelweit verschieden. Es bilden sich bei vorliegender Art auf der Oberfläche der gut entwickelten, fast reifen Beere noch grössere, manchmal fast einen Centimeter in ihrer grössten Ausdehnung messende Flecken, welche aber nicht beinalse kreisrund sind, wie bei Pestalozaia uvicola Spegaz., sondern eine ganz muegelmässige Gestalt haben; ihre Farbe ist ebenfalls schwärzlich, die Masse härtlich, die Häufchen betinden sich in grosser Anzahl dicht zusammen gedrängt darauf. Sie sind von einer länglich zusammengedriickten Gestalt, zu Anfang unter der Epidermis, dieselbe blasig emportreibend, alsdann dieselbe der Länge nach spaltend und hervorbrechend, 300-350 mm. lang und 60-90 mm. breit. Die Sporen oder Conidien haben eine ganz besonders eigenthümliche Form, sie sind richtig keilförmig gestaltet, nach unten hin sind sie verschmälert und entspringen aus kriechenden, rauch- 
granen, $3-4 \mathrm{~mm}$. dicken, getheilten Hyphen. Sie sind ferner fünfzellig, hell olivenbräunlich, die beiden Endzellen kaum etwas heller gefürbt als die drei nittleren, in saimmtlichen finden sich zahlreiche Guttuli, die Länge beträigt $35 \mathrm{~mm}$., die Breite $6 \mathrm{~mm}$, der versehieden gestaltete Stiel schwankt von 5-10 mm. in der Länge bei einer Dicke von 2-2.5 mm. Aus der oberen Endzelle, deren Seitenwände ungleich sind, entspringen die beiden Cilien oder Borsten, die eine an Scheitel, die andere an der Seite, sie sind farblos, $15 \mathrm{~mm}$. lang und $1.3 \mathrm{~mm}$. dick. - Ueber den, durch diesen neuen Parasiten verursachten Sehaden lässt sich ebenso wenig etwas angeben, wie bei der vorigen Art, da, zur Zeit, wo ich dieses niedersehreibe, der Sehädling erst drei Woehen bekannt ist; binnen Kurzem dürfte aber wohl auch über diese Art Weiteres publicirt werden. - C. Spegazzini entdeckte unseren Pilz auf reifen Beeren der Dall Ochio-Rebe, einer Form von Vitis vinifera Lin. bei Conegliano in Venetien im September 1877.

Phoma uricola Berk. et Curt.

Berkeley, Notices of North American Fungi in Grevillea II. p. 82, no. 382. Pirotta, funghi parassiti dei Vitigni p. 52.

Ph. irregulare cuticula anguste cinetum; sporis oblongis. Berk. 1. e. - Ph. peritheciis dense gregariis, acinos ambiens, minutis, prominulis, epidermide cinctis, primo tectis, demum liberis, nigris; sporis numerosis, variis, globosis, ellipticis rel oblongis, uni- vel binueleatis, utrinque rotundatis, achrois, $4-6 \mathrm{~mm}$, diam.

Ad acinos subrivos et maturos Titis aestivalis Melix. America septentrionalis: Carolina australis (Ravenel.).

Auf den Beeren der in den sïdlichen Theilen der nordamerikanischen Freistaaten viclfach eultivirten Sorte "Warren" oder "Herbemont Madeira" bildet dieser Pilz sehr dicht bei einander stehende, die ganze Beere umgebende, kleine Peritheeien, welche Anfangs bedeckt, später aber frei sind und von der durchbohrten Cuticula randartig ungeben werden, ihre Farbe ist schwärzlich; die zahlreichen Sporen sind von verschiedener Gestalt, bald sind sie kugelig, bald elliptisch, bald oblong, sie haben ein oder zwei Nuclei, je nach der Grösse, sind an beiden Enden ab- 
gerundet, wasserhell und messen zwischen 4 und $6 \mathrm{~mm}$. im Durchmesser. - Ohne Zweifel haben wir es hier mit einem wirklichen und zwar sehr heftig' auftretenden Schädiger des Weinbaus zu thun; die vielen Hunderte von befallenen Beeren, welche mir vorliegen, sind nach erfolgter Reife sämmtlich eingeschrumpft und ganz saftlos geworden, und da, mir zugegangenen Berichten zufolge, der Parasit epidemisch auftritt, ist der Schade ohne Zweifel ein sehr bedentender. - Ich kenne den Pilz nur auf Beeren von Titis aestivalis Mchx., und zwar auf oben genamnter Sorte, er ward im Staate Süd-Carolina von Ravenel gesammelt. (Tab. III. fig. 11.)

Phoma uricola Berk. et Curt. nor. rar. Labruscae Thüm.

A forma typica differt sporis regularibus, semper subglobosis, majoribus, $7-8 \mathrm{~mm}$. diam.

Ad Jitis Labruscae Lin. acinos maturos, adhue pendulos sed corrugatos. - America septentrionalis, New-Jersey (J. B. Ellis).

Von der vorstelienden Art unterscheidet sich diese Form, welche ich geneigt bin, nur als T'arietät davon zu betrachten, äusserlich durch die etwas kleineren Perithecien, welche aber ausserdem denen der Hamptart vollkommen gleichen; die Sporen sind regelmässiger geformt, ihre Gestalt ist stets eine fast kugelige, sie sind grösser, nur mit cinem Yucleus versehen und messen im Durchmesser 7-8 mm. - Von meinem Freunde J. B. Ellis ward im Sommer 1877 vorstehende For'm in Newfield im nordamerikanischen Staate New-Jersey an fast reifen, noch hängenden, aber stark eingeschrumpften Beeren von Titis Labrusca Lin. aufgefunden und mir eingesehickt.

\section{Phoma baccae Catt.}

Cattaneo in Rendiconti R. Istituto Lombardo di scienze e lettere, Ser. II. X. fasc. VII. - Id. in Archivio triennale Laborat. crittogam. di Pavia. II. Tab. \&. fig. 1-3. - Pirotta, funghi parassiti dei Vitigni p. 56.

Ph. peritheciis maculis brunneis cireumdatis, atris, globosis, ostiolo punctiformi, minutissimo pertusis, primo sub epidermide latentibus, demum erumpentibus; nucleo albido, gelatinoso, basidiis e stromate centrali oriundis centrifugis, clavatis, conidia bi- vel 
tristerigmatibus subuliformibus adfixa gerentibus; conidiis ovoideis, utrinque rotundatis, unilocularibus, bi- vel trinucleatis, $12 \mathrm{~mm}$. long. - Catt. 1. c.

In Vitis riniferce Lin. baccis submaturis. Autumno. Italia in Etruria leg. Targioni-Tozzetti.

Diese weitere Species der artenreichen Gattung Ploma, welche anf den Weinbeeren vorkommt, scheint mir bestimmt von Phoma uvicola Berk. et Curt. verschieden zu sein. Die Perithecien, von bräunlichen Flecken rund nmgeben, sind kugelig, schwarz, zuerst von der Epidermis bedeckt und sich unter derselben vollkommen ausbildend durchbrechen sie späterhin dieselbe mit einer sehr winzigen, punktförmigen Mündung. Der imnere Kern ist weisslich, gallertartig, die central aus dem Stroma sich entwickelnden Basidien sind keulenförmig und tragen die zwei bis drei pfriemligen Sterigmen, woran wieder die eiförmigen, an beiden Enden abgerundeten, einzelligen, zwei bis drei Nucleis enthaltenden Sporen von 12 mm. Länge, gebildet werden. Prof. Targioni-Tozzeti entdeckte diesen Parasiten, welcher ein Einschrumpfen der Beeren verursacht und sie zur Bereitung von Wein ganz ungeeignet macht, an mehreren Orten Toscanas und auf mehreren Sorten von Vitis vinifera Lin. im Spätherbst, kurz vor der Traubenreife.

\section{Myrothecium convexum Berk. et Curt.}

Berkeley, Notices of North American Fungi in Grevillea III. p. 99. no. 616. Pirotta, funghi parassiti dei Vitigni p. 74.

II. receptaculis papillaeformibus; sporis breviter fusiformibus, $4 \mathrm{~mm}$. longis. - Berk. l. c.

Ad acinos emortuos Vitis Labruscae Lin. America septentr. Pennsylvania, leg. Michener.

Die, schon mehr als lakonische, Beschreibung dieser Art lautet beim Autor: Das Fruchtlager ist warzenförmig und wird sehr schnell von einem weissen Ueberzuge bedeckt; die Sporen von $3 \mathrm{~mm}$. Länge sind kurz spindelförmig, melı als um die Hälfte schmäler als lang. - Auf welken Beeren von Vitis Labrusca Lin. im nordamerikanischen Staate Pennsylvanien durch Michener entdeckt. 


\section{Sphaceloma ampelinum De By.}

De Bary in Annalen der Oenologie IV. p. 165-167. - Asteroma viniperda Thiim. Herb. mycolog. oeconomicum no. 129.

Sph. maculas sparsas, plus minusve orbiculatas, griseo-fuscas, obscure marginatas, postremo dilaceratas in foliis, maculas solitarias, magnas, atras, pallide cinctas, exeoriatas in sarmentis petiolisque nee non maculas fusco-nigras, subplanas, vix marginatas, minutas in acinis uvarum formans; hyphis paucis, repentibus tenuissimis, hyalinis sub cuticula nidulantibus, sporas minutissimas, subeylindricas, $2 \cdot \overline{\mathrm{o}}-3 \mathrm{~mm}$. long., $1 \mathrm{~mm}$. 'crass., hyalinas gerentibus.

Ad folia, petioles, sarmenta acinoscule viva Vitis viniferce Lin. - Palatinat. rhen. (Schmidt), Nassovia, Hassia (Thümen), Alsatia, Badenia (De Bary), Silesia superior (Sorauer), Bohemia septentr. (Thümen), Hungaria (Menyhard), Sabaudia (Rösler).

Seit dem Jahre 1873 erst ist dieser Schmarotzer der Reben bekannt und, zuerst nur in einem sehr beschränkten Raume zwischen Rhein, Nahe und Lauter auftretend, erscheint der Pilz jetzt alljährlich fast in allen weinbautreibenden Gegenden zum Schrecken der Bevölkerung. Am Rhein hat er den Vulgäinamen "Brenner" oder "Pech" der Reben, anderwärts bezeichnet man ihn mit "Schwindpocken" u. s. w. Die erste und bis nun einzige eingehendere. Untersuchung ïber den in Rede stehenden Pilz hat Prof. De Bary im Jahre 1873 vorgenommen und a. a. O. veröffentlicht. Er beschreibt den Pilz folgendermassen: "Er ist charakterisirt durch brame, bald schwarzwerdende, etwas vertiefte und mit einem wulstig-erhabenen Rande versehene Flecke, welche auf allen grünen Theilen, Laub wie Beeren, vorkommen. Später vertrocknen die Flecken und in dem Maasse, als sie zahlreich sind, der ganze befallene Theil. Kleine weisse Pünktchen treten dann oft auf ihnen hervor, zumal wenn man sie in eine etwas fenchte Umgebung bringt. In den jüngsten, zur Untersuchung gekommenen Fleckchen fand sich in der Oberhaut ein kleiner, höchst unscheinbarer Pilz. Seine Fäden sind zuerst in der dicken Aussenwand der Oberhautzellen in der Richtung der Oberfläche verbreitet, später treten ihre Verzweigungen anch auf die Oberfläche, bilden hier dichte Knäucl und treiben von diesen aus, dicht bei einander zu Büschelchen vereinigt, kurze, spitze 
Aestehen, welche sich senkrecht zu der befallenen Oberfl̈̈ehe erheben und an ihren Enden kleine, längtich cylindrische Sporen abgliedern. Diese haben ctwa die Gestalt, Grösse und Structur der, bei der Erysiphe Tuckeri-Krankheit vielfach beschriebenen Cicimobotus-sporen. Auch in dicsem, Sporen abschnïrenden, Zustande ist der Pilz selbst so unscheinbar, dass ich ihn mit der Lupe nicht erkemen komnte, selbst wo seine Anwesenhoit sicher bekannt war. Seine Fiden seheinen jetzt anch tiefer in das Gewcbe der befallenen Theile einzudringen, doch bin ich dariber, aus sogleich anzugebenden Criunden, nieht ausser \%weifel. Die erwähnten kleinen Sporen sinrl, gleich vielon anderen, ähnlich erzeugten, mit ciner Aussenhaut oder Aussenschieht versehen, welche im Wasser zerflicsst, im trockenen Zustande hart wird wie Crummi; anf einer trockenen Oberfläche hatten sie daher fest, in einem Wassertropfen vertheilen sie wieh sofort, ihr Verbreitung im Freien wird also wesentlich unter der Mitwirkmng von Regen und Than geschehen. Man erhält sie rein und rochlich, wenn man junge Flecken mit Wasser in Beriihrung bringt; sie keimen in reinem Wasser, indem sie in der gewöhnlichon Form der Pilzkeimungen wieder zu Fäden auswachsen. Bringt man Wassertröpfchen mit den sporen auf die gesunde Oberffäche griuner Rebentheile, so dringen die Keime in diese ein und es entwickeh sich im Verlaufe von acht Tagen an den besäten Punkten wiederum die charakteristischen, gesehwïrartigen Fleeken, in denen der Pilz seine Sporen von Nenem bildet."

In vicler Hinsicht hat der hier beschriebene Pilz mit dem Gloeosporium ampelophagum. Sacc. eine grosse Aehnlichkeit, bei beiden treten die Pilzfleeken an grumen Ranken, Blattstielen, Blättern und an Beeren auf, die Flecken selbst sind makroskopiseh wenig unterschieden, nur in der Färbung sind sie anders, bei Sphaceloma braun, dann schwarz, bei Gloeosporium rosenroth, in der Mitte asehgran. Die Hyphen stehen bei beiden in Biindelchen, welehe aus der Oberhaut hervorbreehen, doch sind die Sporen unseres Pilzes fast cylindriseh und viel kleiner, nämlieh nur $2 \cdot 5-3 \mathrm{~mm}$. lang, und circa $1 \mathrm{~mm}$. breit, während die des Gloeosporium eirund sind und fast die doppelte Grösse erreichen. Aber trotz diesen angefiihrten Verschiedenheiten glaube ich an eine nahe Verwandtsehaft, wenn nicht gar an eine Identitä beider Formen und wäre, wenn letztere Annahme sich bewahrheiten 
sollte, wohl das Gloeosporium als die höher entwickelte Form zu betrachten. Leider steht mir frisehes Material der Sphaceloma nicht zu Gebote, um der Sache auf den Grund zu kommen, doch hoffe ich binnen Jahresfrist etwas Positives über das Verhältniss beider, vorlänfig noch anseinander zu haltender Pilze publiciren zu können! - Die Sphaceloma tritt, wie oben bemerkt, an Ranken, Blättern und grinen Frichten von Vitis vinifera Lin. anf und ist bis jetzt aus der bairisehen Rheinpfalz (Schmidt), Nassan, Hessen, Böhmen (Thïmen), Oberschlesien (Soraner), Ungarn (Menylıard), Elsass, Baden (de Bary), Savoyen (Rösler) bekannt. (Tab. I. fig. 1.)

\section{Sclerotium urae Desm.}

Desmazieres in Ammales des sciences naturelles, II. Série 1S41. XV. p. 134.

S. subadnatum, rotundum, gregarium, confluens, album, fuscesciens, demum nigrum, rugulosum, intus griseum. - Villo albo aestate evanescenti obtectum. - Desm. 1. c.

In acinis uvarum Titis viniferce Lin., adhuc vivis, plermmque formae coeruleae. - Gallia, Paris, Septembre (1)esmazieres).

Diesen Pilz habe ich nicht zu Gesicht bekommen, habe anch nirgends in der sehr reichhaltigen Literatur, welche ich zu Rathe ziehen komnte, einen Hinweis entdecken können, dass er auch von anderen Botanikern noch gefunden worden sei. Man muss daher den Schluss ziehen, dass er sehr selten ist, Desmazieres gibt über seine Verbreitung und Häntigkeit a. a. O. gar nichts an. Ihm zufolge ist das Sclerotium dem substrate, der Beere, eng anliegend, rundlich, es wäichst gesellig und ist in Folge dessen oft zusammenfliessend; die Farbe ist zu Anfang weiss, wird dann bräunlich und geht zuletzt in schwarz iiber, in welchem Zustande der Pilz mit feinen Runzeln bedeckt ist. Im Innem ist die Farbe gran; der Anfangs vorhandene, wollige Ueberzng der Sclerotien ist wenig dauerhaft, bald verschwindend. - Im September 1839 ron Desmazieres auf fast reifen blanen Trauben von Vitis vinifera Lin. bei Paris entdeckt. 


\section{Sclerotium Vitis Peyl.}

Peyl in Lotos 1857 p. 68 no. 13. Tab. II. fig. 13. - Klotzseh, Herbarium viv. mycolog. no. 1319.

S. compactum, innatum, plus minus hemisphacricum, magnum, meandriforme, rugosum, fusco-atrum, primo album, intus albescens, homogenum, induratum.

In acinis siccis maturis uvarum Titis viniferce Lin. Hieme. Bohemia (Peyl).

In meinem Besitze befinden sich Original-Exemplare aus der Hand des Entdeckers dieser Art. Die Individuen des Sclerotium sitzen entweder cinzeln oder zu mehreren auf den reifen aber eingetrockneten Beeren. Sie hängen nur lose mit deren Schale zusammen und fallen leicht ab, der Duchmesser schwankt zwischen $3 / 4$ und $2 \mathrm{Mm}$. Die Form ist im Allgemeinen eine halbkugelige, doch im hïchsten Grade unregelmässig durch eine Menge Wiulste und Runzeln, welche die ganze Oberfäche labyrinthförmig bedecken. In der Jugend soll der Pilz weiss sein, meine älteren Exemplare sind schwärzlich braun; im Innern ist die Substanz ganz gleichmässig, hart, weisslich. - Auf trockenen Beeren blauer Trauben von Titis vinifera Lin,, vereinzelt an feuchten Stellen im kalten Gewächshause im Winter. Kačin in Böhmen (Peyl). 
II. Die Pilze der holzigen Theile.

\title{
II. Die Pilze der holzigen Theile.
}

\author{
A. Auf lebenden Stämmen und Reben.
}

\section{Cladosporium Fumago Lk.}

Link, Observationes mycologicae II. pag. 37. - Id. in Linné species plantarum cura Willdenow VI. 1. p. 40. - Fuckel, Symbolae mycologicae p. 142 pr. p. Fries, Systema mycologieum III. p. 372 - Kühn, Krankheiten der Culturgewächse P. 140 . - Thïmen in Wiener Landwirthschaftl. Zeitung 1877 p. 177. Thiimen, Herbarium mycologicum oeconomicum no. 76. - Funago vagans Persoon, Mycologia 1. p. 9.

Cl. maculas ampligenas, sed plerumque epiphyllas, late effusas, saepe totam paginam occupans, subernstaceas, suberassas, atras, fumigatas, solubilibas formans; hyphis suberassis, faseieulatis, erectis, panciramosis, brevibus, septatis, septis sublongis, aequalibus, dilute olivaceis; sporis acrogenis, clavulatis, utrinque rotundatis, vertice dilatatis, basi angustatis, medio septatis, subincrassatis, 16-20 mm. long., $5 \mathrm{~mm}$. crass., coloris hypharum. Ad folia, petioles, racemos vivos Vitis viniferae Lin. Sat frequens ubique, autumno.

Unter dem Namen "Russthau" ist dieser Pilz allgemein bekannt und von Gärtnern und Landwirthen gefïrchtet. Wie ich in meinem oben citirten Artikel in der "Wiener Landwirthschaftliehen Zeitung" des Breiteren ausgefuihrt habe, erscheint diese Art auf beinahe allen Bäumen und Sträuchern und sehr vielen krautartigen Pflanzen unserer Culturen und Gärten. Auf dem Weinstock allerdings tritt Cladosporium Fumago nicht häufig wirklich in rerheerender Menge auf, dass es einen effeetiven 
Schaden verursacht habe, ist mir bisher nur aus 'Travemünde bei Lübeck bekannt. Dort trat der Pilz im Herbste 1872 so massenhaft auf, und zwar an den Spalier- und GewächshausReben, dass er nicht nur die sämmtlichen Blätter, jüngeren Triebe und Aeste bedeckte, sondern sich sogar auf den, zum Binden verwendeten, Bast ausdehnte. Die Trauben, deren Kämme dicht mit den Rasen des Pilzes iiberzogen waren, komnten gar nicht zur Reife gelangen und die Weinstöeke kränkelten derart, dass sie zum grössten Theil ganz abgeschnitten werden mussten. Auf benachbarte edlere Obstsorten siedelte der Pilz ebenfalls ïber! - Der Pilz bildet auf beiden Blattflächen weit ansgebreitete, zu Anfang dïnne, späterhin sehr dicke und ablösbare Ueberzïge, auf der oberen Seite herrscht er beim Weinstock und den meisten anderen Nährpflanzen vor, ja auf vielen tritt er oft in Massen vou $1 \mathrm{Mm}$. Dicke auf der Oberseite auf, wälırend die Unterseite ganz frei ist! Die Hyphen sind ziemlich diek, mehr oder minder aufrecht stehend, zu lockeren Bündeln vereinigt nud mit, ziemlich weit auseinanderstehenden, Seheidewinden versehen, ziemlich häufig sind sie einfach verzweigt, die Farbe ist ebenso, wie die der Sporen ein helles Olivenbraun. Die Sporen sind langkeulenförmig, am oberen Ende etwas verbreitert und abgerundet, an der Basis ein wenig versehmialert, in der Mitte haben sie eine Seheidewand und sind hier auf beiden Seiten sehwach eingebogen, ihre Länge beträgt $18-20 \mathrm{~mm}$., ilıre Breite $5 \mathrm{~mm}$. - Ich kenne diesen Pilz, wie schon oben angedentet, bisher auf fast allen lebenden Theilen des Weinstockes, Vitis vinifera Lin. auf Blïttern, Aesten, Wickelranken, Kämmen der Trauben, sowie auf dem Bast, welcher zum Binden gebrancht wird. (Tab. III. fig. 16.)

\section{Cladosporium fasciculatum $\mathrm{Cda}$.}

Corda, Icones fungorum I. p. 14 Tab. 3, fig. 216. - Id. in "Hedwigia" 1862. Tab. 10, fig. 6. - Rabenhorst, Deutscllands Kryptogamen - Flora I. p. 115. no. 1050. - Fuckel, Symbolae mycologicae p. 355. - Cattaneo in Archivio triennale del Laboratorio crittogam. di Pavia II, p. 112. - Pirotta, funghi parassiti dei Vitigni p. 32.

C. acervulis gregariis, minutis, oblongis, olivaceis, floccis brevissimis, simplicibus, fasciculatis, supra septatis, infra continuis, olivaceis; sporis homogeneis, di- vel tridymis. - Cda. l. c. 
Ad sarmenta adhuc viva Titis viniferce Iin., Italia: Firenze (Cattaneo).

Mir ist diese Species sehr wohl bekannt, jedoch nur auf den faulenden Halmen von Scirpus-Arten, auf welchem Substrate allein sie anch ron allen Autoren angegeben wird. Cattaneo will sie nun auch auf noch lebenden Weinranken gefunden haben und zwar in Gesellschaft und auf einem und demselben Mycelium seiner Sphaerella fumaginia. Es wäre höchst wichtig, genau auf diese Pilze zu achten, die vermuthlich auch noch an anderen Localitäten aufgefunden werden dïrften. Dic Räschen des Pilzes sind nur klein, aber dicht gedrängt wachsend, oblong, olivenbraun, die Hyphen sind sehr kurz, unverästelt, in Bündel vereinigt, in ihrem oberen Theile septirt, gegen die Basis hin jedoch nicht, ebenfalls olivenfarben, sie tragen an der Spitze die lomogenen, zwei- bis dreimal septirten Sporen. - In Italien bei Florenz auf noch lebenden Panken von Titis vinifera Lin. (C'attaneo).

\section{Fusisporium Biasolettianum Saec.}

Saccardo in litt. ad me. - Id. Mycotheca reneta no. 1040. - Pirotta, funghi parassiti dei Vitigni p. 72. - Fusarium Biasolettiunum Cda. Icon. fung. II. p. 3. Tab. 8, fig. 14. - Rabenhorst, Deutschlands Kryptogamen-Flora p. 52, no. 514.

F. polymorphum vel effusum, carnoso-tremellosum, crassum, aurantiacum; stromate carnoso, albido, flocesos, floceis septatis; strato sporidiorum crassiusculo-gelatinoso, aurantiaco-rubro, viseido; sporis fusiformibus, utrinque atuminatis, episporio diaphano, glaberrimo, nucleo vesiculoso. - Cda. l. c.

In Titis viniferce Lin. truncis vivis; Istria: pr. Triest (Biasoletto), Italia: Vercelli (Cesati), Padova (Satcardo).

Ich habe keine Gelegenheit, diese, wie es scheint, auf dem Weinstocke nur selten rorkommende Art auf diesem Substrat zu untersuchen und kemnen zu lemen, Exemplare auf Birkenstämmen besitze ich allerdings in meinem Herbar und da dieselben, den Angaben des Autors zufolge mit jenen auf Titis völlig übereinstimmen, so will ich eine Beschreibung nach diesen geben, zuvor jedoch die Bemerkungen Corda's a. a. O. reproduciren. Der Autor sehreibt: "Dieser Pilz bildet 2 Linien bis 6 Zoll lange, mehrere Zoll breite, gallertartige Massen und ähnelt in Farbe und äusserer Form sehr dem Fusisporium Betae Desm. Der 
weissliche 'Trïger' ist oft bis $1 / 1$ roll dick und mit der $1 / 2$ bis 1 Linie dicken Sporenschichte bedeckt. Diese besteht aus dicht verwebten Zellfasern, deren untere Lage vielfaltig verästelt und kriechend ist, während die obere Lage, anfrecht und gedrängt stehend, die Form von Stiitzschläuclıen annimmt. Alle Zellen dieser Flecken sind mit gelblichen Schleimkörnchen erfïllt und zwischen ihnen und den verschieden gekrimmten Sporen sind abortive Zellglieder in Gestalt umegelmässiger Körner eingestreut, welche ein minder geïbter Beobachter sehr leicht für Conidien hält, welche den Pilzen fehlen. Anch hier ist die Spore höher organisirtes, keimfähig gewortenes crlied des Zellfadens des Träigers". So weit Corda. - Die aufrechten und ausserst dieht an einander gedrängten Hyphen sind nehr oder minder nach ihrem Scheitel zugespitzt und haben cine zicmlich dicke Membran, sie sind, ganz analog den Fiporen mit einem könnigen, unregeluässigen Plasma erfïllt. Die selr grossen Sporen sind spindelförmig, mehr oder weniger gekrimmt, manchmal in Form eines griechischen Sigma, an beiden Euden sind sie scharf zugespitzt, an meincon Exemplaren (ob aber immer?) einfach, unseptirt, durchsichtig, wasserhell und haben ein sehr diunnes und zartes Episporium. - Nach seinem Vertrocknen oder besser Eintrocknen auf dem Substrat, bildet der Pilz eigenthümliche, sehr an zarte Tremellincen erinnernde, Massen von schön orangegelber Farbe, sie sind ganz hart und spröde gevorden, lösen sicll aber in einem 'Tropfen Wrasser' sofort wieder anf. - Von Dr. Biasoletto an lebenden, saftstrotzenden Stiimmon von Vitis vinifera Lin. zuerst bei 'Triest in Friihjahr gefunden und rom Autor diescm zu Fhren benamnt, später in Italien auch von Cesati bei Vercelli und von Saccardo bei Padova enteleckt.

\section{Fusisporium Zavianum Sace.}

Saccardo in "Michelia" I. p. 83. no. 44. - Id. in Fungi italici antografice delineati no. 44. - Pirotta, funghi parassiti dei Vitigni p. 73.

F. effusum, albo-flocculosum, tandem medio dilute carneum, erumpenti-superficiale; hyphis undique rersis, parce ramosis, continuis, saepe guttulatis, hinc inde sporophora repetito dichotome ramosa gerentibus, ramulis sursum attenuatis; conidiis fuscideis, falcatis, $30-40 \mathrm{~mm}$. long., $5-5.5 \mathrm{~mm}$. crass., utrinque acatius- 
culis, triseptatis, ad septas parum constrictis, e hyalino dilute roseis. - Sace. 1. c.

In ramis tenellis, petiolis, cirrhis, pedunculisque vivis, quibus plagulas irregulares fuscas affert, quosque tandem enecat, Vitis viniferce Lin., praecipue varietatis etruscae quae Salomona audit. Venetia, prope Vittorio, Mayo 1876 unde misit Dr. I. Zava.

Ein, wie es den Anschein hat, dem Weinstock sehr schädlicher Parasit! Der Pilz bildet auf den lebenden dümnen Ranken, Blätter'n und Blïthenstielen, sowie den Wiekelranken unregelmässige, ausgebreitete, bräunlichrothe Flecken, welche bald das befallene Organ zum Vertrocknen und Absterben bringen. Die Oberfläche der Flecken ist erst weisslich-faserig, dann von der Mitte an sich roth fürbend, die Iyphen sind hin und her gebogen, nur wenig verïstelt, ungetheilt, meistentheils viele Nuclei enthaltend, die fruchttragenden Hyphen-Spitzen sind wiederholt dichoton veräistelt und diese Verästelungen wieder gegen einander geneigt; die Sporen sind spindelförmig, dreimal septirt, etwas gebogen, beiderseits scharf zugespitzt, an den Theilungsstellen unmerklich eingeschnïrt, haben eine Länge von 30 bis $40 \mathrm{~mm}$, eine Breite von $5-5.5 \mathrm{~mm}$. und eine von Wasserhell ins Hellrosa iibergehende Färbung. - In Venetien bei Vittorio ward dieser neue Schädling zuerst im Mai 1876 von Dr. L. Zava anf der Varietait Salomona des gemeinen Weinstockes, Vitis vinifera Lin. aufgefunden. (Tab. IV. tig. 4.)

\section{Amphisphaeria sylvana Sacc. et Spegaz. nor. spec.}

A. peritheciis superficialibus, lignum late circum circa stromatice dealbicantibus, hemisphaericis, rugulosis, carbonaceis, $300-400 \mathrm{~mm}$. diam.; ascis cylindraceo-clavatis, breve stipitatis, $220-230 \mathrm{~mm}$. long., 30-40 mm. crass., octisporis, paraphysibus longioribus, filiformibus, septulatis obvallatis; sporidiis elliptico-ovoideis, uniseptatis, non vel vix ad septum constrictis, utrinque obtusis, olivaceo-fuligineis, $35-40 \mathrm{~mm}$. long., $18-22 \mathrm{~mm}$. crass.

In trunco vivo vetusto, decorticato Vitis viniferae Lin. Venetia: Treviso leg. et comm. Spegazzini Aut. 1877. 
Bisher ward diese schönc neue Species nur auf Reben der venetianischen Malvasier-'Traube gefunden, doch diurfte sie wohl auch auf anderen Sorten vorkommen. Die kaum in die Holzschicht eingesenkten, eigentlich oberflïchlich aufsitzend zu nennenden, Perithecien sitzen anf einem grossen, weitverbreiteten, weissgefärbten Fleck, dicht bei einander, sie sind halbkugelig, schwarz, runzelig, von kohliger Substanz und messen im Durchmesser 300-400 $\mathrm{mm}$. Die zahlreichen Schläuche, welche von fadenförmigen, undeutlich septirten, weit längeren, wasserhellen Paraphysen ïberragt werden, sind keulentörmig-cylindrisch, iiusserst kurz gestielt, achtsporig und haben eine Liinge von 220-230 mm., bei einer Breite von nur 30-40 mm.; sie enthalten die eirundlich-elliptischen Sporen, welche einmal in der Mitte getheilt sind, an dieser T'heilungsstelle sind dieselben jedoch nicht oder wenigstens nur höchst unbedeutend eingeschnürt, an beiden Polen sind sie abgestumpft, die Farbe ist aus dem Rauchgrauen in das Olivenfarbene spielend, die Läinge beträgt 35 bis $40 \mathrm{~mm}$., die Breite 18-22 mm. - In Venetien bei Selva in der Provinz Treviso entdeekte diese Art mein Freund C. Spegazzini in September 1877 auf lebenden, aber kranken und theikweise entrindeten Stöcken vou Vitis viniferc I in.

\section{Sphaerella pampini Thüm. nov. spec.}

S. peritheciis minutis, dense gregariis, Phomate immixtis, vix prominulis, subglobosis, epidermide perforantibus, nigris; ascis mediis, cylindrico-subclavatis, rectis vel minime curvatis, vertice dilatatis, rotundatis, basi angustatis, hyalinis, $62-66 \mathrm{~mm}$. long., 10-12 mm. crass.; sporis late-fusiformibus, distichis, octis, rectis vel subeurvulatis, triseptatis, ad septas non constrictis, utrinque subacutatis, in cellulis mediis bi-, in cellulis lateralibus uni-nucleatis, subpellucidis, olivaceo-flavidis, 14-16 mm. long., $5 \mathrm{~mm}$. crass.

Ad samenta subviva languidave Vitis viniferce Lin. Italia: Parma, vere 1877 (Passerini).

Die sehr kleinen Perithecien dieser neuen Art stehen dicht gedrïngt, untermischt mit Perithecien von Phoma Vitis Bon. sie sind fast genau kugelig, nur wenig aus der, von ihnen durchbrochenen, Epidermis hervorragend, schwarz; die Schläuche 
haben eine keulig-cylinderförmige Gestalt und sind fast immer etwas gebogen, nur ausnahmsweise gerade, an Scheitel sind sie verbreitert, abgerundet, nach dem unteren Ende hin werden sie schmäler, sie sind farblos und besitzen eine Länge von 62 bis $66 \mathrm{~mm}$. und eine Breite von 10-12 mm.; die acht darin enthaltenen Sporen sind zweizeilig angeordnet, sie sind breit spindelförmig, gerade, auch manchmal etwas gekriummt, haben drei Scheidewände und sind an beiden Enden stumpflich zngespitzt. An den Scheidewänden sind sie nicht eingesehnürt, in den beiden mittleren Zellen sind je zwei, in den beiden Endzellen je ein Nucleus, sie sind ziemlich durchsichtig; gelblich, $14-16 \mathrm{~mm}$. lang und $5 \mathrm{~mm}$. breit. Paraphysen sah ich nicht. - Auf noch lebenden and welken Ranken von Titis vinifera Lin. bei Parma in Ober-Italien im Frïhjahre 1877 vom Professor Passerini entdeckt und mir eingesendet. (Tab. III. fig. 2\%.)

\section{Sphaerella fumaginia Ca t a $n$.}

Cattaneo in Archivio triennale del Laboratorio crittogam. di Pavia II. p. 112. Id. Rendic. R. Istituto Lombardo d. Science e Lettere Ser. II. vol. X. fasc. VII. - Pirotta, funghi parassiti dei Vitigni p. 32.

S. mycelio nigrescente superficiale, libere cvohto, e floceis brevibus, contortis, moniliformibus, ramosis, fnscis, dense intricatis composito. Peritheciis atris, globosis, plus minusve dense sparsis, 40-60 mm. latis; ascis clavatis, sessilibus, octisporis, 15 - $20 \mathrm{~mm}$. long.; sporis biserialibus, obovato-clavatis, uniseptatis, ad sepimentum constrictis, loculo superiore crassiore, hyalinis, 5-6 mm. long., $2 \mathrm{~mm}$. crass. - Catt. l. c.

Ad sarmentos vivos Vitis viniferce Lin. Italia, Firenze (Cattaneo).

Mir ist diese Species lediglich aus der oben angeführten Literatur bekannt, der Autor zieht als Conidienform Cladosporium fasciculatum Cda. dazu, welche Art er vermischt mit den Perithecien des Schlauchpilzes auf denselben Rebenstöcken fand. Seine Beschreibung des Schlauchpilzes lantet: Das Mycelium ist aufsitzend, schwarz, und besteht aus kurzen, gedrehten Hyphen, welche ästig, bräunlich, schnurförmig und dicht verwebt sind. Die schwarzen Perithecien sind kugelförmig, mehr oder weniger dichtstehend, $40-60 \mathrm{~mm}$. breit; die Schläuche sind ungestielt, 
keulig, achtsporig, $15-20 \mathrm{~mm}$. lang und enthalten die, in zwei Reihen angeordneten Sporen von eiförmig-keulenförmiger Gestalt, sie sind cimmal septirt, an der Theilungsstelle etwas eingeschnïrt, der obere Theil ist dicker als der untere, die Farbe ist wasserhell, in der Breite messen sie $2 \mathrm{~mm}$., in der Länge $5-6 \mathrm{~mm}$. Bis jetzt ward diese Form erst ein einziges Mal von Dr. Cattaneo bei Florenz auf noch lebenden Ranken von Vitis viniferc Lin. gefunden.

\section{Leptosphaeria Cookei Pirotta.}

Pirotta, funghi parassiti dei Vitigni p. 34. Tab. X. fig. 3-5.

L. ramulicola. Peritheciis sparsis, discretis, epidermide tectis, sphacrico-depressis, superne carbonaceis, nigris, inferne molliusculis, luteolis, e cellulis polygonis obscure contextis, $160-200 \mathrm{~mm}$. latis; ascis crebris, magnis, totum perithecii cavum occupantibus, cylindraceis, vel eylindraceo-clavatis, breviter pedicellatis, curvatis, paraphysibus filiformibus, simplicibus, hyalinis commixtis, $45 \mathrm{rel}$ $100 \mathrm{~mm}$. longis, $12-25 \mathrm{~mm}$. latis, octisporis; sporis fusiformibus, quadrilocularibus, luteolis, medio saepe ralde constrictis, apice obtusis, in aseo oblique uniserialibus, rarius biserialibus, flavis, episporio subtilissimo, absque nucleis, $22 \mathrm{~mm}$. longis, $5 \mathrm{~mm}$. latis.

Ad corticem sarmentorum vivorum Vitis viniferae Lin. Anglia leg. Cooke.

Nur ans der Diagnose, Beschreibung und Abbildung Pirotta's kenue ieh diese Art. Demzufolge sind die Perithecien zerstrent stehend, einzeln, von der Oberhant bedeckt, zusammengedrïcktsphärisch, aussen schwarz, kohlig, innen weich, gelblich, aus vielcekigen Zellen gebildet, 160-200 mm. im Durchmesser. Die Schläuche sind gross, zahhreich, den ganzen Innenraum der Perithecien völlig ausfüllend, eylindrisch oder keulig-cylindriseh, kurz gestielt, gekriimmt, achtsporig $45-100 \mathrm{~mm}$. lang, 12 bis $25 \mathrm{~mm}$. breit und mit zahleeichen, einfachen, farblosen, fadenförmigen Paraphysen untermischt. Die spindelfürmigen Sporen sind vierfächerig, gelblich, meistentheils in der Mitte eingeschnïrt, ein-, selten zweireihig schief im Schlauche angeordnet, ohne Nuclei, mit sehr zarter, dünner Sporenhaut und bei $22 \mathrm{~mm}$. Länge 5 mm. breit. - In England von Cooke auf der Rinde lebender Ranken von Vitis vinifera Lin. entdeckt. 


\section{Cenanginm viticolum Fuek.}

Fuckel, Symb. mycol. p. 270. - Pirotta, funghi parassiti dei Vitigni p. 21. Tympanis viticola Fr. Syst. mycol. II. p. 176. - Schweinitz, Syn. of North American Fungi in Transact. of the Philadelphia Society IV. p. 237, no. 1965. Peaiza viticola Schwntz. Syn. fung. Carol. in Sehriften d. naturforseh. Gesellsch. zu Leipzig I. T. 123 no. 1263 .

C. minutum, sessile, lemisphaericum, rugulosum, opacum, fuscescenti-nigrum, diseo marginato. Species distinctissima, habitu fere Sphaeriae herbarum, substantia molliori, tremelloso-coriacea, ad primam speciem deflectans; sparsa solitaria, innata, disco primo impresso, punctiformi, obtuse marginato, dein dilatata subelapso. Fr. 1. c. - (. peritheciis minutis, sparsis, sessilibus, subhemisphaericis, opaco-nigris, diseo marginatis; ascis clavuligeris, vertice rotundato-dilatatis, basi angustatis, subrectis, hyalinis, $40-46 \mathrm{~mm}$. long., 10-1t mm. crass.; sporidiis octis, fusiformibus vel subcylindricis, subcurvulatis, utrinque acutatis, simplicibus, hyalinis, $15 \mathrm{~mm}$. long., $1 \mathrm{~mm}$. crass.; paraphysibus nmmerosis, ascis aequalibus, filiformibus, gracillimis, hyalinis.

Ad corticem vivam vel emortuam Vitis vinifercte Lin. Europa, locis diversis sed raro, et Vitis Labruscae Lin., America septentr.: Newtield, New-Jersey (J. B. Ellis).

Durch ganz besonders kleine, unscheinbare Perithecien ist diese Art gekennzeichnet und der Vergleich, welchen Fries a. a. O. mit Sphaeria (Pleospora) herbarum anstellt, ist mir nicht recht erklärlich, denn auf allen mir vorliegenden Exemplaren von den versehiedensten Standorten sind die Perithecien des Cenangium um mindestens ein Drittel kleiner als die der genamten Pleospora. Die Gestalt der ziemlich vereinzelt auftretenden Perithecien ist fast halbkugelig, etwas gefurcht, der Rand um die innere Scheibe oder den Discus ist nur wenig erhaben, die Farbe ist schwärzlich oder tief schwarzbraun; die Schläuche haben eine fast keulige Gestalt, sind am Scheitel etwas breiter, abgerundet, unten an der Basis jedoch verschmälert, fast gerade oder wenigstens nur gering gebogen und sind $40-46 \mathrm{~mm}$. lang, 10-14 mm. breit und wasserhell, sie enthalten acht spindelförmige oder schwach gebogen-cylindrische, wasserhelle Sporen, welche an beiden Enden scharf zugespitzt sind, keine Scheidewand besitzen und bei nur circa $1 \mathrm{~mm}$. Breite $15 \mathrm{~mm}$. lang sind. Zahlreiche schlanke, fadenförmige Paraphysen von ungefähr gleicher Länge finden sich 
zwischen den Schläuchen. - In Europa scheiut dieser Pilz sich iiberall, wo Iritis rinifera Lin. gebaut wird, zu finden, jedoch auch iiberall recht selten zu sein; er tritt bei uns nur an abgestorbenen Ranken anf, in Nord-Amerika jedoch kommt er auf der Rinde der lebenden Titis Labrusca lin.-Stöcke vor; ich erhielt ihu aus Newfield in New-Jersey, wo ihn J. B. Ellis sammelte. (Tab. II. lig. 4).

\section{Phoma ampelinmm Berk. et Curt.}

Berkeley, Notices of North American Fungi in Grevillea II. p. 81. no. 380. Pirotta, funghi parassiti dei Vitigni p. 55.

Subenticulare, hysteriforme, sporis fusiformibus, 0.0005 nue. long. - Berk. l. e. - Pl. peritheciis numerosis, dense gregariis, magnis, elevatis, hysteriiformilus, griseo-nigris, sublongis, saepe seriatis; sterigmatibus longis, dense faseiculatis, tenuissimis, hyalinis; sporis acrogenis, late fusiformibus, rectis, numerosissimis, ntrincue acutatis, binucleatis, achrois, $5 \mathrm{~mm}$. long., $3 \mathrm{~mm}$. erass.

Ad sarmenta languida, emortuave Vitis viniferae Iin., Italia: Parma (Passerini), ad Vitis Labruscae Lim. sarmenta, America septentrionalis, Pennsylvania (Michener).

Ziemlich grosse, für die Gattung sogar sehr grosse, Perithecien zeichnen diese Art von den anderen auf Weinreben vorkommenden Phoma-Species aus. Die Perithecien erinneru, wie Berkeley a. a. O. sehr richtig bemerkt, lebhaft an ein Hysterium, sie sind länglich, erhaben, stehen in grosser Anzahl dicht bei einander, manchmal reihenförmig angeordnet und haben eine grau-schwarze Farbe. Auf den zahlreichen, zu dichten Bündeln vereinigten, langen, zarten, farblosen Sterigmen bilden sich die breit spindelförmigen Sporen, diese sind gerade, an beiden Enden stumpflich zugespitzt, ausserordentlich zahlreich, haben zwei Nuclei, sind ganz farblos und messen in der Länge $5 \mathrm{~mm}$., in der Breite $3 \mathrm{~mm}$. - Diese zuerst aus Nord-Amerika bekannt gewordene Art, wo sie Michener in Pennsylvanien auf Reben von Vitis Labresca Lin. fand, ward im Frihjahre 1877 auch bei Parma in Ober-Italien von meinem Freunde, dem Professor G. Passerini, anf welken und abgestorbenen Ranken von Vitis vinifera Lin. entdeckt. (Tab. III. fig. 1t.) 


\section{Phoma Vitis Bon.}

Bonorden, Abhandlungen aus dem Gebiete der Mykologie p. 141. - Pirotta, funghi parassiti dei Vitigni p. 54.

Ph. peridiis rotundis, tenuibus, membranaceis, depressis, ostiolo conico, epidermidem perforante ornatis; basidiis simplicibus, subventricosis, apice sporam orato-ellipticam exserentibus; pustulis minutis, subnigris. - Bon. 1. c. - Sporae 3-3.5 mm. long., $2 \mathrm{~mm}$. crass., hyalinae.

Ad sarmenta viva emortuave Titis riniferce Iin., Austria inferior (Thïmen), Parma (Passerini).

Bonorden gibt a. a. O. woch ferner an: die Peridien werden nicht frei, sondern bedeckt von der Epidermis gebildet, die Zellen der Peridie sind schwäizlich, klein, rundlich, von ihrer inneren Lage entspringen eoncentrisch die Basidien, welche aus langen, oben zugespitzten, unten bauchig erweiterten Zellen bestehen, die an ihrer spitze eine oval-elliptische spore tragen. Ich habe zu dieser, im Allgemeinen ganz guten Beschreibung noch hinzuzufügen, dass die Perithecien (von Bonorden stets Peridien genamnt) ziemlich bald, und zwar sofort nachdem die Sporen ausgereift sind, die Epidermis durchbohren und von derselben in einem kleinen Wulste nmgeben sind. Die Sporen sind vom fast Kreisrunden durch alle Uebergänge bis zum Ovalen, sie sind farblos und messen durchschnittlich $3-3.5 \mathrm{~mm}$. in der Länge und $2 \mathrm{~mm}$. in der Breite.

Es herrscht einige Confusion wegen des mit dem Namen Phoma Vitis bezeichneten Pilzes. Jerlenfalls scheint mir soviel festzustehen, dass die Bonorden'sche Art und der Bonorden'sche Name die ältesten sind, ihnen mithin die Priorität gebührt. Der von den Engländern als Phoma Titis Berkl. et Br. angesprochene Pilz ist von dem unserigen versehieden, wie ich mich durch Untersuchung von Original-Exemplaren iiberzeugt habe; ich gab demselben bereits einen Namen, doch muss derselbe dem Pirottaschen Phoma Cookei, als friiher publicirt, weichen, weiter unten folgt die Beschreibung der nenen Art. - Phoma Vitis Bon. kenne ich bisher nur auf dürren und auf halbdïrren Reben von Vitis vinifera Lin. aus Nieder-Oesterreich (Thümen), und ans Parma in OberItalien (Passerini); von wo die Specimina waren, nach denen der Autor seine Art aufstellte, gibt er leider nicht an. (Tab. III. fig. 13.) 
Ferner kommen auf lebcnden Reben noch folgende, friiher bereits abgehandelte, Species vor:

Glveosporium ampelophagum Sace. - Seite 9.

Splaceloma ampelinum De By. - Seite 18.

\section{B. Auf todten Stämmen und Reben.}

\section{Cladosporium herbarum Lk.}

Link, Observationes mycologicae II. p. 37. - Id. in Car. a Linné, Species plantarum, cur. Willdenow, VI. I. p. 39. - Nees ab Esenbeck, Das System der Pilze p. 67, fig. 64 B. - Martius, Flora cryptog. Erlangensis p. 351. - Acladium herbarum Lk. Observ. mycolog. I. p. 10. - Dematium herbarum Pers. Syn. fung. p. 699. - Id. Mycologia europaea. I. p. 15.

Cl. thallo effuso, floceis dense aggregatis, obscure viridibus, arete adnatis, sporidiis globosis. - Thallus magis minusque effusus, dum recens est tomentum densum efficit coloris obscure viridis fere olivacei. Vetustus non nisi maculam efficit. Sub microscopio composito flocei conspicimtur dense aggregati simplices ant ramo uno alterove brevi, basi contimui septis nullis at transparentes, apices septis pancis distincti, et hine in articulos constricti, qui decidumnt. Sporidia laud frequenter incumbunt parva globosa. Flocei pluvia depressi curvantur et decumbunt, tandem pereunt, collabuntur et nil nisi massa grumosa remanet. Tum est Fumago Pers. Color magis minusque obscurus est, interdum fere niger ut itaque plantula varietates plurimas formet. - Lk. l. c. - Sporis diversissimis: globosis, 2-5 mm. diam., ellipsoideis, ovatis, cylindrico-ellipticis, 2-5 $\mathrm{mm}$. crass., 6-20 mm. long., simplicibus vel uni-, bi-, tri- et pluriseptatis, dilute olivaceis, pellucidis.

Ad sarmenta et folia arida vel subputrescentia Vitis viniferce Lin. Passim.

Ohne alle Uebertreibung kann man sagen, dass es keinen Pilz gibt, welcher so häufig auftritt, als Cladosporium herbarum, dass es aber auch andererseits kcinen gibt, welcher äusserlich sich auf so verschiedene Art präisentirt und dessen Sporen bei eincm und demselben Exemplar so verschiedene Formen annehmen. Bedingt wird diese ganz beispiellose Variabilität durch das Vorkommen auf den verschiedensten Substanzen. Wir finden 
Cladosporium herbarum nicht nur auf todten Blättern und Stengeln aller Pflanzenarten, seien es Bämme, Kräuter, Gräser, sondernn auch auf todten grösseren Pilzen, Agaricus und Polyporus-Arten, auf abgestorbenen Conio- und Myphomyceten, auf Moosen und Moosfrüchten, auf Lichenen, auf entrindetem Holz, auf faulendem Papier, auf Blumentöpfen und Lappen u. s. w. und nicht nur in Europa, sondern auch in allen anderen Erdtheilen. Naturgemäss ist er deshalb hänfig rerkannt und unter verschiedenen Namen beschrieben worden, denn wie nicht nur das Substrat so ungemein verschieden ist, worauf der Pilz vegetirt, so ist auch sein Anftreten ebenso vielgestaltig, bald sind es grosse, zolllange, weiche, olivenfarbene Rasen, bald kleine, licke, grangrine Räschen, bald unscheinbare, fast kam merkliche Piunktchen, bald grosse Colonien. - Der Formen dieses vielgestaltigen Pilzes, welche hier in Betracht kommen, sind es zweierlei. Eimmal diejenige auf abgestorbenen Blättern und dann diejenige auf todten Reben. Anf den Blättern bildet Cladosporium herbarum mehr oder weniger grosse, stets aber ausgebreitete Rasen ron tiefbrauner oder fast schwarzer Farbe, zumeist sind dieselben unterseits, doch erscheinen sie auch auf der oberen Blattfläche. Sie sind nicht umgräinzt, haben ein mattes Ansehen und sind in geringem Grade abwischbar. Die äusserst zahlreichen Hyphen sind mehr oder minder aufrecht stehend, dicht gedrängt, unverzweigt und bestehen aus ziemlich langen Gliedern, an deren Spitzen die Sporen sich bilden. Diese letzteren, welche sofort rom Hyphenende abfallen, sind in ungemeiner Anzahl vorhanden und zeigen uns, um den Polymorphismus des Pilzes auch hier durchzufïhren, die grundverschiedensten Formen, bald sind sie vollkommen kugelig, bald kurz-elliptisch, einfach, bald oval, bald lang elliptisch, bald eylindrisch-elliptisch, man findet einfache, aber auch ein-, zwei-, drei- und vielfach septirte, alle unter einander. Die Grösse ist demzufolge ebenfalls äusserst schwankend, von $2.5 \mathrm{~mm}$. im Durchmesser bei den kugeligen und in der Dicke bei den länglichen, bis zu $20 \mathrm{~mm}$. in der Länge. - Die Form auf abgestorbenen Ranken tritt in weit kleineren, fast polsterförmig zu nennenden Räschen auf, deren Farbe ein schwach ins Dunkelgraue schimmerndes Olivenbraun ist, die Consistenz ist entweder grumös oder fast sammtartig. Der innere Ban ist derselbe wie bei der Form auf den Blättern nnd zeigt uns dieselbe Verschiedenheit in 
den Sporen. Was nun diese Verschiedenheit verursacht, ist noch nicht ganz sicher festgestellt. Fresenius meint a. a. O., es seien verschiedene Alters- und Entwiekelungsstufen. - Tulasne ziehen 1. e. das Cladosporium herbarum als Conidienform zu Pleospora herbarum Rabh. Wenn ich nun auch weit entfernt bin, die epochemachenden Entdeckungen dieser grossen Forseher in Betreff des Generationsweehsels vicler Pilzarten zu bezweifeh, so muss ich mich doeh anch hier abermals, wie schon öfters an anderen Orten mit aller Entsehiedenheit dagegen ausspreehen, solche \%usammenziehmngen verschiedener Pilzformen generell vorzunehmen. Es ist möglich, sogar wahrscheinlich, dass auf einzelnen Substraten, wie Dipsacus, Chenopodium album u. s. w. das Cladosporium herbarum der Vorläufer der genannten Pleospora ist, obwohl bisher nur äusserst wenige directe Culturversuche rorliegen; aber dass aus sehr vielen, ja den meisten Formen des Cladosporium nicht die Pleospora herbarum Rabh. entsteht, unterliegt nieht dem allergeringsten Zweifel und zu diesen Formen gehört auch die, uns hier ganz allein beschäftigende Form auf Weinreben und Blättern. Hier vergeht das Cladosporium nach kïrzerer oder längerer Zeit und entwickelt sich niemals zu Pleospora. --. Auf todten Blättern und Reben des Weinstockes, Vitis vinifera Lin. Vom Herbst bis Friihjahr, ïberall gemein. (Tab. V. fig. 5.)

\section{Arthrobotryum atrum Berk, et Br.}

Berkeley and Broome in Annales of Natural History 1859. III. no. S22. Tab. 9, fig. 6. - Cooke, Handb. of British Fungi p. 563, no. 1685. - Saceardo, Mycologia veneta p. 181. - Id. Michelia I. p. 76, no. 12. - Id. fungi italici autogr. del. no. 12 .

A. individuis dense gregariis, atris, minutis, erectis; stipite communi e hyphis connatis composito, brevi, sursum sensim dilatato, laevi, fusco; sporidiis in eapitulo eonfertis, numerosis, ellipticis vel ovatis, utrinque subacutatis, tri- vel quadriseptatis, inaequiseptatis, $30-35 \mathrm{~mm}$. long., $15-18 \mathrm{~mm}$. crass., loculis extimis pallidioribus, caeteris fuligineis.

In sarmentis putridis Vitis viniferce Lin. Venetia: Conegliano, leg. C. Spegazzini.

Auf den halbfaulen Aestchen und Stengeln verschiedener Weiden, dann von Urtica, Salvia glutinosa, Aster Novi Belgï und 
Anderen ist dieser Pilz nicht gerade sehr selten, obwohl er, seiner Kleinheit und Unscheinbarkeit halber gewiss häufig äbersehen wird. Auf den Weinranken bildet er kleine, dichte Rïschen, welche aus eng bei einander stehenden, kurzen, schwarzen, fast pfriemlichen Individuen bestehen. Unter dem Mikroskop zeigt sich ein gemeinschaftlicher Stiel, welcher aus vielen, zusammengewachsenen Hyphen gebildet wird, er ist kurz, nach oben und unten nur unbedeutend verdickt, glatt und braun. An seiner Spitze trägt er die zahlreichen Sporen in Form eines Köpfchens; sie sind elliptisch oder eirund, beiderseits schwach zugespitzt, drei- bis viermal ungleichmässig septirt, $30-35 \mathrm{~mm}$. lang und 15-18 mm. breit, die äusseren Zellen sind hell-, die mittleren aber ganz dunkelbraun gefärbt. - Auf faulenden Reben von Vitis vinifera Lin. bei Conegliano in Venetien von C. Spegazzini gefunden und mir eingesendet.

\section{Chalara fusidioides C $d a$.}

Corda, Icones fungorum, II. y. 9, Tab. 8, fig. 43. - Rabenhorst, Deutschlands Kryptogamen-Flora p. 38. no. 368. - Klotzseh, Herbarium vivum mycologicum Ser. I. no. 1761.

Ch. tenuissima, effusa, alba, Hoccis rigidis, fragillimis, sporis eylindricis, solidis; hyphopodiis lageniformibus, eavis, hyalinis, concoloribus; sporarum long. 21-28 mm., hyphopodiarum long. $8 \mathrm{inm}$. Cda. l. e.

In caudicibus emortuis Vitis viniferae Lin., Saxonia borussica: Hoyerswerda (Preuss).

Dieser ganz originell gebaute Pilz tritt im Allgemeinen nur auf der inneren Eläehe der Rinde von Nadelbäumen auf, wo ihn Corda zuerst auffand von Preuss ward er dann auch auf faulenden Laubblättern und auf Stämmen des Weines gefunden. Er bildet ausserordentlich zarte, weissliche, leicht abwischbare, kleine Räschen, welche meistentheils einzeln stehen, nur selten zusammenfliessen und Spinngeweben gleichen. Das Mycel ist aus steifen, einfachen (nach Corda), sehr zerbrechlichen Hyphen gebildet, daraus erheben sich eigenthümlich flaschenförnig gebildete Fruchtträger von circa $8 \mathrm{~mm}$. Länge mit einer ziemlich dicken Membran und an deren Spitze bilden sich die Sporen. Diese letzteren sind in lange (nach den Angaben des Autors 21-28 mm.) Fäden oder Ketten 
vereinigt, deren Länge durchaus nicht gleich ist, sie bestehen aus den einzelnen Sporen von cylindrischer Gestalt, welche an beiden Enden scharf abgeschnitten sind; sie sind farblos, durchsichtig und messen $4 \mathrm{~mm}$. in der Länge und $1.5-2 \mathrm{~mm}$. in der Dicke. Häutig sind die Sporenketten winkelförmig gebogen. Von Prenss bei Hoyerswerla in Prenssisch-Sachsen auf abgestorbenen stöeken ron Vitis rinifera lin. gefunden. (Tab. IV. fig. 10.)

\section{Circinotrichum maculaeforme Nees a. E.}

Nees ab Esenbeck, das System der Pilze p. 19. Tab. 5, fig. 66 a. - Martius, Flora Erlang. p. 349. - Persoon, Mycologia europaea I. p. 19. - Link in Linné, Species plant. cura Willdenow. VI. I. p. 35. - Psilonia maculaeformis Fr. Syst. mycol. III. p. 452. - Id. S. veg. Scand. p. 495.

C. caespitibus tenubus, maculacformibus, floccis tenellis, circinnato-intortis sporidiisque fusiformibus, rectis, olivaceis. Eximie differt ab aliis maculis floccosis irregularibus, suberumpentibus; flocei circinnato-intricati, subcontigui, sporidia e matrice cnata obtegentes; haec fusiformia, pellucirles, diffluentia. - Fr. l. c.

Ad sarmenta subputrida Vitis viniferce Lin. Venetia: pr. Conegliano leg. C. Spegazzini.

Auf trockenen, zu faulen begimnenden Blättern mehrerer Laubbäume, so narnentlich von Tilic und Quercus tritt dieser Pilz zuweilen, jedoch durchaus nicht oft und überall auf; zum ersten Male sah ich ihn in den Exemplaren, welche ich Herrn C. Spegazzini verdanke, auf Weinreben. Er bildet hier auf den, schon ganz entrindeten Rankenstiicken weit ausgebreitete, staubige, sehr zarte Rasen ohne feste Begrenzung; sie sind im Centrum tief sammtartig schwarz, gegen den Rand hin dagegen matt grau schwärzlich. Die Hyphen sind ungemein zart, kreiselartig zusammengedreht, fast verwachsen, olivenfarbig, sie schniren an ihren Spitzen die zahlreichen, mehr oder weniger spindelig gestalteten, zarten, bald zerfliessenden, geraden, durchscheinenden Sporen von derselben Farbe ab. - Auf halbfaulenden Reben von Vitis vinifera Lin. bei Conegliano in Venetien von C. Spegazzini gefunden. 


\section{Gonytrichum caesium Nees a. E.}

Nees ab Esenbeck in Nova Acta Acad. Natur. Leopold. IX. p. 244, Tab. 5, fig. 14. - Persoon, Mycol. europ. I. p. 19. - Link in Linné, Spec. plant. cura Willdenow VI. 1, p. 3\%. - Cooke, Handb. of Brit. Fungi p. 613, no. 1843. Schwz., Synopsis of North American Fungi p. 275, no. 2572. - Corda, Icones fung. II. fig. 51. - Myxotrichum cuesium Fr. Syst. mycol. III. p. 345 - Sporotrichum verticillatum Spr. Syst. veget. IV. p. 548.

G. fibris caespitosis, intricatis, cinereo-caesiis, ad ortum ramorum ramulorumque patentium nodosis, sporidiis conglobatis, inspersis, globosis, pellucidis. - Caespituli hemisphaerico-pulvinati, una vel duo lineas lati, saepe tamen conflucntes, in statu recenti rore caesio-cinereo obducti, quo demum evanescente fusco-olivacei. Fibrae tenues, rigidae, flexusae, ramosissimae, per intervalla regularia nodis globosis floceo duplo crassioribus, hispidulis praediti, a quorum singulo ramuli solitarii subulati inaequales patentes oriuntur. Ramuli longiores iterum nodosi, breviores simplices, et in his praecipue glomeruli sporidiorum, quae aqua adfusa diflumt, minutissima, globosa, pellucida, copiosissima. Fr. 1. c. - Sporidia ovoidea vel elliptica, $1.5 \mathrm{~mm}$. long., $1 \mathrm{~mm}$. crass. hyalina.

Ad frustula corticis Vitis Labruscae Lin. America septentr.: Pennsylvania. (Schweinitz). Vitis viniferce Lin. et Vitis cordifolice Mchx., Conegliano, Venetiae (Spegazzini).

In Europa ist diese Art ziemlich häufig an abgefallenen Acsten von Laubbäumen, namentlich Eichen; an Weinreben ist sie mir aber erst ein einziges Mal vorgekommen. Der Pilz bildet ziemlich grosse, 1-3 $\mathrm{Mm}$. im Durchmesser haltende und oft in einanderfliessende Rasen von wollig-sammtartiger Consistenz, in der Jugend sind sie graublau, werden jerloch im Alter stets kastanienbraun. Die zahlreichen IIyphen sind sehr diun, zart, fast immer gerade, aufrecht, gebrechlich, manchmal gebogen und sehr ästig, in ganz regelmäissigen Abständen haben sie eigenthïmliche kugelartige Knoten von ungefähr doppeltem Durchmesser der Hyphen, und diese Knötchen sind dicht mit ziemlich langen, steifen Borsten besetzt, zwisehen diesen Borsten stehen ausserdem noch pfriemliche Aestchen hervor, so dass das Ganze unter dem Mikroskop beinahe einer Morgenstern-Waffe ähnelt. Die ungehener zahlreichen Sporen werden von den kuirzeren, nicht knotigen Hyphen abgeschnürt, sie sind winzig klein, wasserhell, 
durchsichtig, elliptisch oder eirundlich (nicht, wie die Autoren sagen und auch Cooke a. a. O. abbildet, kugelig) und messen nur $1.5 \mathrm{~mm}$. in der Länge und knapp $1 \mathrm{~mm}$. in der Breite. Auf einzeln liegenden Stiickehen der Rinde von Vitis Labrusca Lin. bei Bethlehem in Pennsylvanien (Schweinitz); auf todten Ranken von Vitis vinifera Lin. und Vitis cordifolic Mchx. bei Conegliano in Venetien (Spegazzini). (Tab. II. tig. 5.)

\section{Gyrocerus Ammonis Cda.}

Corda, Icones fungorum I. p. 9, Tab. ^, fig. 141. - Rabenhorst, Dentschlands Kryptogamen-Flora p. 38, no. 372.

G. acervulis atris, confluentibus; stromatis strato inferiore atro, superiore luteo, hyalino, celluloso; floceis infra atris, supra attenuatis, huteis; sporis ovalibus, discoideis, depressis. - Cola. l. e.

In ligno sarmentorm putridorum Vitis viniferae Lin. Bohemia: pr. Prag (Corda).

Nach dieser äusserst dïrftigen und ungenügenden Diagnose wird man sich gewiss kein Bild von diesem, allerlicbsten, ganz originellen Pilze entwerfen können. Obzwar ich ihn nicht gesehen habe, will ich doch den Versuch wagen, der Diagnose und Zeichnung zusammen folgend, eine kurze Beschreibung zu liefern, und zwar ganz besonders aus dem frrunde, um Botaniker und andere Leser dieses Buches anzuregen, auf diese reizende Form zu fahnden und sie hoffentlich auch in anderen Gebieten anfzufinden. - Der Pilz bildet sehwarze, zusammenfliessende Häuchen, deren Mycel in scinem unteren Theile schwarz, im oberen gelblich, zellig ist. Die gerade aufsteigenden Hyphen sind am unteren Ende ebenfalls schwarz und am oberen gells. Die Sporen sind mehr oder minder scheibenförmig zusammengedriickt, oval oder rundlich und - das ist das Schöne an unserem Pilz - zu langen, oft aus sechzig und mehr einzehnen sporen bestehenden Ketten verbunden, welche sich schneckenartig in einer Spirale zusammendrehen. Die untersten und demnach anch ältesten Sporen sind die grössten, die obersten die kleinsten und so sieht denn eine solche Sporenkette auf das Täuschendste einem sogenannten Ammonshorn ähnlich, und von diesem leitete Corda auch den specifischen Namen her! - Auf dem Holze von faulenden Reben des gemeinen Weinstockes, Titis vinifera Lin., 
soviel ich weiss, bisher nur allein in Böhmen, bei Prag von Corda gefunden. (Tab. II. fig. 2.)

Helminthosporium decacuminatum Thü m. et Pass. nor. spec.

H. caespitibus effusis, expersis, subgrumulosis, tenuissimis, nigricantibus; hyphis ramosis, tenuibus, eximie brevi-articulatis, tortuosis, inaequalibus, atro-fuseis, 4 mm. crass., sporis longeelavatis, apice decaenminato, deorsum in pedicello angustatis, 4-5 septatis, pallide fusco-griseis, 40 - $45 \mathrm{~mm}$. long., $10 \mathrm{~mm}$. crass.

Italia: Parma in sarmentis aridis Titis riniferce Lin. Majo 1877. (Passerini.)

Ziemlieh dïnne und vielfach unterbrochene, dabei aber doch grosse, schwärzliche Flecken werden ron dieser neuen Art der Gattung "Wurmspore" gebildet. Die befallenen Reben haben über" und ïber eine asehgraue Färbung angenommen, auf welcher die Pilzrasen sich angesiedelt haben. Die Hyphen sind bei unserer Art ästig, ganz ausserordentlieh viel- und dabei kurzgegliedert, diinn, ziemlich ungleich dick, im Durchschnitte $4 \mathrm{~mm}$, und schwarzbraun von Farbe. Die Sporen sind länglieh, keulenförmig, unten gleichsam in einen Stiel versehmälert, am Scheitel aber gerade abgestumpft, ein sehr charakteristisehes Merkmal, QuerScheidewände finden sich $t-5$, die Farbe ist gran-bräunlich, die Länge beträgt 40-45 mm., die Dicke $10 \mathrm{~mm}$. - Diese Art ward in Ober-Italien bei Parma vom Professor G. Passerini im Mai 1877 an sehr alten, diimen Reben des gemeinen Weinstockes, Titis vinifera Lin. gefunden und mir freundlichst mitgetheilt. (Tab. V. fig. B.)

\section{Helminthosporium siliquosmm Berk, et Curt.}

Berkeley, Notices of North American Fungi in Grevillea III. p. 101, no. 624. -.Pirotta, funghi parassiti dei Vitigni p. 80.

H. floceis brevissimis e myeelio repente oriundis; sporis longissimis, apicalibus, linearibus, flexuosis, obtusis, pluriseptatis. Berk. 1. e.

In Vitis vulpinae Lin. sarmentis aridis. America septentr.: Carolina australis. (Curtis.) 
Das Mycelium dieser interessanten Art, welche ich zu meinem grossen Leidwesen nicht persönlich untersuchen konnte, hat, den Autoren a. a. O. zufolge, dickliche, kurze, kricchende Fäden, aus denen ganz besonders kurze, aufrecht stehende Hyphen entspringen. Diese tragen an ihrer Spitze sehr lange, lineale, abgestumpfte Sporen, welche der Quere nach von füufzehn bis zwanzig Mal getheilt sind. Es ist diese Art ganz ausserordentlich von allen anderen derselben Gattung verschieden und mit kemer anderen zu verwechseln. Sie ward von Curtis im nordamerikanischen Staate Sür-Carolina auf todten Ranken von Vitis vulpina Lin. gefunden.

\section{Pyrenotrichum Vitis Schlzr:*)}

Schulzer in Verhandl. der zool. botan. Gesellschaft zu Wien, XX. 1872. p. 645. Pirotta, funghi parassiti dei Vitigni p. 57.

P. peritheeiis plus minus globosis, tuberculatis, nigris, punetiformibus, nucleo albo-griseo; hyphis anguinosis, dense contextis, hyalinis: sporis filiformi-eylindraceis, eurvatis, utrinque non

*) In den Verhandlungen 'der k. k. zoologisch-botanischen Gesellschaft zu Wien, Band XX., 1872, p. b41-648, veröffentlicht Herr Stephan Schulzer von Miiggenburg die dentschen Beschreibungen von 21 Pilzen, davon 20 neue, von ihm aufgestellte Species, welche er alle auf einem einzigen, kaum anderthalb Fuss langen Stiick einer abgestorbenen Rebe von Vitis viniferce gefunden hat. Da der Herr Autor principiell keine Exemplare seiner, wie der Sand am Meere zahllosen, nova species an andere Mykologen vertheilt, auch die, eventuell von ihm ausgefiihrten Zeichnungen nur ganz ausnahmsweise publicirt, anch endlich keine, wie es in der wissenschaftlichen Welt doch Sitte ist, lateinisclien Diagnosen veröffentlicht, so werden seine Arten im Allgemeinen mit grossem Misstrauen aufgenommen und meistentheils von den Mykologen ganz ignorirt. Ich wïrde sicherlich ebenso gehandelt haben, wenn es mir nicht um möglichste Vollständigkeit dieser Zusammenstellung zu thun gewesen wäre. Ich erkßäre jedoch ausdrücklich, keine Garantie für die Schulzer'schen Arten zu ïbernehmen. Die kurzen, vorangestellten Diagnosen in lateinischer Sprache habe ich, so gut es ging, nach seinen Beschreibungen verfasst. - Interessant ist schliesslich auch die Bemerkung, dass der Sprachschatz des Herrn Schulzer ihm keinen anderen Trivialnamen zu Gebote stellte, als "Vitis" und er damit sämmtliche zwanzig neue, von ihm benannte Species belegte!

Ich enthalte endlich mich aller und jeder Bemerkung zu den von Herrn Friedrich Haszlinsky in den Verhandlungen der k. k. zoologisch-botanischen Gesellsehaft zu Wien, 1873. p. 366 und 367, gegebenen Notizen über einige 
acutatis, simplicibus, $17 \mathrm{~mm}$. long., 1.5 mm. crass., hyalinis. Fortasse Gibberae Vitis Schlzr. fungus spermogonicus.

In sarmentis emortuis Vitis viniferce Lin. - Slavonia (Schulzer.)

Der Autor gibt a. a. O. die nachstehende deutsche Beschreibung: Perithecien mehr oder weniger kugelig, höckerig, sehwarz, fast nul punktgross, mit weissgrauem Kerne, zellig gebaut. Nach innen gehen die Zellen ins Branngelbe iiber und erzengen an der ganzen Innenwand concentrisch geschlängelte, in einander dicht verflochtene hyaline Hyphen, welche sehr bald in die wasserhellen, gekrïmmten, fadenförmig-cylindrisehen, an den Enden nicht zngespitzten, unseptirten, durchschnittlich $17 \mathrm{~mm}$. langen und $1.5 \mathrm{~mm}$. rlieken Sporen zerfallen. Im Januar, meistens unmittelbar an Gibbera Vitis Schlzr. anstossend; ich kann es nur für eine Spermogonienform davon halten. - An abgestorbenen Reben von Vitis vinifera I in. in Slavonien von Schulzer gefunden.

\section{Sporodum conopleoides Cida.}

Corda, Icones fungorum I, p. 18, Tab. 4, fig. 217. - Fnckel, Symbolae mycologicae p. 89. - Cooke, Handb. of British Fungi p. 586, no. 1756. - Rabenhorst, Deutschlands Kryptogamen-Flora p. 76, no. 713. - Corda, Anl. z. Studium der Mykologie Tab. B. 14, fig. 1, 2. - Denatium graninun Lib. Crypt. ard. exsicc. no. 284.

S. acervulis minutis, lineam latis, hemisphaericis vel applanatis, atris, densissime gregaris, subdetergibilibus; hyphis erectis, plus minusve simplicibus, primo saepe connatis, demum disjunctis, septatis, fusco-olivaceis; sporidiis globosis vel ellipsoideis, primitus flavidis dein fuscis, nucleatis, nucleo obscuriore.

In Vitis viniferae Lin. sarmentis subputridis, socia Anthostomellae limitatae Sacc. Venetia: Conegliano, autumno leg. C. Spegazzini.

An faulenden und feucht liegenden Halmen, Pflanzenstengeln und hauptsächlich Grasblättern kommt dieser Pilz sehr häufig vor, auf abgestorbenen Ranken und Zweigen viel seltener

dieser Pilze, umsomehr da Rehm in Briefen an mich, die dort aufgestellte neue Gattung und Art Enchusicus Vitis Haszl. als Synonym zu der sehon früher bekannteu und durchaus nicht so sehr seltenen Cryptovalsa ampelina Fuck. zieht. 
und auf Weinreben sah ich ihn zum ersten Male in den, mir giitigst vom Einsender iiberlassenen Exemplaren. Fr bildet hier sehr kleine, kaum eine Linie breite, dicht gesellig bei einander wachsende Räschen, diese sind entweder abgeplattet oder halbkugelig, schwarz und ziemlich leicht verwischbar; die Hyphen sind aufreeht, einfaeh unverästelt, vielfach septirt, olivenbraun; zuerst dicht unter einander verwachsen, trennen sic sich später, die zahlreichen Sporen von kugeliger oder elliptiseher Form sind in der Jugend gelblich, im späteren Stadium nehmen sie dieselbe Olivenfarbe an wie die Hyphen, im Centrum haben sie einen kleinen, dunkler gefürbten Nucleus. - Auf halbfaulem, schon meist entrindeten Ranken von Vitis vinifera Lin. in Gemeinschaft mit Anthostomella limitata Sace. von C. Spegazzini bei Conegliano in Venetien gefunden und mir mitgetheilt.

\section{Sporotrichum alutaceum Sehwz.}

Schweinitz, Synopsis of North American Fungi p. 272, no. 2524.

S. thallo indeterminatim effuso, alutaceo-subolivascente, e floceis laxe et quasi reticulatim intertextis, crassiusculis, aretim cortici adpressis; sporidiis concoloribus, nudis, inspersis. Schwz. l. e.

In cortice putrido Titis Labruscae Lin. longe lateque effusum. America septentr.: Pennsylvania pr. Bethlehem legit Schweinitz.

Ich kenne diese, unzweifelhaft gute und charakteristische Species leider nicht. Das Mycelium derselben ist nubestimmt, sehr weit, sowohl der Länge als der Breite nach àusgebreitet, seine Farbe schwankt zwischen ledergelb und olivenbraun, es besteht aus diunnen, zerstreuten Hyphen, welche netzartig verflochten erscheinen, sehr dick sind und der Rinde dicht angeschmiegt liegen. Die eingestreuten Sporen sind glatt und von derselben Farbe wie die Hyphen. Der Pilz iiberzieht bei Bethlehem in Pennsylvanien die faulende Rinde von Vitis Labrusca Lin. in grossen, langen und breiten Rasen. (Schweinitz.)

\section{Sporotrichum ampelinum 'Thiim. et Pass. nor. spec.}

S. caespitibus tenuibus, sparsis, velutinis, parvulis, austeroolivaceis; hyphis longis, brevi- et multiarticulatis, crassiuseulis, 
inaequalibus, curvulatis, non ranosis, griseo-olivascentibus: sporis globosulis, numerosis, hyalinis, pellucidis, $4-5 \mathrm{~mm}$. diam.

Italia: Parma in sarmentis aridis Vitis viniferce Lin. Martio 1877. (Passerini.)

Vorliegendes Sporotrichum scheint äusserst selten zu sein, es bildet ziemlich kleine, dunkelolivenfarbige Räschen anf abgestorbenen Reben des Weinstockes, Vitis vinifera Lin. Die Hyphen sind lang, verhältnissmässig dick, kurz- nnd vielgliedrig, mehr oder weniger gebogen, aber nicht ästig und graulich-olivenfarben, die kleinen, kugeligen Sporen finden sich zwischen den Hyphen in grosser Menge, sie haben ungefähr $4 \mathrm{~mm}$. im Durchmesser, sind wasserhell und durchsichtig. - Bei Parma in Ober-Italien von Professor G. Passerini im März 1877 aufgefunden. ('Tab. IV. fig. 12.)

\section{Sporotrichum anreum $\mathrm{Fr}$.}

Fries, Systema mycol. III. p. 418. - Rahenhorst, Deutschlands KryptogamenFlora p. 80, no. 754. - Trichodema aurea Pers. Syn. fungorum p. 232. Botrytis aurantiaca Lk. Observ. mycol. I. p. 12, fig. 18. - Id. in Linné, Species plant. cura Willdenow VI. 1, p. 56. - Persoon, Mycologia enropaea I. p. 35. Wallroth, Fl. cryptog. german. II. p. 293, no. 1910. - Westendorp, Les cryptog. d'après 1. stat. naturelle p. 106.

S. floccis ramosissimis, erectis, aurantiacis; sporidiis globosis concoloribus. - Caespites format late effusos ad plures pollices expansas, ad lineam unam crassos, colore persistente. Siccum difficillime a Sporotricho aurantiaco Fr. distinguitur. - Fr. l. c.

Ad pampinos Vitis viniferce Lin. putrescentes. Thuringia (Wallroth).

Die Synonymie dieser Art ist ziemlich verworren und ich glaube, dass sie nicht selten mit Sporotrichum aurantiacum Fr. verwechselt ward und wohl noch wird. Sowohl Link als Fries deuten a. a. O. auf dasselbe hin. Auf faulenden Kräuterstengeln, besonders von Heracleum Sphondylium Lin. und von Cirsium-Arten tritt unser Pilz durchaus nicht selten auf, ebenso auf faulenden Baumrinden und Hölzern, auf Weinranken jedoch sah ich ihn noch nicht. Er bildet meistentheils grössere Rasen (so gross wie Link und Fries angeben, mehrere Zoll lang, sah ich sie allerdings noch nicht), welche fast polsterförmig dick sind und ein dicht verfilztes, kranses, wolliges, fest umrandetes Gewebe bilden. Die aufrechten Hyphen sind ungemein reichästig, goldgelb, dïnn; die 
Sporen sind kugelig, sehr zahlreich, von gleicher Farbe, sie messen eirca $2 \mathrm{~mm}$. in Durchmesser. - Von Wallroth in Thüringen auf faulenden Ranken von Vitis vinifera Lin. gefunden.

\section{Sporotrichum viticola $\mathrm{Seh} w \mathrm{z}$.}

Schweinitz, Synopsis of North American Fungi p. 27:3, no. 2534.

S. thallo longitudinaliter ad dne vel tres uncias effuso, pallido, e floceis basi in membranulam aut pelliculum contextis, ceterum autem subereetis et sublanosis quamquam intertextis, superne onustis ereberrimis sporidiis rubris ac lateritiis, nullimodo unquam vellatis. - Schwz. 1. e.

In rimis corticis Vitis Labruscae Lin. exsoleti. Pennsylvania, America septentr. (Schweinitz.)

Noch eine Art der vielgestaltigen Gattung Sporotrichum, aber auf den ersten Blick von der vorhergehenden unterschieden. Das Mycelium ist bei unserer Species bis zu einer Länge von zwei und drei Zoll - fünf bis acht Centimeter - lang ausgebreitet, hellfarbig und besteht aus Hyphen oder Fäden, welche an ihrem unteren Ende gleichsam zu einer Art Membran oder Deckhaut verflochten sind, dann erheben dieselben sich fast ganz gerade anfrecht, sind fast wollig und an ihren oberen Enden ungemein dicht und massenhaft mit den rothen oder ziegelfarbenen Sporen bedeckt. In den Spalten und Rissen der Rinde alter, abgestorbener Vitis Labrusca-Staimme in Penusylvanien, Nord-Amerika, von Schweinitz entdeckt.

\section{'Trichothecium roseum Lk.}

Link, Observationes mycolog. I. p. 16, fig. 27. - Hoffimann in Bot. Zeitung 1854. p. 249. Tab. VIII. A. fig. a-p, A-Q. - Bischoff, Kryptogamen-Kunde fig. 3803. - Loudon, Encyclopedia of plants fig. 16575. - Fries, Summa veg. Scand. p. 492. - Link, in Linné, species plantarum, cura Willdenow, VI. Pars I. p. 28. - Fuckel, Symbolae mycologicae p. 360. - Fries, Syst. myeol. III. p. 427. -- Puccinia rosea Corda, Icones fing. I. p. 6, Tab.2, fig. 98. - Botrytis rosea De C. Flore française II. p. 71. - Sporocephalum roseum Chev. Flora paris. I. p. 60. - Trichoderma roseum Pers. Syn. fung. p. 231. - De C. Flore française VI. p. 13. - Trichodemia rosea. Hoffmann, Flora german. II. Tab. 10, fig. 1. - Dactylium rosenm Berkeley in Ann. of Natural Hlistory no. 242. Cooke, Handbook of British Fungi p. 608.

'Tr. thallo crassiusculo, limitato, floceis intricatis, densis, sporidiis didymis, oblongis roseis. - Caespites format pulvini 
instar elevatos lineae aut duarum diametro, tum confluentes et majores, colore primum albo tum roseo. Adultum saepe latas plagas occupat, sat crassum. -- Lk. 1. c. - Sporae hyalinae, didymae, ovatae, utrinque rotundatae, saepe basi minus subacutatae, 8-10 mm. crass., $12-14 \mathrm{~mm}$. long.

In Vitis vimiferae Lin. sarmentis, foliisque subputridis vel minus bene siceatis. Ubique.

So wie auf allen anderen regetabilischen Substanzen, welche in der Zersetzung begriffen sind, tindet man auch dieses Trichothecium auf halbfaulen oder auf schlecht und ungenügend getrockneten Reben und Blättern des gemeinen Weinstockes, Titis vinifera Lin. und vermuthlich auch, obgleich ich weder Exemplare sah, noch in der betreffenden Literatur eine diesbezïgliche Notiz fand, anf denen der anderen Species der Gattung Titis. Der Pilz bildet auf den Blättern kleine, gedrängt stehende, wollige Häufchen, auf den Reben hingegen manchmal solche von 30 bis 40 Millimeter Länge und entsprechender Breite, polsterförmig und, im frischen Zustande, stets von wunderschön zarter rosa Farbe. Die Hyphen sind mchr oder weniger aufrecht, etwas gebogen, vielfach septirt, manchmal an den Scheidewänden ein wenig eingeschniirt und stehen in diinuen Bündeln zusammen. Ihre Farbe ist, so wie die der Sporen, unter dem Mikroskop eine wasscrhelle. Die Sporen stehen zu dreien bis sechsen an der Spitze der schlanken Hyphen, sie sind mehr oder weniger oval, zuweilen an der Basis ein klein wenig verschmälert, am Scheitel stets abgerundet. In der Mitte haben sie eine Scheidewand, sind hier jedoch wenig oder kaum merklich eingesehnürt. Die Grössendimensionen belaufen sich auf $12-14 \mathrm{~mm}$. in der Länge und 8-10 $\mathrm{mm}$. in der Breite. Das Episporium sowie die Scheidewand sind verhäitnissmässig dick. (Tab. III. fig. 2.)

\section{Trichothecium candidum Wallr.}

Waltroth, Flora germanica cryptogamica II. p. 285. - Bonorden, Handbuch der Mylkologie p. 99. Tab. VI. fig. 167. - Corda, Anleitung zum Studium der Mykologie Tab. B. 9, fig. 2. - Regel, Gartenflora 1852. Tab. 21, fig. 7-10.

Tr. hyphis tenerrimis, remote septatis, primum in acervulos subrotundos, exiguos, lanosos congestis, dein confluentibus; hyphasma effusum, contiguum, laxum, candidum mentientibus; spo- 
ridiis ovato-oblongis, utrinque aequaliter obtusatis, concoloribus, mediotenus septatis, lyyalinis, creberrime interspersis. - Color immutabilis candidus, nec rosam immiscens. - Wallı. 1. c. Sporidia 16-22 mm. long., 9-11 mm. erass.

Ad pampinos putres Vitis imiferae Lin. Austria inferior. Raro. Hieme. (Thiimen). Thuringia (Wallroth).

Ueber diesen Pilz gehen die Meinungen der Mykologen sehr auscinander; während der Begriinder der Art, Wallroth, die Sporen einmal getheilt nennt, bilden sowohl Corda als anch Bonorden a. a. O. dieselben mit drei Scheidewänden ab. Während Wallroth die Sporen oben und unten gleichmässig abgestumpft nennt und auf diese Gleichmässigkeit sogar eine Unterabtheilung der Gattung gründet ("sporidiis utrinque aequalibus", l. e. p. 284), zeigt die Bonorden'sche Abbildung Sporen, welche an Scheitel abgerundet, an der Basis aber verschmälert, also eigentlich keulenfürmig sind, und Corda bildet sie oben und unten gleichmässig zugespitzt ab. Diese Widerspriiche dïrfte es wohl unmöglich sein zu vereinigen. Meine Exemplare entsprechen auf das Allergenaneste der Wallroth'schen Beschreibung und ich kann mich nur zu der Ansicht hinneigen, dass sowohl Bonorden als Corda andere Pilze vor sich hatten. Der Pilz, wie ich ihn auffand, bildet kleine, höchstens $2 \mathrm{Mm}$. lange und $1 \mathrm{Mm}$. breite, wollige, erhabene Rasen von reinweisser Farbe und ziemlich lockerer Structur, welche, nur selten zusammenfliessend, auf einem äusserst dümen Mycel auf den Reben wuchern. Die Myphen sind sehr zart, mit scheidewänden versehen, einfach und liegen fast einzeh, also nicht verwebt, neben einander; die Sporen sind elliptisch oder länglich-oval, oben und unten abgerundet-abgestumpft, haben ein ziemlich starkes Episporium und eine Scheidewand in der Hitte. An derselben sind sic nicht eingeschnïrt, die Farbe ist wasserhell, die Grösse beträgt 16-22 mm. in der Länge nnd 9-11 mm. in der Breite. - Von dem nahe verwandten Trichothecium roseum Lk. unterscheidet vorliegender Pilz sich durch die stets rein weisse Farbe der Häufehen und deren Kleinheit, dann auch besonders durch die in der Mitte nicht eingeschniirten Sporen. - An halbfaulen oder wenigstens lange im Freien gelegen habenden Reben von Vitis vinifera Lin. - Thüringen (Wallroth), Nieder-Oesterreich (Th.) - Dass Fuckel Recht hat, indem er dieses Trichothecium als Conidiempilz zu Hypomyces ro- 
sellus Tul. zieht, vergl. Symbolac mycologicae p. 182, muss ich ganz entschieden bezweifeln. Soviel mir bekannt ist, regetirt unser Pilz äberhaupt gar nicht auf faulenden Blättern, sondern nur an Ranken, Reben, Aestchen u. dgl. und wahrscheinlich hat Fuckel eine der anderen, unter dem fälschlichen Namen Trichothecium candidum Wallr. gehenden Arten, von denen ich oben gesprochen habe, vor sich gehabt. (Tab. II. fig. 9.)

\section{Septocylindrium virens Sace.}

Saccardo in "Nuovo Giomale botanico italiano" VIII. p. 186. - Id. Mycotheca veneta no. 284. - Id. Michelia I. p. 89 , no. 79. - Id. Fungi italici autografice delineati no. 73. -- Pirotta, funghi parassiti dei Vitigni p. 84. - Septonema Titis Sace. Mycologia veneta p. 176, non Lév.

S. varie effusum, maculiforme, e glauco virens; conidiis catenulatis, cylindraceis, utrinque obtusiusculis, triseptatis, viridulis, $15 \mathrm{~mm}$. long., $3 \mathrm{~mm}$. erass. - Sace. 1. e.

In foliis ramisque putrescentibus Vitis viniferce Lin. Autumno. Venetia. (Saccardo.)

Dieser Pilz bildet rerschiedenartig geformte, doch immer ziemlich grosse, ausgebreitete, fast sammtartige Rasen ron einer matt graugrümen Farbe; die aufrecht stehenden Sporen, die Conidien, sind zu dreien bis sechsen schnurförnig aneinander gereiht, sie sind cylindriseh, beiderseits rundlich abgestumpft, durch drei (selten eine) Querwände getheilt, an den Theilungsstellen nicht eingeschniurt, graugrinlich und $15 \mathrm{~mm}$. lang, $3 \mathrm{~mm}$. breit. Saceardo fand diese Art auf faulenden, diinnen Ranken und Blättern von Vitis vinifera Lin., sowic auch auf verschiedenen anderen Pflanzen in Venetien. (Tab. IV. fig. 2.)

\section{Sporocybe byssoides Fr.}

Fries, Systema mycologicum III. 1. 343. - Cooke, Handb. of British Fungi p. 566. - Saccardo, Mycologia veneta p. 181. - Bonorden, Handb. d. Mykologie Tab. X. fig. 217. - Cooke, Fungi brit. exsicc. no. 278. - Berkeley, Notices of North American Fungi in Grevillea III. p. 100. - Periconia byssoides Pers. Syn. fung. p. 687. - Link in Linné, Species plant. cura Willdenow, VI. 2, p. 109. Fuckel, Symbolae mycologicae p. 136.

S. nigra, capitulo globoso compacto, sporidiis globosis, stipite subulato, apice pellucido. - Mycelium nune maeulare eineras- 
centi-nigrum, uune obsoletum. Stipes tenuis, strictus, 1/2 lineam haud attingens; sporidia globosa, majuseula, in capitulum inaequale compacta. - Fr. 1. c.

Ad folia sarmentaque putrida Vitis species indeterminatac; America septentrionalis, Carolina australis. (H. W. Ravenel.)

Ob auch in Europa diese Art auf Weinreben auftritt, ist mir nicht bekannt, aufgeführt wird sie wenigstens auf diesem Substrate von keinem einzigen Schriftsteller. - Unser Pilz bildet auf einem mehr oder minder deutlichen, oft kaum merklichen Mycelium staubig schwarzbraune Räschen, es erheben sich daraus steife, schwarze, 2-4 Mm. hohe, aufreclite Stiele, welche dicht zusammengedrängt wachsen, an ihren Spitzen tragen sic kugelförmige, aber ungleiche Sporenköpfe von brauner Farbe, welche aus unendlich vielen kugeligen, schwärzlichen Sporen bestehen. Der ganze Pilz erinnert lebhaft an eine Lichene, ein Calicium; er ist ungemein häufig an allerlei faulenden Blättern, Stengeln u. s. w. und ward im nordamerikanischen Staate Süd-Carolina von H. WV. Ravenel auch an Weinblätter'n und Ranken aufgefunden. (Tab. III. fig. 20.)

\section{Fusarium Cesatii Th $\mathrm{T}$ m.}

Fusarium Biasolettianum Cda. Cesati in Klotzsch Herb. viv. mycol. no. 1985 non Corda Ieon.

F. longe lateque effusum, truncos, tam junioribus quam adultorum, usque ad ulnae longitudinem plasmate fulgidi coloris miniati vel cimnabarini, undique effuso et viscide gelatinoso induens. Hyphis tenuibus, ramosis, achrois, flexuosis, longissinis, obsolete septatis, apice obtusatis, $3.5-4 \mathrm{~mm}$. crass., sporidiis solitariis (in speciminibus jam 1853 lectis!), ellipsoideis vel ovatis, utrinque rotundatis, simplicibus, uni- vel binucleatis, dilute rubrofuscis, 6-8 mm. long., $4 \mathrm{~mm}$. crass., vix pellucidis, acrogenis.

In Vitis viniferae Lin. truncis emortuis. Pedemontium: pr. Vercelli leg. Cesati.

Im "Herbarium vivum mycologicum" von Klotzsch, fortgesetzt von Rabenhorst, liegt unter no. 1985 dieser Pilz, welchen der Einsender, Cesati, selbst nur frageweise zu der Corda'schen Art zieht. Da nun aber das Corda'sche Fusarium Biasolettianum spindelförmige, an beiden Enden zugespitzte Sporen hat, so muss 
es ron unserer Art ganz entschicden getrenut werden und wählte ich den Namen des Sammler's und Entdeckers für die neu unterschiedene Species. Der Pilz bildet, wie ähnlich $F$. Biasolettianum, ausgedehnte, fünfzig und mehr Centimeter grosse, ergossene, dünnkrustenförmige, fest dem Holze oder der Rinde anliegende Massen von feuerother oder zimmtbrauner Farbe. Seine Hyphen sind selur zart und dümn, ästig, hin und her gebogen, undentlich septirt, farblos, sehr lang, an den Enden abgestumpft und ungefaihı 3-4 mm. dick. An ihren Spitzen schniuren sie die nicht sehr zahlreichen Sporen ab, diese haben eine eiförmige oder clliptische Gestalt, sind beiderseits abgerundet, einfach, habèn einen oder zwei Nuclei und sind von sehr helhöthlichbräunlicher Farbe; sie sind fast undurchsichtig und messen 6-s $\mathrm{mm}$. in der Länge, $4 \mathrm{~mm}$. in der Breite. - An alten, sowohl als auch an ganz jungen Stämmen des Weins, Vitis vinifera Lin. bei Vercelli in Piemont von Cesati gesammelt. (Tab. I. tig. 9.)

\section{Fusarinm pampini Thüm. et Pass. nor. spec.}

F. acervulis dense gregariis, minutis, globosis, subprominentibus, lineari dispositis, lurido-carneis, sporis areuatis vel raro etiam subrectis, simplicibus, apicibus acutatis, hyalinis, $16-20 \mathrm{~mm}$. long., $4 \mathrm{~mm}$. erass.

Italia: Parma in sarmentis emortuis Vitis viniferae Lin. Martio 1877. (Passerini.)

Von Fusarium tortuosum Thiim. et Pass. unterscheidet sich vorliegende Art sofort dadurch, dass die Häufchen nicht wie bei jenem flache Scheiben, sondern halbkugelige, hervortretende, kleinc Wärzchen bilden, die Farbe ist ebenfalls ein schmutziges Schwärzlich-Roth, die Anordnung auch innerhalb der Rinnen der Oberhaut strichförmig. Die Sporen siud zumeist fast halbmondförmig gebogen, cylindrisch, nur selten beinahe gerade, an beiden Enden scharf zugespitzt, wasserhell, ohne Querwand, $16-20 \mathrm{~mm}$. lang und $4 \mathrm{~mm}$. dick. - Ich erhielt diese Form aus Parma in Ober-Italien, wo sie auf abgestorbenen Ranken von Vitis vinifera Lin., dem gemeinen Weinstocke, im März 1877, von Prof. G. Passerini gefunden wurde. (Tab. III. tig. 9.) 


\section{Fusarium Rösleri 'T'hüm. nor. spec.}

F. acervulis depresso-globosis, primo sub epidermide nidulantibus, demum in rimis erumpentibus, mediis, earneis, solitariis vel sparsis; sporis subrectis, fusiformibus, simplicibus, utrinque acutatis, numerosis, hyalinis, 24-30 mm. long., 5-6 mm. crass.

Ad sarmenta arida Vitis viniferce Lin. Austria inferior: Klosterneuburg (Thümen.)

Ich habe diese neue Art zu Ehren des Leiter's der Klosterneuburger k. k. Versuchsstation für Wein- und Obstbau, des berühmten Oenologen, Professors Dr. Rösler, benannt. Die Häufchen, welehe zu Anfang von der Rindenoberhaut bedeckt sind, brechen späterhin in den Rinnen der gespaltenen Epidermis hervor und stehen hier entweder einzeln oder mehrere zerstreut, sie sind zusammengedrïickt-kugelig, von mittlerer Grösse und fleisehfarben. Die zahlreichen Sporen sind gerade oder nur sehr wenig gekrümmt, spindelförmig', ungetheilt, au beiden Polen zugespitzt, farblos, haben keine Nuclei und messen in der Länge 24-30 mm., in der Breite 5-6 mm. - Wie es scheint, ist dieser Pilz sehr selten, ich fand ihn nur zwei- oder dreimal bisher an abgestorbenen, jedoch noch festen, nicht faulenden Reben von Vitis vinifera Lin. bei Klosterneuburg in Nieder-Oesterreich. (Tab. III. tig. 7.)

\section{Fusarium tortuosum Thüm. et Pass. nor. spec.}

F. acervulis dense gregariis, immersis, orbiculatis, turbatocarneis, minutis; hyphis brevissinis, ramosis, continuis, temubus, hyalinis; sporis suboblongo-cylindraceis, arenatis vel etiam tortuosis, continuis, apicibus rotundatis, hyalinis, $18-25 \mathrm{~mm}$. long., $3-3 \cdot 5 \mathrm{~mm}$. crass.

Italia: Parma in sarmentis aridis Vitis viniferce Lin. Dec. 1876. (Passerini.)

Dieses Fusarium bildet kleine, kreisrunde, ganz flache Scheiben, welche in die ausgebleichte Rinde eingesenkt sind und nur durch ihre triibrothe Färbung sich schwach bemerklich machen. Sie stehen ziemlich gedrängt bei einander und zwar an zahlreichsten in den Rimnen der Oberhaut. Die Sporen, welehe auf sehr kurzen, verzweigten, hyalinen Hyphen gebildet werden, 
sind cylindrisch oder schwach oblong-cylindrisch, gebogen, häufig sogar hin und her gebogen, an beiden Enden abgerundet, ohne Zwischenwände, wasserhell, und haben eine Länge von $18-25 \mathrm{~mm}$. und eine Breite von $3-3.5 \mathrm{~mm}$. - Diese Art ward bisher nur bei Parma in Ober-Italien an abgestorbenen Reben des gemeinen Weinstockes, ritis vinifera Lin. gefunden, und zwar im December 1876 von Professor G. Passerini.

\section{Fusarium riticolum Thïm. nor. spec.}

Nectriae viticolae Berk. et Curt. fungus coniodophorus Pass. in litt. ad me.

F. acervulis solitariis vel sparsis, nonnunquam confluentibus, magnis, elevatis, subepidermali nidulantibus et tum corticem perforantibus, subrugulosis, nitido-subcarneis, Nectriam viticolam Berk. et Curt. saepe toroso ambiens; sporis exacte fusiformibus, subcurvulatis vel etiam rectis, utrinque subacutatis, tri- vel quinqueseptatis, ad septas non constrictis, intus subnucleatis vel grumulosis, achrois, 36- $40 \mathrm{~mm}$. long., $4 \mathrm{~mm}$. crass.

In Vitis viniferce Lin. sarmentis aridis; Rapallo in Liguria orientali. Julio 1876. (Passerini).

Professor Passerini, der Entdecker dieser Art, bezeichnete sie in Briefen an mich als Conidienform der Nectria viticola Berk. et Curt. Ich kann dieser Ansicht nur beipflichten, obwohl eine absolute Gewissheit der Zusammengehörigkeit nicht erbracht ist und eventuell anch $n u$ eine Cohabitation stattfinden kann. Bei Besprechung des erwähnten Schlauchpilzes werde ich die Gründe anführen, warum ich für vorliegende Form einen neuen Namen gewählt habe, kann demnach hier gleich zu der Beschreibung des Pilzes übergehen. Wer sich weiter für die, mich bestimmenden Gründe interessirt, mag eine ausführliche Auseinandersetzung über dieses Thema in meinen "Aphorismen über den Generationswechsel der Pilze, speciell der Uredineen" (im V. Berichte des Botanischen Vereins zu Landshut 1875) nachlesen. - Der Pilz bildet ziemlich ansehnliche Häufchen, welche auf der Holzsubstanz der Rebe aufsitzen und an denjenigen Stellen, wo die Rinde noch nicht abgeworfen ward, durch dieselbe hervorbrechen, die Häufchen stehen entweder einzeln oder zerstrent, zuweilen fliessen auch mehrere in einander, sie sind hoch, haben eine ziemlich rauhe Oberfläche und eine matt 
fleischrothe Farbe. Die sehr zahlreichen Sporen sind äusserst fragil, sie sind genau spindelförmig, an beiden Enden schwach zugespitzt, nur wenig gebogen, oft fast ganz gerade, drei- bis fünfmal septirt, an den Scheidewänden aber nicht eingesehnürt, im Innern grumös oder fast ganz mit winzig kleinen Nucleis angefiillt, farblos, und haben $36-44 \mathrm{~mm}$. in der Länge, $4 \mathrm{~mm}$. in der Dicke. - Es kommt nicht selten vor, dass die Häufchen des Fusarium dic Perithecien der genannten Nectria vollständig umgeben, ein Grund mehr, an die Zusammengehörigkeit beider Formen zu glauben. Andererseits widerspricht wieder dieser Ansicht ganz und gar der Umstand, dass die beiden Autoren Berkeley und Curtis des Fusarium a. a. O. gar nicht erwähnen, sondern nur von einem sehr zarten, weisslichen, dünnen Mycelium sprechen, aus welchem die Nectria entspringt. - Bei Rapallo im östlichen Ligurien an abgestorbenen Ranken unseres gemeinen Weinstockes, Vitis viniferc Lin., im Juli 1876 von Professor Passerini entdeckt. ('Tab. III. fig. 3.)

\section{Fusoma Vitis Sehlzr.}

Schulzer in Verhandl. d. zoolog. botan. Gesellschaft zu Wien. XX. 1872. p. 647. Pirotta, funghi parassiti dei Vitigni p. 71.

F. acervulis minimis; hyphis brevibus, hyalinis, plasmodiophoris; sporis simplicibus vel binis, rectis, fusiformibus, sexseptatis, septemnucleatis, dilutissime flavescentibus, $22-24 \mathrm{~mm}$. long., 3-4 mm. crass.

In Vitis viniferce Lin. sarmentis emortuis, socia Polynemae Vitis Schlzr. - Slavonia. (Schulzer.)

Von diesem Pilze gibt der Autor folgende Beschreibung: Die Sporen entstehen bei dieser Art an der Spitze kurzer, hyaliner, Plasmakügelchen führender Hyphen einzeln oder paarweise, sie sind gerade, spindelförmig, sechsmal septirt, in jedem Fache mit einer Sporidiole (Nucleus), unter dem Mikroskop angefeuchtet, sehr lichtgelblich, 22-24 mm. lang, 3-4 mm. diek. Zwischen Juli und August wegen der Kleinheit der Räschen nur zufällig beim Untersuchen des Polynema Vitis Sehlzr. angetroffen. - In Slavonien auf den abgestorbenen Reben des gemeinen Weinstockes, Vitis vinifera Lin, 


\section{Gloeosporium samentitium Mntg.}

Montagne in Castagne, Catal. plant. Marseille, Supl. p. 58. - Id. Sylloge plant. cryptog. p. 196. no. 663. - Pirotta, funghi parassiti dei Vitigni p. 70.

G. punctiforme, fuscum; maculis orbicularibus, gregariis, haud eonfluentibus; basidiis $40 \mathrm{~mm}$. longis, sporas oblongo-fusiformes, hyalinas, nucleola bina globosa includentes, $10-20 \mathrm{~mm}$. longas gerentibus. - Mntg. - Pirotta 1. c.

In sarmentis emortuis Vitis viniferce Iin. Gallia: Montaudlès-Miramas, leg. Castagne.

In der sehr grossen Sammlung von Castagne'schen Originalspecies, welche meinem Herbar einverleibt ist, fehlt leider gerade diese und einige andere auf Weinstöeken rorkommende Arten. Ieh muss mich daher an Pirotta halten, welchen, den Anschein nach, Originale zu* Vergleichung und Untersuchung zu Gebote standen, denn cr ergänzt die oben gegebene Diagnose des Autors durch Mitheilung der Sporenmasse. - Der Pilz besteht aus kleinen, braunen, punktförmigen Individuen, welche sundliche Flecken bilden, jedoeh meist nur gesellig, selten zusammenfliessend wachsen; die Basidien haben eine Länge von 40 mm., sie sehnüren die Sporen, deren Gestalt von Eiförmigen ins Spindelförmige ïbergeht und deren Farbe wasserhell ist, an den Spitzen ab. Im Innern baben die, 10-20 mm. langen Sporen zwei kugelige Nueleoli. - Bei Montaud-lès-Miramas unweit Marseille in Frankreich von Castagne auf abgestorbenen Reben von Vitis vinifera Lin. entrleckt.

\section{Leptostroma sphaeroides Fr.}

Fries, Observat. mycol, I. p. 196. Tab. 1, fig. 6. - Id. Systema mycologicum II. p. 600. - Schweinitz, Synopsis of North American Fungi p. 250, no. 2184. Rabenhorst, Deutschlands Kryptogamen-Flora p. 141, no. 1286. - Fuckel, Symb. mycol. p. 367. - Wallroth, Flora cryptog. germ. p. 135. - Xyloma nitens Schwz. Synops. fung. Carol. p. 51, no. 262.

L. orbiculatum, tenue, convexum, laeve, secedens, atrum. Punctiforme, regulare, vix nisi fructificans a Sphaeriis caulincolis distinguendum, in ambitu passim dilatato-tenuissimum. Fr. l. c. - Sporidia simplicia, subellipsoidea, hyalina, $25-3 \mathrm{~mm}$. long., $1-1.5 \mathrm{~mm}$. erass. 
In stipitibus emortuis Titis Lrabuscae Lin. America septentr.: Pemsylvania. (Schweinitz.)

Auch in Europa kommt dieser Pilz und zwar ziemlich häufig vor, allerdings nicht auf Weinreben, sondern an Stengeln abgestorbener grösserer Kräinter, wie z. B. Angelica, Chaeroplygllum u. a. m. Er bildet kleine, rundliche, zarte, convexe, glatte, schwarze Pseudoperithecien, welche ohne Ordnung anf den betreffenden Pflanzentheilen zerstreut stehen und kaum halbkugelig hervorragen, am aufsitzenden Rande sind sie meistentheils etwas verbreitert, gleichsam eine Art von Stroma bildend. Die im Innern frei entwickelten Sporen sind ungemein klein, kurz eirund oder auch cylindrisch, farblos, einfach, an beiden Enden abgerundet, olne Nuclei, 25-3 $\mathrm{mm}$. lang, 1.5-2 $\mathrm{mm}$. breit. Von Sehweinitz in Nord-Amerika zu Bethlelıem in Staate Pennsylvanien auf todten Ranken von Vitis Labrusca Lin. entdeckt. (Tab. II. fig. 15.)

\section{Graphium cinerellum Spegaz. nor. spec.}

G. dense gregarium, griseum; stipitibus cylindraceis, atrofuligineis, compositis, sursum parce dilatatis, vertice rotundatis, ex hyphis divergentibus undique villosulis; hyphis fertilibus in apicem hyalinum desinentibus; conidiis ellipticis vel ellipsoideoovatis, hyalinis, biguttulatis. - Certe hoe Graphium Valsae Vitis status conidicus est; accedit ad Grophium fissum Fr. sed hyphis monosporis atque conidiis seorsum non acutatis differt. - Spegaz.

Ad Valsam Vitis in ramulis emortuis Vitis viniferce Iin. Venetia: Conegliano, leg. C. Spegazzini.

Diese nelue Art der Gattung Graphium, die dritte, welche auf dem Weinstock gefunden wird, kenne ich aus einem OriginalExemplar und der dazu gehörenden Zeichnung aus der Hand des Autors. Der Pilz ist grau, wächst gesellig; seine Stielchen sind cylindrisch, dunkel russfarben, aus vielen Glierlern zusammengesetzt, nach oben hin unbedeutend verdickt, am Scheitel abgerundet und bestehen aus divergirenden, wolligen Hyphen. Die fruchttragenden Hyphen sind sehr kurz, gehen in ein wasserhelles Spitzchen aus und tragen die elliptischen oder eirundlich-elliptischen, farblosen, zwei Nuclei führenden sporen. - Nach der Ansicht des Entdeckers soll diese Art den Conidienpilz von T'alsavitigera Cooke 
(Valsa Vitis Nke.) repräsentiren. Ich bin nicht ganz mit dieser Meinung einverstanden, nach dem mir zu Gebote stehenden, allerdings nicht reichen Materiale halte ich dieses Graphium viel eher für einen Parasiten der Talsa, denn es geht dem Schlauchpilze nicht voran, sondern folgt demselben, indem es sich auf den reifen Perithecien desselben entwickelt. Weitere Untersuchungen an Ort und Stelle werden ja zeigen, welche Ansicht die richtigere ist. - Bis jetzt erst einmal bei Conegliano in Venetien von C. Spegazzini auf Talsa vitigera Cooke schmarotzend gefunden.

\section{Periconia chlorocephala Fres.}

Fresenius, Beiträge zur Mykologie p. 21, Tab. 4, fig. 10-15.

P. caespitibus laxis, tenuissimis, parvis, atris, penicillatis; hyphis erectis, nitido-atris, strictis, semi millimetro longis, rectis vel subarmatis, deorsum sensim incrassatis; sporis capitulatis in catinulis dichotomis, ovoideis, subfuscis, nucleo obscuro in centro, 10-14 mm. long.

Ad sarmenta putrida Vitis viniferce Lin. Venetia: Conegliano. (Spegazzini.)

Die Räschen dieses seltenen Pilzes bilden schwarze, etwas ins Grünliche schillernde, bürstenartige, feine und diunne Ueberziige auf den Reben; die aufrecht stehenden Hyphen sind nicht septirt, glianzend schwarz, steif, bis zu $1 / 2 \mathrm{Mm}$. hoch, entweder gerade aufrecht oder ein wenig gebogen, gegen die Basis hin sich unmerklich verdickend; an ihrer Spitze tragen sie das grünlich schillernde Sporenköpfehen, welches aus kurzen, doppelt sich verzweigenden Ketten besteht. Die einzelnen Sporen messen 10-14 mm. in der Länge und sind eiförmig, hellbraun mit einem dunkleren Nucleus in der Mitte. - Auf halbfaulen, dicken Reben von Vitis vinifera Lin. bei Conegliano in Venetien von C. Spegazzini gefunden und mir mitgetheilt.

\section{T'ubercularia sarmentorum Fr.}

Fries, Observationes mycologicae I. p. 208. - Fr. Summa veg. Scand. p. 361. Tubercularia vulgaris Tode var. sarmentorum Wallr. Fl. crypt. Germ. II. p. 238.

T. peritheciis dense gregariis, interdum confluentibus, irregulariter dispositis, globosis vel verrucaeformibus, laevibus, mediis, 
pulchre rubris; sterigmatis subbrevibus, rectis, numerosis, cylindraceis, eontinuis, hyalinis; sporis numerosissimis, rectis, eylindrieis, utrinque subrotundatis, simplicibus, hyalinis, $6-8 \mathrm{~mm}$. long., $2 \cdot 5-3 \mathrm{~mm}$. crass.

In sarmentis aridis Titis riniferce Lin. ubique, per annum!

Ein sehr häufiger und wohl in allen Ländern, in denen Wein gebaut wird, rorkommender Pilz. Er bildet dunkel fleisehrothe oder hell ziegelfarbene, mehr oder weniger kugelige Warzen, deren Grösse von einem Stecknadelkopf bis zu $2 \mathrm{Mm}$. Durchmesser schwankt. Die Oberfläehe ist glatt und eben. Die ungemein zahlreichen Sporen, welche am Ende von aufrecht stchenden, geraden, cylindrischen, wasserhellen Sterigmen abgeschnürt werden, haben die Form eines Cylinders, sind farblos und an beiden Enden ganz unbedeutend abgerundet, ihre Länge beträgt 6-8 mm., ilure Dicke nur 2.5-3 mm. - Wie bereits oben gesagt, kommt dieser hübsche Pilz anf abgestorbenen Ranken des gemeinen Weinstockes, Vitis vinifera lin., iiberall vor, auch an keine Jahreszeit ist sein Auftreten gebunden, ich fand denselben sowohl im Winter als im Sommer und Frïhjahr.

Die Vermuthnng, dass diese Tubercularia, sowie andere Arten derselben Gattung als Conidienform zu einer Nectric gehören, fand soeben ihre Bestätigung, indem C. Spegazzini bei Conegliano in Ober-Italien zuerst die Nectria cimabarina Fr. gemeinsam auf einem Rasen mit unserer Tubercularia sarmentorum auffand. (Tab. II. fig. 22.)

\section{Tubercularia subdiaphana Schwz.}

Schweinitz, Synopsis of North American Fungi p. 302, no. 3020.

T. sporidochiis subrotundis globosisve, primum pallide rubris, subdiaphanis; demum nigricantibus aut fuscescentibus. Strato sporidifero satis crasso; basi strigoso-floceosa; aetate demum fatiscit. - Schwz. l. c.

In stipitibus putridis Vitis Labruscae Lin. Raro. America septentr.: Pennsylvania. (Schweinitz.)

Mir ist diese Art unbekannt geblieben, weshalb ich lediglich die kurzen Angaben des Entdeckers reproduciren kann. Das Receptaculum orler Köpfchen des Pilzes ist mehr oder weniger kugelig, zu Anfang blassroth, beinahe durchsichtig, wird aber 
späterhin dunkelbraun oder schwärzlich. Die Sporenschicht ist ziemlich dick, an der Basis striegelig-flockig, im Alter zerfallend oder zerfliessend. - An faulenden Reben von Vitis Labrusca Lin. in Pennsylvanien bei Bethlehem von Schweinitz entideckt.

\section{Volutella ciliata Fr.}

Fries, Syst. mycol. III. p. 467. - Id. Summa reg. Scand. p. 363. - Cooke, Handb. of British Fungi p. 556, no. 1667. - Bischoff, Kryptogamenkunde fig. 3827. - Tubercularic ciliatc Alb. et Schwz. Consp. fung. Nisk. p. 58, Tab. 5, fig. 6. - Schweinitz, Synopsis of North American Fungi p. 301, no. 3007. Fuscrium ciliatum Lk. in Linné, Spec. plant. cura Willdenow VI. 2 p. 105. Atractium ciliatum Lk. Observ. mycol. II. p. 32.

V. substipitata, ex albido rosea, in ambitu pilis erectis ciliata. - Receptaculo plano-cupulari, orbiculari, pezizoideo, deorsum in stipitem intra matricem plus minus delitescentem producto. Discus capitatus, circa marginem pilis densis erectis aut demum patulis cinctus. Sporidia fusiformia, septata, coacervata in discum compacta; color laetus. - Fr. emend. l. c.

In ramulis cariosis Titis Labruscae Lin. America septentr.: Pennsylvania. (Schweinitz.)

Anf abgestorbenen Aesten und Rindenstiickchen verschiedener Laubbäume und Sträucher kommt dieser Pilz in Europa nicht zu selten vor, liäutig ist er allerdings wohl nirgends; aber auf Weinranken kenne ich ihn nur aus Amerika. Er bildet sehr kleine, gelblich rosenrothe, an der Basis zusammengezogene aber doch nicht gestielt zu nennende Köpfchen, welche zerstrent auf der Nährpflanze sitzen. Rund herum sind dieselben mit gerade abstehenden steifen Haaren oder Borstchen besetzt, welche ziemlich dicht stehen und dem Köpfchen ein eigenthümliches Ansehen verleihen. Die zahlreichen Sporen werden an der Spitze fadenförmiger, zarter, wasserheller Basidien oder Hyphen abgeschnürt, sie sind farblos, oblong-spindelförmig und undeutlich septirt, an beiden Enden zugespitzt. - Schweinitz fand diesen hübschen Pilz an todten Ranken von Vitis Labrusca Lin. bei Bethlehem in Pennsylvanien. 


\section{Ditiola sulcata Fr.}

Fries, Systema mycologicum 11. p. 17\%. - Id. Summa veg. Scand. p. 363. Bischoff, Kryptogamenkunde fig. 337т. - Schweinitz, Synopsis of North American Fungi p. 179, no. 974. - Tulercularic sulcatu Tode, Fungi Mecklenb. I. 1. 21, Tab. 4, fig. 34. - Rabenhorst, Dentsehlands Kryptogamen-Flora p. 57, no. $552 .-\ldots$ Wallrotl, Flora eryptog. germ. II. p. 547.

D. sessilis, erucibuliformis, sulcata, subvillosa, radicata; disco depresso, fulvo. - Affinis D. radicatae, tamen superficie suleata et loco natali certe distineta; historia fere eadem; junior nempe tuberculiformibus, velo tenui villoso, albo, fugaci tecta; mox vero hymenium apice denudatum nudum, tenue, sed firmum et cum reeptaculo coneretum. Receptaculum cum stipite plane confluens, subrotundum, eum uno alterove eontini connascens; basi fibrillis albis radicatum; sensim magis magisque dilatatum, tres vel quinque linea latum; longitudinaliter sulcis profundis exaratum, unde margo undulato-lobatus et fungus superne speetatus, stellatus, vel floriformis apparet. Hymenium fulvum, demum plicatum, gelatinosum. Effoetum et tune temporis haud raro umbilicato-exeavatum dentibus humanis molaribus, corruptis et cariosis non inepte assimilaveris. - Fr. 1. c.

In rimis corticis vetustis Vitis Labruscae Lin. America septentr.: Pennsylvania. (Schweinitz.)

Die anderen Species dieser Gattung sind häufiger als vorstehend diagnosirte Art und namentlich $D$. radicata Fr. ist wohl schon Jedermann auf altem Holze vorgekommen. Der Pilz ist nicht eigentlich gestielt, sondern fast sitzend, eingewachsen mit seinem untersten Theile, etwas zottig, gefurcht, die Scheibe niedergedrückt, röthlichgelb. In semer Jugend hat unser Pilz ungefähr das Aussehen einer Tubercularia und ist in diesem Zustande über und über mit einem vergänglichen, weisslichen Zottenanflug bedeckt, bald daranf verschwinden am Seheitel diese Zotten und das Hymenium beginnt sich dort zu entwickeln. Dieses breitet sich immer mehr aus und erreicht schliesslich eine Breite von einem halben bis ganzen Centimeter, es ist in diesem Zustande fest, gelblich fleischroth, fast kreisrund, in der Mitte niedergedriickt und von einem gefaltet krausen Rande umgeben; der untere Theil des Receptaculum hat noch seine weissen Zottenhaare. Im Reifezustande soll das Hymenium (ich habe diese An- 
merkung Tode's, welche auch Fries a. a. O. wiederholt, niemals bestätigt gefunden) einen sehr unangenehmen, an cariöse Zähne erinnernden Geruch verbreiten. Die Sporen, deren Erwähnung die älteren Autoren ganz übergehen, werden auf fadenförmigen, sehlanken, farblosen Basidien gebildet und sind elliptisch oder eiförmig, sehr klein, am unteren Ende verschmälert, wasserhell. - Schweinitz fand die Ditiola in den Rissen alter Rinde von Vitis Labrusca-Ranken in Pennsylvanien, Nord-Amerika.

\section{Dacryomyces viticola Seliwz.}

Schweinitz, Synopsis of North American Fungi p. 186, no. 1133.

D. biformis. Ex cortice aut epidermide prorumpens, stipite crasso praeditus, basi tomento involuta aut volvata, in eapitulum gyrosum aurantio-rubrum dilatato. - In ligno decorticato autem, effusus gyroso-plicatus, tenuis, ejusdem coloris. Utraque forma servat structuram internam Daerymyeis. - Schwz. 1. c.

Ex epidermide sarmentorum emortuarum Vitis Labruscae Lin. propullans. - America septentr.: Pennsylvania. (Schweinitz.)

Diese niedliche Art der Gattung Dacryomyces, auf deutsch "Thränen-Tropfenpilz", tritt in zwei verschiedenen Formen auf, bedingt durch die verschiedenen Partien der Reben; diejenige Form, welehe aus der Rinde hervorbricht, hat einen sehr dicken, festen Stiel, ist am unteren Theile von einem dichten, wolligen, weisslichen Haargeflecht umschlossen und verbreitert sich oben zu einem runden, gefalteten, scheibenartigen Hymenium von schön orangerother Farbe. Die zweite Form hingegen, welche auf dem Holze der entrindeten Partien sitzt, ist flach ausgebreitet, kreisrund-faltig, sehr zart und dün und von derselben Farbe wie die erst erwähnte. Der innere Bau, sowie die Sporen sind bei beiden Formen gleich. Ietztere, von denen der Autor gar nichts erwähnt, sind elliptiseh, $6-7 \mathrm{~mm}$. lang und $3 \mathrm{~mm}$. breit und werden an der Spitze langer, unten etwas dicker, schlanker Basidien abgeschnürt, ihre Farbe ist wasserhell. - Auf abgestorbenen Ranken von Vitis Labrusca Lin. im nordamerikanischen Staate Pennsylvanien. (Schweinitz.) 


\section{Agaricus Crepidotus proteus Kalehbr.}

Thïmen in „Flora: 1876 p. 424. - Thïmen, Mycotheca universalis no. 503.

Differt ab Agarico variabili Pers. pileo minore, glabro, pallicle fuscescente, non vero tomentoso-albo. Cetero congruunt et evolutionis modus in utroque idem.

Promontorium bonae spei: Somerset-East in ligno humido, fabrefacto, elathrato, vitifero, hortensi, raro etiam in cortice vetusta Vitis viniferae Lin. Jan. 1876. (P. Mac Owan.)

Dieser Hutpilz kommt nur selten und ausnahmsweise auch an der Rinde des untersten Theiles der alten Weinstöeke, Vitis vinifera Lin., vor, sein eigentliches Substrat sind die feucht liegenden, alten, durchlöcherten Weinpfähle. Er bildet an denselben oblonge oder halbkreisförmige Hüte, von einem Durchmesser, welcher zwischen 4 und 25 Millim. schwankt. Der Hut ist oberseitig lederfarben, häufig durch Abblättern der äusseren Sehicht gelbfleckig, der gleichfarbige Rand ist glatt, uur wenig gewellt; die excentrisch stehenden Lamellen sind ziemlicl eng zusammengeriiekt, gegen den Rand hin verästelt, manchmal anastomosirend, braun. Geruch scheint keiner vorhanden. Einen Stiel hat der vorliegende Pilz nicht, sondern er sitzt dem Holze an derjenigen Stelle, an weleher auch sïmmtliche Lamellen zusammenlaufen, unmittelbar auf. - Bisher ist dieser Hutpilz nur vom Vorgebirge der guten Hoffunng bekannt, wo er im Januar 1876 von Professor Mae Owan aufgefunden ward.

\section{Marasmius calopus Fr.}

Fries, Epicrisis syst. mycol. p. 379. - Id. Hymenomycetes europaei p. 472. Quelet, Champ. du Jura p. 222. Tab. 13, fig. 5. - Passerini, Funghi parmensi no. 348. - Agaricus calopus Pers. Syu. fung. p. 373. - Fr. Observ. mye. p. 151. Id. Syst. mycol. I. p. 130. - Weimmann, Hymeno- et Gasteromyc. Rossiae p. 97. Bulliard, Champignons, Tab. 550, fig. 1.

M. inodorus, pileo carmosulo, lento eonvexo-plano depressove, laevi, demum rugoso; stipite fistuloso, aequali, glabro, arrhizo, nitido, badio-rufo; lamellis emarginato-adnexis, tenuibus, albis. Stipes fistulosus, uncialis, lineam unam crassus, sursum leviter attenuatus, laevis, glaber, tenax, rufus vel rufo-badius, nitidus, subradicatus. Pileus leviter carnosus, convexulus, mox explanatus, obtusus, raro depressus, quatuor lineas circiter latus, albidus, tenax, 
laevis, exsiceatus rugulosus, glaber. Caro tenuissima, alba, plane inodora et insipida. Lamellae laeviter emarginato-adfixae, bi- vel quadrinatae, tenues, albidae. - Fr. 1. c.

In sarmentis emortuis Vitis viniferae Lin. Parma. (Passerini.)

An kleinen, halbfaulen Aestchen, Stengehn, Graswurzeln und dergleichen ist dieser Pilz zu finden, doch ist er nirgends häufig zu nemnen. Der Hut ist kaum etwas fleischig, wenig convex gebogen und demnach bald ganz gerade, zuletzt sogar im Centrum einwärts gedriickt, ganz glatt, erst im Alter etwas runzelig, stumpf am Rande, glänzend weisslich, circa 1 Millim. breit, zähe; der $2-2 \cdot 5$ Millim. hohe und $1 / 4$ Millim. dicke Stiel ist fast wurzellos, rölrig-hohl, nach oben unbedeutend verdickt, glatt, zähe, glänzend rothbraun. Die Lamellen sind ausgerandet-angeheftet, zu zwei bis vier verbunden, weisslich, düm. - Auf todten Ranken von Vitis vinifera Lin. unweit Parma im September von Passerini gefunden.

\section{Marasmins viticola Berk, et Curt.}

Berkeley et Curtis in Ravenel, Fungi Carolinae exsiccati, Fasc. V. no. 8. 26. Report of the New York State Museum p. 65.

Ad samenta emortua Vitis Labruscae Lin. - America septentr.: Carolina australis (Ravenel), New-York (Peck).

Es war mir nicht möglich, mir die Beschreibung oder Original-Exemplare dieses Pilzes zu verschaffen. Zu meinem grossen Leidwesen kann ich ihn demnach nur mit Namen anführen. Peck bemerkt iibrigens a. a. O., dass die Species nicht auf Weinranken allein beschränkt sei, sondern auch noch auf anderen abgefallenen Aesten vorkomme. - Dieser Pilz wird ans Nord-Amerika von Ravenel in Siid-Carolina und von Peck in New-York anf abgestorbenen Ranken von Vitis Labrusea Lin. angegeben.

\section{Marasmius candidus Fr.}

Fries, Epicrisis system. mycol. p. 381. - Id. Hymenomycetes europaei p. 474. Quelet, Champign. du Jura p. 199. - Berkeley, Ontlines of fungology p. 22:. Passerini, Funghi parmensi no. 350. - Afaricus candidus Bolton Fungi Tab. 39, fig. D. Agaricus allus Secret. Mycographie suisse no. 801. - Agaricus ramealis Pers. var. Weinmann, Hymenomyc. Rossiae p. 100.

M. albus, pileo submembranaceo, ex hemisphaerico-plano depressoque, pellueido, undo, demum sulcato-ruguloso; stipite 
fareto teuni, incurvo, subtiliter pruinoso, basi floccoso, demunque fuscescente; lamellis adnexis, ventricosis, distantibus. 'Tenax, persisteus; statura varia, pusilla tamen semper. - Fr. l. c.

In Vitis viniferce lin. sarmentis aridis. Parma. (Passerini.) Ziemlich selten kommt diese Art anf Aestchen verschiedener Laub- und Nadelbäume, auf Craswurzeln, todten Kräuterstengeln u. s. w. vor. Der Hut ist weiss, dïnnhäutig, zu Anfang halbkugelig, später flach niedergedriickt, so dïnn, dass er fast durehscheinend ist, sehr klein, kreisımud, glatt, nackt, erst im Alter ein klein wenig runzelig, der Rand ist glatt, ummerklich herabgebogen, ebenfalls rein woiss. Der nicht röhrige Stiel ist etwas gebogen, von der Dicke eines dïnnen Streichhölzchens, an Grunde weissflockig behaart, wenig bewurzelt, bräunlich mit zartem, weissem Reif bedeckt. Die Lamellen sind bauchig erweitert, angeheftet, weisslich und weit auseinander stehend. Von Passerini bei Collecchio unweit Parma auf dürren Reben von Vitis vinifera Lin. im Sommer und Herbst gefunden.

\section{Marasmius epiphyllus Fr. nov. var. sarmentornm 'Thüm.}

Fries, Epicrisis syst. mycol. p. 386. - Id. Hymenomycetes enropaei p. 479. -Berkeley, Outl. of fungology p. 2:4. - Saccardo, Mycol. veneta p. 44. Fuckel, Symıol. mycol. p. 14. - Cooke, Handb. of Brit. Fungi p. 240 no. 679. -Quelet, Les champign. du Jura p. 224. - Agaricus epiphyllus Pers. Syn. fung. p. 468. - Id. Syst. mycol. I. p. 139.

M. (Rotulae) pileo membranaceo, planiusculo, demum umbilicato, glabro, plicato-1ngoso; stipite subcorneo, fistuloso, subtiliter velntino, deorsum spadiceo, insititio; lamellis adnatis, paucis, distantibus, integris, venosis, albis. - Tenellus, sed admodum lentus, revivescens, pileo lacteo. - Fr. l. c.

In samentis emortuis ritis viniferce Lin. Venetia: Conegliano, aestate 1877. Leg. C. Spegazzini.

Das Vorkommen dieses, anf faulenden Blättern, Blattstielen und dïmnen Kräuterstengelı iiberall häufigeu Pilzes, anch auf Weinreben, veranlasste mich, nur des Standortes wegen, eine neue Varietät aufzustellen. In Uebrigen ist vorliegende Form von der Hauptart nicht unterschieden. Der Hut ist dümhäntig, abgeflacht, später oft genabelt, glatt, schwach faltig-r'unzelig, milchweiss und ungemein klein und zart, vielleicht den Durch- 
messer von 11/2 Mm. kaum ïbersteigend; der Stiel ist verhältnissmäissig lang, hin- und hergebogen, sehr zart und schlank, kaum hornartig zu nemnen, röhrig, zart sammthaarig, gleichsam eingepfropft, weisslich gelb, gegen oben hin hellkastanienbraun. Dic Lamellen sind nur wenig zahlreich, angewachsen, weit auseinanderstehend, aderig, haben eine gerade Scheide und sind weiss. Der ganze Pilz macht einen iiberaus zarten und hinfailligen Eindruck. - C. Spegazzini fand ihn bei Conegliano in Venetien auf faulenden Reben von Vitis vinifera Lin.

\section{Lenzites atropurpurea Sace.}

Saccardo, Mycologiae venetae specimen p. 45. in Atti d. soc. Ven. Trent. di Padova II. 2. 1873.

L. pileo contextu lutescente, suberoso-crassiusculo, rigido, sessili, basi breve decurrente, concentrice sulcato radiatimque ruguloso, glabro, unicolori, atropurpureo; lamellis crebris, dichotomis interruptisque, lutescenti-fuscis, marginem obtusiusculum subexcdentibus; sporidiis sphaeroideis, minimis, $2 \mathrm{~mm}$. diam., hyalinis. - Pileus $4-6 \mathrm{~cm}$. latus, 4-5 $\mathrm{mm}$. crass. - Sace. l. c.

Ad truncos ramosque Vitis vinifercte Lin. Italia: Selva pr. Treviso. Aprili 1873. (Saccardo pater.)

Mir ist dieser Hutpilz nur aus der Saceardo'schen Beschreibung a. a. O. bekannt. Der Hut ist dicklich, von lederartiger Consistenz, innen gelblich, aussen glatt, einfärbig-schwärzlichpurpurroth; er ist sitzend, das heisst sticllos, am Ansatz kurz herablaufend, concentrisch schwach gefurcht, $t-6 \mathrm{~cm}$. breit, 4-5 Mm. dick. Die Lamellen von gelb-bräınlicher Färbung sind dicht aneinandergestellt, mit stumpflicher, ein wenig ansgefressener Scheide; die Sporen sind farblos, sehr klein, sphäroidisch geformt und haben einen Durchmesser von $2 \mathrm{~mm}$.

Bisher ward dieser Pilz nur einmal bei Selva in der Provinz Treviso, Venetien, an Stämmen und Ranken von Vitis vinifera Lin. anfgefunden, und zwar vom Vater des, um die Mykologie so hochverdienten Dr. P. A. Saccardo. 


\section{Xerotus viticola Berk. et Curt.}

Berkeley, Notices of North American Fungi in Grevillea I. p. 34, no. 105. Pirotta, funghi parassiti dei Vitigni p. 12. - X. lateritius Ravenel, Fungi Caroliniani exsiccati Fasc. IV. no. 3.

$\mathrm{X}$. pileo tenui, nigro, ramoso-sulcato, scabro, margine pallidiore, lamellis latiusculis. - Berk. 1. c.

In Vitis vulpinae Lin. truncis emortuis. America septentr.: Carolina australis. (Curtis, Ravenel.)

Mein sehr dürftiges, rom Eutdecker dieser Species, Ravenel, selbst gesammeltes Exemplar, zeigt einen kleinen, ungefähr $1 \mathrm{~cm}$. im Durchmesser haltenden schwarzen, fast häutig zu nennenden Hut, dessen Oberseite durch dichtstehende halbsteife Schuppenhaare rauh ist, ausserdem hat er, vom Centrum ausgehende, schmale Falten und diesen entsprechende schmale Rinnen, der Rand ist sehr dünn, gelblich-schwarz, die Lamellen, im getrockneten Zustande bräınlich, weit anseinanderstehend, der sehr kurze Sticl ist schuppig-harig, honiggelb, hin und her gebogen, 1/2 cm. dick. - Von Ravenel erhielt diese Art den Namen Nerotus lateritius, aus welchem Grunde ist mir aber vollkommen unklar, denn ich wiisste nicht, dass irgend ein Theil des Pilzes eine riegelrothe Färbung besaisse. - Auf abgestorbenen Stämmen von Vitis valpina Lin. in nordamerikanischen Staate Süd-Carolina von Curtis und Ravenel gefunden.

\section{Polyporus riticola Fr.}

Fr. Elenchus fungorum p. 115. - Id. Epicrisis system. mycol. p. 4\$2, no. 247. Pirotta, funghi parassiti dei Vitigni P. 12. - Boletus viticola Schwz. in litt. sec. Fr.

P. effusus, glaber, fuscus, poris difformibus, subangulatis, acutis, glabris. - Pro loco natali majuscula species, firma, lineam crassa, cortici omnino innata, plures uncias longa. Pori mediae magnitudinis, micantes, intus glanci rel cinerascentes, dissepimento tenui acuto. Contextus ferruginens, quo et poris intus glaucis a proximis certo dignoscitur. - Fr. 1. e.

In Vitis Labruscae Lin. salmentis emortuis, America septentr.: Salem, Pennsylvaniae. (Schweinitz.)

In Anbetracht der Nährpflanze eine sehr grosse Speeies, da sie auf mehrere Zoll in der Länge die Rinde der Ranke voll- 
kommen einhüllt. Der Pilz ist von fester, derber Beschaffenheit, circa 1 Linie diek, glatt, braun, die Poren sind von mittlerer Grösse, ungleichmäissig, beinahe eckig zu nennen, spitzmündig, schillernd, aussen glatt, immen meergriin oder hellgran und in die zarte, dïnne und spitze Scheiderand der Mïndungen ansgezogen. Die innere Substanz ist rostfarben und dadurch sowohl als durch die inmerhall, meergrinlichen Poren ist diese Art leicht von allen verwandten zu muterseheiden. - Schweinitz entrleckte diese Speeies an todten Ranken und Stämmen ron Titis Labrusca Lin. bei Salem in norlamerikanischen State Pemsylvanien, seitdem seheint sie nicht wieder gefunden zu sein, da nenere amerikanische Autoren ihrer nicht Erwaihnung thum.

\section{Polyporus vaporarins Fr. var. papyracens Schwz.}

Fr. Elench. fung. I. p. 121. - Id. Ëpicrisis system. myeol. P. 487. - Boletus papyrarews. Schwz. Syn. fung. Carol. p. 99, no. 931.

P. membranacens, tenuissimus, sicca adnatus, candidus, poris maximis, obliquis, pallidis. - - Nembrana omnino refert Racodium papyraceum. Pers. (Hupha papyracea Rabh.). Margine sterilis; in longitudinem expansus. - Sehwz. l. c. - Praecipue ob stationem ad Vites emortuas notabilis; ceterum tenuior, poris integris; sed non varietas distincta. - Fr. l. e.

In Vitis Labruscae Lin. cortice emortua. America septentr.: Carolina septentrionalis. (Sehweinitz.)

Eine jedenfalls eigenthiumliche Form orler Varietät des, auch bei uns so gemeinen Polyporus raporarius Fr. Unter den vielen Polyporen, welehe ich aus Nord-Amerikia und besonders aus den beiden Carolina besitze, befindet diese Art sich nicht, sie muss also wohl ziemlich selten sein. Beschrieben wird sie wie folgt: Sehr dïnnhäutig, zart, im troekenen Zustande dem Nährboden dieht angepresst, weiss; der Rand steril, ohne Poren, die Poren ganzrandig, sehr gross, schief und heller gefärbt. Der ganze Pilz erinnert sehr an die, auf faulenden Baumstämmen so häufige Hypha papyracea Rabh. (Racodium papyraceum Pers.); er ist viel kleiner und dïnner als die Normart. - Schweinitz fand ihn an abgestorbener Rinde von Vitis Labrusca Lin. in Nord-Carolina. 


\section{Merulius corium Fr.}

Fries, Elenchus fungorum p. 58, - I. Hymenomycetes enropaei p. 591. Greville, Flora cryptog. Scotica Tab. 47. - Montagne in Annales des sciences natur. 1836. - Fuckel, Symbol. mycolog. p. 22. - Cooke, Handb. of british Fungi p. 289. - Saccardo, Mycologia veneta p. 56. - Berkeley, Outlines of British fungology p. 255. - Berkeley, Notices of North American Fungi in Grevillea I. p. 68. - Polyporus corium Pers. Mycologia europaea II. p. 60. - Boletus pupurascens De C. Flore française VI. p. 41.

M. effusus, mollis, ambitu demum libero-reflexo, subtus villosus albus, hymenio obsolete reticulato-poroso, pallescente. Membranam sistit longitudinaliter effusam, 2-3 uncia et ultra longam atque saepe aeque latam contextu molli bombycino inque pagina sterili omnino bombycinam albam. Fungus junior totus resupinatus, ambitu subbyssino, adultus fere liber, subrevolutus. Hymenium in adultis eximie poroso-reticulatum, demum subgyroso-undulatum, alutaceo vel rufescenti-pallescens. - Fr. l. c. - Sporidia oblongo-laneeolata, uniguttulata, hyalina, $10 \mathrm{~mm}$. long., $3 \mathrm{~mm}$. erass. - Fuckel l. c.

Ad truneos Titis Labruscae Lin. America septentrionalis. (Murray.)

Die auf Weimeben wachsende Form, von welcher a. a. O. in "Grevillea" ïbrigens nicht gesagt wird, dass sie von der normalen, welehe anf verschiedenen Bäumen in der alten und neuen Welt durchaus nicht selten ist, sieh unterscheidet, kenne ich nicht. Die erwähnte, anch bei uns häufige Form hat einen verkehrt aufsitzenden, ausgebreiteten, dïmnen, fast papierartigen, im Umfange endlich freicn und ungeschlagenen, unten zottig weissen, häufig eoneentrisch gezahnten Hut mit wachsartigem, blassgelblich oder blassröthlich gefürbtem, undentlieh netzförmig-löeherigem Fruchtlager. Die Sporen sind nach Fuckel a. a. O. oblong lancettförmig, mit einem Tröpfehen in der Mitte, wasserhell, $10 \mathrm{~mm}$. lang, $3 \mathrm{~mm}$. breit. - In Nord-Amerika, und zwar in den NeuEngland-Staaten auf Stämmen von Vitis Labrusca Lin. (Murray) nach Angaben Berkeley's.

Corticium hypopyrohinum Berk. et Curt.

Berkeley, Notices of North American Fungi in Grevillea I. p. 179, no. 266.

C. subiculo pyrrhino marginem hic illic tenuissimum formante; hymenio albido. - Berk. l. c. 
In Vitis species indeterminatae truneis. America septentrionalis: Carolina australis. (Ravenel.)

Auch diese Species kemne ich nicht aus Autopsie. Sie wird a. a. O. mit nu wenigen Zeilen beschrieben, und zwar: mit einem ganz ausserordentlich dümnen Hypostroma (Myeelium) von feuerrother Färbung, welches zuweilen einen zarten und dümnen Rand bildet; das Hymenium ist sehmutzig-weisslich, zu Anfang pulverig bestrent. - Auf einer unbestimmten Art von Vitis im norlamerikanischen Staate Siid-Carolina von H. W. Ravenel entdeckt.

Corticium crocicreas Berk, et curt.

Berkeley, Notices of North American Fungi in Grevillea 1. 1. 178, no. 257. Pirotta, fungli parassiti dei Vitigni p. 13.

C. subiculo amplo, tomentoso, lateritio: hymenio tenui, flavo. - Berk. 1. e.

In truncis emortuis Vitis speeies indeterminatae. Anerica septentrionalis: Alabama. (Peters.)

Von dieser Species, welche die Antoren a. a. O. selbst "merkwürdig" nemen, wollte es mir durchaus nicht gehingen, Exemplare zur Ansicht zu erhalten. Den mehr als diirftigen Bemerkungen der Autoren zufolge ist das Subiculum oder Hypostroma des Pilzes sehr weit ausgebreitet, leuchtend safrangelb, filzig, das Hymenium zart und dïmn, hell- oder dunkelgells. Dieser Parasit ward im nordamerikanischen Staate Alabama, wie es scheint, bisher nur eimmal von Peters anf dem Stamme einer leider nicht näher bezeichneten Vitis-Art gefunden.

\section{Corticium calceum Fr.}

Fries, Epicrisis systematis mycologici p. 562, no. 31 - Id. IIymenomycetes europaei p. 652, no. 25. - Berkeley, Notices of North American Fungi in Grevillea I. p. 180. - Berkeley, Outlines of fungology 1. 274. - Cooke, Handbook of British Fungi, p. 323, no. 933. - Thelephora calcea Pers. Mycologia europaea 1. 1. 153. - Fries, Elenchus fungorum p. 215. - Weinmann, Hymenoet Gasteromycetes Rossiae p. 396.

C. effusum, adglntinatum, ceraceum, glaberrimum, album, ambitu similari: hymenio laevi, glabro, sicco, rimoso, rigido. Species valde polymorpha. Color variat argillaceus et albido- 
fuscescens. Hymenium interdum in glebulas minutas solutum. Praemature exsiccatum glebulosum fit. - Fr. l. c.

In Vitis species indeterminatae truncis. America septentrionalis: Pennsylvania. (Michener.)

Auf der ganzen Erde ist dieser Pilz verbreitet, ich besitze ihn wenigstens in meinem Herbarium bisher aus fast allen Ländern Europas, aus Nord-Amerika, Sibirien, Süd-Australien und vom Vorgebirge der guten Hoffnung. Wie alle solche, ïberall vorkommende Species, variirt auch Corticium calceum ganz ungemein, Fries hat schon in seinem "Elenchns" a. a. O. fünf Varietäten unterschieden, zu welchen im Laufe der Jahre noch ebenso viele nene gekommen sind. Bedingt wird dieser grosse Polymorphismus ganz besonders durch die enorme Verschiedenheit der Substrate, auf welchen unser Pilz vorkommt. Er ist bisher auf der Rinde einer sehr bedentenden Anzall von Laubbaum-Arten auf verschiedenen Nadelholzbäumen, auf entrindetem sowohl wie auf bearbeitetem hartem und weichem IIolze, auf Dachschindeln u. s. w. gefunden worden. Das Vorkommen nun, welches uns hier speciell interessirt, ist das auf Stämmen von Vitis, es findet sich darïber nur eine einzige Notiz in der ganzen, äusserst reichhaltigen und vollständigen Literatur, welche ich durchgesehen habe, und zwar bei Berkeley in der "Grevillea" a. a. O. Ich besitze unseren Pilz aus der nordamerikanischen Union auf sehr verschiedenen Substraten, abcr anf Weinstöcken leider nicht, da jedloch a. a. O. nicht erwähnt wird, dass die Form auf Vitis von der Normalform abweiche, so folgt hier eine Beschreibung derselben und gebe ich mich der Hoffnung hin, dass dieselbe dazu beitragen möge, darauf aufmerksam zu machen, den Pilz auch in Europa an alten Weinstöcken aufzusuchen. - Der Pilz ist mehr oder weniger weit ansgebreitet, am Rande niemals strahlig verlaufend, sondern immer fest umgrenzt, sehr verschieden geformt, oft gross, oft klein, fest an die Unterlage angewachsen, wachsartig, ganz glatt, kahl, in der Jugend reinweiss, später schmutzig werdend, den weissen Ton aber stets behaltend; getrocknete Exemplare werden meistens rissig; das Hymenium oder die Fruchtschicht ist glatt, kahl, trocken, rissig. - Im nordamerikanischen Staate Pennsylvanien von Michener auf einer unbestimmten Vitis-Art gefunden. 


\section{Corticium viticola $\mathrm{Fr}$.}

Fries, Epicrisis systematicis myeologici p. 561, no. 26. - Berkeley, Notices of North American Fungi in Grevillea I. 1. 178. - Ravenel, fungi Carol. exsicc. III. no. 34. - Pirotta, funghi parassiti dei Vitigni p. 13. - Thelephora viticola Schweinitz, Synopsis fungormm Carolinae p. 107, no. 1037. - Id. Synopsis of North American Fungi p. 168, no. 691. - Fr. Elenchus fungorum p. 205.

C. effusum, confluens, subtus strigoso-tomentosum margineque byssino aurantiacis, hymenio papilloso, sulfureo, nudo, rimoso. - Species pulchra, serl minuta temuis. Hymenium, quod laevissimum, contigum, et glabrum apparet, sub lente fortissima tantum setulosum. Maenlae hujus primordiales coeruleae, hoc loco ob colorem inserui; color variare videtur. Specimina a clarissimo Sehweinitz missa fulvo-ferruginea, medio subcanescentia (et revera in statu pelliculari lacta videntur, in quo plurimorum hymenium cineraseit); alia a el. Schwaegrichen data hymenio sulfureo genuino gaudent. - Fr. l. c.

Ad sarmenta Vitis speeies indeterminatae America septentr.: Carolina inferior. (Schweinitz, Ravenel.)

Diese mir leider unbekannt gebliebene Ant, vermag ich nur nach der dürftigen Diaguose von Fries 1. c. zu besehreiben. Darnach ist sie eine sehr hübsche, aber kleine, zarte Species, welche ausgebreitet, oft zusammenfliessend wächst, sie ist striegelig-haarig, der Rand mit gelbem, byssusartigem Belege; das Hymenium ist warzig, schwefelgelb, rissig, mit kurzen Borsten berleckt. Die Originalexemplare von Schweinitz sind gelbbraun, in der Mitte fast grau, während die von Schwägrichen gesendeten, aber ebenfalls von Schreinitz gesammelten Exemplare, eine schöne Schwefelfarbe hatten. - An dürren Aesten und Stöcken einer Vitis, deren specifischer Name leider nicht angegeben ist, im nordamerikanischen Staate Süd-Carolina. (Ravenel, Schweinitz.)

\section{Corticium albido-carnem Thiim.}

Thelephora (Ceraceae) albido-camea Schweinitz, Synopsis of North American Fungi p. 169 , no. 717 .

C. subceraceum, aretissime adnatum, longissime confluens sed valde angustatum, ambitu byssino, fibilloso, candido, pruino, carnescente centro tectum. Siccitate rimosum. - Sehwz. 1. c. 
In cortice Vitis Labruscue Lin., passim. America septentr.: Pennsylvania. (Schweinitz.)

Nur aus der kuren Diagnose a. a. O. ist mir diese Art bekannt, doch unterliegt es nicht dem geringsten Zweifel, dass dieselbe zu der, von Fries von Thelephora mit Recht getrennten und längst allgemein anerkannten Gattung Corticium gehört. Der Pilz ist von fast wachsartiger Substanz, der Nährpflanze dicht anliegend und angewachsen, oft in sehr langen, dabei aber auch sehr schmalen Streifen zusammenfliessend. Der Rand ist faserig, flaumig, weiss, die Nitte hingegen mit einem fleischfarbenen Reif bedeckt, im trockenen Zustande ist der Pilz rissig. - Häutig in Pennsylvanien, Nord-Amerika, auf der Rinde von Titis Labrusca Lin. (Schweinitz.)

\section{Corticium lactescens Berkl.}

Berkeley, Outlines of Fungology p. 274. - Fries, Hymenomye. europaei p. 650. Passerini, Funghi parmensi no. 484. - Cooke, Handb. of British Fungi p. 323, no. 932. - Thelephora lactescens Engl. Flora V. p. 169.

C. ceraceo-molle, adglutinatum, undulatum, carneum, lactescens, margine byssoideo, brevi; hymenio demum rimoso, interstitiis sericeis. Sapor Lactarï quieti Fr. Lac aquosum, album. Fr, l. c.

Ad Titis viniferae Lin. sarmenta emortua. Vigheffio pr. Parma. Autumno - hieme. (Passerini.)

Auf halbfaulendem TVeidenholze kenne ich diese, sehr seltene Species; sie ist dem Substrat fest anliegend, von wachsartiger Substanz, uneben gefältelt, fleischfarbig, der Rand ist flockig faserig, weisslich, sehr schmal, die Fruchtschicht ist, bei meinem Exemplar wenigstens, etwas rissig und mit einzelnen Wärzchen und Borsten besetzt. Der ganze Pilz ist beim Zerschneiden milchend, von Geruch und Geschmack konnte ich nichts verspïren. - Bei Vigheftio in der italienischen Provinz Parma von Professor Passerini auf todten Reben von Vitis vinifera Lin. gefunden. 


\section{Corticimm armeniacum Thüm.}

Corticium molle Berkeley et Curtis, Fungi Cubenses in Journal of the Linnean Society X. 1867, p. 336, no. 446. - Berkeley, Notices of North American Fungi in Grevillea I. p. 180, no. 275. - Pirotta, funghi parassiti dei Vitigni p. 13.

C. lesupinatum, effusum, immarginatum, armeniaco-rufum; subiculo pallidiore; hymenio glaberrimo, nitido. - B Berk. et Ci11't. 1. c.

In truncis emortuis Vitis species, fortasse Vitis aestivalis Mehx. America septentr.: Carolina australis. (Curtis.)

Das Subiculum dieser Species ist hellröthlich, meistentheils byssusartig-fädig und nu selten iiber das Hymenium heransragend, dieses letztere ist verkehrt aufgewachsen, weit ausgebreitet, sehr zart und diimn, fast häutig zu nennen, ungerandet orler wenigstens am Rande nicht verschieden gefärbt, und von einer Farbe zwischen Aprikosenroth und Dunkelbraun. - Bisher ward diese Species nur von Curtis in Nord-Amerika, SüdCarolina auf Stämmen einer Titis, wahrscheinlich aestivalis Mchx. gefunden, während sie auf anderen Substraten sowohl in den anderen siddichen Staaten der Union als auch auf der Insel Cuba nicht selten ist. - Da der Fipeciesnamen molle, wenn auch erst im Jahre 1874 von Fries in seinen .. Hymenomycetes enropaei" p. 660, no. 65, vergeben ward, aber der alten Speeies Thelephora mollis Fr. Syst. mycol. I. 1. $t+3$ entspricht, sah ich mich genöthigt, den, wenn auch um sicben Jahre älteren Namen von Berkeley und Curtis umzuäudern.

\section{Stereum Leveilléanum Berk. et Curt.}

Berkeley, Notices of North American Fungi in Grevillea I. p. 163. - Corticium

Leveilléanum Berk. et Curt. in Hooker, Jonrnal of Botany I. p. 238.

St. effusum, resupinatum, molle, crassinsculum, carneum, margine demum libero. - Berk l. e.

Ad sarmenta Titis species indeterminatae. America septentr.: Carolina australis. (Curtis.)

Dieser ganz ausnehmend hübsehe Pilz bildet zu Anfang kleine, runde, schildförmigre Flecken oder Häufchen, diese sind 
dicht an die Unterlage angeschmiegt, nur der Rand ist zumeist frei, dick, wulstig und mit anderen Individucn zusammenfliessend; das Hynenium ist manchmal kleingrubig. Die Farbe des Pilzes ist ein schönes Himbeerroth mit weisslichem Anflug, ältere Exenplare, welche bereits sehr grosse Dimensionen angenommen, haben eine fahl-weissliche Färbung. - Auf diirren Ranken einer nicht genazer bezeichneten Vitis-Art in Süd-Carolina, Nordamerikanische Union, von Curtis entdeckt.

\section{Stereum cristatum Berk, et Cnrt.}

Berkeley, Notices of North American Inngi in Grevillea I. p. 163, no. 235.

St. parvum, flabelliforme vel cyathiforme, pallidum, subzonatum, postice tibris pallidis cristatum. - Berk. l. c.

In Titis species indeterminatae truncis in paludibus. America septentrionalis: Carolina inferior (no. 2038). (Ravenel.)

Mir ist diese Art nul aus der Beschreibung bekannt, ich kann daher hier nur anfïhren, was Berkeley a. a. O. von ihr sagt: Klein, fächel- oder becherförmig, blass, kanm gezont, zuletzt mit kammförmig gestellten Fibern besetzt. Manche Exemplare sind ganz genan in der Mitte gestielt, andere hingegen mehr fächelförmig, hellgefärbt, mit Zonen und sehr kleinen Strichen oder Linien gezeichnet, etwas gelappt am unteren Ende oder an der Basis mit dentlichen, cylinderförmigen Fortsätzen versehen. Die Grösse erreicht nur selten einen halben Zoll, der Stiel, sofern cin solcher vorhanden ist, kaum eine halbe Linie. Eine merkwürdige, kleine Art, welche an todten Ranken einer Vitis in den Sümpfen Süd-Carolina's (Nord-Amerika) wächst, wo sie Ravenel sammelte.

\section{Anricularia mesenterica Pers.}

Persoon, Mycologia europaea I. p. 97. - Fries, Epicrisis p. 555. - Id. Hymenomycetes europaei p. 646. - Berkeley, Ontlines of fungology p. 272. - Saccardo, Mycologia veneta 1. 64. - Id. Mycotheca veneta no. 34. - Thelephora mesenterica Persoon, Synopsis fungorum p. 571. - Phlebia mesenterica Fr. Elenchns fungorum p. 154. - Ielvella mesenterien Dickson, Cryptog. I. p. 20.

1. pileis dimidiatis e resupinato reflexis, integris, villosis, fasciato-zonatis, fuscescenti-cinercis; hymenio costato-plicato, fusco 
violaceo. - Subimbricata, coriaceo-mollis, subgelatinosa, junior resupinata, effusa, mox reflexa; supra villo brevi, griseo rufescente vel olivaceo-scricea, plermugue zonis concentricis faseiata. Hymenium glaberimum, inferum, ubscure purpurascens vel fusco-violaceum, plicis sparsis flexuosis, ramulosis, nunquam papillosum. Er. l. c.

Ad caudices Titis rimiferae Lin. Venetia: Treviso, Padova. (saccardo.)

Das mir vorliegende, anf Wreinreben gewachsene Exemplar unterscheidet sich in nichts von den andern, deren Substrate: Aesculus (Kastanien), Ulmus (Uhmen), Castaned (Maronen), Carpinus (Weissbuchen) und vicle andere Iaubbäume sind. Die verkehrt aufgewachsenen, ziemlich grossen Hiite sind auf der Oberseite (welche also in diesem Falle eigentlich die mntere, am Holz angewachsene ist) grau bräunlich, haarig, fast zottig, etwas gezont und haben einen ganzen, unzerschlitzten Rand. Das Hymenium ist tief aschgrau, im feuchten Zustande ctwas gallertartig und wird höchst nmegelmässig von stark hervortretenden Adern durchzogen und dadurch in viele, ganz ungleich grosse Felder getheilt. Die Falten uder Adern haben eine, meist etwas gefurchte, sehr stumpfe, hellgraue schneide, im Jugendzustande treten sie nur wenig hervor, je älter der Pilz wird, desto mehr ist es der Fall. - Bisher scheint dieser hübsche Pilz, welcher zu der Familie der'Aumicularinei, deren eigentlicher Typus er ist, gehört, nur erst in Venetien auf alten Weinstöcken von Vitis vinifera Lin. gefunden worden zu sein. Da er dort aber auf diesem Substrate sehr luäutig ist, so häutig, dass ihn Saccardo in seiner "Mycotheca reneta" auf dieser. Wirthspflanze ausgeben konnte, dürfte er wohl sicherlich auch in anderen Ländern mit Wembau noch gefunden werden, besonders in den wärmeren, da Auricularia mesenterica überhampt ein Pilz der wärmeren Klimate ist und je weiter nach Norden immer seltener wird. 


\section{Cyphella villosa Karst.}

Karsten, Mycologia femnica III. p. 325. - Pexiza villose Pers. Syn. fung. 1. 655. Schweinitz, Aynopsis fung. Carolinae p. 120, no. 1213. - Id. Synopsis of North American Fungi p. 173, no. 834. - Fr. Systema mycolog. II. p. 104. - De Candolle, Fl. franç. VI. p. 26. - Cooke, Handb. of British Fungi p. 690, no. 2055. - Trichoperiza villosa Fuck. Symbolae myeolog. p. 296. - Saceardo, Mycologia veneta 1.163.

C. sessilis, minuta, persistens, globosa, villosa, alba, ore subconnivente. - Granula superficialia, nunc aggregata, nunc absque ordine sparsa, tempestate pluviosa modo aperta. Stipitis rudimentum vix perspicum; villus non semper distinctus. - Fr. 1. c.

Ad sarmenta emortua T'itis viniferce Lin., Austria inferior (Thiimen); Titis Labruscae Lin. America septentr.: Carolina, Pennsylvania. (Schweinitz.)

An faulenden Stengeh grösserer Kräiuter, sowie an Aesten verschiedener Laubbäume ist diese Art in Europa sehr häufig, an Weinreben fand ich sie erst ein einziges Mal bei Klosterneuburg in Nieder-Oesterreich. Persoon und alle seine Nachfolger stellten unseren Pilz zur Gattung Peziza und Fuckel, als er dieses alte Genus in viele neue Genera zerlegte, zu seiner Gattung Trichopeziza. Aber merkwiirdiger Weise, trotzdem man also diesen Pilz zu den Discomyceten brachte, hat noch niemand bei ihm Schlänche gesehen, sondern nur sporen. Ich bin deshalb ganz mit Karsten einverstanden, welcher diese und andere schlauchlose, bisher bei den Discomyceten untergebrachte Arten zu den Auricularineen bringt und sie bei der Gattung Cyphella einreiht. - Unser Pilz steht meistentheils heerdenweise aber doch ziemlich zerstreut und nur ausnahmsweise dicht beisammen auf der Rinde, er ist klein, ungestielt, fast kugelig und ganz weiss, ïber und über mit feinen aber dichten weissen Haaren bekleidet. Bei feuchter Witterung öffnet sich der Pilz oben und zeigt einen etwas umgeschlagenen Rand, sowie ein weisses Hymenium. Auf und in diesem werden die kleinen, elliptischen, wasserhellen, wie es scheint, immer farblosen Sporen an kurzen Basidien abgeschnïrt. - An abgestorbenen Ranken von Vitis vinifera Lin. in Nieder-Oesterreich (Thïmen), von Titis Labrusca Lin, in Carolina und Pennsylvanien. (Schweinitz.) 


\section{Cyphella albo-violascens $K$ arst.}

Kirsten, Mycologia fennica III. p. 322. - Peziva albo-violascens Alb. et Schwz. Consp. fung. Lusat. 1'. 322, e icon. - Cooke, Handbook of British Fungi p. 686. Fries, Systema mycol. II. 1. 96. - Id. Elenchus fungorum II. p. 9. - Schweinitz syn. fung. Carol. p. 120, no. 1206. - Id. Synopsis of North American Fungi 7. 173, no. 815. - Lactenflle alto-violascens Fr. Summa veg. Scand. p. 365. Saccardo, Mycologia veneta p. 161. - Fuckel, Symbolae mycologicae p. 380. Quelet, Les champignons du Jura II. p. 418. - Pirotta, funghi parassiti dei Vitigni 1. 22. - Cyphella Curreyi Berk. et Br. Annal. of Nat. Hist. 1861. Ascobolus Vitis Wallr. in sched.

C. subsuberosa, sessilis vel subsessilis, e subsphaeroidea subhemisphaeriea, albo-villosa. Hymenium laeve pallescens vel violaceo-pallens. - Gregaria, dura, junior subsphaeroidea, dein applanato-hemisphaerica, sicea clausa, intus margineque demum nigrescens, latitudo $1-5$ Mm., jassim prolifera. Sporae ovoideosphacroideae vel subsphaeroideae, inaequilaterales, $11-16 \mathrm{~mm}$. long., 9-12 mm. crass. - Karst 1. e.

In Vitis viniferce Lin. sarmentis subputridis. Venetia (Saccardo), Thuringia (Wallroth).

Auch diese Species ist wie die vorhergehende von Karsten in seinen Werken mit vollstem Rechte von den Discomyceten zu den Basidiomyceten versetzt worden, denn es ist cben keine Peziza, keine Lachnella, da ihr die Schläuche fehlen and die Sporen frei auf Basidien abgeschniurt werden. Es ist ein Unsinn, diese und andere Arten unter den Discomyceten aufzuzählen und ganz einfach hinzuzusetzen: ,ascos non vidi“. - Der Pilz wächst gesellig, er ist fast korkartig hart zu nennen, stiellos oder kaum in einen stielartigen Fortsatz verschmälert, die Gestalt hält die Mitte zwischen der kugeligen und halbkugeligen, in der Jugend kann man ihn sphärisch nennen, im reifen Zustande ist er mehr abgeflacht. Die ganze Aussenfläche ist mit weissem Filz iiberdeckt. Trocken ist die innere Scheibe durch den Rand verdeckt, welcher sie ganz umschliesst, öfnet sich derselbe, so sieht man die Innenseite, sowie den Rand schwärzlich, das Hymenium aber blassviolett. Die Sporen sind eirundlich oder fast kugelig, jedoch unregelmässig, ihre Farbe ist wasserhell, sie messen in der Länge 11-16 mm., in der Breite 9-12 mm. Zuweilen sind mehrere Iudividuen zusammengeflossen, auch proliferirende kommen vor. - A uf halbfaulenden Ranken von Vitis vinifera Lin. in Thïringen von Wallroth, in Venetien von Saccardo beobachtet. 


\section{Calloria rinosa $\mathrm{Fr}$.}

Fries, Summa reg. Scand. p. 359. - Fuckel, Symb. myeolog. 1'. 243. - Peziza vinose Albert et Sclwweinitz, Consp. fung. Lusatiae p. 308. - Fries, syst. myc. II. p. 141. - Engl. Flora V. p. 205. - Ravenel, Fungi Carol. exsicc. IV. no. 19. - Berkeley, Outl. of Fung. 1. 370. - Walloth, Flora cryptog. German. II. 1. 469. - Karsten, Peziza et Ascobolus 1. 37. - Karsten, Monogr. Peziz. Fenn. 1. 176. - Orbilia vinose Karst. Mycologia fennica I. p. 101.

C. minuta, sessilis, subtremellosa, planiuscula, glabra, integerrima, incarnato-rubella. - Alb. Sch.1.c. - Apotheeia subsparsa, subgelatinosa, planiuscula, sicca concava, subeupuliformi-contracta, integra, laete carneo-rubra vel carneo-cuceinea, $0.4-0.7$ milim. lata. Asci cylindraceo-clavati, subrecti, 44-55 mm. long., 1-5 mun. crass. Sporae aciculari filiformes, $11-16 \mathrm{~mm}$. long., $1-1.5 \mathrm{~mm}$. erass. Paraphyses graciles, apice incrassato. - Karst. 1. c.

Ad sarmenta putrida Vitis Labruscue Lin. - America septentr.: Newfield New-Jersey (J. B. Ellis) 1877.

Diese Pezizee, oder nach Fuckel's Ansicht, welcher ich mich anschliesse, Bulgariee, ist bisher in Europa, wo sie iibrigens durchaus nicht selten ist, nur auf faulenden Hölzern der Laubbäume gefunden worden. Fries und Karsten führen speciell Quercus an, wïhrend die anderen Autoren nur von Holz und Aesten im Allgemeinen sprechen. In Nord-Amerika jedoch tritt unsere Calloria auf faulendem Holze ron Vitis Labrusca Lin. auf und wäre daher auch bei uns auf diesem Substrate zu suchen. Sie bildet äusserst kleine, meist ziemlich zerstreut stehende Apothecien von schwach gallertartiger Consistenz, diese sind flach, werden erst beim Trocknen etwas concav und haben eine röthliche oder dunkel fleischrothe Färbung. Die langcylindrischen Schläuche stehen bündelförmig verbunden zwischen äusserst zahlreichen, schlanken, fadenförmigen Paraphysen und enthalten die acht nadelförmigen, 11-16 mm. langen und nur 1-1.5 mm. breiten, wasserhellen Sporen. In den weitaus meisten Fällen sind übrigens die Sporen nicht völlig entwickelt, und Fuckel hat, beispielsweise, wie er a. a. O. sagt, dieselben gar nicht gesehen. - J. B. Ellis fand diese Art und theilte sie mir mit, bei Newfield, New-Jersey in den Vereinigten Staaten. 1877. (Tab. V. fig. 9.) 


\section{lachuclla macrochacta Spegaz. nor. spec.}

Spegazrini in litt. ad me.

L. cupulis mediis, gregariis vel densis, eleratis, hemisphaerico-orbiculatis vel rerrucacformibus, primo clausis dein apertis, sparlicen-fuscis, villosis, villo cinereo, dense; ascis cylindraceis, leniter attenuatis, rertice rotundatis, $50-55 \mathrm{~mm}$. long., $4 \cdot 5-5 \mathrm{~mm}$. crass., paraphysibus hyalinis, septulatis, paullo longioribus, 60 vel $62 \mathrm{~mm}$. long., $1-1 \cdot 3 \mathrm{~mm}$. crass. obrallatis; sporis fusoidois, utrinque acutiusculis, biguttulatis, quandoque curvulis, 7-10 mm. long., $15-2 \cdot 2 \mathrm{~mm}$. crass., hyalinis. Contextu excipuli parenchymatico, laxo, griseo-fuligineo, cellulis polyedris, hyalinis, setulis densis, olivaceo-fuligineis, apice circinatis, expallidioribus, septulatis, crassiuscule tunicatis, $100-200 \mathrm{~mm}$. long., 4-5 mm. crass. Spegaz. in sched.

In sarmentis emortuis, putrescentibus Titis viniferae Lin., Venetia: Conegliano leg. Spegazzini. Aut. 1877.

Die Becherchen dieser neuen Art stehen meistens gedrängt zusammen, jedoch ohne sich zu berïhren oder gar zusammenzufliessen, sie sind anfänglich geschlossen, dam geöffnet, erhaben, halbkngelig oder hochwarzenförmig, kastanienbraun und dicht nit aschgrauen, feinen Haaren bedeckt. Die Schläuche haben eine eylindrische Gestalt, sind nach der Basis unbedeutend verengert, am Scheitel abgerundet, $50-55 \mathrm{~mm}$. lang, 4.5-5 $\mathrm{mm}$. breit und werden von farblosen, septirten, nur wenig längeren, fadenförmigen, 60-62 $\mathrm{mm}$. langen und nur $1-1.3 \mathrm{~mm}$. dicken Paraphysen umgeben. Die spindelförmigen Sporen sind an beiden Enden zugespitzt, manchmal etwas gekrimmt, sind farblos, messen in der Länge $7-10 \mathrm{~mm}$. und in der Breite $1 \cdot 5-2.2 \mathrm{~mm}$. und lıaben zwei Nuclei. - C. Spegazzini entdeckte im September 1877 bei Conegliano in Tenetien diese bübsche nene Art auf faulenden Reben ron Titis vinifera Lin.

\section{Propolis promintala Thüm.}

Stictis prominula Schweinitz, Synopsis of North American Fungi p. 180, no. 997.

P. majuscula, valde prominens, primum immersa, demum fere libera aut superficialis, disco ime excavato albido-pallido, 
limbo valde dilatato, vix laecrato, sed saepe irregulari pluribus quasi in unum confluentibus. -- Schwz. 1. e.

In libro ramentarum Titis Labruscae Iin. America septentr.: Pennsylvania. (Schweinitz.)

Schweinitz führt diese Art unter dem Subgenus Propolis von Stictis an, und obzwar über Schläuche und Sporen, die Kriterien zur 'T'rennung dieser beiden Gattungen, kein Wort gesagt ist, glanbe ich doch nieht fehlangreifen, wenn ich diese species gleich definitiv zn Propolis bringe. Da mir der Pilz unbekannt ist, fïge ich nur lediglich eine dentsche Uebersetzung der lateinisehen Original-1)iagnose des Autor's bei. Dieselbe lantet: Sehr gross, stark hervorragend, zu Anfang eingesenkt, späterhin beinahe frei und oberflächlich aufsitzend. Die blassweissliche Scheibe ziemlich ausgehöhlt, der Rand derselben sehr stark rerdickt, kaum etwas zerschlitzt, aber dafür häufig mit anderen zusammenfliessend und sich verbindend. - Auf dem Baste abgestorbener Ranken von Vitis Labrusca Lin. bei Bethlehem im nordamerikanischen Staate Peunsylvanien von Sehweinitz entdeckt.

\section{Patellaria atro-fusca Berk. et Curt.}

Berkeley, Notices of North American Fungi in Grevillea IV. pag. 2, no. 756. Pirotta, funghi parassiti dei Vitigni p. 16.

P. orbicularis, margine elevato, atro fusea; aseis elavatis; sporidiis oblongis, triseptatis. -- Berk. l. e.

In sarmentis tenuibus Vitis vulpinae Lin. America septentr:: Carolina septentrionalis. (Curtis.)

Ieh habe diese Species nicht zu Gesicht bekommen, sic wird von den Autoren a. a. O. als sehr klein, vom Habitus der Patellaria atrata beschrieben; die Seheiben sind rundlich, schwärzlichbraun, mit einem erhabenen Rande, sie entspringen aus einem zarten, schwarzen Mycelium, welehes die Zweige rundherum umgibt. Die keulenförmigen Schläuche enthalten oblong-eiförmige, dreimal getheilte Sporen, die einreihig angeordnet sind. - Der Pilz wächst auf dïnnen Ranken von Vitis vulpina Lin., er ward von Curtis im nordamerikanischen Staate Nord-Carolina, wie es scheint, nur einmal gefunden. 


\section{Peziza viticola Pers.}

Persoon, Mycologia europaea p. 309. - Fries, Systema myeolog. II. p. 151. Rabenlorst, Deutschl. Krypt.-Flora p. 344, no. 2642. - Pirotta, funghi parassiti dei Vitigni 1. 28. - Schweinitz, Synopsis of North American Fungi p. 177, no. 950. - Peaisa Titis viniferae Kirchner in Lotos 1856 p. 216.

P'. sessilis, subcoriacea, crassiuscula, cupulis planiusculis, sordide nigris, margine temi einetis, disco superticiali, rufocarneo. - Subiculum tenue, nigrescens, subpulrerulentum; eupulae subseriatae, regulares, $P$. atro-virentis, praesertin colore, haud absimiles. - Pers. 1. c.

In rimis ramorum Titis viniferae Lin. und Labruscae Lin. Saxonia (Rabenhorst), Gallia (Cauvin), Bohemia (Kirehner), Pennsylvania (Schweinitz).

Diese Species wird von keinem unserer neuen Mykologen, wie Fuckel. Saccardo, Karsten ete. erwähnt, sie scheint sehr' selten zu sein, auch mir gelang es nicht, authentische Exemplare mir zu rerschaffen, trotzdem Rabenhorst sie als .häufig bei Dresden" a. a. O. auffihrt! Die Becherchen sind reihenweise angeordnet, sie sind sitzend, von lederartiger Consistenz, ziemlieh schmutzig, schwarz und abgeflacht, von einem kleinen zarten liande umgeben. Die innere Scheibe ist Hach, rothbraun. Schläuche und Sporen werden gar nicht erwähnt, zu welcher der jetzt allgemein anerkannten Gattungen der Pezizeen dieser Pilz zu bringen ist, muss also vorläufig dahingestellt bleiben. - Sie wähst in den Ritzen alter Reben von Titis vinifera Lin., von Caurin ward sie in Frankreich, von Rabenhorst in Sachsen, von Kirchner in Böhmen gefunden, auf Titis Lrbrusca Lin. gibt sie Schweinitz in Pennsylvanien an.

\section{Peziza tumida Pers.}

Persoon, Mycologia europaea I. p. 269. - Fries, Elenchus fungorum II. p. 15. - Id. Systema myeol. II. p. 97. - Wallroth, Flora german, cryptog. II. p. 454. - Rabenhorst, Deutschl. Kryptog. Flora p. 360, no. 2776. - Dermatea tumida Fr. summa veg. Scand. p. 362 (in nota). - Pirotta, funghi parassiti dei Vitigni p. 22.

P. sessilis, subcoriacea, depresso-ventricosa, leviter tomentosa, opaca, gilvo-pallida, diseo tumido-nigrescente. - Ab initio tota clausa videtur, saltim tomento involuta, in medio dein aperitur ore circulari; discus tandem conspicitur, qui est superfieialis seu 
promiscens, rugulosus quasi et immarginatus; latitudo linearis. Fr. l. e.

In sarmentis emortuis ritis viniferce Lin. Helvetia (Chaillet), Saxonia (Rabenhorst), Thuringia (Wallroth.)

Die Angabe ron Fries a. a. O., dass der Pilz sehr selten sei, ist jedenfalls richtig, denn ich besitze diese Art weder in meinem sehr grossen Herbarium, welches namentlich an Pezizeen sehr reich ist, noch findet sich bei irgend einem der neueren Autoren, wie Fuckel, Saccardo, Karsten, Cooke, Quelet, dieser Pilz auch nur erwähnt! Jedenfalls sehr auffallend und dazu auffordernd, diesen verschollenen Bürger unserer Flora eifrigst wieder aufzusuchen. - Eine dentsche Uebersetzung der Fries'schen Beschreibung gebe ich hier, mit Zuhilfenahme der von Rabenhorst a. a. O. mitgetheilten. Die Peziza ist gesellig, sitzend, fast lederartig, niederged riickt-bauchig, schwach tilzig, matt-hellzimmtfarben; die Scheibe ist aufgeschwollen, schwärzlich; zu Anfang ist der ganze, ungefähr $1-1.5 \mathrm{Mm}$. hohe Pilz von einem hellen Filz bedeckt und eingeschlossen, später bekommt er dann eine kreisrunde Mündung, bis endlich die Scheibe hervortretend angeschwollen, runzelig' und ungerandet ist. Weder von Schläuchen noch von Sporen ein Wort, nach der Manier der alten Mykologen, welche lediglich das makroskopische Aussehen der Pilze beschrieben. - An dürren Ranken ron Titis vinifera Lin. in der. Sehweiz von Chaillet, in Thüringen von Wallroth, in Sachsen bei Dresden von Rabenhorst gefunden.

\section{Peziza pruinata Schwz.}

Schweinitz, Synopsis fungorum Carolinae p. 120, no. 1216. - Id. Synopsis of North American Fungi p. 174, no. 855. - Fries, Systema mycologicum II. p. 109. - Pirotta, funghi parassiti dei Vitigni p. 29. - Peziza conspersa Pers. Mycologia europaea I. p. 271. - ? Thelebolus hirsutus Fr. Elench. fung. II. p. 51.

P. minuta, dense aggregata, membranacea, nigra, cinereopulverulenta cum subiculo, eupulis subelausis. - Subiculo tenuissimo insident cupulae complanatae, concavae, subclansae, membranaceae, nigrae, omnino pulvere farinaceo, cinereo tum dense testae, ut Sphaerias credas, madidae aperiuntur ore inflexo, disco nigrescente. - Schwz. 1. e. 
In corticibus emortuis Vitis Labruscae Lin. longe lateque profusa. America septentrionalis: Carolina australis et Pennsylvania. (Schweinitz.)

Aus diesem Pilze werde ich nicht reeht klug; ich habe leider keine Original-Exemplare mir zu verschaffen vermocht, und muss mich demnach ganz auf die Wiedergabe der Originaldiagnose beschränken; was aber anffallend ist, das ist die Angabe ron Streintz in seinem "Nomenelator fungorum" p. 595, wo er unsere Peziza und die Persoon'sche Peziza conspersa als Synonyme zu Fries's, Thelebolus hirsutus zieht und für letztere Art als Quelle den "Elenchus fungorum" II. p. 51 angibt. Auf dieser Seite des betreffenden Werkes ist aber gar kein Thelebolus hirsutus beschrieben, iiberhaupt kommt in dem ganzen Abschnitt über Thelebolus in diesem Buche der Name hirsutus gar nicht vor. Man muss demnach wohl annehmen, dass der gute Streintz hier wieder einen seiner, schier zahllosen, Lapsi gemacht hat, ron denen bekanntlich sein Werk in einer Art wimmelt, welche cine Beniitzung desselben nur mit der alleränssersten Vorsicht gestattet. - Nach Sehweinitz ist das Subiculum unseres Pilzes sehr zart, die Becherchen sind ungemein klein, stehen nahe beieinander, sind häutig, schwarz, zusammengedriickt, concav gebogen, beinahe ganz geschlossen und auswendig ganz mit einem mehligen, pulverigen Belege ron aschgraner Farbe bedeckt, welcher übrigens auch das Subiculum ïberzielnt. Der Rand der Becherchen ist wenig gebogen, die Scheibe schwärlich. - Bedeckt die abgestorbene Rinde todter Titis Labunsca-Stämme weit und breit. Der Pilz ward in den beiden nordamerikanischen Staaten Siid-Carolina und Pennsylvanien von Schweinitz beobachtet.

\section{Peziza cinereo-fisca Sehwz.}

Schweinitz, Synopsis fungorum Carolinae p. 119, no. 1192. - Id. Synopsis of North American Fungi p. 173, no. 817. - Fries, Systema mycologicum II. p. 97. - Berkeley, Notices of North American Fungi in Grevillea III. p. 155. Pirotta, funghi parassiti dei Vitigni p. 28.

P. sessilis, applanata, firma, farinaceo-hirta, cinereo-virens, disco fusco-badio - Gregaria, minuta, lineam dimidian lata, cupulae hemisphaericae, regulares (ut in $P$. flammea), margine involuto, saepius clausas. - Fr. 1. c. 
In sarmentis emortuis Titis vulpince Lin. America septentr.: Carolina septentrionalis. (Curtis, Schweinitz.)

Ich habe diese Species, welche nach ihren nächsten Verwandten bei Fries, wohl zur Gattung Lachella und damit zu den. Patellariaceen zu stellen wäre, nicht gesehen, leider sind auch weder dic Schläuche, noch die sporen, auf welche frïher ja gar kein Gewicht gelegt ward, beschrieben, irgend ein Urthcil abzugeben, bin ich daher nicht in der Lage. Die Autoren beschreiben den Pilz als sehr klein, dicht zusammenstehend, kaum 1/2 Linie breit, sitzend, abgeplattet, fest von Consistenz, bestäubt rauh, graugriin ron Farbe; die Becher halbkugelig, regehmässig; mit emporgeschlagenem Rande, häntig geschlossen bleibend; die Scheibe von tiefbrauner Farbe. - An abgestorbenen Ranken von Titis vulpina Lin. im nordamerikanischen Staate Nord-Carolina ron Schweinitz und Curtis gesammelt.

\section{Peziza pennicillata Schwz.}

Schweinitz, Synopsis fungorum Carolinae p. 120, no. 1204. - Id. Synopsis of North American Fungi p. 173, no. 829. - Fr. Syst. mycol. II. P. 102. - Pirotta, funghi parassiti dei Vitigni p. 28.

P. gregaria, minutissima, alba, eupula concara, extus pilis longis, cinereis. - Punctiformis, madido tempore aperta, intus glabra, margine crinito; siecitate contrabitur, ita ut pili longi einerei peunicillatim insidere videantur ligno, ut Byssus. - Schwz. l. e.

In rimis corticis T'itis Labruscae Lin. Frequens. America septentr.: Pennsylvania, Carolina australis. (Schweinitz.)

Es ist diess eine Pezizee, welche ich leider ebenfalls nicht selbst untersuchen kounte. Sie ist dem Autor zufolge sitzend, kaum hervorragend, punktförmig, nur bei fenchter Witterung geöfnet, die Becherchen sind klein, dicht stehend, weissheb, concav, aussen mit langen, aschgranen Haaren bekleidet, imnen glatt. Die erwähnten Haare sind gleichsam pinselförmig gestellt und hüllen beinahe das Holz der Reben, auf denen der Discomycet wuchert, ein. - In Nord-Amerika, sowohl in Süd-Carolina als anch in Pemsylvanien, in den Rindenrissen von Vitis Labusca Lin. von Schweinitz entdeckt. 


\section{Peziza Vitis Schwz.}

Schweinitz, Synopsis of North American Fungi p. 173, no. 843.

P. minuta, difformiter globosa, clausa, carnea, sed villo albo extus laxius involuta, margine crenulato-plicato, disco pallido; punctiformis. - Schwz. 1. c.

In rimis corticis Titis Labiuscae Lin. Pennsylvania, America septentr. (Schweinitz.)

Es dürfte diess der Besclireibung nach wohl eine, ron allen anderen auf WTeinreben vorkommenden Pezizeen ganz verschiedene Art sein. Der Autor beschreibt sie als punktförmig, sehr kilein, ungestaltet kugelig, geschlossen, fleischröthlich, auswendig von zarten, dümnen, weissen, zottigen IIaaren umgeben; der Rand ist gefaltet-kerbig, die Scheibe blassfärbig. — In den Spalten und Rissen der Rinde von Titis Labrusca Lin. bei Bethlehem in Pennsylvanien, Nord-Amerika, von Schweinitz gefunden.

\section{Peziza ascoboloidea Schwz.}

Schweinitz, Synopsis of North American Fungi p. 175, no. 877.

P. minutissima, sparsa, extus tibrosa, candida, turbinata carne, sed vix stipitata; disco subcarneo quasi ascis ascoboloideis punctato, subconvexulo, siccitate clauso; vix semilineam excedit. - Schwz. 1. c.

In rimis corticis Titis Labruscae Lin. America septentr.: Pennsylvania. (Sehweinitz.)

Ich kenne diese $\Lambda$ rt nur aus der etwas confusen und eigenthümlichen Diagnose des Autors a. a. O. Er beschreibt sie folgendermassen: Sehr klein, zerstrent stehend, die Becherchen auswendig faserig behaart, weisslich, kreiselförmig, aber doch kaum gestielt zu nennen. Die Scheibe hell fleischfärbig, gleichsam durch ascobolusartige Schläuche punktirt, fast convex gewölbt, im trockenen Zustande geschlossen. Die Grösse erreicht kaum 1/2 Linie. - In den Rindenrissen von Titis Labruscae Lin. bei Bethlehem in Pennsylvanien, nordamerikanische Freistaaten. (Schweinitz.) - Was der Ausdruck: ,gleichsam durch ascobolusartige Schläuche punktirt" eigentlich bedeuten soll, ist mil vollständig unklar! 


\section{Pyrenopeziza Vitis Rehm.}

Rehm, Ascomyceten no. 67. - Winter in „Flora" 1872 p. 526. - Pirotta, funghi parassiti dei Vitigni p. 24. - ? Peziza viticole Pers. conf. Rabenhorst, Dentscltlands Kryptogamen-Flora 1. p. 344, no. 2642. - Peziza ampelina Pass. in Rabenh. Fungi europaei no. 1706 (sec. Rehm. in litt.).

P. cupulis sparsis guegariisve, primo globosis, margine involuto fere clausis, demum apertis, hemisphaericis vel ovatis, margine subcrenato, irregulariter inciso, incurvo, sessilibus, opaco fusco-atris, verruculoso-rugosis, basi pilis pallidioribus, arachnoideis, repentibus cinctis, disco concavo, pallidiore, $0.3-0.5 \mathrm{Mm}$. (non Mikromill. ut Winter 1. c.) latis. Ascis cylindraceis, breviter stipitatis, octisporis, $43-57 \mathrm{~mm}$. long., $4-6 \mathrm{~mm}$. crass.; paraphysibus filiformibus, ascos aequantibus; sporidiis in asci parte superiore inordinatis, cylindraceo-clavuliformibus, continuis, hyalinis, rectis, 7-10 $\mathrm{mm}$. long., 1-2 mm. crass. - Winter 1. c. In cortice truncolum emortuorum Vitis sylvestris Gmel. Hungaria (Lojka); in Vitis viniferae Lin. Parma (Passerini).

Ich besitze in meinem Herbar sehr reiche und höchst instructive Exemplare dieses neuen Discomyceten und will an der Hand derselben es versuchen, eine genügende Beschreibung zu entwerfen. Auf der $1-1 \frac{1}{2} \mathrm{Mm}$. dicken alten, abgestorbenen Rinde sitzen die Individuen einzeln zerstreut, sie sind in der Jugend fast kugelig geschlossen, öffnen sich aber später bald und nehmen eine mehr oder weniger halbkugelförmige Gestalt an ; ihr nur unscheinbarer Rand ist wenig zerschlitzt, die Scheibe ist schwach gebogen und matt schwarz, während die Farbe des Pilzes selbst ein tiefes Schwarz ist. Die Becherchen sind ungeheuer klein und von der durch Alter und Fäulniss geschwärzten Rinde mit unbewaffnetem Auge nur schwer zu unterscheiden, sie haben ungefähr 1/3 Mm. Durchmesser (nicht wie Winter a. a. O. sagt, $0.3-0.5$ Mikromillimeter), sie sind ungestielt und an ihrem Anheftungspunkte zeigen sich einzelne feine, schwärzliche Härchen. Die Schläuche sind in den meisten Individuen zum grössten Theile noch nicht ganz reif, doch finden sich iberall anch vollkommen ausgebildete; ihre Gestalt ist schlank-keulenförmig bis fast cylindrisch, am Scheitel sind sie stumpf zugespitzt, an der Basis sehr verschmälert und in eine Art von kurzen, dünnen, hyalinen Stiel ausgezogen. Die Membran ist ziemlich dünn, 
durchsichtig, die acht Sporen sind ohne alle Ordnung in der oberen Hälfte vertheilt, die Länge schwankt zwischen 40 und $55 \mathrm{~mm}$., die Breite ist constant zwischen 4 und $6 \mathrm{~mm}$. Die Sporen sind fast cylindrisch, gerade, an beiden Enden rundlichabgestumpft, farblos, einfach und messen $7-10 \mathrm{~mm}$. in der Länge, 1-2 mm. in der Breite. - Auf der Rinde eines armdicken Stammes von wilder Vitis vinifera Lin. (nach meines Meinung ist darunter wohl die als Vitis sylvestris Gmel. bekannte Form zu verstehen) bei Kaposval im südlichen Ungarn von H. Lojka gesammelt, ferner bei Parma von Passerini auf Vitis vinifera Lin. gefunden. -- Dass zu dieser Art die von Rabenhorst a. a. O. anfgezählte Peziza viticola Pers. als Synonym zu ziehen sei, halte ich nicht für wahrscheinlich, denn die Ausdrüicke Rabenhorst's a. a. O.: „reihenweise, fast dick, gransehwarz, Scheibe flach, rothbraun", passen durchaus nicht auf unsere Alt! (Tab. III fig. 25.)

\section{Helotium sarmentorum De Not.}

De Notaris, Proposte di aleune rettificazioni al profilio dei Discomyceti in "Commentario della società crittogamol. italiana" p. 379. — Saccardo in ..Michelia" 1. p. 67. - Pirotta, funghi parassiti dei Vitigni p. 35.

Aseomata e basi contracta biatoroidea, disco plus minusve protuberante, aurantiaco; sporiclia fusoidea, nucleola $2-3$ foventia, hyalina. - De Not. 1. c. - Asei $90 \mathrm{~mm}$. long., $13 \mathrm{~mm}$. crass., sporidia $16 \mathrm{~mm}$. long., $5 \mathrm{~mm}$. erass.

In sarmentis emortuis ritis vimiferce Lin. - Italia: Milano (De Notaris), Parma (Passerini), Venetia (Spegazzini).

Dieser hiibsche Pilz wächst anf abgestorbenen Ranken des Weinstockes, und zwar gesellig. Die Individuen sind ohne alle Ordnung rund herum zerstreut, von mittlerer Grösse (im Verhältniss zu anderen species der Gattung Helotium), sitzen auf der Rinde selbst, sind kamm merklich, oft gar nicht gestielt, höchstens am unteren, aufsitzenden Ende etwas zusammengezogen, die Scheibe ist mit cinem sehr zarten, kanm hervortretenden, etwas helleren Rande versehen, ihre Farbe ist ein mattes Gelbbraun oder bräunliches Orangeroth, die Oberfläche ist glatt. Die zahlreichen, in Bündeln stehenden Schliuche sind aufrecht, keulenförmig, an Scheitel zugerundet, an ihrer Basis etwas (nach und nach) verschmälert, haben eine dïnne 
Membran und sind farblos, sie enthalten acht, in einer Reihe stehende Sporen. Diese letzteren sind breit-spindelförmig oder spindelig-elliptisch, einfach, wasserhell und enthalten zwei oder drei Nuclei, die beiden Enden sind stumpflich zugespitzt, ihre Grösse beträgt 16. $\mathrm{mm}$. in der Länge und $5 \mathrm{~mm}$. in der Breite, während die Schlänche $90 \mathrm{~mm}$. lang und $13 \mathrm{~mm}$. breit sind. Zahlreiche, wasserhelle, fadlenförmige Paraphysen, welche am oberen Ende kaum merklich verdickt sind, umgeben die Schläuche. - Dieser Pilz scheint in Italien nicht selten zu sein, wenigstens in einigen Gegenden, bei Mailand sammelte ihn De Notaris auf trockenen Reben von Vitis vinifera Lin., von Parma erhielt ich ihn in grosser Menge durch meinen Freund, Professor Passerini, in Venetien fand ihn Spegazzini. - Ausseritalienische Standorte sind mir bisher nicht bekannt geworden. (Tab. IV. fig. 11.)

\section{Helotium vitigenum De Not.}

De Notaris, Proposte di alcune rettificazioni al profilio dei Discomyceti in "Commentario della società crittogamol. italiana" p. 377. — Saceardo in Atti Soc. Veneto-Trentina Scienzia Natur. II. P. 137. - Id. Mycotheca veneta no. 959. - Pirotta, funghi parassiti dei Vitigni p. 27.

H. ascomata stipite mediocri instructa, Lecanorina; disco pallide stramineo, tenuiter marginato, convexo, subtus pallescentia; sporidia ellipsoideo-fusoirlea, hyalina, nucleolis quatuor refecta, Iongitudinis $20 \mathrm{~mm}$. parllo excerlentia. - De Not. 1. c.

H. cupulis sparsis, stipite mediocri, crasso instructis, primo excavatis, marginatis, demum planis subconvexisque, patellaeformibus, ceraceis, pallide flavis, disco pallide stramineo, tenuiter marginato, glabris; stipite plerumque curvato, hyalino, diaphano, demum pallide flavo; ascis cylindraceis vel subclavatis, pedicello brevissimo instructis, octisporis, 90-110 mm. long., $16-18 \mathrm{~mm}$. crass.; sporis confuse serialibus vel in asci parte superiore conglobatis, oblongo-fusiformibus, continuis, bi- vel ruadriguttulatis, hyalinis, $16-20 \mathrm{~mm}$. longitudinem, 4-6 $\mathrm{mm}$. crassitudinem metientibus; paraphysibus numerosis, filiformibus, simplicibus (an semper?), obscure septatis, ascos non superantibus. - Pirotta l. c.

Ad ramos èmortuos Vitis viniferce Lin., Italia: Val d'Intrasca (De Notaris), Padova, Treviso (Saccardo). 
Die Becherchen dieser Art stehen zerstrent auf den Ranken, sie sind zu Anfang ausgchöhlt, gerandet, später aber flach und sogar convex gebogen, schüsselförmig, wachsartig, hellgelb, ein ziemlich dicker Stiel trägt sie, die Scheibe ist wenig berandet, blass strohgelb, der Stiel meistens ein wenig gebogen, farblos, durehscheinend, zuletzt sehr hell gelblich. Die cylindrischen oder fast keuligen Schläuche haben ein sehr kurzes Stielchen, sind achtsporig und messen $90-110 \mathrm{~mm}$, in der Länge und 16 bis $18 \mathrm{~mm}$. in der Breite, sie enthalten die oblong-spindelförmigen Sporen, welche einfach sind, zwei bis vier Nuclei enthalten, $16-20 \mathrm{~mm}$. in der Länge und $4-6 \mathrm{~mm}$. in der Dicke messen und von wasserheller Farbe sind. Sie sind entweder unordentlich im Schlauche eingereiht oder auch in dessen oberem Ende zusammengeballt. Die zahhreichen Paraphysen sind einfach, fadenförmig, undeutlich septirt und mit den Schläuchen von gleicher Länge. - Ob, wie Pirotta a. a. O. behauptet, diese Species mit Helotium hyalopes Fuck. identisch ist, muss ich bezweifeln, denn Fuckel gibt die Schlänche seiner Art mit $126 \mathrm{~mm}$. an, also $11 \mathrm{~m} 16-36 \mathrm{~mm}$. mehr als bei vorliegender Species, und ich bin der Ansicht, dass eine so grosse Differenz genügend ist, beide Formen vorläutig noch anseinander zu halten! - Bis jetzt ward unsere Art nur in Italien gefunden, und zwar von De Notaris im Val d'Intrasea und von Saccardo bei Padova und Treviso, stets auf abgestorbenen Ranken von Vitis vinifera Lin.

\section{Helotium hyalopes Fuck.}

Fuckel, Symbolae mycologicae, Nachtrag II. p. 63. - Id. Fungi rhenani exsiceati no. 2685 .

H. cupulis ceraceis, sparsis, distincte stipitatis, primo excavatis, marginatis, demum planis subconvexisque, patellaeformibus, pallide-flavis, glabris, lineam unam latis, stipite plerumque eurvato, hyalino-diaphano, demum pallide flavo; ascis subclavatis, sessilibus, octisporis, $126 \mathrm{~mm}$. long., $18 \mathrm{~mm}$. crass.; sporidiis plerumque in asci superiore parte conglobatis, oblongo-fusiformibus, continuis, subinaequilateralibus, biguttulatis, hyalinis, $16 \mathrm{~mm}$. long., $6 \mathrm{~mm}$. erass.; paraphysibus numerosis. - Fuck. l. c.

In sarmentis emortuis, acervatis Vitis viniferce Lin. Nassovia. Raro. (Frnckel.) 
Die ziemlich kleinen, deutlich gestielten Becherchen dieses Discomyceten sind von fast wachsartiger Consistenz, sie sitzen zerstreut auf der Rinde, sind zu Anfang mit cinem kleinen, niedrigen Rande versehen, breiten sich aber später flach oder kaum convex gebogen aus; sie sind ungefuhr 1.5-2 Mm. hoch, aussen glatt, schïsselförmig, hell goldgelb, ihr Stiel ist mehr oder weniger gebogen, farblos, bei der Reife des Pilzes von derselben Farbe wie die Scheibe. Dic Schlänche, welche der Autor fast kenlenförmig „subclavatis" nennt, möchte ich lieber mit cylindrisch-keulenförmig bezeichnen, sie sind ungestielt, oben ein wenig abgerundet, haben eine sehr dünne Membran, acht Sporen und sind $126 \mathrm{~mm}$. lang, $18 \mathrm{~mm}$. breit. Die, stets im obersten Theile des Schlauches angehäuften Sporen messen $16 \mathrm{~mm}$. in der Länge und $6 \mathrm{~mm}$. in der Breite, sie sind breit spindelförmig, an der einen Längsseite fast gerade, an der andern ausgebaucht, einfach, oben und unten verschmälert zugerundet, mit einem oder mit zwei Nucleis und nach meinen Untersuchungen hellgelblich, mach Fuckel wasserhell. Die zahlreichen Paraphysen sind ungefähr halb so lang als die Schläuche, sie sind wasserhell, sehr durchsichtig, fadenförmig, an den Spitzen unbedeutend verdickt. - Fuckel fand diesen Pilz auf, zu Haufen geschichteten Reben von Vitis vinifera Lin., einmal im Herbst bei Budenheim in Nassan, aber da sehr zahlreich ïber den sehr grossen Haufen verbreitet. (Tab. III. fig. 18.)

\section{Helotium pullatum Gèr.}

Gerard in Bulletin of the Torrey Botanical Chub of New York 1875 §. 24. Hedwigia 1875 p. 189.

H. acervulatum, obscure fusco-luteo, sicco obscuriore cinereo, primo clavato demum obconico; pedicello brevissimo in cupula dilatato, disco plano, concavo, non marginato, 1-2 Mm. lato; asci cylindracei, angustissimi; sporae lincariformes, truncatae, bivel quatnor nucleatae, obsolete demum septatae, $18-20 \mathrm{~mm}$. long., $4 \mathrm{~mm}$. crass., flavidae. - Ger. l. c.

Ad sarmenta emortua Vitis Labruscae Lin., locis humidis. America septentrionalis: Poughkeepsie, New York. (Gerard.)

Der Autor, welcher mir den grössten Theil seiner Funde mittheilt, hat mir leider gerade diese Species nicht zugesendet, 
aus Autopsie kann ich daher eine Beschreibung nicht liefern und setze an deren Stelle die a. a. O. in der Hedwigia publicirte. Haufenweise, dunkel braungelb im frischen Zustande, trocken dunkley und rauchgrau, anfangs keulen-, dann verkehrt kegelförmig; Stiel kurz, in den Becher erweitert; Scheibe Alach, trocken concav, nicht berandet, 1-2 Mm. breit; Schläuche cylindrisch, schmal; Sporen linealisch, alygestumpft, mit zwei bis vier Nucleis, später scheinbar septirt, $18-20 \mathrm{~mm}$. lang, $9 \mathrm{~mm}$. breit, gelblich. - An Ranken von Vitis Labrusca Lin., an feuchten Orten. Poughkeepsie im nordamerikanischen Staate New York von Gerard entdeckt.

\section{Stictis Saccardoi Rehm.}

Rehm in litt. ad Saccardo. - Saccardo in "Nuovo Giornale botanico italiano" VIII. p. 184. - Id. Mycotheca veneta no. 258, - Stictis radiata Sace. Mycol. veneta p. 156, Tab. XV. fig. 48--51 et prob. plur. anctorum.

St. peritheciis gregariis vel sparsis, immersis, orbicularibus, urceolatis, primitus clausis, demum apertis, margine reflexo, in lacinias obtusas radiatim patentis fisso, niveis vel albidis, pulverulentis, epithecio testaceo vel subaurantiaco, circiter 0.8 MIm. lato; ascis cylindraceis, $130-140 \mathrm{~mm}$. long., 7-8 mm. crass., jodii ope non coerulescentibus; sporis conglobatis, filiformibus, guttulatis, hyalinis, tenuibus, non septatis, $100 \mathrm{~mm}$. long., 1 bis $1.3 \mathrm{~mm}$. (neque $2 \mathrm{~mm}$.) crass.; paraphysibus numerosis, filiformibus, $1.5 \mathrm{~mm}$. crass. - A Stictis radicata Pers. differt ascis angustioribus, brevioribus, sporidiis tenuioribus, non septulatis. Sacc. 1. c.

In Vitis viniferce Iin. sarmentis subputridis. Venetia: Conegliano, vere leg. C. Spegazzini.

Es hat den Anschein, als sei diese, erst vor ganz Kurzem von Rehm unterschiedene Art vielfach mit Stictis radiata Pers. verwechselt worden und ein genaues Studium der Exemplare dieser Species in den verschiedenen Herbarien dürfte sicherlich einen grösseren Verbreitungsbezirk der neuen Form nachweisen. Bis jetzt war sie, so viel ich weiss, nur auf Salvia glutinosa bekannt. - Die, entweder dicht bei einander oder mehr zerstreut stehenden Perithecien des Pilzes sind fast kreisrund, etwas eingesenkt, schïsselfürmig, zu Anfang ganz geschlossen, dann später 
geöffnet, schneeweiss oder" grauweisslich, schwach bestäubt, uнgefähr acht Zehntel eines Millimeter im Durchmesser haltend, ihr Rand ist zurtickgeschlagen und meistentheils in mehr oder weniger stumpfliche Lappen zerschlitzt, das Epithecinm oder die Scheibe ist gelblich oder schwath orangerithlich gefärbt. Die Schlaiuche sind schnnal-eylindrisch, 130-140 $11 \mathrm{~m}$. lang und 7 bis $8 \mathrm{~mm}$. breit, von Jodtinctur werden sie nicht geblänt; die Sporen sind zusammengeballt, lang farlenförmig, gekömelt, sehr dïm und zart, unseptirt, wasserhell und im Durchmesser $100 \mathrm{~mm}$. lang und nur 1-1\%3 mm. hreit; die zahlreichen Paraphysen sind fädig, farblos und eirca 1.5 mm. dick. - Durcl dic kiüzeren und schmäleren Schlänche, durch dis Wirkungslosigkeit von Jor auf dieselben und durch die dimneren und nicht septirten Sporen ist diese Species hinlänglich von Stictis radiata unterschieden. C. Spegazzini fand diese Art im Frïhjahr 1877 bei Conegliano in Venetien an diinnen, hall,faulen, meistens bereits entrindeten Ranken von Titis vinifera Lin.

\section{Stictis uberrima $\mathrm{I} o \mathrm{nt}$.}

Montagne in Annales d. se. nat. 3. Sér. XII. 1849, p. 315. - Castagne, Suppl. Catalogue plantes Marseille p. 41. - Pirotta, funghi parassiti dei Vitigni p. 15. - Spheric uberima Cast. Cat. plantes Marseille p. 172.

S. peritheeiis conicis, primo cincraseentibus, deinde nigris; ostiolo unieo; aseis unmerosis, elougatis, flexuosis, saepe incurvatis, paraphyses aequantibus; sporis plurimis (quadraginta et ultra in unoquoque asco), simplicibus, ovatis ant truncatis. Pirotta 1. e.

Ad sarmenta arida Vitis viniferce Lin. enltae et sylvaticae, pr. Marseille, Gallia. (Castagne.)

Mir ist diese Species lediglich aus dem Pirotta'schen WVerkchen bekannt, ich muss mich demnach darauf beschränken, dessen a. a. O. gegebene Beschreibung zu reproduciren. Auf den ausgebleichten, fast ganz weiss gewordenen Ranken befinden sich die kleinen, kegelförmigen Perithecien, welehe zu Anfang eine aschgraue, späterhin eine schwarze Farbe besitzen; es ist nur ein Ostiolum oder eine Mïndung vorhanden, die sehr zahhreichen Schläuche sind sehr lang, hin und her gebogen, doch auch zuweilen ganz gerade, sehr schmal und mit den Paraphysen von 
gleicher Länge vermischt. Die Sporen, von denen sich oft vierzig und mehr in einem Schlauche finden, sind einfach, eirund, an den beiden Polen abgestutzt. Ueber die Dimensionen von Schläuchen und Sporen finden sich keine Angaben. - Montagne a. a. O. glaubt nicht zu irren, wenn er diese Stictis für den .Jugendzustand der Stictis pupula Fr. hält, einer ausserordentlich polymorphen und auf den verschiedensten Substraten vorkommenden Art.

Bis jetzt ward unsere Stictis nur von Castagne auf diurren Ranken von cultivirter sowohl als von wilder Vitis viniferc Lin. in Süd-Frankreich bei Marseille gefunden.

\section{Hysterinm Curtisi Duby.}

Duby, Mémoire s. 1. tribu des Hysterinées p. 42 in Ann. d. 1. Soc. d'histoire naturelle de Genéve 1860 .

H. erumpens, demum omnino superficiale, sparsum, ovatoglobosum, convexum, complanato-convexumve, rectum nec minime flexuosum, atrum, opacum; labiis tumidis, latis, longitudinaliter uni- vel bistriatis, stria externa non profundiori rimam angustissimam relinquentibus; ascis (thecis) amplis, clavatis, sessilibus, limbo hyalino cinctis, sporas magnas elliptico-elongatas, utrinque rotundatas, uni- vel biseptatas, non merenchymaticas, hyalinas aut dilute fuscescentes, limbo hyalino cinctas, inordinate dispositas foventibus; paraphysibus nullis. - Duby 1. c. - Asci $140 \mathrm{~mm}$. long., $30 \mathrm{~mm}$. crass., pedicellus $30 \mathrm{~mm}$. long., sporae $40 \mathrm{~mm}$. long., $11 \mathrm{~mm}$. crass.

Ad ramos Vitis species indeterminatae. America septentr.: Carolina australis. (Curtis.)

Von dieser seltenen Species besitze ich in meinem Herbar ein Curtis'sches Original-Exemplar. Dasselbe zeigt ziemlich nahe bei einander stehende, aber nicht zusammenfliessende Perithecien, welche nur der Oberhaut aufsitzen und leicht von derselben losgelöst werden können. Sie sind convex, entweder fast kreisrund, oval oder elliptisch, zum Theil gerade, zum Theil gebogen, manche ziemlich niedergedrückt, mattschwarz, mit einer, nur selten mit zwei Längsrinnen. Diese letzteren sind sehr schmal, die sie einschliessenden Lippen etwas aufgeschwollen, oben abgerundet. Die Schläuche haben ein doppeltes, hyalines Episporium von 6-8 mm. Dicke, sie sind mehr oder minder keulenförmig, 
haben unten einen $30 \mathrm{~mm}$. langen Fortsatz, welchen ich, entgegen der Ansicht Duby's, für einen Stiel halte und weleher aus dem erwähnten doppelten Episporium, welehes sich an der Basis des Sehlauches vereinigt, gebildet ist, die Länge des Sehlanches beträgt $140 \mathrm{~mm}$., die Breite $30 \mathrm{~mm}$. Die acht sehr grossen Sporen sind lang-elliptiseh oder lang eiförmig, dunkelbraun (hyalin, wie Duby a. a. O. angibt, wohl nur im unreifen Zustande), undurehsichtig, oben abgerundet, unten etwas verschmälert, fast immer zweimal septirt, ebenfalls von einem hyalinen Doppelepisporium eingehïllt und in zwei Reihen angeordnet. Thre Länge beträgt $40 \mathrm{~mm}$., ihre Breite $11 \mathrm{~mm}$. Paraphysen sind nicht vorhanden. - Im nordamerikanischen Staate Süd-Carolina ron Curtis an todten Reben einer nicht näher bestimmten Vitis-Art gefunden. (Tab. I. fig. 3.)

\section{Hysterium australe Duby.}

Duby, Mémoire sur la tribu des Hysterinées p. 44. Tab. I. no. 13 a-e in Ann. d. 1. Soc. d'histoire naturelle de Genève 1860 .

H. erumpens demum superficiale sed paulo prominens, aggregato-crustaceım, atrum, nitidum, ovato-lineare, saepius lineare et elongato-lineare, labiis tumidis, angustis, acic obtusa, subcomplanata, stria marginali una et etian duplici plerumque notatis, rimam angustam demum paulo dilatatam et intus rufescentem relinquentibus; ascis cylindricis paraphyses filiformes aequantibus, spores mediocres ellipsoideas, hyalinas, medio constrictas, primo uni-, demum tri- vel quinqueseptatas, loculis merenchymaticis, plerumque universales foventibus. IIysterio biformi inter species sporis fuscis donatus analogum. - Duby 1. e.

In Vitis Labruscae Lin. sarmentis aridis. - Albany, NewYork, Newfield, New-Jersey (Ellis). America septentr. (Peck.) Vere 1877.

Von Duby, dem berïhmten Monographen der Familie der Hysterineen, ward diese Species auf Exemplare begründet, welche er selbst in Siid-Frankreich bei Castel Roussillon gefunden hatte, und zwar auf entrindeten, halbfaulenden Stämmen der Olivenbäume, Olea sativa Lam. Es ist nun hochinteressant, dass diese selbe Art in einem anderen Erdtheile auf Weinranken auftritt, während sie in Europa, so weit wenigstens bis jetzt bekannt, noch nicht auf diesem Substrat gefunden ward. - Der Pilz bildet dicht bei einander stehende schwarze Peritheeien, welche die, allen 
Hysterien eigenthümliche längliche, rundlich erhabene Form zeigen und in der Mitte der Iä̈nge nach gespalten sind, die dadurch entstehenden beiden lippenförmigen Wulste sind stumpf abgerundet. Die Schläuche von cylindrischer Gestalt sind von zahlreichen, gleich langen, fadenförmigen, wasserhellen Paraphysen umgeben und enthalten die acht Sporen. Letztere sind ellipsoidisch, wasserhell, in der Mitte etras eingeschnürt, zuerst nur eimmal, später meist drei-, anch fünfmal septirt, sie stehen fast immer in einer Reihe in den Ascis. - Es wäre sehr wichtig, genan, namentlich in Sïd-Europa und ganz speciell auf Ranken von Vitis Labrusca Lin, nachzuforschen, ob dieser Pilz nicht auch bei uns anfzufinden wäre. Ich erhielt ihn bisher nur aus Nord-Amerika, wo er auf den abgestorbenen Ranken ron Titis Labrusca Lin., sowohl im Staate New-Tork (Peck) als anch in New-Jersey (Ellis) gefunden ward.

\section{Hysterographium viticolum Rehm.}

Rehm, Ascomyceten no. 316. - Hysterium viticolum Cooke et Ellis in Grevillea IV. p. 778, Tal. 68, fig. 9. - Pirotta, funghi plarassiti dei Vitigni p. 20.

H. peritheciis dense gregariis, elevatis, tandum confluentibus in utraque pagina corticis vetustis, lineari-elipsoideis, medio longitudinaliter fissis, labiis rotundato-obtusis, atris, nitidis; ascis longissimo-anguste-clavatis, basi angustatis, $80-90 \mathrm{~mm}$. long., $20 \mathrm{~mm}$. erass., hyalinis; sporis octis, distichis, ovato-ellipticis, $4-8$ septatis, ad septas constrictis, vertice obtuso-rotundatis, dilatatis, basi rotundato-angustatis, $30 \mathrm{~mm}$. long., $10 \mathrm{~mm}$. crass., fuscis; paraphysibus non vidi.

Ad ramos emortnos Vitis viniferae Lin. et Vitis Labruscae Lin. - America septentr.: Poughkeepsie, New-lork (IV. R. Gerard), Newtield, New-Jersey. (J. B. Ellis.)

Bis jetzt ist diese schöne Species mur ans Nord-Amerika bekannt, und zwar auf abgestorbenen Ranken und alter Rinde von Vitis vinifera Lin., als auch von Vitis Labrusca Lin. Die glänzend schwarzen Perithecien stehen dicht gedraingt und finden sich, wenn der Pilz auf alter, noch hängender, aber fast schon vollkommen abgelöster Rinde, vegetirt, sowohl auf der Ober-als anch auf der Unterseite derselben. Die Perithecien sind elliptisch, in der Mitte gespalten und mugefähr $3 / 4 \mathrm{Mm}$. lang, die, durch 
den Spalt entstehenden beiden, sogenannten lippen sind rundlich. Die langen Schläuche ron schmal kenlenförmiger Form sind oben rerbreitert, abgermolet, unten ein wenig gebogen und ziemlich stark verschmälert, von wasserheller Farbe und enthalten acht Sporen, ihre Länge beläuft sich auf $80-90 \mathrm{~mm}$., ihre Breite nur auf $20 \mathrm{~mm}$. Die zweireihig gestellten Sporen sind eirund-elliptiseh, in der Jugend zwei-, später vier- bis achtnal septirt, an allen Scheidewänden schwach eingeschnürt, am Scheitel rund, an der Basis etwas verschmälert. Thre Grösse beträgt $30 \mathrm{~mm}$. in der Länge, $10 \mathrm{~mm}$. in der Breite, die Farbe ist ein, Anfangs sehr helles, später immer dunkler werdendes Bram. Ich besitze diese Form ans dem Staate New-York, wo sie bei Poughkeepsie von W. R. Gerard und ans New-Jersey, wo sie von J. B. Ellis bei Newfield gesammelt ward. (Tab. V. fig. 2.)

\section{Hysterographium flexuosum Rehm.}

Rehm, Ascomyceten no. 215. - Hysterium flexuosum Schwz. Synopsis fung. Carol. p. 49, no. 249. - Id. Synopsis of North American Fungi 1. 244, no. 2083. Fries, Systema mycologicum II. 1. 585. - Duby, Mémoire s. l. tribu des Hysterinées 1. 42. - Thïmen, Mycotheca universalis no. 181. - Ravenel, fungi Carol. exsicc. no. 48. - Berkeley, Notices of North American Fungi in Grevillea IV. p. 11.

H. superficiale, sparsum, sublineare aut lanceolato-lineare, durmm, flexuosum rectumve, atropiceum, opatum, labiis tumidis latis, longitudinaliter uni- vel bistriatis, stria exteriori profundiori et marginem simulante rimam angustam relinquentibus; ascis (theeis) amplis, clavatis, interdum pedicellatis, limbo hyalino cinctis, sporas magnas, ovoideo-elongatas, medio plerumque constrictas, utrinque attemuatas ant obtusas, merenchymaticas, intense fuscas, demun ommino opacas, triseriales foventibus; paraphysibus filiformibus, apice ramosis immixtis. - Duby 1. c. - Asci $140 \mathrm{~mm}$. long., $25 \mathrm{~mm}$. crass., sporae $42-45 \mathrm{~mm}$. long., $15 \mathrm{~mm}$. crass.

Ad sarmenta arida Tritis ripariae Mchx. Anerica septentr.: Carolina australis. (H. W. Ravenel.)

Bis in die neueste Zeit wurde diese Art zur Gattung Hysterium gerechnet, welche bekanntlich nur parallel septirte Sporen hat, erst Rehm gab ihr den richtigen Platz Jei Hysterographium, der vielfach getheilten Sporen wegen! Die Perithecien sitzen vereinzelt 
oder mehrere zusammen, niemals aber gedrängt, auf der OberHäclıe der Rebe, sie sind meistentheils linearisch oder auch lanzettlich-linearisch, hart, kaum etwas gebogen, tiefschwarzbraun, matt, die Labien oder Lippen, welche der Länge nach das Perithecium ein- oder meistens zweimal durchfurehen, sind etwas aufgeschwollen, die innere Rinne oder Furche ist niemals so tief eingeschnitten, als die äusseren. Die Schläuche, welche nach meinen Messungen $140 \mathrm{~mm}$. lang und $25 \mathrm{~mm}$. breit sind, sind keulenförmig, etwas gebogen, am Scheitel breit abgerundet, gegen die Basis hin stark verschmälert und gebogen, zuweilen scheinbar gestielt, die Membran ist dick, wasserhell, die sechs bis acht Sporen füllen den Schlauch von unten bis oben aus. Die Sporen sind mehr oder weniger elliptisch, häutig in ihrer unteren Hälfte etwas schmäler als in der oberen, an beiden Enden abgerundet und in der Mitte regelmässig schwach eingeschnürt, sie sind sowohl der Länge als der Breite nach vielfach septirt, gleichsam mauerförmig und tief dunkelbraun; von einer regelmässig dreireihigen Anordnung, wie Duby sie a. a. O. angibt, konnte ich bei meinen Exemplaren nichts bemerken, im oberen Theile des Schlauches lagen sie einfach, im unteren zwei- und dreireihig übereinander, ihre Länge beträgt $42-45 \mathrm{~mm}$, ihre Breite $15 \mathrm{~mm}$. Viele fadenförmige Paraphysen, welche sich an der Spitze mehrfach theilen und verästeln, umgeben die Schläuche, an Länge werden sie aber von denselben um das Doppelte überragt. - Die amerikanischen Autoren geben viele verschiedene Nährpflanzen an, auf welchen dieses Hysterographium vorkommt, sowohl Bäume als Sträucher, auf Vitis riparia Mchx. aber dürfte es wohl nur Ravenel in SüdCarolina gefunden haben, vermuthlich tritt es aber auch auf den anderen dortigen Vitis-Arten auf. (Tab. II. fig. 7.)

\section{Hypoderma commune Duby.}

Duby, Mémoire s. l. tribu des Hysterinées p. 53. - Fuckel, Symbolae mycologicae 1. 258. - Saccardo, Mycologia veneta P. 158. - Pirotta, funghi parassiti dei Vitigni p. 16. - Hysterium commune Fr. Syst. mycolog. II. p. 593. - Cooke, Handb. of British Fungi p. 761. - Duby, Botanicon gallicum II. p. 720. Hypoderma virgultornem var. $\beta$ et $\gamma$. De Cand. Fl. franç. VI. p. 165.

H. innatum, sparsum, ovatum, ellipticum, oblongum rotundumve, obtusum, tenue, opacum, atro-fustum, demum depressum, 
diffractum dimiatumque, labiis planis, arcte conniventibus, demum acie interdum pallescente, elcvatis, rimam angustissimam relinquentibus, ascis (thecis) e basi plus minus elongato, ovato-clavatis, sporas hyalinas, lineares, obtusas, inordinate dispositas homogeneas forentibus; paraphysibus filiformibus, flexuosis, brevioribus. Duby 1. c. - Asci $60-70 \mathrm{~mm}$. longi, 8-10 mm. crassi; sporae $10 \mathrm{~mm}$. longae, $2-2.5 \mathrm{~mm}$. crassae.

Ad Titis Labruscae lin. sarmenta emortua. America septentrionalis: Poughkeepsie, New-York (W. R. Cerard.)

Dieses Hypoderma ist in allen europäischen Ländern auf Stengeln grösserer Kräuter, namentlich Umbelliferen, sowie auf Hopfen sehr häufig, auf Weinranken hingegen ist es nur aus Amerika bekannt. Der Pilz bildet auf, meistens ausgebleichten, Reben länglich-elliptische, mitunter auch runde und zusammenfliessende, dïnne, nur wenig hervorragende, der Matrix fest anliegende Perithecien, diese sind schr zahlreich, matt brïunlichschwarz, im Zustande der Reife niedergedrickt, zerschlitzt und halbirt, die dadurch entstehenden zwei Labellen oder Lippen sind fast abgeflacht, abgerundet mit niederer Scheide and schliessen eine enge Rinne ein. Die zahlreichen Schläuche sind eirundlich-elliptisch, sitzend, gegen die Basis so sehr verschmälert, dass man sie füglich auch schmal keulenförmig nennen könnte, oben abgerundet, haben eine ziemlich dicke Membran und sind farblos. Sie enthalten acht Sporen von spindelig-linealischer Gestalt, welche oben und unten abgestumpft, einfach und ohne bestimmte Ordnung im Schlauche vertheilt sind. Thre Grösse beträgt $10 \mathrm{~mm}$. in der Länge bei $2-2.5 \mathrm{~mm}$. in der Breite, während die Schläuche $50-70 \mathrm{~mm}$. lang und $8-10 \mathrm{~mm}$. breit sind. Die zahlreichen Paraphysen erreichen kaum die Hälfte der Schlauchlänge, sie sind sehr diunn, fadenförmig, farblos und hin und her gebogen. - Wie es scheint, in Nord-Amerika auf abgestorbenen Reben von Titis Labrusca Lin. nicht selten; die Exemplare meines Herbars sind im Staate New-York, bei Poughkeepsie ron W. R. Gerard gesammelt. (Tab. I. fig. 16.) 


\section{Hypoderma Rubi De Not.}

De Notaris, Memorie in Giornale botanico Italiano II. 2. p. 35. - Pirotta, funghi parassiti dei Vitigni p. 17. - Hypoderma virgultorum De C. Fl. franç. V. p. 165. - Duby, Mémoire s. 1. tribu des Hysterinées p. 53. - Fuckel, Symbolae mycol. p. 258. - Cooke, Handb. of British Fungi p. 761, no. 2295. - Saccardo, Mycologia veneta p. 158. - Hysterium Rubi Pers. Observ. mycol. I. p. 84. Id. Syn. fung. p. 100. - Fries, Systema mycolog. II. p. 587. - Schweinitz, Syn. fung. Carol. p. 49, no. 246. - Id. Synopsis of North American Fungi p. 245 , no. 2099.

H. innatum, demum superficiale, gregarium sparsumve, interdum extremitate confluens, ex ovato- ad lineari-elongatum, acutum, laeve, nitidum, atrum, labiis tumidis, conniventibus, rimam angustam dein latiorem relinquentibus; ascis (thecis) clavatis, obtusis, longe pedicellatis, paraphysibus filiformibus superatis, sporas hyalinas, lineari-ellipsoideas, utrinque obtusas, inordinate dispositas foventibus. - Receptacula caduca in matrice maculam nigram relinquunt, labia saepe expallescant. - Duby 1. c.

In ramis junioribus Vitis Labruscue Lin., frequens. America septentr.: Carolina septentrionalis. (Schweinitz.)

Auf Ranken von Rubus fructicosus Lin., sowie auf Aesten der versehiedensten Bäume und Sträncher, als Rosa, Salix, Acer platanoides, Acer. Negundo, auf Blattstielen und Blättern von Juglans regia, Fraximus excelsior, dann auf abgestorbenen Ferula-Stengeln (Algerien) vegetirt dieser Pilz, auf Weinranken jedoch ist er ausschliesslich aus Nord-Amerika bekannt. Fr bildet auf dieser Nährpflanze mehr oder weniger gesellig wachsende Perithecien von eirunder oder linealischer Gestalt, dieselben sind zu Anfang eingewachsen, damn nur aufsitzend, zuweilen mit ihren Enden in einander zusammenfliessend, glatt, mattschwarz, in der Mitte sind sie, wie alle Hysterineen, der Länge nach gespalten, die dadurch entstehenden Labien oder Lippen sind etwas anfgeschwollen, neigen sich gegen einander, die Rimne zwischen beiden ist erst schmal, verbreitert sich aber bald. Die Schlänche sind abgestumpft kenlenförmig, sehr lang gestielt und werden von fadenförmigen, wasserhellen, zahlreichen Paraphysen, die sie an Länge überragen, umgeben. Die linealisch-elliptischen Sporen sind farblos, beiderseitig abgestumpft, einfach und olne Ordnung im Schlanche vertheilt. - An denjenigen Stellen, wo die Perithecien des Pilzes bereits abgefallen sind, bleibt ein schwarzer Fleck auf 
der Nährpflanze zuriick. Die Grösse der Schläuche beträgt in der Länge 45-60 mm., in der Breite $12 \mathrm{~mm}$, die der Sporen $12 \mathrm{~mm}$. in der Länge und $6 \mathrm{~mm}$. in der Breite. - Auf jüngeren, abgestorbenen Ranken von Vitis Labrusea Lin. in Nord-Carolina, Vereinigte Staaten. (Schweinitz.) (Tab. II. fig. 3.)

\section{Valsa ritigera Cooke.}

Cooke in Grevillea V. p. 125. - Valsa Vitis Fuck. Fungi rhenani no. 607. Id. Symbolae mycologicae p. 199. - Nitschke, Pyrenom. germ. I. 1. 190. Saceardo, Mycologia veneta p. 133, Tab. XIII. fig. 19-21. - Id. Mycotheca veneta no. 186. - Pirotta, funghi parassiti dei Vitigni p. 47.

Stroma alte immersum, e basi orbiculari vel ovali per corticem superiorem fibrosam, ductu lineali longitudinaliter parumque emergens. Perithecia monosticha, minuta, in singulo stromate $10-16$, angulata, collo brevi instructa. Stromatis substantia albida. Ostiola abbreviata, eylindrica, truncata, poro angustissimo pertusa, atra, nitida, in disculum ovalem vel subrotundum, stromatis substantia fuscescente plerumque cinctum, planum vel nonnihil convexum stipata. Spermogonia situ et magnitudine stromatibus peritheciigeris simillima, apice emersa primo albido-pulverulenta, collo centrali, nigro, poro pertuso praedita, multilocularia, locellis radiatim dispositis. Spermatia cylindrica, curvula, $4-5 \mathrm{~mm}$. longa, $1 \mathrm{~mm}$. paullo crassiora, in sterigmatibus simplicibus, longiusculis acrogena, tandem in cirrhos pallide luteolos protrusa. Asci sessiles, anguste clavati, octispori, $48 \mathrm{~mm}$. long., $7-8 \mathrm{~mm}$. crass. Sporae conglobatac, cylindricae, curvatae vel subrectac, unicellulares, hyalinae, 10-12 mm. long., 2-3 mm. crass. - Nke. l. e.

In sarmentis emortuis Vitis viniferce lin. Guestphalia (Nitschke), Nassovia (Fuckel), Venetia (Saceardo).

Es ist mir eigentlich nicht recht erklärlich, wie Nitschke a. a. O. sagen kann: „Splaceria Vitis Schwz. ist nach zweien, von mir untersuchten Original-Exemplaren des Kunze'schen Herbars in der That vorliegende Art. Doch zeigen beide Stiicke fast nur die Cytisporenform und scheint Fries nach seiner Beschreibung a. a. O. gleichfalls diese vor sich gehabt zu haben. Schläuche und Sporen konnte ich uibrigens an den amerikanischen Exemplaren nicht mehr finden!" Unser, hier besprochener Pilz wird 
weiter von Nitschke mit folgenden Worten beschrieben: „In der Regel brechen zwei bis drei, am Grunde anderthalb Millimeter breite Stromata, dicht genährt, in einer kleinen Längsspalte der oberen, fibrösen Rinde hervor. Die Ostiola bleiben in meinen Exemplaren stets verkïrzt, iiberragen den Scheitel des Stromas nur wenig, stehen ziemlich dicht beisammen, sind sehr klein und von einem, nur mit guter Lupe deutlich sichtbar zu machenden, Porus durchbohrt. Der hervorragende Scheitel der Spermogonien ist Anfangs weiss bestäubt; in seinem Centrum erhebt sich der kleine, papillenförmige Hals mit kleinem Porus. Nicht selten fliessen mehrere Spermogonien zu grösseren, stärker hervorragenden und mit mehreren Oeffnungen versehenen, warzenförmigen Körpern zusammen". - Die Perithecien sind nur klein und stehen ohne alle Ordnung zerstreut, sie durchbrechen die Oberhaut und bilden halbkugelförmige, fast ganz regelmässige Wärzchen, ihre Farbe ist brätmlich. Die kurzen Mündungen iiberragen kaum den Scheitel des Perithecinms und sind sehr klein, cylindrisch abgestutzt und von einem winzigen Porus durchbohrt. Die Schläuche haben eine Länge von $48 \mathrm{~mm}$. und eine Breite von $7-8 \mathrm{~mm}$, sie sind ungestielt, schmal keulenförmig, wasserhell und enthalten acht Sporen, welche in zwei Reihen angeordnet, gerade, oder nur wenig gebogen-cylindrisch, farblos, einfach sind und $10-12 \mathrm{~mm}$. in der Länge, bei $2-3 \mathrm{~mm}$. in der Breite messen. - Vergleicht man num mit dieser Beschreibung diejenige, welche weiter unten von Valsa Vitis Berk. et Curt. folgt, so wird man angenblicklich den bedentenden Unterschied zwischen beiden Arten bemerken. Einen Unterschied allerdings, welcher sich fast ausschliesslich auf makroskopische Merkmale begriundet, aber mir denuoch vollkommen genïgend zu sein scheint, beide Formen zu tremen. Das hat denn auch a. a. O. Cooke gethan und dadurch sich den Dank aller Mykologen verdient. Zu bedauern ist nur, dass weder Cooke noch Berkeley die Schläuche der amerikanischen Art beschreiben und auch die Exemplare derselben, welche ich in meinem Herbar besitze, keine solchen im reifen Zustande besitzen. - Die Hauptunterscheidungsmerkmale beider Species sind die bei Valsa Vitis mehr als noch einmal so grossen Perithecien, welche sich um das Doppelte so hoch erheben als bei vorliegender Art. Dann der durch die blasig emporgehobene Cuticula gebildete, 
wulstartige, schwärzliche Ring und endlich die mehrfach zerschlitzten, gleichsam gezähnten Mïndungen der amerikanischen Pflanze. Diese vegetirt ausserdem nur auf jungen und dünnen, wie es den Anschein hat, noch nicht lange abgestorbenen Ranken, während unser Pilz alte, abgesehnittene, dicke Reben bewohnt. Wie schon bemerkt, sind die Schläuche bei meinen Exemplaren ans Amerika nicht ganz reif, trotzdem lässt sich aber mit Sicherheit behaupten, dass dieselben viel grösser sind, als bei der europäischen Art, dass sie breit kenlenförmig und am Scheitel breit abgerundet sind. - Wie es scheint, finden sich in den Schlauchperithecien bei beiden Arten zallreiche Spermogonien oder Spermatien, deren Form ziemlich ïbereinstimmt, nur sind die amerikanischen grösser; ihre For'm ist bei unserer Art gebogen cylindrisch, eigentlich richtiger ausgedriickt, schmal spindelförmig; sie werden an der Spitze langer, fadenförmiger Sterigmen abgesehniurt, bei vorliegender Species sind sie $4-5 \mathrm{~mm}$. lang und $1 \mathrm{~mm}$. breit, während sie bei den Exemplaren aus Amerika reichlich $7-8 \mathrm{~mm}$. in der Läinge und $1-2 \mathrm{~mm}$. in der Breite messen. - Auf alten, abgestorbenen Reben ron Vitis vinifera Lin. in Westphalen von Nitschke, in Nassan von Fuckel, in Venetien von Saccardo gefunden. (Tab. III. tig. 8.)

\section{Valsa Vitis Berk. et Curt.}

Berkeley, Notices of North American Fungi in Grevillea IV. p. 101. - Cooke in Grevillea V. p. 1:5. - Sphaevic Vitis Schweinitz, Synops. fung. Carol. p. 39, no. 117. - Id. Synopsis of North American Fungi 1. 202, no. 1362. - Fries, Systema mycolog. II. p. 401. - Peck, XXV. Report of the New-York State Museum p. 103.

V. pustulata, circinata, nigra, peritheciis majusculis, subtrinis coalitis, ostiolis pulveraceis. - Tres vel quatuor sphaerulae majusculae sub cortice inferiori seu libro nidificant, corticem bullosum reddunt et in pustulam coalescunt. Ostiola irregularia, subpulveracea nigra; sphaerulae farctae, materia indurascente. Fr. 1. c. - Ascos maturos non vidi, sed plane majores quam in Valsa vitigera Cooke.

In sarmentis junioribus, tenuibus Vitis Labruscae Lin. America septentr.: Carolína australis, Pennsylvania (Schweinitz), New-York (W. R. Gerard); Vitis viniferae I.in., Venetia: Conegliano (Spegazzini). 
Bereits bei Besprechung der T'alsa vitigera Cooke habe ich dargelegt, wie diese und die vorliegende Species mit einander verwechselt wurden und wie Cooke das Verdienst gebührt, diess anfgeklärt zu haben. Ich bin ebenfalls im Besitz von amerikanischen Exemplaren dieses Pilzes und kann Cooke nur vollkommen beistimmen, wenn er die beiden Arten auseinander hält. Leider sagt aber weder dieser Forscher, noch die älteren irgend etwas über Schläuche und Sporen und da meine, makroskopisch prächtig entwickelten Exemplare noch keine reifen Asci besitzen, so möchte ich mich beinahe zu der Ansicht himneigen, dass anch Cooke keine solchen gesehen habe. - Schon äusserlich ist unser Pilz sehr auffallend. Auf der zarten und dünnen, wie es scheint, noch gar nicht lange abgestorbenen Rinde erheben sich, ohne alle Ordnung zerstreut, aber ziemlich dichtstehend, in bedeutender Anzahl die grossen Peritheeien des Pilzes. Sie treiben die Rindenoberhaut blasenartig in die Höhe, dieselbe dabei zugleich schwärzlich färbend. In der Mitte dieser Erhöhung, welche oft bis zu $3 / 4$ Mm. im Durchmesser hält, erhebt sich später das Ostiolum, die Nündung, und durchbricht die Oberhaut. Es sind diese Mündungen ganz ausnahmslos, in zwei bis vier conische, ziemlich lange, oben schwach abgestumpfte Theile gespalten oder tief gefurcht und diess ist einer der wichtigsten Unterscheidungspunkte von der europäischen Art. Die emporgezogenen Mündungen sind sehwärzlich, oben verdïnnt und, wie gesagt, mehrere Male gespalten, nach unten verbreitert und sitzen auf den blasenartigen Emportreibungen der Rinde, so dass das Ganze einer Brustwarze (lat. uber) ähnelt. Wie ich schon oben erwähnte, sind meine Exemplare nicht vollkommen reif; sie enthalten allerdings Schläuche von breit-keulenförmiger Gestalt, wie es scheint ungestielt und am Scheitel sehr verbreitert, aber diese sind noch ohne Sporen oder enthalten wenigstens nur Anfänge zu deren Bildung, auf jeden Fall aber sind che Asci vorliegender Species weit grösser als die von Valsa vitigera Cooke. - Auf dïnnen, jungen Ranken von Vitis Labrusea Lin. in Nord-Amerika, wie es scheint, nicht selten, wenigstens ward der Pilz bisher in SïdCarolina und Pennsylvanien von Schweinitz, in Nord-Carolina von Curtis und in New-York von Gerard und Peck gefunden; bei Conegliano in Venetien fand ihn C. Spegazzini anf Titis vinifera Lin. 


\section{Diaporthe vitirola Nke.}

Nitschke, Pyrenomycetes germanici I. p. 264.

Stroma diatrypeum, breve, plagas minntas in rami longitudinem extensas, ovales, ellipticas vel irregulares, hinc inde confluentes occupans, quoad immersum nigrolimitatum, ceterum substrati materia specie hand diversum vel saepius obscuratum, cinerascens, immo nigricans, ligni superficiem maculis atris, opacis aspergens, corticis libro fibroso primo omnino tectum, deinde saepe mudatum. Perithecia exigua, depresse-subglobosa, stromati alte immersa, plerumque in series longitudinaliter directas, breves, plerumque simplices ordinata, mox dense stipata, mox distantia, in collum longinsculum subito attenuata. Ostiola basin versus sensim incrassata, conica vel plus minus elongata, tenuissime eylindrica, nodulosa, recte vel varius Hexuosa, per libri rimis angustis ordine lineari erumpentia. Asci anguste clavati, octispori, sessiles, 60 inm. long., 7 -8 mm. crass. Sporae distichae, snbfusiformes vel saepius clavaeformes, bi-vel quadricellulares, haud constrictae, saepissime parum curvatae, hyalinae, $10-12 \mathrm{~mm}$. long., $3 \mathrm{~mm}$. circiter in latudine aequantes. - Nke. 1. c.

Ad samenta emortua Vitis viniferce Lin. Guestphalia (Nitschke), Venetia (Saceardo).

Mir sind nur Exemplare dieses Pilzes, welche saccardo bei Treviso sammelte, und die sich in meinem Herbar betinden, zugänglich, an anderen Orten, mit Ausnahme des Original-Sitandortes, scheint bisher der Pilz nicht beobachtet worden zu sein. Das Stroma vorliegender Art ist ziemlich unscheinbar, "nach Entfermung der längsspaltigen, meist nur lose aufsitzenden Bastschicht, bemerkt man kleine, meist 3-6 $\mathrm{Mm}$. lange Reihen von Perithecien, in deren Umgebung die Substratoberfläche geschwärzt ist. Häufig verlaufen mehrere Perithecienreihen, dicht genähıt, einander parallel und bilden einen grösseren Stromaflecken, die ihrerseits wiederum vereinzelt oder genährt bis zusammenfliessend sich finden. Lagern indess die Peritheeien, wie nicht selten, in ungleichen, meist aber ziemlich grossen Entferuungen von einander, so erscheinen sie ganz ohne Ordnung unregelmässig zerstreut. Das Stroma besitzt dann in der Regel eine grössere Ausdehnung und fäbt die Holzoberfläche oft nur schmutzig-bräunlich. Der eingesenkte, schwarzberandete Stroma- 
theil ist dagegen gerade bei vorliegender Art oft stärker verfärbt als bei anderen Arten, zuweilen selbst schwärzlieh." Soweit Nitschke a. a. O. Ich füge noch folgende Bemerkungen hinzu. Die Peritheeien sind ungewöhnlich tief ins Holz versenkt, sie sind gedriickt kugelig, ihre kegelfürmigen Nündungen sind ziemlich lang, eylindrisch, knotig und mehr oder weniger gebogen, sie durchbreehen in linienfïrmigen Streifen die Oberfläche. Die sehr schmal keulenförmigen Schläuche sind ungestielt, achtsporig, $60 \mathrm{~mm}$. lang, 7-8 mm. breit. Die Sporen, welche in zwei Reihen angeordnet sind, haben eine beinahe spindelförmige, oft fast keulige Gestalt, an einem Ende sind sie oft dicker als am anderen, an jenem abgerundet, an diesem allmälig zngespitzt, sie haben zwei bis vier Abtheilungen, sind kaum an den Theilnngsstellen eingeschnïrt, wasserhell, oft etwas weniges gebogen und messen 10-12 $\mathrm{mm}$. in der Länge, $3 \mathrm{~mm}$. in der Breite. - Anf abgestorbenen Ranken von Vitis vinifera Lin. zuerst vom Autor bei Münster in Westphalen, später anch von Saceardo bei Treviso in Venetien gefunden.

\section{Eutypa ludibunda Thïm.}

Valsa ludibunda Sace. Mycotheca veneta no. 938, 939. - Id. in Michelia I. p. 15. Valsa referciens Sace. Myc. veneta p. 128, pr. parte. - Id. Mycotheca veneta no. 196, 197, 198. - Talsa cerviculata Erh. crittog. ital. Ser. II. no. $6+1$ non Fr. Valsa lata Sacc. Myeol. veneta p. 128 pro parte non Pers.

Species maxime ludibunda; perithecia submonosticha, nune subsparsa ad instar Ciyptosphaeriae, nune in ligni superficie denigrata, densissime stipita ut vera Eutypa, nune in acervolos quasi Eutypellae hine inde aggregata, initio extus albo-furfuracea; stroma modo latum nigrumque, modo tenue et vix percipiendum; ostiola plerumque brevia, rarius vere longiuseula, non tamen exserta, vertice eonoideo vel obtusato, modo profunde quadri- vel quinquesuleato, modo leviter rimoso, neutiquam laevi, nt Valsa lata. A $V$. referciente Nke. differt praecipue stromate in cortice interiore plerumque nigro-limitato, peritheeiis extus albo-furfuraceis, monostichis, sed et haee forte ejusdem speciei formam rariorem sistit. - Acervulis corticolis valseis bullato-prominulis; ostiolis tri- vel quadriexaratis; asci $35-40 \mathrm{~mm}$. longi, $7-8 \mathrm{~mm}$. crass., sporae 8-12 mm. long., 2-3 mm. crass., luteolae. - Sacc. l. c. 
In ritis viniferce Lin. sarmentis emortuis. Venetia (Saccarto.

Ich keme diese Species sehr gut aus den, vom Autor in seimer schönen "Mycotheca vencta" ausgegebenen Excmplaren, jedoch nur auf anderen Substraten, deren er nicht weniger als achtunddreissig aufführt! Auf Weinreben ist mir dieser Pilz nicht bekamnt und da bei allen Formen die Schläuche und Sporen sehr in der Grösse verschieden sind, gebe ich anch keine Abbildnng dieser Art. Dic sehr undentlichen Perithecien stehen meistentheils auf dem schwarzen Stroma, welches die Oberflache des Holzes bedeckt, sie sind einreilig gestellt, anssen weisslichkleiig; die Perithecienhanfen sind blasenförmig hervortretend. Die Mündungen sind mehr oder minder kurz, nicht eigentlich hervortretend, am Scheitel kegelförmig abgestumpft, entweder vier-bis fünffurehig oder wenig gespalten, glatt. Die Schlänche sind $35-40 \mathrm{~mm}$. lang ind $7-8 \mathrm{~mm}$. breit und enthalten acht gelbliche Sporen von 8-12 mm. Lünge und 2-3 mm. Breite. Auf abgestorbenen Reben von Vitis vinifera Lin. in Venetien von Saccardo beobachtet.

\section{Cryptoralsa Rabenhorstii Sace.}

Saccardo, Mycol. veneta p. 135, Tab. XIV. fig. 17-20. - Id. in Michelia I. p. 21. - Valsa Rabenhorstii Nke. Pyrenom. german. I. p. 158.

Stroma effusum, plerumque breve, maculaeforme, immo valsaeforme, peridermio hand nigrefacto tectum, corticis parenchymati immersum ejusque substantia, specie immutata formatum, ligno adnatum, nigrolimitatum, matricem elevando crustam formans rimoso-verrucosam. Perithecia submonosticha, densissime stipata, subglobosa vel mutua pressione angulata, immersa, atra, collo brevissimo eylindrico, crasso, ostiolo nomihil incrassato, obtusissimo, rotundato, tandem obscure quadrisuleato, parum exserto, rarissime elongato, cylindrico instructa, hine inde, peridermio secesso, tandem libera. Asci clavati vel fere oblongi crassiusculi, longissime pedicellati, polyspori, $80 \mathrm{~mm}$. long., $14 \mathrm{~mm}$. crass. Sporae conglobatae, cylindricae, curvulae, micellulares, fuscescentes, $14 \mathrm{~mm}$. long., $3 \mathrm{~mm}$. crass. (Dimensiones sec. cl. Saccardo l. c.) - Nke. l. c.

Ad sarmenta emortua Vitis viniferae Lin. Venetia. (Saccardo.) 
Diese Species, welche nach Nitschke a. a. O. nui auf Zweigen vou Robinia Pseudacacia vorkommt, ward von Saccardo auf nicht weniger als zweiundzwauzig versehiedenen Nährpflanzen, lauter Bäumen und Strïuchern, gefunden! Sie ist mir auf verschiedenen dieser Substrate bekannt, leider aber gerade auf den hier in Frage kommenden Weinreben nicht. - Das Stroma unserer Art wird von dem anscheinend unveräinderten Rindenparenchym gebildet und ist zuletzt deutlich schwarz berandet. Die einzeilig ungemein nahe beisammen stehenden Perithecien sind fast kugelig, schwarz, haben einen sehr kurzen, cylindrischen Hals und verursachen durch die aufgetriebene Rindenoberfläche ein fast gefeldertes Ansehen der letzteren. Die Schläuche sind ziemlich breit keulenförmig bis oblong, selbst manchmal birnförmig, sehr lang gestielt, vielsporig, und haben eine nur wenig und fast gleichmässig verdickte Membran und darum ein, der äusseren Form des Schlanches entsprechendes Lumen, ihre Grösse beträgt nach Saccardo bei der Form auf Weinreben $80 \mathrm{~mm}$. in der Länge und $14 \mathrm{~mm}$. in der Breite. Die vielen zusammengeballten, gebogen-cylindrischen Sporen sind einfach, gelblich braum, $14 \mathrm{~mm}$. lang und $3 \mathrm{~mm}$. dick. - Auf abgestorbenen Ranken von Vitis vinifera Lin. in Venetien von Saccardo aufgefunden. (Tab. 1. fig. 7.)

\section{Cryptoralsa ampelina Fuck.}

Fuckel, Symbolae mycologicae p. 212. - Pirotta, funghi parassiti dei Vitigni p. 49. - Valsa ampelina Nke., Pyrenomycetes germanici p. 156. - Cryptovalsa motracta De Not. Sferiacei italiani p. 40, Tab. 46, pr. p. - Enchusias Vitis Has\%]. in VerbandIungen der k. k. zoolog,-botan. Gesellschaft zu Wien 1873 p. 367 , sec. cl. Rehm in litt. ad me.

Stroma nunc longe lateque effusum Vitis sarmenta continue ambieus, nunc contra breve, maculaeforme, cortici immersum ejusque substantiam nec non ligni suppositi superficiem tandem atroinquinans, corticis strato supremo immaculato tectum, haud raro elevato-protuberans. Perithecia ligno adnata, monosticha, dense conferta, nunc ordine aequali disposita, nunc seriatim ordinata, majuscula, erecta, atra, exacte globosa, in collum breve, crassum, cylindricum subito attenuata, ostiolo plus minus prominulo, rotundato vel tunico-truncato, ruguloso, vix unquam conspicue sulcato instructa. Asci cylindrico-clavati, longissime pedi- 
cellati, polyspori, $75-90 \mathrm{~mm}$. long. (pars sporifer), $8-9 \mathrm{~mm}$. crass. Sporae in asci lumine apicem versus plerumque vehementer attenuato conglobatac, cylindricae, curvulae vel subrectae, unicellulares, pallide firscescentes, $9-10 \mathrm{~mm}$. $\operatorname{long}, 2 \cdot 5)$ nm. crass. - Nke. 1. c.

Ad samenta arida Titis viniferae Iin. Pedemontium (De Notaris), Nenchâtel, Helvetiae (Morthier), Nassovia (Fuckel), Parma (Passerini).

Zu Anfang ward dieser Pilz von De Notaris a. a. O. mit der Fries'schen Sphaeria protracta Syst. mycol. II. p. 425 vereinigt. Auch Nitschke vermochte Anfangs, wie er a. a. O. angibt, beide Formen nicht zu trennen, fand aber späiter doch genügende Merkmale zu einer specitischen Unterscheidung heraus und betont auch ausdriicklich, dass ausserdem die Verschiedenheit des Substrates (Cryptovalsa protracta De Not. im engeren Simne bewolnt diure Aeste von Acer campestre Iin.) ilm auch mit als 'Tremnungsgrund gelte; ich kann dieser letzteren Meinung' mich nur ruickhaltslos anschliessen und glanbe, dass auf die Substrate bei Abgrenzung der einzelnen Speciés noch viel zu wenig Riicksicht bisher genommen wird! Der Pilz selbst tritt zumeist ziemlich dicht gedrängt stehend auf dunkel gefürbten Partien des Holzes auf, er ist entweder unregelmässig zerstrent oder reihenweise geordnet und durchbohrt die Rindenoberhaut mit einem kurzen Halse, die Perithecien sind kugelig, schwarz, anfrecht, der Hals ist ganz dentlich abgesetzt, die Miundungen desselben undeutlich vierfurchig. Die Schläuche sind cylindrischkeulenförmig, sehr lang gestielt, vielsporig, 75-90 mm. lang', S-9 mm. breit, umgeben von äusserst zarten, kurzen, fadenförmigen Palaphysen. Die wenig gebogenen oder fast geraden Sporen sind cylindrisch, im oberen Theile des Schlauches zusammengeballt, einfach, sehr hell braun gefärbt und bei $2.5 \mathrm{~mm}$. Breite, 8-9 mm. lang. - Dor Pilz wächst an diuren Reben des gemeinen WTeinstockes, Vitis vimifera Lin., er ist mir bisher bekamnt aus Piemont (De Notaris), Parma (Passerini), Nassan (Fuckel) und Neuchâtel (Morthier).

Ob als Spermatienform zu diesem Pilze das Cryptosporium ampelinum Thium. zu ziehen sei, und ob dasselbe mit dem, von Fuckel a. a. O. beschriebenen Pilze identisch sei, werde ich bei 
der Beschreibung des gedachten Pilzes ausführlich erörtern und ist iiber diesen Punkt dort nachzuschlagen. (Tab. V. tig. 8.)

\section{Calosphaeria minima Tul.}

Tulasne, Selecta fung. carpol. II. p. 112, Tab. 13, fig. 23-24. - Nitschke, Pyrenom. germ. I. p. 96. - Saccardo, Mycol. veneta p. 149, Tab. 15, fig. 1--4. - Fuckel, Symb. mycol. Nachtr. II. 1. 42.

Perithecia in soros minutissimos, orbiculares vel ovales, densissime stipata, circinatim decumbentia, atıa, globosa, minima, glabra, demum collabescentia, in cortice interiore omnino superficialia, peridermioque nonnihil pustulato-elerato tecta. Peritheciorum colla brevissima, apicibus attenuatis, assurgentibus ac subjunctis periderminm perforantibus nec exsertis. Asci cuneiformi-clavati, apice obtusissimi, rotundati, in pedicellis ramosis fasciculatim conjuncti, octispori, longitudine $28 \mathrm{ltm}$. (pars sporifer), crassitudine 4 vel $5 \mathrm{~mm}$. Pseudoparaphyses septatae, ascos longe superantes, simplices, 5-6 mm., crassae. Sporae subdistichae, cylindraceae, nonnihil curvatae, unicellulares, hyalinae, exilissimae, 5-7 $\mathrm{mm}$. longae $1 \mathrm{~mm}$. vix crassae. - Nke. l. c.

Sec. cl. Saccardo l. c. asci $25 \mathrm{~mm}$. long., $5 \mathrm{~mm}$. crass., sporae $5 \mathrm{~mm}$. long., $1.5 \mathrm{~mm}$. crass. et paraphyses $100-110 \mathrm{~mm}$. long., $3 \mathrm{~mm}$. crass.

In ligno emortuo sarmentormm Vitis vinifercae Lin. Venetia: Conegliano. (Spegazzini.)

Die äusserst kleinen, kugeligen Perithecien lagern zu mehreren, dicht gedrängt in runden Häufchen von kaum 1 Mm. Durchmesser, welche in unserem Falle dem Holze dicht aufsitzen. Die Schläuche sind vollkommen keilförmig;, am Ende abgestutzt, wie abgerissen; erst bei genauerer Untersuchung gewahrt man die verhältnissmässig sehr stark verdickte Schlauchspitze, die ungefähr halbkugelig, dem Schlauche wie eine Kappe anfsitzt. Die Verdickung setzt sich unten kaum bemerkbar als äussere Contour des Schlauches fort. Ueberdiess sitzen die Schläuche in etwas ungleicher Höhe, meist zu fünfen, anf verzweigten Stielen ohne durch Scheidewände von diesen abgegliedert zu sein. Die Paraphysen sind sehr lang, farblos, fadenförmig und erreichen die doppelte Länge der Schläuche. Die Sporen sind in zwei Reihen angeordnet, cylindrisch, manchmal ein wenig gekrümmt, 
einzellig, farblos. - Dieser, zum Theil Nitschke a. a. (). entnommenen Beschreibung fiige ich noch die Maasse hinzu, welche nach den Angaben der Antoren etwas schwanken. so gibt Nitschke die länge der Schläuche zu $28 \mathrm{~mm}$., der Sporen zu $5-7 \mathrm{~mm}$, die Breite zu 4-5 mm., respective zu kaum $1 \mathrm{~mm}$. an, die Paraphysen fand er $5-6 \mathrm{~mm}$. dick. Dagegen gibt Saccardo an: Schläuche $25 \mathrm{~mm}$. lang, $5 \mathrm{~mm}$. dick, Siporen $5 \mathrm{~mm}$. lang, $1.5 \mathrm{~mm}$. breit und Paraphysen 100-110 mm. lang und $3 \mathrm{~mm}$. dick. - Ein einziges Mal nur ward dieser, bisher auf Prunus spinosa, Cornus sanguinea, Salix vitcllina und Fagus sylvatica beobachtete, aber trotzdem sehr seltene und seiner Kleinheit halber leicht zu ïbersehende Kernpilz von C. Spegazzini bei Conegliano in Venctien auf entrindeten, dicken, halbfaulen Ranken und Stöcken von Vitis vinifera Lin. gefunden und das Exemplar mir freundlichst ïberlassen.

\section{Diatrype Vitis Berk.}

Berkeley, Notices of North American Fungi in Grevillea IV. p. 96.

Was Berkeley für einen Pilz unter diesem Namen versteht ist mir ganz unbekannt, der Gattungsname Diatrype kommt in keiner der beiden Schweinitz'schen Arbeiten vor und doch führt Berkeley a. a. O. ohne jede weitere Bezeichnung: Diatrype Vitis Schwz. an!

\section{Dothidea myriococea Mntg.}

Montagne, Cent. I. des plantes cellulaires exotiques in Annales d. sciences nat. $\therefore$ VIII. p. 359. - Id. Sylloge plant. eryptog. p. 222, no. 773.

1). erumpens, lineari-clongata, rufo-fusca, intus cinereo-nigra; cellulis periphericis minutissimis, albo-farctis; ascis . ...

Ad ramos Vitis vinifercle Lin. Gallia: pr. Lemovicem. (Lamy.)

Ich habe diese Art, welche, wie es scheint, nur eimmal vom verstorbenen Lamy bei Limoges in Mittel-Frankreich an abgestorbenen Zweigen des gemeinen Weinstockes, Vitis vinifera Lin., gefunden worden ist, niemals zu Gesicht bekommen. Uebrigens sah auch Montagne weder Schläuche noch Sporen, brachte den Pilz also lediglich seiner äusseren, makroskopischen Merkmale wegen zur Gattung Dothidea. Er sagt von ihm nur, dass die Perithecien hervorbrechen, länglich-linealisch, aussen rothbraun 
und innen schwärzlich-aschgran sind; die Randzellen gibt er als sehr klein und weiss ausgefüllt an, welch letztere Bemerkung sich wohl anf den Nucleus bezichen dïrfte.

\section{Dothidea picea Berk. et Curt.}

Berkeley, Notices of North American Fungi in Grevillea IV. p. 105, no. 888. Pirotta, funghi parassiti dei Vitigni p. 51.

D. maculis minutis, orbieularibus; ascis brevibus; sporidiis angustis, cymbaeformibus, hyalinis. - Berk. 1. e.

In sarmentis emortuis Titis aestivalis Mehx. Ameriea septentrionalis.

Aeusserst kurz ist die Beschreibung und die Diagnose dieser mir ganz unbekannt gebliebenen Species abgefasst; danach bildet der Pilz kleine, papillöse, schwarzbranne, runde Perithecien, welehe kurze, keulenförmig’ Schläuche mit kahnförmigen, schmalen farblosen Sporen enthalten. - In Nord-Amerika anf abgestorbenen Ranken von Vitis aestivalis Mehx.

\section{Dothidea viticola Sehwz.}

Schweinitz, Synopsis of North American Fungi p. 235, no. 1936.

D. teeta, maculis minoribus, confluentibus, nigro fuscis, subvernicosis. Fibrillulis erassis, ramoso-furcatis, radiantibus, plerumque indistinetis. Cellulis elevatis, apice applanatis, difformibus. - Schwz. 1. c.

In ramulis junioribus Vitis Labruscae Lin., frigore enecatis. Frequens. America septentrionalis: Bethlehem, Pennsylvaniae. (Schweinitz.)

Sehweinitz führt diese Species unter der Abtheilung Asteroma von Dothidea an und obzwar ich keine Exemplare des Pilzes sah, so glaube ich doch fast mit positiver. Bestimmtheit behaupten zu können, dass vorliegende Art, nach unserer jetzigen Eintheilung, nicht zu Dothidea gehört und wahrscheinlich eine echte Asteroma ist. Für diese Annahme sprechen anch mehrere Stellen der Diagnose, wie man aus nachfolgender Uebersetzung derselben ersehen wird. Die Peritheeien sind von der Epidermis bedeckt, bilden kleine, zusammenfliessende Flecken von glänzend schwarzbrauner Farbe. Die Fibrillen oder Zasern (sie geben den Asteroma-Arten das eigenthümliche, fast dendritische Ansehen) sind dicklich, gabel- 
ästig, strahlenförmig ausgebreitet, meistcntheils undeutlich. Dic aufiechten Zellen sind an Scheitel abgeplattet und unfömig. (Diesen letzteren Kusatz verstehe ich nicht - oder sollte der Antor damit die eigentlichen Perithecien meinen, während er vorher mehr von dem Pilz im Ganzen, besonders von dem, strahlig ausgebreiteten, oberflächlichen Mycelium gesprochen hat?) Auf jüngeren, durch Frost getödteten Ranken von Vitis Labrusca Lin. in Pennsylvanien, Nordamerikanische Union. (Schweinitz.)

\section{Cucurbitraria Vitis Schlzr.}

Schulzer in Verhandl. d. zoolog.-botan. Gesellschaft zu Wien XX. 1872, p. 643. - Pirotta, funghi parassiti dei Vitigni p. 44.

C. peritheciis globosis, gregariis, connatis, ostiolatis, nigris, ostiolis longioribus demum deciduis; ascis rectis, clavatis, octisporis; sporis oblongo-ovatis, basi minime angustatis, gradatim dispositis vel inordinatis, triseptatis, ad septas paullo constrictis vel crenulatis, quadrinucleatis, achrois, $22-28 \mathrm{~mm}$. long., $6 \mathrm{~mm}$. crass.; paraphysibus filiformibus, simplicibus, densissime contextis.

In sarmentis aridis Vitis viniferae Lin. Slavonia. (Schulzer.) Schulzer gibt a. a. O. die folgende ausführliche Beschreibung: „Mit Leptosphaeria Vitis Schlzr. und deren Begleitern in geselligen Räsehen von zwei bis sechs verwachsenen Individuen, doch auch gereiht, aus der Rinde hervorbrechend, in welcher der Pilz, bis zum Holze reichend, entsteht. Die einzehen Räschen liegen nach der liänge des Zwveiges und sind 1/7-1/5 Koll lang. Die schwarzen, kugeligen, stumpfen Pyrenien öffnen sich am Scheitel mit einer längliclıen Mindung. Śpäter fällt der obere Theil ab und man sieht nur noch Schälchen. Sie sind fest mit einander verwachsen und die Zwischenräume mit derselben hornartigen, schwarzen Masse ausgefiillt, aus welcher sie bestehen; sie vegetiren sonach in einer Art von Stroma, aus welchem nur die Scheitel der einzelnen Individuen hervorragen. Unter diesem sieht man noch meistens ein zerreibliches, schwarzbraunes, theilweise in das Holz eindringendes Afterstroma von geringer Mächtigkeit; ein ganz eigentliches Myceliumgebilde. Der weissgraue Kern besteht aus aufrecht stehenden, keulenförmigen, achtsporigen Schläuchen und aus fadenförmigen, dicht verfloehtenen und deshalb ästig scheinenden Paraphysen. Trotz aller ange- 
wandten Mïhe, eine wirkliche Verästelung zu constatiren, gelang mir dieses nicht, ich muss sie sonach für einfach annelımen. Die oblong-ovalen, an unteren Ende kaum merkbar mehr verdünten Sporen sind im Schlauche bald staffelförmig geordnet, bald nicht, fuihren in jedem Alter vier Sporidiolen, zwischen welchen sich ziemlich spät drei Septa bilden. Sie sind an den beiden äusseren sanft geschnürt und in der Mitte gekerbt, farblos oder sehr blass gefärbt und haben eine Länge ron 22-28 mm., eine Dicke von $6 \mathrm{~mm}$. - Ungeachtet der abweichenden schlauchform und der kaum merkbar weniger schlanken Sporen der Sphaerella sarmentorum (Sphaerella Vitis Schlzx.) drängt sich der Gerlanke von selbst auf, dass diese nur die vereinzelte, bedeckte Form dieser Cucurbitaria sei. Unser Pilz hat die Substanz von Cucurbitaria, Schlanchform von Botryosphaeria."

Lediglich der Vollständigkeit halber, habe ich, wie ich bereits oben gesagt, diese und die anderen von Schulzer aufgestellten Species hier mit anfgenommen. Durch frihere Erfahrungen gewitzigt, bringe ich den Arten dieses Autors eine bedeutende Portion Skepsis entgegen und wiirde nichts sehnlicher wiinschen, als mich an Original-Exemplaren cinmal selbst von der Richtigkeit oder Falschheit überzeugen zu kömnen. Was den Nachsatz anbelangt, dass seine Sphaerella Titis nur die einzelne bedeckte Form vorliegender Cucurbitaria sei, so verlohnt es sich, meiner Meinung nach, keines Wortes, um diesen Unsinn zu widerlegen. Sofern beide Arten vom dutor zu ihren, ihnen zukommenden Gattungen richtig gestellt wurden, ist es mir ein völliges Räthsel, wie man Speeies aus diesen beiden, so weit anseinander stehenden, gut umsehrjebenen Familien, wie die Spharelleen and die Cucurbiturieen sind, zusammenwerfen mag!

\section{Botryosphaeria cyanogena Niessl?}

Niessl, Beiträge zur Kenntniss der Pilze, p. 47, in Verhandl. d. naturforschenden Vereines in Brünn X. 1872. - Sphaeria cyanogena Desm. Ann. sc. natur. 1848, X. p. 352. - Gibberce Saubinetii Fuck. Symb. myc. p. 168.

Mycelium ramulosum, effusum, crustosum, lntescens; conidia nunc solitaria, nune eaespitosa, fusiformi-lunulata, apiculata, univel tri-, raro quinqueseptata, subhyalina; peritheeia conferta, oblonga, vertice obtuso conico demum collabentia, umbilicata, plicata 
vermeosarue, sordide coeruleo-amethystea; asci clavati, apice obtusi et rotundati, octispori; sporidia fusiformi-oblonga, nunc reeta inaequilateralia, nunc leniter curvata, utrinque obtuse rotundata, subhyalina (nucleo dilutissime violaceo), triseptata et parum constricta; perithecia $150-200 \mathrm{~mm}$. in diam., sporidia $25-32 \mathrm{~mm}$. long., $7 \mathrm{~mm}$. crass. - Niessl 1. c.

Ad sarmenta emortua Titis viniferce Lin., Parma, Italiae. (G. Passerini.)

Wenn ich diese Art hier mit aufnehme und die vorzügliche Diagnose Niessl voransetze, so muss ich einige wenige Worte der Aufklärung hinzufügen. Von Ilerrn Professor G. Passerini zu Parma in Ober-Italien ward mir nämlich unter sehr vielen anderen Pilzen des Weinstockes anch ein solcher mitgetheilt, wozn er anf die Etiqnette schrieb: "Gibbera -, aseos non vidi“. Der Pilz bildete kleine Häufchen von Perithecien, welche auf einem entrindeten Rebenstiicke aufsassen und ein gelbliches Mycelium hatten; sie besassen eine Mïndıng und waren von ziemlich dünner, schlaffer, leicht zerdrückbarer Substanz, zeigten anch die, allen Arten der Gattung Botryospharia eigenthümliche amethystblane Färbung unter dem Mikroskop. Dass ich es hier mit einer celiten Botryosphaeria zu thun hatte und nicht mit einer Gibbera, welche durch sehr harte, feste, mit Haaren bedeckte Perithecien sich unterscheidet, lag auf der Hand. Ob aber die vorliegende Species zu Botryosphaevia cyanogena zu ziehen sei oder zu einer anderen Art, das zu entscheiden war mir leider nicht möglich, denn anch ich fand, ebensowenig wie Passerini Schläuche und Sporen und lediglich die äusserlich vollkommene Uebereinstimmung in Form, Farbe und Grösse der Perithecien mit echten Exemplaren von Botryosphaeria cyanogena bewog mich, den Pilz interimistisch dazu zu stellen. Hoffentlich gelingt es bald, reife, entwickelte Exemplare dieser interessanten Form aufzufinden und ihr dam ihren richtigen Namen zu geben.

\section{Bertia Vitis Schlzr.}

Schulzer in Verhandl. d. zool.-botan. Gesellschaft in Wien XX. 1872, p. 644. Pirotta, funghi parassiti dei Vitigni p. 42.

B. peritheciis rotundatis, gregariis, saepe connatis, ostiolatis, ostiolo detruso, demum aperto, nigris, carbonaceis; ascis clavatis, 
vertice acutatis, octisporis; sporidiis tenuibus, eylindricis, subcurvulatis, uniseptatis, dilutissime flavidis, $9 \mathrm{~mm}$. long.; paraphysibus sursum contectis simplicibus.

Ad sarmenta arida Vitis viniferde Lin. Slaronia. (Schnlzer.)

Die Beschreibung dieser Art, welche ron Schulzer an abgestorbenen Reben des Weinstockes, Vitis viniferc Lin., gefunden ward, lautet folgendermassen: "Mit Leptosphaeria Vitis Schlzr., jedoch in gesonderten Gruppen; gegen Ende Juli noch fast völlig umreif. Die Pyrenien sitzen gruppirt, hänfig zwei bis drei hart aneinander, auf der Rinde; sind durchschnittlich 1/5 Zoll breit, rundlich, mit eingedrücktem, später weit geöffnetem Scheitel, so dass sich der weissgraue Kern wie eine Pezizascheibe darstellt; schwarz, dick aber kohlig, daher sehr leicht zerreiblich, grosszellig, inwendig durchaus mit einer hyalinen Zellenschichte bekleidet, ron welcher ïberall keulenförmige, oben zugespitzte, achtsporige Schläuche und, unten ästig verbundene Paraphysen entspringen. Die dïmen, gekrimmten, cylindrischen, Plasmakiigelchen führenden, einmal septirten Sporen sind 9 mm. lang und kaum wahrnehmbar blass gelblich gefärbt."

\section{Gibbera Vitis Sehlzr.}

Sehulzer in Verhandl. d. zool.-botan. Gesellschaft zn Wien XX. 1872, p. 642. Pirotta, funghi parassiti dei Vitigni p. 43.

Q. peritheciis nigris, globosis, $1 / 5-1 / 6$ unc. latis, sessilibus, dense confertis in stromate obsolete, nigricante, aculeatis, aculeis brevissimis, crassis, demum deciduis, vertice obtusissimo, rotundato, nueleo albo-griseo, intus vestutis; ascis clavatis, octisporis, basalibus; sporis ovatis, $26-27 \mathrm{~mm}$. long., $10-13 \mathrm{~mm}$. crass., hyalinis vel dilutissime coloratis; paraphysibus articulatis, coneretis.

In ramis emortuis Vitis viniferce Lin. Slavonia. (Schulzer.) Ich habe diesen Pilz wie überhanpt fast alle von Schulzer a. a. O. aufgestellten Species weder in Herbar-Exemplaren, noch in Zeichnungen zu Gesicht bekommen, kann desshalb anch ein Urtheil darïber nicht abgeben. Auffallend ist es aber jedenfalls im hohen Grade, dass der Autor, wie es scheint grundsätzlich, keine Exemplare seiner zahlreichen, oder besser ausgedrückt, zahllosen neuen Arten an andere Mykologen vertheilt, wie es doch sonst Sitte ist. Ich glaube aus diesem Grunde auch den 
Schulzer'sehen Species, sofern sie nicht abgebildet werden, keine allgemeine Aufnahme in das System prognosticiren zu können! Seine Original-Beschreibung a. a. (). lạtet folgendermassen : „Die schwarzen, kugeligen Pyrenien sind $1 / 5-1 / 6$ Zoll breit, mit dicken, kurzen, später abfallenden Stacheln besetzt, haben einen völlig stumpf abgerundeten Scheitel, werden sehr bald frei, und sitzen, wenige Individuen dicht gedriingt, auf cinem unseheinbaren sehwarzen Stroma. Sie haben einen weissgraten Kern und sind innen durchans mit einer Zellenschicht bekleidet, doch entspringen die keulenförmigen, achtsporigen Schläuche und die zu einer Masse verwachsenen gegliederten Paraphysen nur am Grunde und an den Seiten. Sporen oval, 26-27 mm. lang, 10-13 mm. dick, hyalin oder kaum merkbar gefärbt, mit ungleich gestellten Sporidiolen. Im .Juli traf ich noch viele umreife Schlïnche an." - In Slavonien bei Vinkovee von Schulzer an abgestorbenen Panken von Vitis vinifera Lin., dem gemeinen Weinstocke, gefunden.

\section{Nectria riticola Berk. et Curt.}

Berkeley, Notices of North American Fungi in Grevillea IV. p. 45, no. 816. Pirotta, funghi parassiti dei Vitigni p. 45.

N. parva, nitido-coccinea, mollis lateraliter collabens e strato albo tenui oriunda; sporidiis uniserialibus, ellipticis, uniseptatis. - Berk. l. e.

In sarmentis emortuis Vitis vinifercue Lin. Italia: pr. Rapallo, Julio 1876. (Passerini.) - America septentrionalis: Alabama (Peters) in Vitis species indeterminatae ramulis.

Diese neue Art der gestaltenreichen, schönen Ascomycetengattung Nectria, welche bisher nur aus Amerika bekannt war, fand Professor Passerini auch in Italien anf, und ihm verdanke ich die Exemplare, nach welchen ich die hier folgende Beschreibung entwerfen konnte. - Die einzeln zerstreut stehenden Peritheeien nisten auf der Holzsubstanz entweder an Stellen, wo die Rinde bereits abgefallen ist, oder sie durchbrechen diese letztere und bilden matt-scharlachrothe Häufchen von ziemlich weicher Consistenz. Nach den Angaben der Autoren entspringen sie bei den amerikanischen Exemplaren aus einem zarten dünnen weisslichen Mycelium; bei den italienischen war ein solches nicht zu 
bemerken, wohl aber das häufig die Nectria-Perithecien umgebende Fusarium, welches ich weiter oben bereits auf p. 52 besprochen habe. Die Schläuche, von denen bei Berkeley gar nicht die Rede ist, sind cylindrisch, dimmwandig, oben und unten etwas stumpf zugespitzt, farblos und etwas hin und her gebogen, sie enthalten acht Sporen von ganz genau elliptischer Form. Diese sind einreihig im Schlauche angeortnet, in der Tfitte einmal getheilt, oben und unten rundlich zugespitzt, farblos and enthalten hin und wieder einen Nucleus in jeder Kelle. Paraphysen sind nicht vorhanden. - Das erwähnte Fusarium, welches sich, wie gesagt, lediglich bei den emropäischen Exemplaren findet, zieht Passerini und wohl mit Recht als Conidienform zu dieser Nectria. Meinem, des Oeftern ausgesprochenen Grundsatze jectoch getren, dic rerschiedenen Formen, welche zu einem Pilze gehören, besonders wenn deren Zusammengehörigkeit noch nicht ganz unwiderleglich dargethan ist, unter besonderen Namen zu beschreiben (Prof. Saccardo befinctet sich in diesem Punkte mit mir in vollster Uebereinstimmmg und gibt allen Conidien-, Spermatien-, Pyenidien- u. s. w. Formen eigene Namen), habe ich dasselbe als Fusarium viticolum Thüm. anfgeführt. - In NordAmerika, Alabama, auf todten Reben einer nicht näher benamten Titis-Art (Peters), bei Rapallo im östlichen Ligurien auf den Ranken von Vitis vinifera Lin. Im Juli 1876. (Passerini.)

\section{Nectria cinnabarina Fr.}

Fries, Summa reg. Seand. p. 388. - Tul. Sel. fung. carpol. III. p. 79, Tab. 12, 13, fig. 14-21. - Fuckel, Symbolae mycologicae p. 177. - Cooke, Handb. of British Fungi p. 781, no. 2346. - Saccardo, Mycologia veneta p. 122. - Karsten, Mycologia fennica II. p. 212. - Sphaeria cimnalsarina Tode, Fungi Mecklenburg. II. p. 9, fig. 68, - Fries, Systema mycolog. II. p. 412.

Perithecia caespitosa, conferta, stromate pulviniformi, haemisphaerico, carnosulo, primitus conidia secernente, instrata, sphaeroidea, corrugata, cinnabarina, demum fuscescente-expallescentia, ostiolo papilliformi. Asci cylindraceo-subclavati, apice leviter attenuati, $60-90 \mathrm{~mm}$. long., 8-12 mm. crass. Sporae octae, distichae vel submonostichae, oblongatae, utrinque obtusae, rectae vel leviter curvulae, uniseptatae, hyalinae, longit. $14-24 \mathrm{~mm}$., crassit. 5-7 mm. Paraphyses nullac. - Karst. 1. c. 
In samentis enortuis litis riniferce Lin., socia Tubereuturine sarmentorum. Fr., Italia, Conegliano. (Spegazzini.)

Meines Wissens zum ersten Male, dass reife Schlauchfrichte dieser, sonst auf allen möglichen Laubhölzern äusserst gemeinen Nectria auf Teinranken aufgefunden wurden! Die Perithecien unserer Art brechen in gedrängten Häufchen dureh Längsrisse in der Rinde hervor, das Stroma ist polsterfürnig, halbkugelig, fleischig; die einzelnen Perithecien stehen dicht aneinander und bilden halbkugelförmige, ziemlich grosse, körnig anssehende, zimmtbraune, dann etwas ausbleichende Haufen. Die Schläuche sind rom Cylindrischen ins fast Kenlenförmige uibergehend, gegen die Spitze sich etwas verjüngend, $60-90 \mathrm{~mm}$. lang und 8-12 mm. breit. Die acht sporen stehen in zwei, nur selten in einer Reihe, sie sind oben und unten abgestumpft, eirund oder oblong, gerade, manchmal auch ein klein wenig gekriummt, einmal getheilt, wasserhell und $14-24 \mathrm{~mm}$. lang und 5-7 mm. diek. Paraphysen sind nicht vorhanden. - Wie es schon nach den schönen Untersuchungen der Gebrïder Tulasne bei einer ganzen Reihe von l aubhölzern, z. B. Acer campestre und Pseudoplatanus, Pyrus Malus, Rhamms Frangula, Aesculus Hippocastrnum u. s. w., u. s. w. nachgewiesen war, dass die darauf vorkommenden Formen von Tubercularia vulyaris Tode die Conidien dieser Néetria seien, so ist es nunmehr auch fuir Tubercularia sarmentorum Fr. nachgewiesen. Auf blosse Analogie gegruindete Annahmen einer solchen Zusammengehörigkeit sind nach meiner Ansicht mstatthaft, durch das Torkommen von Tubercularia und Nectria aber in einem Rasen, wie es meine Exemplare zeigen, ist jeder Zweifel wohl behoben. - Dieser schöne Fund ward von C. Spegazzini, welchem ich ausserdem noch eine ganze Reihe anderer Weinpilze verdanke, auf dürren Ranken ron Vitis vinifera Lin. bei Conegliano in Ober-Italien im Herbst 1877 gemacht.

\section{T'eichospora Mesascium Sace.}

Saccardo, Fungi veneti novi Ser. II. in Hedwigia 1875, p. 75. - Pirotta, funghi parassiti dei Vitigni p. 41. - Sphcueric Mescscium De Not. Sferiacei italiani no. 62 .

Pyrenia sparsa vel geminata, subindeque subseriata, superficialia, e basi arnata, applanata, sphacroidea, vertice obtusiuscule 
subattenuata, vel obtusa, sub lente rugulosa, glabra, fusco-atro, apice ostiolo minutissimo vix pereipiendo hiantia, fragilia, cellulis exiguis contexta, senio fracta. Nucleus gelatinosus, pallescens, ex sporidiis fusco-punctulatus. Asci grandes, teretes, octispori, juniores plasmate lutescente referti, parietibusque crassissimis donati. Paraphyses praelongae, coalescentes; sporidia magna, 40-50 mm. longitudine aequantia, oblongata, matura fuliginea, diaphana, phurilocularia, loculis septis perpendicularibus locellatis, polymorpha. - De Notaris 1. c. - Asci clavati, $150-180 \mathrm{~mm}$. long., $25 \mathrm{~mm}$. crass., paraphysati. Sporidia disticha, ovato-fusoidea, $45-50 \mathrm{~mm}$. long., $20-22 \mathrm{~mm}$. crass., septem- vel octisseptata, at septa leniter constricta, fuliginea, initio cribroso-guttulata, dein muniformia. - Saccardo 1. e.

In truncis annosis Vitis vimiferce I in. Venetia (Saccardo), Liguria (Berti).

Ueberaus selten scheint dieser Pilz aufzutreten, mir sind nur die angegebenen Standorte und von Exemplaren das im Erbario crittogamico italiano, Ser. II. no. 442 vertheilte bekannt. Die zerstreuten Perithecien von sphärischer Gestalt und schwärzlich-brauner Farbe stehen zumeist fast reihenförmig angeordnet. Der innere Kern ist hell, gelatinös und, durch die eingestrenten Sporen, branin-punktirt. Die keulenförmigen Schläuche sind gross, 150-180 mm. lang und $25 \mathrm{~mm}$. dick, achitsporig; in der Jugend gelblich. Die Sporen sind zweizeilig angeordnet, oblong, durchscheinend, graubraun, sieben- bis acht- und mehrfach septirt, an den Scheidewänden ein wenig eingeschnürt und haben eine Länge von 40-50 mm. bei einer Breite von 20-22 $\mathrm{mm}$. Die langen, fadenförmigen Paraphysen umgeben und überragen die Schlänche. - An sehr alten Stöcken von Vitis vinifera Lin. in Venetien (Saccardo) und dem östlichen Ligurien (Berti). (Tab, V. tig. 4.)

\section{Lophiostoma Hederae Fuck.}

Fuckel, Symbolae mycologicae p. 157.

L. peritheciis sparsis, sub corticis epidermide nidulantibus, raro liberis, media magnitudine, globoso-compressis, aterrimis, ostiolo prominulo, lato compresso, semiorbiculari, subcrenulati, concolori; ascis elongatis, sessilibus, octisporis, $80 \mathrm{~mm}$. long., 
$8 \mathrm{~mm}$. crass.; sporithis tistichis, fusiformibus, curratis, quarriguttulatis, triseptatis, hyalinis, $20 \mathrm{~mm}$. long., $4 \mathrm{~mm}$. crass. Fuckel 1. c.

Ad sarmenta arida Fitis viniferce Lin. Italia, pr. Parma, Vere 1877. (G. Passerini.)

Von Fuckel wurde diese species, wie ihr Name ja schon andentet, auf Exemplare begriindet, welche auf diiren, berindeten Aestchen von Hedera Helix Lin., dem gemeinen Epheu, wuchsen, sie wurden von Dr. Morthier bei Neuchâtel in der Schweiz und von Fuckel selbst bei Oestrich in Rheingau, in der jetzigen Provinz Hessen-Nassau gefunden, aber wie es scheint nur in wenigen Exemplaren, denn in den "Fungi rhenani“ desselben Ierausgebers wurde diese neue Art nicht vertheilt. - Sie bildet ziemlich kleine, zerstreut stehende Perithecien, welche sowohl auf der Rinde als auch unter derselben sitzen, etwas zusammengedrïckt-kugelig und dunkelschwarz sind. Am Scheitel öffnen diese Perithecien sich vermittelst eines, schwach hervortretenden, rundlichen, zusammengedrickten Ostiohums oder einer Mündung. Jie Schläuche sind verhältnissmässig äusserst lang, fast cylindrisch, ungestielt, wasserhell, $80 \mathrm{~mm}$. lang, $8 \mathrm{~mm}$. breit und enthalten acht, in Doppelreihen situirte sporen. Letztere sind schwach gebogen-spindelförmig und enthalten vier Oeltröpfehen, ihre Farbe ist, wie die der Schlänche, wasserhell, die Länge beträgt $20 \mathrm{~mm}$., die Breite $t \mathrm{~mm}$. Die von Fuckel, allerding's anch mit einem Fragezeichen angeführte Dreitheilung der Sporen konnte ich bei den mir vorliegenden Exemplaren nicht bennerken. - Herr Prof. G. Passerini fand diese Art im Frithjahre 1877 bei Parma in Ober-Italien auf alogestorbenen Kweigen des gemeinen Weinstockes, Vitis vinifera Lin. (Tab. I. Hig. 10.)

\section{Lophistoma Thümenianum Spegaz. nov. spec.}

L. peritheciis parvulis, ligno immersis, oblongis, 200 vel $290 \mathrm{~mm}$. long., 90-120 mm. crass., ostiolo hysteriiforme, labiis acute adnatis, superficiem attingente vel parum exertum; ascis cylindraceo-clavatis, breve stipitatis, octisporis, paraphysibus filiformibus, guttulatis obvallatis, $150-180 \mathrm{~mm}$. long, $20 \mathrm{~mm}$. crass. ; sporidiis distichis vel raro oblique monostichis, oblongo-fusoideis, 
plerumque vix eurvulis, decem- vel undecimseptatis, ad septum, quum maturi fiant, constrictis, $60-65 \mathrm{~mm}$. long., $10 \mathrm{~mm}$. crass., saepe vel plerumque hyalinis, guttulatis, dein dilute atris, apicibus subhyalinis. - Pro sporidiis postremo eoloratis differt a Lophiostomate alpigeno Fuek. et a L. insidioso Sace. et L. vagabundo Sace. quibus tandem affinis.

In ramulis emortuis dejectis Vitis vinifercue Lin. Venetia: Conegliano. 1877. (C. Spegazzini.)

Die ungemein klemen, nur sehr schwer mit blossem Auge wahrnehmbaren Perithecien dieser Species sind in die Holzsubstanz eingesenkt, oblong, schwärzlich, 200_-290 mm. lang, 90 bis $120 \mathrm{~mm}$. breit, die hervorragende Mündung, das Ostiolum, ist ähnlich derjenigen der Hysterineen, sie besteht aus zwei, einander genaherten, scharfen Lippen, welche nur wenig über die Oberfläche sich emporheben; die Schläuche haben eine keuligcylindrische Gestalt, sind kurz gestielt, haben acht Sporen und messen 150-180 mm. in der Länge, $20 \mathrm{~mm}$. in der Breite, sie werden von längeren, fadenförmigen, mit Guttulis oder Tröpfehen gefiillten Paraphysen uiberragt. Die Sporen sind meistentheils in zwei Reihen angeordnet, nur selten schief in einer Reihe gestellt, sie sind spindelförmig-oblong, gerade, manchmal schwach gekriimmt, zehn- bis eilftheilig, an den Theilungsstellen im reifen Zustande eingeschnürt, $60--65 \mathrm{~mm}$. lang, $10 \mathrm{~mm}$. dick; ihre Farbe ist zu Anfang meist wasserhell, später wird sie aber bei der Reife dunkelgrau bis sehwärzlich und nur die beiden äussersten Enden bleiben fast farblos. Eben dieser späterhin dunkel gefärbten Sporen wegen unterscheidet sich vorliegende Speeies gut von Lophiostoma alpigenum Fuck., sowie von L. inidiosum Sace. und $L$. vagabundum Saec., welchen beiden letzteren Arten sie sonst nahe verwandt ist. - C. Spegazzini entrleckte diese neue Art auf dïnnen, am Boden liegenden Ranken von Vitis vinifera Lin., besonders der Sorte Verdisa bei Conegliano in Venetien im Oetober 1877, und theilte mir freundlichst Exemplare davon mit. Auf den meisten Exemplaren findet sich auch das Helotium sarmentorum De Not. 


\section{Lophiostoma angustatum Fuck.}

Fuckel, Symbolae mycologicae p. 158. - Pirotta, funghi parassiti dei Vitigni p. 40. - Sphaeria angustata Pers. Syn. fung. p. 55. - Schmidt et Kunze, Mykol. Hefte II. Tah. 1, fig. 8. - Fries, Syst. myeol. II. 1. 470. - Wallroth, Fl. cryptog. german. p. 799, no. 3862. - Rabenhorst, Dentschlands KryptogamenFlora 1. 184, 110. 1664. - Rochling, Deutschlands Flora 1. 47. - Lophium angustatum Fr. Act. Holm. 1818, p. 114.

L. peritheciis dense gregariis, sine ordine dispositis, plerumque in stromate nigrescente, ellipsoideo-orbiculatis, subconicis, nitidis, atro-fuscis, mediis; ostiolis prominentibus, conicis, parvulis, acutatis; ascis angustissime clavatis, plus minusve eurvulatis, vertice obtuso rotundato, basi attenuato, subpedicellatis, octisporis, membrana tenui, hyalinis, $120 \mathrm{~mm}$. long., $9-13 \mathrm{~mm}$. crass.; sporidiis oetis, oblongis vel anguste ellipticis, snbeurvatis, utrinque obtuso-rotmudatis, quinque- vel sexseptatis, ad septas non constrictis, distichis, raro etiam longitudinaliter septatis, subfuseis, impellucidis, $28-32 \mathrm{~mm}$. long., $7-8 \mathrm{~mm}$. crass.

Ad samenta emortua Titis viniferce Lin. Thuringia. (Wallroth.)

An entrindeten Aesten verschiedener Laubbäume und Sträncher tritt diese Species nicht selten anf, ich kcnne sie von drei verschiedenen Salix-Arten, von Carpims und von Ephen, auf Weinreben gibt sie nur allein Wallroth a. a. O. an. - Der Pilz bildet mehr oder weniger dicht stehende, alser immer in grosser Anzahl vorhandene, auf' dem entrindeten Aste sitzende Perithecien, welche eine liinglich-runde Form haben. Sie sind von mittlerer Grösse, breit kegelförmig, matt schwarzbr:iunlich und tragen anf ihrem Seheitel das kleine, conische, spitz hervorragende Ostiolum (Miündung) von glänzend schwarzer Farbe. Die in den Perithecien nicht sehr zahlreich vorhandenen Schlänche, sind änsserst schlank-kenlenförmig, immer etwas gebogen, am scheitel abgestumpft-rundlieh, sowohl nach unten als nach oben etwas verschmälert, unten in eine Art von hyalinen Stiel ansgezogen, farblos, $120 \mathrm{~mm}$. lang nnd 9-13 mm. breit. Die Sporen, acht an der Zahl, sind in zwei Reihen im Schlanche geordnet, jedoch mehr im oberen Theile desselben, sie sind lang-elliptisch oder, man könnte auch sagen, breit spindelförmig-elliptisch, an beiden Enden stumpf abgerundet, immer etwas gekrïmmt und haben fünf, zuweilen auch sechs Quer-Theilungswände, oft eine 
solche auch der Länge nach von oben nach unten. An den Scheidewänden sind sie nicht eingeschniurt, die Farbe ist ein dunkles Gelbbraun, die Länge beträgt 28-32 mm., die Breite $7-8 \mathrm{~mm}$. Auf abgestorbenen und entrindeten Reben von Vitis vinifera Lin. in 'Thiiringen von Wallroth gefunden. (Tab. I. fig. 6.)

\section{Lophiostoma sexumcleatum Cooke.}

Cooke in 'Transactions of the Botanical Society IX. 1868. Tab. 6, fig. 8. - Id. Handbook of British Fungi p. 850, no. 2543. - 27. Report of the New-York State Museum p. 110.

L. peritheciis sparsis, elongatis, nigris, subrugosis, primo immersis, demum emergentibus; ostiolo compresso; sporidiis biseriatis, fusiformibus, hyalinis, subcurvis, quinqueseptatis, ad septam mediam constrictis, ad septas alias subconstrictis, in eadem cellulam nncleo uno, $35 \mathrm{~mm}$. long. - Cooke 1. c.

Ad sarmenta cmortua Vitis Labruscae Lin. America septentr.: New-York. (Peck.)

Den Angaben des Autors a. a. O. zufolge, dessen in englischer Sprache verfasste Diagnose ich in lateinischer Uebersetzung gebe, könnte man vielleicht diese Art als Form zu Lophiostoma angustilahnum Berk. et Br. ziehen, bei dieser Species jedoch sind die Sporen nu cimmal in der Mitte septirt und jede Zelle hat zwei Nuclei, im Ganzen sind also nur vier vorhanden. Unsere Art wächst in zerstrenten, verlängerten, schwachfaltigen, schwarzen Perithecien, welehe zu Anfang eingesenkt, dann hervorstehend sind und ein zusammengedrücktes Ostiolum (Miindung) besitzen. Die Schlänche sind lang, schmal kenlenförmig, an Scheitel verschmälert abgerundet und enthalten acht Sporen, diese sind in zwei Reihen angeordnet, breitspindelförmig, wasserhell, kaum gebogen und fiinfinal getheilt. An den Septas oder Theilungsstellen sind sie eingeschnürt, am stärksten an der mittelsten, in jeder der sechs Zellen ist ein Nucleus; die Länge beträgt $35 \mathrm{~mm}$. - Die Exemplare des Pilzes, welche Peck auf Weinranken fand, weichen von dieser Beschreibung in mehreren Stiicken ab, nicht nur, dass die Perithecien enger bei einander stehen, auch die Sporen sind etwas kleiner und messen nur 25-30 $\mathrm{mm}$. in der Länge. Trotzdem ist Peck nicht der Meinnng, diese Form von der typischen Art zu trennen; ich kann, 
da mir keine Exemplare auf Vitis vorliegen, kein Urtheil abgeben, möchte aber doch den Vorschlag machen, die amerikanische Form als var. vitigenum abzutrennen. - Auf diumen Ranken ron Vitis Labrusca Lin, bei North Greenbush im nordamerikanischen Staate New-York von Peek gefunden. (Tab. IV. fig. 5.)

\section{Anthostomella limitata sace.}

Saccardo in $\Lambda$ tti Soc. Veneto-Trentina IV. 1875, fasc. I. 1\% 1. - Id. Michelia I. p. 98, no. 129. - Id. Fungi italiei antografice delineati no. 129.

A. peritheciis gregariis, sub epidermide leniter tumefacta et circum circa breviter infuscata, nidulantibus, mombranaceis, globose depressis, 1/6 millim. diametro, atris, ostiolo breviter papillato, non vel vix perforante; ascis cylindricis, $70-85 \mathrm{~mm}$. long., 4-5 mm. lat., breve crassiuscule stipitatis, apice rotundatis, paraplysatis, octisporis; sporidiis oblique monostichis, ovoideis, utrinque vel uno apice acutiusculis, continuis, $10-12 \mathrm{~mm}$. long., 4-5 mm. crass., dilute fuligineis, biguttulatis. - Sace. 1. c. In sarmentis emortuis Titis viniferce lim. Venetia: Conegliano. (C. Spegazzini.)

Auf den Aesten der verschiedensten Laubbäume und Sträncher ward dicse species vom Autor bercits gefunden, a. a. O. zählt er acht Nährpflanzen auf, worunter jedoch der Weinstock fehlt, auf diesem Substrat wurde der Pilz erst ganz kiurzlich ebenfalls entdeckt. Auf den zum Theil bereits entrindeten, ganz dïnnen Ranken bildet er sehr dicht gedrängt stehende Perithecien, welche unterhalb der Epidermis nisten und dieselbe rund herum schwach bräınen, sie sind kugelig-zusammengedrickt, häntig dünn, schwarz und circa 1/6 Mm. im I)urchmesser laaltend. Das Ostiolum oder die Mïndung ist kurz-warzig und wenig oder gar nicht hervorragend. Die Schläuche sind cylindrisch, haben einen dicken und kurzen Stiel, abgerundete Spitzen, acht Sporen und messen in der Länge 70-85 mm., in der Breite nur 4-5 mm., sie sind mit Paraphysen untermischt. Die Sporen sind in den Schlänchen schief einreihig angeordnet, cirund, an beiden oder manchmal nur an dem einen Ende zugespitzt, ungetheilt, hell rauchgrau, $10-12 \mathrm{~mm}$. lang und $4-5 \mathrm{~mm}$. breit und besitzt jeder zwei Nuclei. - C. Spegazzini fand vor Kurzem diesen 
interessanten Pilz auch auf halbfaulenden Reben von Vitis vinifera Lin. bei Conegliano in Venctien.

\section{Rebentischia appendiculosa Sace.}

Saccardo in "Nuovo Giornale botanico italiano" VIII. p. 177, no. 128. - Sphaeria appendiculosa Berk. et Br. in Annales of Natur. history 1851, VII. no. 613, p. 189, Tab. 7, fig. 20. - Currey in Transact. Linnean Society 1859, XXII. Tab. 58, fig. 97. - Rabenhorst, Fungi europaei no. 52. - Cooke, Handb. of British Fungi p. 892 no. 2678.

R. peritheciis sparsis, globosis, minimis, sub epidermide nigricante in caespitulis minutis, orbiculatis, nitidis, nidulantibus, medio perforantibus; ascis cylindraceis, brevi stipitatis, 130 vel $135 \mathrm{~mm}$. long., 10-11 mm. crass., aparaphysatis, octisporis; sporis sulfusoideis, sursum acutis, basi appendieula rostriformi, obliqua, $8 \mathrm{~mm}$. longa, facile secedenti auctis (ma cum appendice), $28 \mathrm{~mm}$. long., 7-8 mm. crass. quadriguttulatis, subhyalinis. Sace. 1. c. emend.

In sarmentis tenuissimis emortuis Vitis iniferae Lin. prope Conegliano, Venetia semel legit C. Spegazzini.

Die Perithecien dieser bisher nur ausschliesslich auf abgestorbenen Ranken von Rubus Idaeus Lin., dor Himbeere, bekannten Art nisten unter der Epidermis, welche sie rundherum schwärzen, in kleinen, rundlichen, glänzenden Hänfehen, sie sind zerstreut, kugelig, sehr klein und schwarz. Die cylindrischen Schläuche haben einen kurzen Stiel, sind achtsporig und messen $130-135 \mathrm{~mm}$. in der Länge, $10-11 \mathrm{~mm}$. in der Breite. Paraphysen sind nicht vorhanden. Die fast spindelförmigen Sporen sind gegen ihr oberes Ende hin zugespitzt, am unteren haben sie ein schnabelförmiges, schiefes, leicht sich ablöscndes, $8 \mathrm{~mm}$. langes Anhängsel, sie messen $28 \mathrm{~mm}$. in der Länge bei $7-8 \mathrm{~mm}$. Breite, haben vier Nuclei und sind fast farblos. - Bisher ward mur ein einziges, jetzt in meinem Besitz befindliches Exemplar gefunden, und zwar von C. Spegazzini bei Conegliano in Venetien auf einer sehr diinnen, halbfaulen Rebe von Vitis vinifera Iin. 


\section{Rosellinia horrida Haszl.}

Haszlinsky in Verhandl. d. k. k. zoolog. botan. Gesellseltaft zu Wien 1873 p. 365. - Pirotta, funghi parassiti dei Vitigni p. 39.

R. peritheciis liberis, dense aggregatis, rarissime sparsis, obovatis, pseudoparenchymati carbonaceo fragili contextis, rugulosis, aculeatis. Aculeis in tuberculis consociatis parum radiantibus, sublanceolatis, atris, apicibus pellucidis. Mycelinm parce evolutum superficiale, in stratum ligni supremum penetrans, filis paree septatis, ramosis, achloris eontextum. Protosporis ovalibus, achloris, 2-3 $\mathrm{mm}$. long., in apicibus hypharum mycelii ortis, denique mycelio inspersis. Asci paraphysibus simplicibus associati, lineares, octispori, $120-150 \mathrm{~mm}$. long. $15-16 \mathrm{~mm}$. crass. Sporae oblongae, fuscoatrac, simplices, oblique monostiche ordinatae, denique seriatim erumpentes, $18-25 \mathrm{~mm}$. long., $10-13 \mathrm{~mm}$. crass. Haszl. 1. e.

In ramis decorticatis sarmentorum Titis viniferae Lin. Mehadia, Banatus. (Haszlinsky.)

Nur aus der a. a. O. befindlichen Beschreibung ist mir dieser Pilz bekannt; dem Autor zufolge besitzt er freie, dicht zusammengedrängt wachsende, mu äusserst selten vereinzelt stehende, fast eirunde, gerippte, stachelige, mit cinem zerbrechlichen, kohligen Gehäuse versehene Perithecien; die erwähnten Stacheln sind schwarz, lanzettlich md haben durchsichtige Spitzehen. Das nur wenig entwickelte Mycelimn besteht aus schwach septirten Fïden, welche farblos und ästig sind und an ihren Spitzen die eirunden, farblosen, nur $2-3 \mathrm{~mm}$. langen Conidien oder Protosporen tragen. Die Schläuche von schmal cylindrischer Gestalt, haben eine lä̈nge von 120-150 mm. und eine Dicke von 15-16 mm., sie stehen untermischt mit einfachen, gleich langen Paraphysen. Die Sporen, acht an der Zahl, sind oblong, einfach, schwarzbratu und stehen in einer schiefgestellten Reihe im Schlanch, ihre Grösse beläuft sich auf 18 bis $25 \mathrm{~mm}$. in der Länge und auf $10-13 \mathrm{~mm}$. in der Dicke. In Banat bei Mehadia auf abgestorbenen Ranken des Weinstockes, Vitis vinifera Lin. von Haszlinsky entdeckt. 


\section{Valsaria insitira Ces. et De Not.}

Cesati et De Notaris, Schema di classific. degli Sferiacei in Commentario d. soc. crittog. Italiana p. 205. - Saccardo, Mycologia veneta p. 48, Tab. XV. fig. 5-10. - Diatrype insitiva Fr. Summa veg. Scand. p. 285. - Sphcueria insitiva Tode, Fungi Mecklenb. II. p. 36, Tab. XIII. fig. 108. - De Notaris, Micromycetes italiani VII. 1. - Cesati in "Hedwigia" I. p. 73. - Rabenhorst in "Hedwigia" no. 18 c. icon. - Schweinitz, Syn. fung. Carol. p. 31, no. 37. Id. Synopsis of North American Fungi p. 197, no. 1268. - Myrmaecium rubricosum Fuck, var. viticolum Fuck. Symb. myc. p. 228.

Stroma forma et magnitudine variabilissimmm: nunc valseum, nune diatrypeum; aceryuli pulvinati, sinnosi, tumidi, modo $1 \mathrm{Mm}$. diametro non attingentes, modo $5 \mathrm{MLm}$. superantes, atri; sed organa fructificationis semper eadem; asci cylindrici, brevissime stipitati, 90-100 mm. longi, 8-9 mm. crass., paraphysibus copiosis filiformibus, nucleolatis (an pseudoparaphysibus) obvallati, octispori; sporidia constricta, uniseptata, didyua, utrinque rotundata, 15-16 mm. long., 8-9 mm. crass., primo lutescentia, bi- vel quatuornucleolata, dein obscure fuliginea. - Saceardo l. c.

In cortice sarmentorum Titis vinifercle Lin., Venetia (Saccardo) Nassovia (Fuckel); Vitis Labruscae Lin. America septentrionalis: Carolina (S'chweinitz).

Unter der ausgebleicht grau gewordenen Oberhaut der Ranken brechen die flach-halbkugelförmigen Perithecien, sei es einzeh oder zu zwei bis vieren hervor, indem sie die Oberhaut nieht, wie bei den meisten anderen Arten rundlich zerreissen, sondern indem sie sie lang aufschlitzen. Die kürnigen, oben etwas eingedrïckten, dabei aber beinahe aufgeschwollenen Perithecien haben bei der hier in Betracht kommenden Form anf Weinreben nur eine Grösse von circa 1.5-_.5 Mm., die Farbe ist schwärzlich. Die Schläuche, welche ganz kurz gestielt sind, sind cylindriseh und von fadenförmigen, zahlreichen Paraphysen, die im Innern eine Menge Nuclei führen und an Länge den Schlänchen ziemlich gleichkommen, umgeben. Thre Länge beträgt 90-100 mm., die Breite nur 8-9 mm. Die acht Sporen, welche ganz regelmässig in einer Reilıe, schief angeordnet, liegen sind einmal in der Mitte getheilt, an dieser Theilungsstelle etwas eingeschniurt, oben und unten abgerundet und $15-16 \mathrm{~mm}$. lang, 8-9 mm. breit. Die Farbe ist anfangs ein helles Gelb, später geht dieses in ein dunkles Graubraun über, die zwei bis vier Nuclei sind 
von derselben Farbe. - Dieser, wie es scheint, seltene Pilz ist mir nur aus Ober-Italien, wo Saccardo denselben bei Treviso sammelte und von Oestrich in der Provinz Nassan (Fuckel) bekannt. Er bewohnt todte Ranken unseres gemeinen Weinstockes, Titis vinifera Lin., anch ward er von Schweinitz anf Vitis Labrusca Isin. in Carolina und Pennsylvanien gefunden. (Tab. III. fig. 14.)

\section{Ceratostoma Schulzeri Pirotta.}

Pirotta, funghi parassiti dei Vitigni p. 38. - Cerastoma Vitis Scht1lzer in Verhandl. der zool. botan. Gesellschaft zu Wien, XX. 1872. p. 644.

C. erustas compactas, lignicolas formans, peritheciis dense gregariis, globosis, atris, rostratis, rostris longis, tuberculatis, deformatis, laeribus, solitariis vel gregariis; ascis clavato-fusoideis, sex- raro octisporis, tenuissimis, cito evanidis; sporis oblongoovatis, medio constrictis, uniseptatis, bi- vel quadrinucleatis, dilute flavidis, $16-17 \mathrm{~mm}$. long., $4 \mathrm{~mm}$. crass., paraphysibus simplicibus, filiformibus, nucleatis. - Schulzer 1. c.

Ad samenta arida Vitis viniferce Lin. - Slavonia (Schulzer).

Es lautet die dentsche Beschreibung, welche der Autor a. a.O. von dieser ebenfalls auf todten Reben von Vitis vinifera Lin. in Slavonien von ihm gefundenen Art gibt: „Zwischen Juli und August sah ich im Laufe der seit Anfangs Juli fortdanernden Untersuchung der Pilze an Reben, bereits rindenlos gewordene Stellen hier und da mit einem schwarzen, höckerigen Schorfe ïberzogen. Aus diesem ragten die gleichfarbigen, verschieden geformten, geraden oder gekrïmmten, bald kaum vorhandenen, bald bei $2 / 3$ Linien langen, meist unförnlichen, höckerigen, jedoch nicht behaarten Hälse oder Schnäibel der Pilze, entweder vereinzelt oder dicht gedräingt hervor. Sie haben eine runde, von dem vortretenden Inhalte, weisse Mündung. Die Pyrenien vertreten kugelig, von oben gedriickte, $1 / 6-1 / 3$ Zoll breite Höhlen im Holze, bekleidet mit einer iiberaus zarten und farblosen Zellenschicht, von welcher beinahe concentrisch, nämlieh nicht blos vom Grunde, sondern auch von den Seitenwänden bis hoch hinauf, die keulig'spindelförmigen, sechs-, seltener achtsporigen Schläuche und die einfachen, fadenförnigen, Plasmakügelehen führenden Paraphysen entspringen. Erstere sind so zart, dass man die Conturen mur stellenweise zu sehen vermag und letztere zerfliessen 
beim mindesten Druck. Der Kern ist blaulich-grau. Sporen oblongoval, in der Mitte gesehniurt, $16-17 \mathrm{~mm}$. lang, bei $4 \mathrm{~mm}$. dick, sehr blassgelblich, mit zwei bis vier Sporidiolen. Ich sah, und zwar ziemlich spät, nur in der Mitte eine Scheidewand entstehen. Der obere Theil des den Kern umschliessenden, bei 390 maliger Vergrösserung noch nicht darstellbaren Pyreniums geht in den Hals ïber und nimmt Farbe und die hormartige Substanz desselben an, was beim muthmasslichen suceessiven Vortreten desselben während der zur angegebenen Zeit schon begomnenen Verwitterung des Holzes wahrscheinlich anch weiter abwärts geschieht. Sehr häufig liegen zwei bis vier Pyrenien dicht gepresst aneinander, gleichsam wie in einem Neste." - Da Fuckel bereits 1869 eine Ceratostoma Vitis anfgestellt hat, so musste der Name geändert werden.

\section{Rhaphidospora sarmenti Pass. nor. spec.}

Perithecia globosa, peridermio tecta, ostiolo acnto, brevi erumpentia; asci longi, cylindracei, flexuosi, sexspori; sporae filiformes in asci lumine pallide flavescentes, integrae, minutissime nucleolatae. - Pass. in litt. ad me.

In samentis aridis Vitis viniferce Lin. - Italia, Parma, Vere 1877. (Passerini.)

Ebenfalls ein bisher noch nicht beschriebener Schlauchpilz des Weinstockes, dessen Entdeckung wir dem hochverdienten berïhmten Italiener verdanken. Die sehr kleinen, mehr oder minder kugelförmigen Perithceien stehen zerstreut oder in grösserer Anzahl bei einander, jedoch ohne jede regrelmässige Anordnung auf der Holzsubstanz der Reben und sind Anfangs von der Epidermis bedeckt, später jedoch durchbohren sie dieselbe vermittelst des spitzigen aber kurzen Ostiolums, der Mündung; die Farbe ist ein mattes Schwarz. Dic im Nuclens oder Kern der Perithecien enthaltenen zahlreichen Schläuche sind verhältnissmässig sehr lang, cylindrisch oder lang-keulenförmig'-cylindrisch, hin und her gebogen, farblos, oben abgerundet, gegen die Basis nach und nach schmal zulaufend, haben ein äusserst dünnes und zartes Episporium und führen sechs Sporen. Diese letzteren haben eine lange fadenförmige Gestalt, sind hin und her gebogen, manchmal beinahe wurmförmig gekrümmt und erreichen fast die 
Länge der Schläuche; sic sind einfach, ohne Querwände, fiihron aber eine grosse Anzahl ungemein kleiner Nuclei, die spitzen sind beiderseitig abgestumpft, im Schlanche selbst ist ihre Farbe schwach hellgelb, sind sie aber herausgedriickt, wasserhell. Paraphysen scheinen keine vorhanden zu sein. - In Ober-Italien bei Parma auf dürren Ranken des gemeinen Weinstockes, Titis rinifera Lin. Im März 1877. Gefunden und eingesendet vom Professor G. Passerini. (Tab. IV. fig. 7.)

\section{Pleospora coronata Niessl.}

Niessl, Notizen über nene und kritische Pyrenomyceten in Verh. d, naturforsch. Vereins in Briinn, XIV. 1876, p. 6 Tab. 4, fig. 2.

Perithecia sub epidermide haud mutata plus minus gregaria, depresse globosa demum interdum fere concava, atra, coriacea, 250-350 mm. diam., basi fibrillosa, ceterum glabra, ostiolo prominulo papillacformi quasi fimbriato seu: fasciculo setarum microscopico coronato; setae breves, $50-60 \mathrm{~mm}$. longae, dense stipatac pemicillatae, inferne subopacae, superne fere diaphanae; asci clavati stipite brevi turgido, 60-100 mm. long., 13-18 $\mathrm{mm}$. erass., octispori; sporidiis farete di- vel tristichis, clavatis, parum curvatis, vel inaequilateralibus, sex- vel octi-, plerunque septemtransverse-septatis constrictisque, sepimentis sparsis in longitudine, luteis, melleis vel subfuscidulis. 22-27 mm. long., $7-9 \mathrm{~mm}$. crass.; paraphyses superantes, simplices, guttulatae. - Niessl l. c. Arl sarmenta arida Vitis viniferce Lin. Moravia. Aestate. (Niessl.)

Mir ist diese Species bisher nur aus der vorstehenden ansfiihrlichen Beschreibung und der Abbildung bekannt. Derselhe Pilz kommt, Niessl zufolge, auch auf einer grossen Reihe anderer Pflanzen, an deren abgestorbenen Stengehn vor. Niessl sammelte ihn vorzugsweise im Sommer an diuren Reben von Vitis vinifera Lin. in Mähren. (Tab. III. tig. 19.)

\section{Pleospora phaeocomes Ces. et De Not.}

Cesati et De Notaris, Schema di classific. d. Sferiacei p. 44. in Comment. d. società crittog. ital. p. 218 . - Sphaeria phueocomes Berk. et Br. Brit. Fungi no. 207. - Niessl, Notizen über nene und kritische Pyrenomyceten p. 32 in Verhandl. d. naturforsch. Vereins in Brïnn XIV. 1876.

Perithecia sparsa in matrice haud mutata vel parum denigrata sub epidermide nidulantia demum saepe libera, depresso- 
globosa, mox collapsa, media magnitudine (250 mm. in diam.), atra, coriacea, basi valde fibrillosa, versus apicem setigera. Setae nune divergentes nume comatae, rigidae, simplices, opacae, atrae; ascis clavatis dein clavate cylindraceis, octisporis, stipite brevi, $75-115 \mathrm{~mm}$. long., $15-18 \mathrm{~mm}$. lat.; sporidiis initio distichis demum plerumque oblique monostichis, oblongo- vel ellipsoideoovatis, rectis, interdum inaequilateralibus, utrinque late rotundatis, transverse quinqueseptatis, medio plus minus constrictis, sepimento in longitudine une percurrente, ex aureo saturate fuscis, infime subopacis, $18-21 \mathrm{~mm}$. long., $9-11 \mathrm{~mm}$. lat.; paraphyses sparsae, ramosac. -- Niessl l. c.

Ad Vitis viniferce Lin. sarmenta dejecta. Ineunte aestate. Moravia. (Niessl.)

Die Perithecien dieses, nach den Angaben Niessl's a. a. O. gemeinen, nach denen anderer Antoren und meinen eigenen Beobachtungen jedoch ïberaus seltenen Pyrenomyceten stehen zerstreut auf der Holzsubstanz, unterhalb der sich ablïsenden Rinde, sind schwarz, zusammengedriickt-kugelig, bald einschrumpfend, von ungefähr $250 \mathrm{~mm}$. Durchmesser, von zïher Substanz und haben am Grunde Fasern, gegen den Scheitel wenige zerstreut stehende Härchen. Diese Färchen sind steif, einfach, glänzend schwärzlich. Die kenlenförmigen Schlänche haben eine Länge von 75-115 mm., bei einer Breite von 15-18 mm., sie sind kurzgestielt und achtsporig; die Sporen stehen zu Anfang in einer, späterhin fast immer in zwei schiefen Reihen, sind oblongelliptisch, gerade, oben und unten abgerundet, häufig sind die beiden Längsseiten ungleich; der Quere nach sind sie fünfmal getheilt, an den Theilungsstellen etwas eingeschniirt, goldgelbbräunlich, glämzend und $18-21 \mathrm{~mm}$. lang., $9-11 \mathrm{~mm}$. dick. Die Paraphysen stchen vereinzelt und sind ästig. - Auf dürren, abgeschnittenen Ranken des gemeinen Weinstockes, Vitis vinifera Lin. Niessl fand diese Pleospona in Mai, Juni sehr gemein bei Briinn in Mähren.

\section{Leptosphaeria appendiculata Pirotta.}

Pirotta, funghi parassiti dei Vitigni p. 33. - Leptosphaeria Titis Schulzer in Verhandl. đ. zoolog. bot. Gesellschaft m Wien XX. 1872, p. 642.

L. pyreniis confertis, lignicolis, subimmersis rel cortice perforantibus et vertice prominentibus, globosis vel conicis, verru- 
cosis vel etiam filamentosis; ascis brevibus, clavaeformibus, bivel sexsporis, tenuissimis, citissime evanidis; sporis fusiformibus, curvatis, quinqueseptatis, sexnucleatis, dilute luteo-fusceseentibus, utrinque cum appendice filiformi, hyalino, tremelloso, ad septas constrictis, $42 \mathrm{~mm}$. long., $6 \mathrm{~mm}$. crass.

In sarmentis emortuis Titis viniferae Lin. - Slavonia (Sehulzer.)

Am angefïhrten Orte gibt der Autor folgende Beschreibung: Pyrenien gruppenweise unter der klaffenden Rinde frei auf dem Holze, blos mit der Basis etwas eingesenkt, doeh sieht man, dass sie ats diesem herrorbrachen, weil ihr Scheitel schwarz, der untere Theil aber von der mitgenommenen Bast- oder obersten Holzschicht dunkelbraun ist, oder sie brechen bei noch vollstiindiger Rinde, selbige pnstelförmig hebend, ans dieser nur mit dem Scheitel hervor. Ihre Gestalt ist sehr ver'schieden, vom Kugeligen bis ins Kegelförmige, die Breite durchschnittlich 1/5 Zoll. Die Oberfläche ist sehr warzig und zuweilen hier und da mit kurzen, hyalinen Fädchen besetzt, die jedoch unter Wasser und bei weiterer Behandlung abfallen. Der weissgraue Kern besteht aus einfachen, langen, fadenföruigen Paraphysen und aus kürzeren, keulenförmigen, zwei- bis sechssporigen Schläuchen, welche sehr zart sind und noch vor völliger Reife der Sporen zerfliessen. Die Schlänche und Paraphysen entstehen an der Basis und an den Seitenwänden der Pyrenien. Die Sporen sind spindelförmig, meist mondförmig gekriimmt, $42 \mathrm{~mm}$. lang; in der Mitte $6 \mathrm{~mm}$. dick, blass gelbbram, mit sechs Sporidiolen (wohl Nuclei?), welche selbst nach der Bildung der fünf Scheidewände fortbestehen. An jedem Ende befindet sich ein gallertartiges, hyalines, fadenfürmiges, nicht zugespitztes Anhängsel von cirea $1 \mathrm{~mm}$. Lainge. An den Theilungsstellen sind die Sporen sanft gekerbt, was an den mittleren am deuthehsten zu schen ist. - Zusätzlich bemerkt Schulzer noch: Diplodia Heufleri Schlzr. ist steter Begleiter sowohl des vorigen (Gibbera Vitis Schlzr.) als auch dieses Pilzes. Ausserdem fand ich bei letzterem die Sphaerella Titis Schlzr. (Sphaerella sarmentorum Pirotta), Pestalozzia pezizoides De Not. u. A., selbst Myrothecium Titis Bon. - Die Sporenform hat eine nicht sehr entfernte Aehnlichkeit mit jener der Discosia Vitis Schlzr., welche für eine Pycnidenform von no. 2 zu halten, starke Gründe vorhanden sind. - An abgestorbenen Ranken des 
gemeinen Weinstockes, Titis rimifera Lin. von Schulzer in Slavonien gefunden; mir durch Autopsie leider nicht bekannt.

\section{Leptosphaeria Gibelliana Pirotta.}

Pirotta, funghi parassiti dei Vitigni p. 36. Tab. X. fig. 6-9.

L. ramulicola. Pcritheciis cortice immersis, epidermide primum tectis, dein ostiolo elumpentibus, sphaericis, ovatis vel depressis, sparsis, rarissime gregariis, numquam vero confluentibus, ostiolo cylindrico brevi, apice obtuso praeditis, membranaceis, e cellulis polygonis obscure contextis, nigris, laevibus; nucleo luteolo; ascis cylindricis, pedicellatis, octisporis, membrana crassa, 72-100 mm. long., 12-15 mm. lat.; paraphysibus phuribus, filiformibus, flaccidis, tenuissimis, ascos superantibus, simplicibus, continuis; sporis oblique monostichis, rarius distichis, fusiformibus, apice acutis, rectis vel leviter curvatis, quadrilocularibus, loculis anucleatis, ad septa haud raro parum constrictis, flavis, $12-15 \mathrm{~mm}$. long., 4-5 mm. lat. - Pirotta 1. c.

Ad sarmenta arida Vitis viniferce Iin. Ins. Sicilia.

Mir nur aus der angeführten Diagnose bckannt. Die Perithecien sind in die Rinde eingesenkt, zuerst ganz von derselben bedeckt, damn mit der Mïndung hervorbrechend, zerstreut, eirund oder zusammengedrickt-kugelig, nur selten gedrängter stehend, niemals wirklich in einander fliessend, die Miundung ist kurz-cylindrisch mit einer stumpflichen Spitze; die substanz der Perithecien ist häutig, aus vieleckigen Zellen gebildet, sie sind schwarz, glatt; die Schläuche sind eylindrisch, gestielt, achtsporig, dickhäutig, 72-100 $\mathrm{mm}$. lang und $12-15 \mathrm{~mm}$. breit, und werden von den zahlreichen, fadenförmigen, sehr zarten, einfachen, unverästelten, schlaffen Paraphysen an Länge überragt. Die schief ein-, nur selten zweireihig angeordneten Sporen sind spindelförmig; an beiden Polen zugespitzt, gerade oder ein wenig gekriimmt, vierzellig, ohne alle Nuclei, gelblich, an den drei Theilungsstellen unbedentend eingeschnürt und 12-15 mm. lang und 4-5 mm. breit. - An, wahrseheinlich, abgestorbenen Ranken von Vitis vimifera Lin. auf der Insel Sicilien entdeckt. 


\section{Leptosphaeria Vitis Pirotta.}

Pirotta, funghi parassiti dei Vitigni p. 33. - Sphceric Vitis Cast. Catal. plant. Marseille P. 66.

L. receptaculis minutis, elongatis, rotundisve, prominulis, saepe longitudinaliter dispositis, nigris, lugosis; ostiolo unico; (thecis) ascis clavatis; paraphysibus brevibus; sporis fuscescentibus, obscure biseptatis. - Cast. 1. c.

Ad samenta arida Titis viniferae Lin. Gallia: Marseille. (Castagne.)

Die Perithecien diescr Art sind seh" klein, länglich oder rundlich, hervorragend, meistens in Längsstreifen angeordnet, schwarz, runzclig, es ist nur eine Mündung vorhanden; dic schlänche sind keulenförmig und enthalten undeutlich zweimal getheilte, bräunliche Sporen, die Paraphysen sind kürzer als die Schlänche. Ich habe diese Art nicht zu Gesicht bekommen, kamn deshalb auch nicht angeben, ob die Stellung derselben zu der Gattung Leptosphaeria, wozn Pirotta sie rechnet, gerechtfertigt ist. - Bisher nur einmal bei Marseille in Frankreich von Castague auf abgestorbenen Ranken von Vitis rinifera Lin. gefunden.

\section{Leptosphaeria vinealis Pass. nor. spec.}

Passerini in litt. ad me.

Asci clavati, octispori; sporae biseriales, fusiformes, triseptatae, loculo altero ex intermediis subtumidiore, primo hyalinae, dein pallide olivaceae. Paraphyses non visae.

In sarmentis aridis Vitis viniferce Lin. Italia: Parma. (Passerini.)

Die Perithecien dieser neuen, bisher noch unbekannten Art sind in kurzen, recht dicht stehenden Reihen auf der Rindenoberhaut angeordnet, sie sind ziemlich klein, brechen durch das Parenchym hindurch, sind platt zusammengedriickt, rissig und von mattschwarzer Farbe. Die Schläuche sind keulenförmig mit zicmlich starkem Episporium, oben am Scheitel abgerundet, gegen die Basis hin etwas verschmälert, wasserhell und achtsporig. Die Sporen, welche in zwei neben einander liegende Reihen geordnet sind, haben eine Art Spindelform und sind dreimal septirt, die beiden Enden sind zugespitzt, die mittleren zwei Abtheilungen 
der Sporen sind etwas angeschwollen, die Theilungsstellen schwach eingeschniirt. Die Farbe ist zn Anfang wasserhell, später wird sie schwach olivenbraun. Paraphysen sind nicht rorhanden, wenigstens wurden keine solchen beobachtet. - Auf alogestorbenen Reben des gemeinen Weinstockes, Titis viniferct Lin., bei Parma in Ober-Italien im Mäı 1877 ron Prof. Passerini entdeckt und mir fremdlichst mitgetheilt. (Tal,. III. fig. 21.)

\section{Didymosphaeria bacchans Pass. nor. spec.}

Passerini in litt, ad me.

Perithecia cortice exteriore immersa, minuta, seriata, subglobosa, ostiolo brevi, conico, atro, ermmpentia; asci oblongoclavati, basi attenuati, quadri-vel octispori; sporae obliquae, uniseriales, elliptico-naviculares, mniseptatac, fuscae. - Perithecia majora stylosporea adsunt. - Pass.

In sarmentis aridis Titis viniferce Iin. Parma, Italiae superioris. Vere 1877. (Passerini.)

Die Perithecien dieses nenen Ascomyceten sinrl von mittlerer Grösse, in die äussere, obere Rindenschicht eingesenkt, von welcher sie mit einem kleinen, randartigen IVulste ungeben sind, sie sind ganz ungemein klein, kaum mit blossen Augen bemerkbar, stehen in ziemlich langen Reihen und ragen vermittelst der grossen, dabei aber kurzen, kegelfürmigen Miundung aus dem Parenchym, unter welchem sie nisten, hervor, die Gestalt ist ziemlich regelmässig kugelig oder etwas zusammengedrïckt, die Farbe schwarz. Die Schläuche sind keulenförmig-oblong oder breit cylindrisch-keulig, ziemlich häufig in der oberen Hälfte umgebogen, fast hakenförmig darlurch werdend, am Scheitel sind sie etwas rundlich zugespitzt, am unteren Ende stark verschmälert, manchmal scheinbar in einen kurzen Stiel ausgezogen, welcher am untersten Ende einc kleine Ansbuchtung, gleichsam eine Art Knöpfchen trïgt. Es ist aber durchaus kein eigentlicher Stiel, sondern ein integrirender Theil des Schlanches. Die Membran ist sehr dïnn, glatt, durchsichtig, an denjenigen Stellen, wo die einreihig angeordneten Sporen liegen, etwas weniges angeschwollen oder aufgetrieben, an den Zwischenpunkten aber, dem entsprechend schwach einwärts gebogen. Die, wie gesagt, einreihig stehenden Sporen, deren Zahl zwischen vier und acht schwankt (die Mehr- 
zahl der Schläuche zeigt die letztere Anzalıl und diurften wohl die mindersporigen nur in der Entwickelung zuritekgebliebene Individuen sciu), sind melı oder minder sehiefgestaltet, elliptisch, oder was man kahnförmig nennt, in der Mitte getheilt, aber an dieser Scheidewand nicht eingeschniirt, sondern im Gegentheile eher etwas angeschwollen, die Farbe ist ein mattes Braun. Jede Spore hat in jeder ihrer beiden Zellen ein bis zwei, nu selten mehr Nuclei, welche senkrecht ïberemander stehen. Paraphysen sind nicht vorhanden. - Die, zwischen den Perithecien der Didymosphaeria vereinzelt auftretenden, grösseren, tiefschwarzen Perithecien, welche nach des Autors Meinung den Stylosporenpilz bilden, enthalten wohl nur unentwickelt gebliebene Asei. An dïrren Ranken von Vitis viniferc Lin. bei Parma in OberItalien in Frïhjalyr 1877 vom Prof. A. Passerini entdeckt. (Tab. IV. fig. 8.)

\section{Sphaerella sarmentorum Pirotta.}

Pirotta, funghi parassiti dei Vitigni p. 32. - Spheerella Vitis Schlzr. in Verhandl. d. zoolog.-botan. Gesellschaft zn Wien XX. 1872, p. 643.

Sph. peritheciis subglobosis, tenuibus, nigris, ostiolatis, ostiolo subverrueuloso, immersis; ascis rectis, cylindraceis, octisporis; sporis oblongo-ovatis, gradatim dispositis, triseptatis, ad septas constrictis, nucleatis, dilute flavo-fuseis, $26 \mathrm{~mm}$. long., $7 \mathrm{~mm}$. crass.; paraphysibus nullis.

In sarmentis aridis Vitis viniferce Lin. Slavonia. (Schulzer.)

Dic Beschreibung a. a. O. lautet: Die hornartigen, dïnnen, durchschnittlich $1 / 4$ Zoll breiten, schwarzen Pyrenien sind fast kugelig, in eine kaum mehr als warzenförmige Mündung ausgezogen, ganz im Baste, doch nicht völlig bis zum Holze eingesenkt, pustelförmig die Rinde hebend und blos mit der Spitze der Miundung hervorbrechend, in deren Mitte man den hervortretenden, weissgrauen Inhalt sieht. Der Kern besteht aus aufrechten, cylindrischen, achtsporigen Schlänchen und - wenigstens um die angegebene Zeit - zwischen denselben aus einer Menge Plasmakügelchen. Paraphysen in diesem Zustande keine. Die im Schlauche staffelförmig gelagerten Sporen sind oblong-oval, $26 \mathrm{~mm}$. lang, $7 \mathrm{~mm}$. dick, dreimal septirt und sanft gekerbt, in den Fächern zur Zeit noch Sporidiolen (Nuclei) führend, licht braun- 
gelb. Mitte Juli erst beginnt die Reife der Sporen. - In Gruppen dicht untermischt mit Leptosphaeria appendiculata Pirotta (L. Vitis Schlzr.) und Pestalozaia pezizoides De Not. - Ich kenne diese Species, welche ebenfalls in Slavonien an todten Reben von Vitis vinifera Lin, aufgefunden ward, weder durch Exemplare, noch dureh Abbildungen.

Da bereits im Jahre 1869 von Fnekel in seinen .Symbolae mycologicae" p. 104 eine Sphaterlla Vitis aufgestellt wurde, von welcher der Herr Schulzer von Mïggenburg jedoch keine Ahnung zu haben scheint oder wenigstens schien, so konnte sein Name nicht bleiben. Vorausgesetzt natiirlich, die hier beschriebene Species existirt wirklich, so mag sie den Namen, welchen ihr Pirotta gab, führen, und zwar mit Recht, ist sie aber ein Phantasiegebilde, so mag der nene Name der Vergessenheit anheimfallen.

\section{Sphaeria viticola Sehwrz.}

Schweinitz, Synopsis fung. Carol. 1. 34, no. 64. - Id. Synopsis of North American Fungi p. 198, no. 1290. - Fries, Systema mycologicum II. p. 372. - ? Dictrype viticola Berk. et Curt., Notices of North American Fungi in Grevillea IV. p. 96. - Pirotta, funghi parassiti dei Vitigni p. 51.

S. tecta, emersa, in serias parallelas crescens, fusco-nigra, stromate brunneo, peritheciis paucis, globosis, ostiolis latentibus. - Series sparsae, cum epidermide assurgente prominentes, non vero erumpentes; perithecia magna, globosa, crassa, rariora, uni vel tres in singula verruea, stromate brunneo, splendente cincta. - Fr. 1. c.

In ramis emortuis Vitis rotundifolice Mchx. America septentr.: Carolina septentrionalis. (Schweinitz.)

Diese, mir ganz unbekannt gebliebene Art wird vom Autor a. a. O. folgendermassen charakterisirt: Die Perithecien sind anfangs von der Oberhant bedeckt, sie sind vereinzelt, aber in parallellaufenden Streifen angeordnet, sie durchlockern die Epidermis, indem sie dieselbe ein wenig emporheben, können aber doch nicht gerade hervorragend genannt werden, sie sind schwarzbrann, kugelig, gross und dick und stehen zu Einem bis zu Dreien verbunden auf einem glänzend braunen Stroma, welches sie kreisförmig umgibt. - Auf abgestorbenen Ranken von Titis rotundifolia Mchx. in Nord-Carolina, Vereinigte Staaten von NordAmerika. (Schweinitz.) 


\section{Sphaeria ampelos Schwz.}

Sehweinitz, Synopsis of North American Fungi p. 217, no. 1637.

Spl. seriatim distanter sparsa, minnta, circumcissa, subfusca, globosa-applanata. Ostiolo prominente per rimas corticis. Schwz. 1. c.

In valde corruptis sarmentis ritis Labruscae Liu., primo epidermide tuta. - America septentr.: Bethlehem, Penusylvania. (Schweinitz.)

Diese Sphaeria, zur Abtheilung Obtectae gehörig, ist mir räthselhaft; irgend eine Vermuthung iiber ihre systematische Stellung kann ich wegen z̈usserst mangelhafter Diagnosirung nicht aussprechen. - Die Perithecien sind, dem Autor zufolge in zerstreuten Längsreihen angeordnet, sie sind klein, aufspringend, umgeben von der aufgetriebenen Epidermis, bräunlich und abgeplattet kugelig, die hervortretende Mündung durchbohrt die Epidermis. - Auf sehr alten Ranken von Vitis Labrusca Lin. in Pennsylvanien, Nord-Amerika. (Schweinitz.)

\section{Sphaeria subfascieulata Schwz.}

Schweinitz, Synopsis of North American Fungi p. 214, no. 1565.

Sph. primum subtecta, demum omnino denudata, affinis Sphaeriae Bombardae (Bombardia fasciculata Fr.), sed magis sparsa et quasi longitudinaliter seriata; peritheciis subfasciculatis, nigris, vix mollibus, interdum omnino forma S. Bombardae, saepe antem minus elongatis, subrotundis ac obtuse papillatis, minoribus et inter se confluentibus. - Schwz. l. c.

In ramis dejectis Vitis Labruscae Lin. corruptissimac. Pennsylvania, America septentr. (Schweinitz.)

Mir ist diese Art unbekannt geblieben, und da der Autor ïber Schläuche und Sporen nichts erwähnt, kann man nicht cimmal Vermuthungen aufstellen, zu welcher von unseren neueren Pyrenomyceten-Gattungen wohl der Pilz zu bringen wäre. Die, zweimal, in der Diagnose erwähnte grosse Aehnlichkeit und Verwandtschaft unseres Pilzes mit Spluaria Bombarda Batseh., der hentigen Bombardia fasciculata Fr. gibt, da sie wohl lediglich auf makroskopischer Uebereinstimmung beruht, noch kein Recht 
zu der Annahme, dass diese Sphueria ebenfalls in die Familie der Lophiostomei zu stellen sei; nur die Untersuchung von Schweinitz'schen Original-Exemplaren vermag ïber die Stellung im System genügenden Aufschluss zu geben. - Der Autor beschreibt unseren Pilz folgendermassen: Zuerst bedeckt, später jedoch ganz frei, der S. Bombardia ähnlich, aber zerstreuter wachsend und gleichsam längsstreifen bildend; die Perithecien sind beinalie biischelförmig zu nennen, sehwarz, kaum etwas weich, manchnal ganz von der Form jener der S. Bombardia, häufig aber weniger verläingert, rundlich, mit abgestumpften Papillen oder Wärzchen, kleiner und unter sich verbunden und zusammenfliessend. - Auf abgefallenen, schon stark zersetzten Ranken von Titis Labrusca Lin. bei Bethlehem in Pennsylvanien, Nord-Anerika, ron Schweinitz gefunden.

\section{Eurotium herbariorum Lk.}

Link, Observationes mycologicae I. p. 29, fig. 44. - Lk. in C. a. Linné species plantarum, cura Willdenow VI. Pars 1. p. 79. - Nees ab Esenbeck, System der Pilze p. 95, fig. 97. - Martius, Flora Erlang. p. 369. - De Bary in Botan. Zeitung 1854, p. 425, Tab. XI. - Loudon, Encyclopedia of plants fig. 16548. - Corda, Anleitung zum Studium der Mykologie Tab. C. fig. 22, no. 1-3. Bischoff, Kryptogamenkunde fig. 3753. - Fuckel, Symbolae mycologicae p. 90. - Cooke, Handbook of British Fungi p. 654. - Mucor herbariorum Pers. Syn. fungorum p. 202. - De Candolle, Flore française VI. p. 100.

E. mycelio effuso, tenui, griseo albo vel aurantiaco; globulis impositis solitariis vel etiam dense gregariis, placas formans, minutis, numerosis, pulclure flavis; ascis numerosissimis, plus minusve globosis, achrois, octisporis; sporis in asco conglomeratis, globosis vel subovatis, hyalinis, $5 \mathrm{~mm}$. diam.

Ad sarmenta, foliaque putrida vel minus bene exsiccata Vitis viniferce Lin. Ubique.

Nachdem man früher diesen interessanten Pilz, welcher von jeher die Mykologen viel beschäftigt hatte, unmittelbar neben die Gattung Mucor gestellt hatte, wurde erst, so viel mir bekannt durch Riess, constatirt, dass es ein Ascomycet, ein Schlauchpilz sei. De Bary zeigte in seiner Arbeit a. a. O., dass er in innigem Zusammenhange mit Aspergillus glaucus Lk. stehe, welch letztere Form den Conidienpilz des Eurotium darstelle! Sobald organische Substanzen sich zersetzen, tritt bekanntlich in fast allen Fällen 
Schimmelpilz-Bildung auf, und untel den Schimmeln selbst ist Aspergillus glaucus der weitans häutigste. Sehr oft nun folgt diesem oder tritt anch gemeinschaftich mit ihm unser Eurotium anf, so namentlich auf Blätter'n und Pflanzentheilen, wolche in Herbarien schlecht und unaufmerksam gretrocknet wurden, auf eingemachten Früichten, auf Brod, Schinken 11. s. w. Das Mycelium ist entweder graulich-weiss oder hell rothgell gefitrbt, es ist kricchend und auf ihm oder in ihm finden sich dic, dem Eurotum charakteristischen kleinen Kugch von schön hellgelber Färbung, welche entweder vereinzelt stehen oder dicht aneinander gedrängt grosse Colonien bilden. Die Oberfläche dieser Kiigelchen ist feldrig, zuweilen an den Begrenzungsstellen dieser sehr zahlreichen kleinen Felder etwas eingesenkt, so dass das Ganze beinahe den Charakter einer zusammengesetzten Beere annimmt. In dieser Kugel nun, welche ein richtiges Perithecium ist, bilden sich und werden bei der Reife durch Platzen herausgedrückt die ungemein zahlreichen und sehr kleinen Schläuche von fast kugeliger Gestalt. Ihre Farbe ist wasserhell und ebenso auch die der acht darin enthaltenen Sporen, letztere sind eng zusammengedrüickt und bilden eigentlich einen ziemlich festen Ballen, sie sind sehr klein, kugelig oder rundlich-oval und haben nu cinen Durchmesser von $5 \mathrm{~mm}$. - Auf Ranken und Blättern von halbfaulen, namentlich aber schlecht getrockneten Weinreben, Vitis vinifera Lin. Ueberall und das ganze Jahr hindurch. (Tab. III. tig. 6.)

\section{Diplodia interrogativa 'Thüm. et Pass. nor. spec.}

D. peritheciis minutis, solitariis, plerumque lineari dispositis, prominentibus, globosis, atris; sporis forma variae: ellipsoideae utrinque rotundatae, raro ovatae vel globosae, plerumcue integris, ser etiam septatis ad septas non constrictis, fusco-griseis, 16 vel $22 \mathrm{~mm}$. long., $8-12 \mathrm{~mm}$. crass.

Italia: Parma in sarmentis aridis Vitis viniferce Lin. Martio 1877. (Passerini.)

Eine jedenfalls bisher noch unbeschriebene Diplodia, welche sich sowohl durch ihre sehr kleinen, einzeln stehenden Perithecien, als auch durch die meistentheils in der Mitte nicht septirten Sporen von den verwandten Formen unterscheidet. Sie bildet 
kleine, kugelige, schwarze, zumeist linienförmig arrangirte, aber nicht zusammenhängende Perithecien, welche auf der ausgebleichten Rindenoberhant nur sehwer zu erkennen sind, so klein sind sie. Die Sporen sind von verschiedener Form, die meisten sind regelmässig elliptisch, manche aber anch eiförmig und kugelig. Wie bereits bemerkt, fehlt den meisten die, der Gattung Diplodic sonst zukommende Scheidewand, doch findet diese sich bei manchen Sporen und da diess immer die grössten, am regelmässigst gebildeten sind, so kamn das Fehlen der 'Trennungswand bei vielen nu in ungenügender Entwickelung gesucht werden. Kämen überhaupt keine septirten Sporen vor, so wïrde vorliegende Species zur Gattung Sphaeropsis Fr. gezogen werden miissen. Die Farbe der Sporen ist graubräunlich, ihre Grösse schwankt zwischen 16 und $22 \mathrm{~mm}$. in der Länge und 8-12 $\mathrm{mm}$. in der Breite. - Ich erhiclt diese hochinteressante Form aus Parma in Ober-Italien eingesendet, wo sie im März 1877 von Prof. G. Passerini an trockenen Ranken von Vitis viniferc Lin. gefunden ward. (Tab. V. fig. 11.)

\section{Diplodia Bacchi Pass. et Thiim. nov. spec.}

D. peritheciis magnis, gregariis, primo epidermide tectis, demum errumpentibus, liberis, solitariis vel confluentibus, globosis, asperis, opaco-atris; sporis oblongis vel ellipsoideis, utrinque late rotundatis, medio septatis, non constrictis, anucleatis, $16-20 \mathrm{~mm}$. long., 8-12 mm. crass., dihute fuscis, impellucidis.

Italia: Parma in sarmentis aridis Vitis viniferce Lin. (Passerini.) Vere 1877.

Von den verwandten Species derselben Gattung lässt sich Diplodia Bacchi leicht durch die grossen, zu Anfang von der Rindenepidermis bedeckten Perithecien unterscheiden. Diese sind später zwischen der aufgeplatzten Rinde-hervorragend, halbkugelig, schwarz und in Folge ihrer rauhen Oberfläche matt. Die Sporen gleichen ziemlich genau denen von Diplodia viticola Desm., sie sind ebenfalls elliptisch oder oblong, nur sind sie an den beiden Enden breiter abgerundet, die Farbe ist ein helleres Braun, sie sind ganz undurchscheinend und haben eine Iänge von 16-20 $\mathrm{mm}$. bei einer Breite von 8-12 mm. Die Seheidewand befindet sich in der Mitte, die Spore ist aber an dieser 
Stelle nieht eingeschnürt. - Passerini entdeckte diese Art auf todten Reben von Titis vinifera Lin. bei Parma in Italien. (T'ab. II. fig. 20.)

\section{Diplodia fabaeformis Pass. et 'Thim. nov. spec.}

D. peritheenis prominulis, semiglobosis, epidermide einetis, primo immersis, teetis, mediis, subsuleatis, gregariis, irregulariter dispositis, atris; sporis ellipsoideis vel plerumque fabaeformibus, utrinque rotundatis, medio uninueleatis, non septatis, unilaterali inflexis, fuscis, $20 \mathrm{~mm}$. long., $11-13 \mathrm{~mm}$. erass.

Italia: Parma in sarmentis emortuis Vitis viniferce Lin. Nov. 1876. (Passerini.)

Diese Diplodia unterscheidet sich von den anderen Arten derselben Gattung durch die verhältnissmässig grossen, hervortretenden, halbkugelförmigen Peritheeien, welche etwas gefureht auf ihrer Oberfläehe ganz ohne bestimmte Ordnung vertheilt und von sehwarzer Farbe sind. Die Sporen sind nur vereinzelt regelmässig elliptisch, die bei Weitem grösste Anzalıl hat fast die Gestalt von Bohnen, indem sie auf der einen Längsseite etwas eingebogen sind. Eine Seheidewand ist nieht vorhanden, dagegen in der Mitte ein dunklerer Kern oder Nucleus, und ist es nicht unwahrscheinlich, dass aus demselben sieh späterluin doch noch die Theilungswand bildet. Die Sporen, deren Farbe eine hellbraune ist, haben eine Länge von $20 \mathrm{~mm}$. und einen Breitendurchmesser vor 11-13 mm. - Ebenfalls in Ober-Italien bei Parma ward diese sehöne neue Species im November 1876 vom Prof. G. Passerini auf trockenen Reben des gemeinen Weimstockes, Vitis vinifera Lin., entdeckt. (Tab. V. tig. 15.)

\section{Diplodia riticola Desm.}

Desmazieres, Annales des Sciences naturelles 1838, X. p. 311. - Desmazieres, Cryptog. de France no. 989. - Berkeley, Annales of Natural History no. 207. - Cooke, Handb. of British Fungi p. 432. - Fnckel, Symbolae mycolog. p. 395.

- Id. Fungi rlenani no. 541. - Pirotta, fungli parassiti dei Vitigni p. 58.

D. peritheciis prominentibus, derse gregariis, globosis, mediis, papillatis, nigris; sporis longe-ellipsoideis vel obovatis, utrinque 
rotundatis, medio septatis sed non constrictis, fuscis, subpellucidis, $20 \mathrm{~mm}$. long., 6-10 mm. crass.

In Vitis viniferae Lin., Vitis Labruscae Lin. et Titis aestivalis Mchx. sarmentis aridis. Ubique. Europa et America.

Diese, am häutigsten von allen Diplodia-Arten auf Vitis vorkommende Species ist durch die zahlreichen, öfter's sehr gedrängt stehenden, aber doch fast niemals zusammenfliessenden Perithecien ausgezeichnet, dieselben sind mehr oder weniger kugelig, etwas papillös, von mittlerer Grösse (d. h. im Verhältniss zu anderen Arten derselben Gattung') und schwarz. Die zahlieich vorhandenen Sporen sind elliptisch oder oblong, an beiden Enden regehmässig abgerundet, haben in der Nitte eine Scheidewand, sind jedoch an derselben nicht eingeschniirt, ihre Farbe ist ein helles Kastanienbraun, ihre Grösse belänft sich auf $20 \mathrm{~mm}$. in der Länge und auf 6-10 mm. in der Breite. - Aus den verschiedensten Ländern ist mir dieser Pilz bekannt und ich glaube ganz gewiss nicht zu irren, wenn ich annehme, dass er ïberall, wo Wein gebaut wird auch an den trockenen, abgestorbenen Ranken vorkommt, und zwar nicht mu an unserem gemeinen Weinstocke, Vitis vinifera Lin., sondern auch, wenigstens in Nord-Amerika, an Vitis Labresca Lin. und Titis aestivalis Mchx. Mir war es bisher nicht möglich, irgend einen Unterschied, sei es in den makroskopischen, noch sei es in den mikroskopischen Verhältnissen nachzuweisen zwischen den Exemplaren auf den angegebencn drei Arten von Titis. (Tab. Il. fig. 21.)

\section{Pestalozzia pezizoides De Not.}

De Notaris in Acta Acad. Turin. 1841, Tom. III. Dec. 2, fig. 9. - Saccardo, Mycologia veneta p. 199, Tab. XVII, fig. 28. - Berkeley, Notices of Nortl American Fungi in Grevillea II. p. 154. - 26 . Report of the New York State Musenm 1. 77. - Pirotta, funghi parassiti dei Vitigni p. 68.

Acervula nigra, erumpentia, epidermide temniter marginata, dein persistentia, fere perennia. Stroma gelatinoso-filamentosum. Filamenta erecta, hinc sterilis obseure aticulatae, subseriatim ramosa, reliqua fertilia ramosa vel simplicia, continua, superiori parte turgescentia subclavata, inde rudimentis dissepimentormm distincta, taudem in sporidia perfecta pedicellata evolutae. Spo- 
ridia igitur primum stromate gelatinoso pedicellis eorum longitudinem subaequantis ope affixa, dein matura libera, torulosooblonga, plermuque perlicello rupto, mutico, obtuso vel attenuato, vel in setas binas uncinatas producta, supremo conoideo in penicillum filorum sporidis ipso breviorum soluto. Fila haec continua, simplicia vel furcata, subtillina, divergentia recurvaque, numero 4 -8 raria, diaphana, longiturline inter se subaequalia. - De Notaris 1. e.

Ad sarmenta emortua Titis viniferce Lin. Ubique non raro; Vitis Labruscae Lin. America septentr.: New-Jersey (Ellis), NewTork (Peck) et Vitis ripariae Mehx., Carolina sup. (Curtis).

Vorstehende Art bildet mittelgrosse, schwarze Perithecien oder Häufchen auf der Rinde, welche eigentlich auf der Holzsubstanz nisten, aber durch das Rindenparenchym durchbrechen und von demselben dann in einem kleinen Thulste orler hervortretenden Rande ungeben sind. Das Stroma ist grelatinösfudig; diese Fäden sind aufrecht, die unfruchtbaren (gleichsann die Stelle der Paraphysen vertretenden) sind undeutlich gegliedert, katum etwas verzweigt, die ïbrigen fertilen sind entweder ästig oder einfach, am oberen Ende keulenförmig verdickt und die meisten sich zu wirklichen, vollkommenen Sporen ausbildend. Die Sporen sind zu Anfang im noch unreifen Zustande mehrfach an einander geklebt, oder vielleicht besser gesagt, verwachsen; später im Zustande der Reife sind sie einfach, das heisst jede spore steht einzehn für sich anfrecht da. Ihre Gestalt ist keulenförmig, gegen den Scheitel und gegen die Basis stark verschmälert, etwas ungleich geformt. Oben trägt jede Spore die 4-8, das Genus Pestalozzia auszeichnenden, hyalinen Fortsätze oder dicken, haarartigen Gebilde, welehe von ziemlich gleicher I äinge, farlenförmig gestaltet, einfach, mehr oder weniger gebogen, an der Spitze abgestumpft sind. Die Sporen sind der Quere nach durch Scheidewände in vier bis sieben Fächer getheilt, an den betreffenden Theilungsstellen ein klein wenig eingeschniut; sie verlaufen unten meistens in einen Stiel, welcher ziemlich lang ist und keine oder nur eine Scheidewand hat, ilne Farbe ist ein mattes Grauljraun, die beiden ïusseren Zellen sind jedoch vollkommen farblos. Die Sporen sind $40 \mathrm{~nm}$. lang und $8 \mathrm{~mm}$. breit, der Stiel 50-60 mm. lang, $15 \mathrm{~mm}$. dick, die Scheitelhare oder Fortsätze ungefülı 10-15 mm. lang. - Bei den Exemplạren 
auf Titis Labrusca konate ich einen Unterschied nicht auffinden, höchstens dass die Perithecien weit kleiner waren als bei den europäischen speciminis, die Maasse der Sporen u. s. w. stimmten völlig überein. - Es dürfte dieser Pilz wohl überall da auftreten, wo Wein gebant wird, er ist mir bisher auf Vitis vinifera Lin. aus versehiedenen Gegenden Italiens (De Notaris, Passerini, Saccardo), Frankreich (Castagne, Montagne) und Nieder-Oesterreich (Thiimen) bekannt. Aus der nordamerikanisehen Union erhielt ich ihn von Ellis aus New-Jersey und von Gerard und Peck aus dem Staate New-York auf Titis Labrusca Lin. wachsend; von Curtis ward er in Nord-Carolina anf Titis riparia Mchx. gefunden. (Tab. V. fig. 1.)

\section{Coryneum microstictum Berk et $\mathrm{Br}$.}

Berkeley and Broome in Annales of Natural History no. 451. - Saccardo, Mycologia veneta p. 190, Tab. 17, fig. 18, 19. - Id. Mycotheca veneta no. 304. Fuckel, Symbolae mycologicae p. 372. - Id. Fungi rhenani exsicc. no. 1655. - Cooke, Handbook of British Fungi p. 470, no. 1398. - Berkeley, Outlines of Fungology p. 324. - Sporocculus roscecola Rabh. in Klotzsch Herb. mycol. Ser. I. no. 1166.

C. caespitulis minutis, epidermide subtectis, punctiformibus, nitido-atris, gregariis; sporis parvulis, elliptieis vel longe ovatoelliptieis, utrinque acutato-rotundatis, bi- vel triseptatis, ad septas non vel raro minime constrictis pedicellis minutissimis, brevissimis; $11-13 \mathrm{~mm}$. long., $5 \mathrm{~mm}$. crass. dilute fuscis.

In sarmentis aridis Vitis viniferae lin. Anglia. (Berkeley.)

Diesen, sonst eigentlich nur an den abgestorbenen Zweigen von wilden und cultivirten Rosen, dann von Cornus alba, sowie von Brombeeren vorkommenden Pilz geben die englischen Mykologen anch an Weinranken an; ich habe ihm auf diesem letzteren Substrate nicht gesehen. - Die Häufchen des Pilzes, welche immer von der Cuticula der Zweige bedeckt sind, die znletzt nur in Centrum aufplatzt, sind sehr klein, punktförmig, rund, mattschwärzlich und stehen gesellig bei einander. Die zahlreiehen Sporen sind lang elliptisch-eirund oder anch lancettförmig, an beiden Enden spitzlich abgerundet, sehr klein, haben zwei, meistens drei Querwände, sind an den Theilungsstellen jedoeh nur ganz ausnahmsweise etwas wenig eingesehnürt, ihre Farbe 
ist ein helles Braun, ihre Lïnge beträgt 11-13 mm., ihre Breite $5 \mathrm{~mm}$. Sie sind kurz gestielt. - In England auf abgestorbenen Ranken von Vitis vinifera Lin. - Die Abbildung, welche a. a. O. Saccardo gibt, ist ganz falsch und stimmt dieselbe auch durchaus nieht mit den, von ihm selbst vertheilten Exemplaren iiberein! (Tab. II. fig. 16.)

\section{Heudersonia longipes Berk. et Curt.}

Berkeley, Notices of North American Fungi in Grevillea III. p. 4, no. 425b. Pirotta, fungli parassiti dei Vitigni p. 62.

H. peritleciis demum liberatis, collapsis, sporis oblongis, triseptatis, pedicellis longissimis. - Berk. 1. e.

Ad sarmenta emortua Titis species indeterminatae. Ameriea septentr.: Carolina australis. (Ravenel.)

Mir ist diese Species leider unbekannt, ich begnïge mich in Folge dessen mit Wiedergabe der Beschreibung, welehe a. a. O. von den Autoren publicirt wird. Die Perithecien sind zu mehreren vereingt, zuletzt werden sie frei; die Sporen sind von oblonger Form, schmal, dreimal septirt und besitzen sehr lange, ganz ausserordentlich selılanke Stiele, welche aus niederliegenden, articulirten Hyphen entspringen. - Im nordamerikanischen Staate Siid-Carolina an düren Ranken einer Vitis-Art von Ravenel gefunden.

\section{Hendersonia viticola Thä̀m.}

Sphaeria Vitis syluaticae Castagne, Catal. plant. Marseille, Suppl. p. 173. - Hendersonic Vitis sylvaticae Pirotta, funghi parassiti dei Vitigni p. 61.

H. receptaculis rotundis vel ovatis, nigris, epidermirle rupta cinctis, prominulis; ostiolo conico, paraphysibus sporulas gerentibus; sporulis ovoideis, distinctissime biseptatis. - Cast. 1. c.

In Titis sylrestris Gmel. sarmentis aridis. Gallia: pr. Marscille. (C'astagne.)

Dieser Pilz ward von Castagne zu Sphueriu gestellt, wie es damals Sitte war, fast alle Kernpilze mit und ohne Schläuche zu dieser Gattung zu rechnen. Er hat der Beschreibung des Autors zufolge rundliche oder ovale Perithecien von schwarzer Farbe, sie stehen aus der Epidermis, welche sie zerrissen umgibt, hervor 
und haben eine Kurze, kegelförmige Mündung. Die Sporen (an der Spitze von Paraphysen [sic] gebildet) scheinen gestielt zu sein, sie sind deutlich zweifäicherig. - Pirotta a. a. O. hält diese Species, obwohl er sie ebenso wenig wie ich zu Gesicht bekommen hat, auch für eine Hendersonia, die von ihm, auf den ursprünglichen Namen hin, gegebene Bezeichnung lianu jedoch aus zwei Griunden nicht acceptirt werden. Frstens ist es unzulässig, den specifischen Namen einer Pflanze aus zwei Worten zu bilden (conf. Regeln der botanischen Nomenclatur) und damn gibt es gar keine Titis sylvatica, dieser Name existirt nicht, die wilde Rebe wird mit dem Namen Iitis sylvestris Gmel. bezeichnet. Ich hielt ans diescn Gründen mich für wohlberechtigt, den Namen dieser Art zu ändern. - Auf dïrren Ranken der wilden Rebe, Titis sylvestris Gmel., bei Marseille in Frankreich von Castagne entdeckt und wic es scheint, seitdem nicht wieder gefunden.

\section{Hendersonia sarmentornm TVeste.}

Westendorp in Bulletin de l'acad. d. Bruxelles 1s51, p. 391, fig. :- - Id. Cryptog. belg. no. 633. - Saceardo, Myeoth. veneta 1). 200. - Cooke in Seemann's Journal of Botany I. fig. 15. - Id. Handb. of British Fungi p. 435, no. 1279. - Id. Fungi britannici exsice. no. 623. - Id. Fungi britannici exsice. Ser. II. no. 23. - Pirotta, funghi parassiti dei Vitigni p. 52. - Rabenhorst, Fungi europaei no. 449. - 28. Report of the New York State Musenm p. 55. - ITendersonia nodorum Lacr. Nouv. faits P. $2 t$.

H. peritheciis dense gregariis, immersis, primo epidermide tectis postremo per laceram sublongam perforantibus, nigro-fuscis, parvis, planis vel subelevatis; ostiolis punctiformibus, minutis; sporis ellipticis vel obovato-ellipticis vel irregulariter oblongis, triseptatis, ad septas non constrictis vel subangulatis, vertice subrotundatis, basi subangustatis, dilute fuscis, cellula basalia saepe pallidiora, sterigmatibus brevibus, filiformibus, hyalinis gerentibus; 14-16 mm. long., $5 \mathrm{~mm}$. crass.

Ad sarmenta emortua ritis viniferce Lin. Ubique. Hieme - Aestate.

Diese Art scheint wohl iiberall vorzukommen, wo ïberhaupt Wein gebaut wird. Sie bildet sehr dicht gedrängt stehende, stets in grosser Anzahl vorhandene, kleine, runde, eingesenkte, schwarzbraune Perithecien, welche zu Anfang von der Cuticula bedeckt 
sind, später aber durch einen kleinen Längsriss ihr punktfürmiges, kleines Ostiolum often legen, die Gestalt ist entweder flach oder schwach halbkugelig erhaben. An kurzen, fadenförmigen, dimmen und farblosen, zu Bïndeln vereinigten Sterigmen werden die Sporen gebildet, diese sind seh" verschieden von Crestalt, entweder sind sic elliptisch oder oval-elliptisch oder unregehmäsig oblong. am Scheitel etwas abgerundet, an der Basis schwach verschmälert und stumpf zugespitzt; sie sind der Quere nach dreimal getheilt, an den Theilungsstellon sind sie cntweder glatt oder auch zuweilen ctwas kantig ansgebogen, die Farbe ist ein helles Bram, die Basalzelle ist häufig heller gefürbt, lie Länge beträgt 14-16 mm., die Breite $5 \mathrm{~mm}$. - An abgestorbenen, jedoch noch nicht faulenden Ranken von Titis viniferae Lin. iiberall in Europa und Amerika. (Tab. Il. fig. 17.)

\section{Hendersonia ampelina Thïm. nor. spec.}

II. peritheciis gregariis, liberis, plano-orbiculatis vel pseudodisciformibus, minme clevatis vel subcompressis, sublaevibus, atris; sporis subelavatis vel clavato-lanceolatis, utrinque angustatis, subaeutatis, quadri- raro triseptatis, non pedicellatis, dilute fuscescentibus, subprellucidis, $14-16 \mathrm{~mm}$. long., $6-7 \mathrm{~mm}$. crass.

In samentis emortuis Vitis aestivalis Mchx. - Albany N. I., America septentr. Vere 1877. (Peck.)

Diese vierte Art aus der Gattung Hendersonia hat fast scheibenfömige, rundliche, nur wenig erhabene, dicht bei einander stehende Perithecien, welche immer unbedeckt sind, eine glatte Oberflache besitzen und von Farbe schwarz sind. Die zahlreichen Sporen sind lancettförmig-kenlig, nach oben und unten versehmälert, stumpflich zugespitzt, vier-, nur selten zwei- oder dreimal getheilt. Sie laben keinen Stiel, sind gering durehscheinend, sehr hellbraun und ihre Dimensionen betragen 14-16 mm. in der Lïnge, 6-7 mm. in der Breite. - Ich rerdanke diese Species dem Herm Staats-Botaniker Ch. H. Peck zu Albany N. Y. in den Vereinigten Staaten von Nord-Amerika, wo er sie im Frühjahre 1877 an abgestorbenen Ranken der Vitis aestivalis Michx. entdeckte. 


\section{Cryptostictis hysterioides Fuck.}

Fuckel, Fungi rhenani exsiccati no. 1838. - Hendersonia hysterioides Fuck. Symbolae mycolog. 1. 392. - Pirotta, funghi parassiti dei Vitigni p. 63.

C. peritheciis spuriis gregariis, innatis, ellipticis, lineam longis, fuscis, parallele dispositis, demum rima oblongo-lineari dehiscentibus, disco carnoso, excavato; conidiis pedicellatis, oratis, subinaequilateralibus, utrinque attenuatis, antice plerumque obtusioribus, triseptatis, rarius nni- rel biseptatis, flavis, loculis duo ultimis pallidionibus, utringue in latere ciliis conirlium aequantibus, $16 \mathrm{~mm}$. long. (sine ciliis), $7 \mathrm{~mm}$. crass. - Fuckel l. c.

Ad sarmenta arida, corticata Vitis viniferae I in. Antommo. Nassovia. (Fuckel.)

Torliegender Pilz bildet ziemlich kleine, in örosser Anzahl dicht bei einander stehende l'erithecien, diese sind eingesenkt, mehr oder weniger länglich rund, $0 \cdot 3$ Mrm. im Durchsehnitt lang, bräunlich (Fuckel gibt, wohl in'thiimlich, schwarz an) und ziemlich genan in parallele Reihen angeordnet, die kleine, röthlichbranne Scheibe ist fast rund; die sporen sind lang gestielt, länglich-elliptisch, aber die beiden Läingsseiten nicht gleich geformt, sondern die eine ziemlich gerate herablanfend, die andere nach auswärts gebogen, oben und unten sind sie verschmälert stumpflich abgerundet, mit drei Querwinden, nur selten kommen auch solche mit nur einer oder zwei 'Theilungswänden vor, die oberste und die unterste Zelle sind farblos, die anderen gelblich; an der gerade verlanfenden läingsseite der Spore befinden sich, nach oben und nach unten je eine lange Wimper, diese sind farblos, äusserst dïm und zart, meist etwas nach anssen (d. h. von der spore ab) gebogen und ungefäh von gleicher Iä̈uge unter einander als auch mit rler Spore; die lainge der Spore beträgt $16 \mathrm{~mm}$, die Breite $7 \mathrm{~mm}$. - An abgestorbenen Ranken ron Vitis vinifera lin. in Nassan, sehr selten. (Fuckel.)

Meiner Meinung naeh hat Fuckel Unrecht gehabt, diesen interessanten Pilz zu Hendersonia zu stellen. Die Aufstellung der neuen Gattung Cryptostictis in den .Fungi l'henani" war ganz correct. Unser Pilz unterscheidet sich in mehrfacher Hinsicht sehr wesentlich von Hendersonia, namentlich durch die scheibenförmig*en, an eine kleine Stictis erinnernden Perithecien und dam dureh die beiden Wimpern, die Cilien, welche lebhaft an die Arten der 
Gattung Discosia erinnern und sich bei keiner anderen Art von Hendersonic finden. Aus diesen Gründen führte ich den Pilz unter seinem älteren Namen auf und restiture damit die Gattung Cryptostictis Fuck. (Tab. II. tig. 14.)

\section{Sphaeropsis Peckiana 'T'hü um. nov. spec.}

Sph. peritheciis gregaris, primo epidermide tectis, demum erumpentibus, liberis, conico-globosis, papillatis, mediis, nigris ; sporis non pedicellatis, longe ellipsoideis vel oblongo-ovatis, utrinque obtuso-rotundatis, medio non vel minime inflexis, simplicibus, uni- vel trimucleatis, nucleis magnis, $30 \mathrm{~mm}$. long., $10-$ 12) $\mathrm{mm}$. crass.

In salmentis emortuis Vitis Labruscae Lin. - Albany N. Y., America septentr. Vere 1877. (Teck.)

Im äusseren Ansehen ähnelt diese Splateropsis einer Diplodia, die Perithecien sind zu Anfang ziemlich lange von der (Oberhaut bedeckt, wodurch dieselbe wie gekörnelt aussieht, zuletzt durchbrechen sie aber dieselbe und sind num von einer kugelig-kegelförmigen Gestalt, mit vielen Papillen bedeckt um schwärzlich. Die grossen Sporen sind oblong-eiförmig oder elliptisch, beiderseits stumpflich abgerundet, haben ein bis drei ziemlich grosse Nuclei und sind zuweilen an der einen Längsseite unmerklich eingebogen; ihre Farbe ist wasserhell, die Grösse beträgt $30 \mathrm{~mm}$. in der Lïnge und 10-12 mm. in der Breite. Ich nannte diese Art zu Ehren des Entrleckers, des Staats-Botanikers Ch. H. Peck, weleher sie an diurren Ranken von Vitis Labrusea Lin. bei Albany N. Y. in den Vereinigten Staaten von Nord-Amcrika in Friihjahr 1877 auffand. (Tab. V. tig. 14.)

Sphaeronaema viticolum Berk. et Curt.

Berkeley, Notices of North American Fungi in Grevillea II. p. 179, no. $407 \mathrm{~b}$. - Pirotta, funghi parassiti dei Vitigni p. 58.

S. peritheciis gregariis quandoque congestis, erumpentibus, conicis, late truncatis; pulverulentis parietibus crassis. - Berk. l. c. Ad sarmenta arida Titis species indeterminatae. America septentr.: Carolina australis. (H. W. Ravenel.) 
Eine mir unbekannt gebliebene Speeies; ich muss mich daher damit begnügen, hier die lakonische Beschreibung der Autoren zu reproduciren. Die Perithecien wachsen gesellig, zuweilen auch dicht aneinander gedrängt, sie sind von conischer Gestalt, brechen aus der Epidermis hervor, sind kurz abgestumpft, mit einem dicken Rande mmeben und (?) pulverig. Die Beschreibung der Sporen fehlt gänzlich, doch wird zusätzlich bemerkt, dass unsere Art der vorhergehenden Sphaeronaema glomeratum Mntg. mit kleinen, kurz oblongen Sporen sehr mahe stände. In Süd-Carolina, Nort-Amerika, anf den alogestorbenen Reben einer, nicht nähıe bezeichneten Titis-Art von Ravenel gesammelt.

\section{Phoma confluens Berk, et Curt.}

Berkeley Notices of North American Fnngi in Grevillea II. p. 82. no. 383. Pirotta, funghi parassiti dei Vitigni p. 54.

Ph. maculis marginatis, elevatis; peritheciis eonfuentibus; sporis brevibus. - Berk. l. e.

Ad Vitis species indeterminatae sarmenta arida. America septentr.: Carolina septentrionalis. (Ravenel.)

Der kurzen Besehreibung der Autoren a. a. O. zufolge bildet vorliegende Species kleine, emporstehende, hysteriumartige Flecke, welche von einem deutlichen Rande umgeben sind, in diesen Flecken betinden sich die schwarzen in einander verfliessenden Perithecien, welche kurze, oblonge, 0.0002 engl. Zoll lange Sporen beherbergen. - Im nordamerikanischen Staate Nord-Carolina auf trockenen Ranken einer Vitis-Art von Ravenel gesammelt.

\section{Phoma pallens Berk. et Curt.}

Berkeley, Notices of North American Fungi in Grevillea II. p. 81, no. 381.

Ph. subcuticulare, hysteriforme; sporophoris sporis utrinque apiculatis, subaequalibus. - Berk. 1. c.

Ad sarmenta arida Vitis species indeterminatae. America septentr.: Carolina septentrionalis. (Ravenel.)

Von diesser und den vorhergehenden heiden Species war es mir leider nicht möglich, mir Original-Kxemplare zu beschaffen, ich muss demzufolge mich darauf beschränken, eine Uebersetzung der, leider, äusserst nurollkommen und bündig abgefassten Dia- 
gnosen und Beschreibungen der Antoren zu geben. Phoma pallens wuchert unterhalb der Cnticula der Reben, die Perithecien sind denen eines Hysterium ähnlich; die Sterigmata sind mit den Sporen von ziemlich gleicher Länge, diese letzteren sind oblongspindelfürmig;, an einem Ende zugespitzt und 0.0002-0.0003 englische Zoll lang. Diese Art wächst anf trockenen Ranken einer Vitis-Art, welche in Folge des Auftretens dieses Parasiten ausgebleicht werden. - Nordamerikanische Union: in Nord-Carolina. (Ravenel.)

\section{Phoma Cookei Pirotta.}

Pirotta, funghi parassiti dei Vitigni p. 55. - I'homa Titis Berk. et Br. in Cooke, Fungi britamici exsice. no. 618. - Id. Ser. II. no. 14. - Id. in Grevillea III. p. 177 .

Ph. peritheciis gregariis, minutissimis, vix subprominulis, nigris, epidermide ostiolo eonico minuto perforantibus; sterigmatibus brevissimis, erectis, tenuibus; sporis oblongo-cylindricis, utrinque rotundatis, non vel obsolete nucleatis, achrois vel raro dilute griseis, $6-9 \mathrm{~mm}$. long., $3 \mathrm{~mm}$. crass.

Ad sarmenta arida Vitis viniferce Lin., Kings Lynn, Angliae. (C. B. Plowright.)

Von Phoma Tritis Bon., mit welchem, wic es den Anschein hat, diese Art oft verwechselt wird, unterscheidet sie sich in vieler Hinsicht sehr auffallend. Ersteres lebt zumeist anf lebenden, unsere vorliegende Art ansschliesslich auf abgestorbenen, ausgebleichten Reben. Unser Phoma bildet sehr kleine, kanm bemerkbare, gesellig, jedoch nicht dicht bei einander stehende, kaum hervorragende, schwarze Perithecien, welche durch cinc kurze, winzige Mündung, womit sie die Epidermis durchbrechen, die Sporen entleeren. Diese letzteren bilden sich an den Spitzen äusserst kurzer, fadenförmiger, aufrecht stehender Sterigmen, sie sind oblong-cylindrisch, an beiden Enden abgerundet und haben keinen Nucleus oder höchstens dic Andeutung cines solchen, ihre Farbe ist wasserhell, manchmal mit einem schwachen granen Schimmer, die Grösse beträgt $6-9 \mathrm{~mm}$. in der Länge und $3 \mathrm{~mm}$. in der Breite. - Mit eben so vielem Rechte könnte man wohl diese Art zu Sphaeropsis stellen. Ich kenne sie bisher nur aus der Gegend von Kings-Lymn und Terrington St. Clements, 
Norfolk, in England, wo sie von C. B. Plowright anf ganz dïrren Reben von Vitis vinifera Lin. gefunden und in den beiden oben genannten Sammlungen englischer Pilze ausgegeben ward. (Tab. II. fig. 12.)

\section{Leptothyrium Passerinii Thïm. nor. spec.}

L. peritheciis magnis, gregaris, late lineariformibus, planis, seriatis, subepidermalibus vel epidermide perforantibus, glanconigris, sublaevibus; sporis perpancis, tenuissimis, minutissimis, ovoideis, utrinque rotundatis, simplicibus, athrois, $1.5-2 \mathrm{~mm}$. long., 1 mm. crass.

Ad samenta subputrida Titis viniferre Lin. Vere. Italia: Parma. (C. Passerini.)

Eine Form der Gattung Lequthyrium, wolche von allen bisher bekannten ganz und gar verschieden ist. Sic bildet ziemlich lange, in Lïngsreihen angeordnete, breit-strichförmige, ganz flache Perithecien von mattschwäm Holzsubstanz und durchlorechen an denjenigen Stellen, wo die todte Rinde noch vorhanden ist, dieselbe; die nur vereinzelt anftretenden sporen sind ungemein klein, bei $15 \tilde{5}-2 \mathrm{~mm}$. Iänge besitzen sie nu $1 \mathrm{~mm}$. Breite, sie sind sehr zart, eiförmig, oben und unten abgerundet, einfach, farblos. - Anf halbfaulenden Ranken von Vitis vinifera Lin., dem gemeinen Weinstocke ward diese Species in Ober-Italien bei Parma im Frihjahre von Herrn Professor G. Passerini entdeckt; die Benenunng zu Ehren des Entdeckers möge dieser hochbegabte beriihnte Botaniker, dessen guitiger Unterstiitzung ich so viel verdanke, freundlichst als ein ganz geringes Zeichen meiner Hochachtung und Fremischaft amehmen. (Tab. III. fig. כ.)

Leptothyrium perpusillum Pass. et Thüm. nor. spec.

L. peritheeiis minutissimis, gregariis, subprominulis, subconicis, epidermide perforantibus, liberis, atris; sporis eylindraceoellipticis vel subelavulato-eylindricis, rectis, vertiee obtuso-rotundatis, subdilatatis, basi minime angustatis, uniseptatis, nedio non constrictis, numerosissimis, hyalinis, $6-8$ mm. long., 3 mun. crass. 
Ad sarmenta arida Vitis vinifercue Iin. Italia: Parma. Hieme 1877. (G. Passerini.)

Dieses, bisher noch mbeschriebene Leptotlyyium bildet eine Unmenge winzig kleiner, ziemlich gleichmässig vertheilter Perithecien, welche die Rindenoberhant durchbohren, von fast kegelförmiger Gestalt, nielıt von der Epidermis bedeckt und tiefschwarz von Farbe sind. Die zahllosen, kleinen Sjoren sind entwerler elliptisch-cylindrisch, orter, jerloch weit seltener, kenlenförmig-eylindrisch, indem sie an ihrem oberen Ende etwas breiter als am unteren sind. In der Mitte haben sie eine scheidewand, sind jedoch an derselben nicht eingeschnïrt, beide Enden sind abgermelet, die Farbe ist wasserhell, die läinge betriggt $6-8 \mathrm{~mm}$, die Breite $3 \mathrm{~mm}$. - Bei Panma in Ober-Italien ward diese Art auf trockenen Ranken des gencinen Weinstockes, Vitis vinifera lin., im Winter 1876 zu 1877 von Herrn Professor C. Passerini anfigefunden und mir fremullichst mitgetheilt. (Tab. Il. fig. 10.)

\section{Leptothyrium longisporum Thïm. et Pass. nov. spec.}

I. peritheenis parvulis, dense gregariis, in epidermidis partibus expallescentibus, imposito-prominulis, subeompresso-globosis, atris; sporis sterigmatibus faseiculatis, phus mims longis, rectis, temuibus, hyalinis fultis, eylindraceis, subrectis vel minime curvatis, simplicibus, utrinque obtnso-rotundatis, achoris, $20 \mathrm{~mm}$. long., 4-4\% mm. crass.

In Titis vimiferae Lin. samentis aridis. Italia: Parma, Vere 1877. (Passerini.)

Auf beinahe ganz weissgebleichten Reben, welche ihre Rinde bereits verloren haben, stehen in grosser Anzalnl, dicht bei einander die kleinen Perithecien dieser Art. Sie ragen nur etwas hervor und man kann sie eigentlich aufsitzend nennen, ihre Gestalt ist zusammengedrickt-kngelig, die Farbe tief schwarz. Auf langen, bündelfürmig an Grunde vereinigten, geraden, zarten, wasserhellen Sterigmen werden die Sporen gebildet. Diese sind ebenfalls lang, cylindriseh, fast gerade oder wenigstens nur etwas gebogen, an beiden Enden stumpf-abgerundet, ohne Scleidewände und ganz farblos. Ihre Länge betriigt $20 \mathrm{~mm}$., ihre Breite 4 bis $4.5 \mathrm{~mm}$. - An abgestorbenen Ranken des gemeinen Weinstockes, 
Vitis viniferc Lin. bei Parma in Ober-Italien, im Frühjahre 1877 von Professor Passerini anfgefunden und mir mitgetheilt. (Tab. III. fig. 12.)

\section{Cychpora incerta 'Thiom.}

Cytispma Vitis Schulzer in Verhandl. d. zoolog. botan. Gesellschaft zu Wien. XX. 187.. p. 647. - Pirotta, funghi parassiti dei Vitigni p. 67.

C. psendoperitheciis diversis, aut simplicibus ant conjunetis, temissimis, parte emmerso nigris, plemmque immersis, postremo evanescentibus; hyphis paulhulo ramosis; sporis cylindrico-curvatis, hyalinis, $6 \mathrm{~mm}$. long.

In sarmentis emortuis Titis viniferde Lin. - Slavonia. (Schulzer.)

Die Beschreibung dieser Art gibt der Autor a. a. O.: ,Säckchen sehr verschieden, bald einfach, bald mehrere verbunden, immer aber überaus zart, meistens farblos, der hervorbrechende Theil schwarz. Sie wohnen im Baste, oft beinahe bis ins Holz eingesenkt, und bilden nach abgefallener Oberhaut Pusteln von $1 / 4$ - $1 / 5$ I inie Länge. Sie öfnen sich länglich, und zwar noch vor der Reife; später verschwindet der ganze obere Theil. Inwendig sind sie iiberall mit einer zelligen Bekleidung versehen, von welcher ästige Hyphen entspringen, welche an den zugespitzten Zweigenden gekrümmte, cylindrische, wasserhelle Sporen von (j mm. Tainge erzengen. Kern trocken oder im unreifen Zustande schwarz, im reifen Zustande angefenchtet, immer weissgran. Gegen Ende Juli zum Theile noch mreif. Gesellig mit Leptosphaeria Vitis Sethlz1. und ihren Nebenformen, besonders aber mit Sphaerella samentomum Pirotta (Sphaerella Vitis Schlzr.) - An Stellen, wo sich die Oberhant noch nicht spontan vom Baste löste, lelote gruppenweise in nächster Nähe dieses Pilzes die genannte Sphaevella, allgemein aber noch so umreif, dass der Kern beinahe ganz aus verflochtenen Hyphen und zahlreichen Plasmakïgelchen verschiedener Crösse bestand; nu einzelne Schläuche und ausgebildete Sporen constatirten die Identität der Art". - In Slavonien auf abgestorbenen Ranken von Vitis vinifera Lin.

Da der Autor sich in vornehmer Ignoranz entweder iiber alle Gesetze der botanischen Nomenelitur hinweghebt oder aber, was wohl wahrscheinlicher ist, mit Ausnahme der klassisch- 
merkwürdigen Schriften Bonorden's und seinen eigenen Schöpfungen ron der ganzen botanischen, respective mykologischen literatur keine Ahmung hat, so war ich abermals gezwnogen, seincn Trivialnamen zu änderı, dem gerade neunumlzwanzig Jahre vor Herrn Schulzer von Mïggenburg hat schon Montagne eine Cyfisporce litis, die folgende Species, anfgestellt! Teh wïhlte den Fpeeiesnamen, ,incerta", da mir nach der ganzen Beschreibung es mehr als zweifelhaft int, dass dieser Pilz eine Cytisporre ist, wenigstens wird von dem Heranstreten der Sporen ans der Oeffinung in gelatinösen Ranken, was das Hamptunterscheidungsnerkmal der Gattung von den verwandten ist, kein Wort gesagt! Gott weiss, was da Merr Schulzer wieder gesehen hat; allerding's ist anch die Vermuthung nicht ganz ausgeschlossen, dass die vorliegende Species mit der Montagne'schen identiseh ist nud nur des rankenförmigen ILeranstretens der sporen gar nicht gedacht ward.

\section{Cytispora Vitis Intg.}

Montagne in Mérat, Revue de la flore parisienne p. 138. -- Id. Sylloge plant. cryptog. 1. 260, no. 925. - Pirotta, funghi parassiti dei Vitigni p. 67.

C. conceptacnlo nullo; cellulis irregularibus, circinatibus, epidermide tectis, disco nigrescente, poroso; cimhis succineis; sporophoris parietalibus, eentrum versus cellularun convergentibus; sporas cylindricas, corvulas fulcientibus. - Mntg. 1. e.

In sarmentis emortuis Titis viniferae Lin. Paris, Galliae. (Mérat.)

Die eigentlichen Peritheeien fehlen dieser Art, sie bestehen nur ans unregelmäissigen, kreisfümig gestellten, von der ()berhaut bedeekten, einzelnen oder sich berührenden, farblosen $/$ ellen mit einer schwarzen Scheibe in der Mitte. Die hervorgestossenen Sporenranken sind honigfarben, die Basidien odor Sterigmen sind gleich lang, gegen das Centrum hin eonvergirend, sic tragen an ihrer Spitze dic cylindrischen nur wenig gebogenen Sporen. Die '/usammengehörigkeit dieser speeies mit der, von mir Cytispora incerta genannten Schulzer'schen Art, ist meines Erachtens nicht auszuschliessen, ohne jedoch Original-Exemplare beider Formen verglichen zu haben, ist diese Frage nicht endgiltig zu entsehejden. - Auf diuren Ranken von Titis vinifera I in. bei Paris von Mérat entdeckt nud seitrlem nicht wieder aufgefunden, 


\section{Cytispora coryneoides Berk. et Curt.}

Berkeley, Notices of North American Fungi in Grevillea II. p. 99.

Die Autoren beschränken sich a. a. (). darauf zn bemerken, dass unter obigen Namen eine C'ytispora mit wurstförmigen Sporen auf Vitis Labruscn Lin. wachsend, sub no. 5938 vertheilt worden sei. Ausser dieser lakonischen Notiz war ïber diesen Pilz niehts weiter in Erfahrung zu bringen. Gesammelt wurde er, wie ersichtlich, in Nord-Amerika.

\section{Cytispora chrysosperma Fr.}

Fries, Systema mycologienm II. p. 542. - Wallroth, Fl. cryptog. germ. p. 751, no. 3639. - Rabenhorst, lentsclll. Kryptogamen-Flora 1. 146, no. 1325. Fnekel, Symb. myeol. p. 198. - Cuoke, Handb. of British Fungi p. 462. Westendorp, Les cryptog. d'apries 1. stat. natur. 1) 106. - Nremasporce chrysosperme I'ers. Syn. fung. 1. 108. - Martins, Fl. Erlang. p. 498. - Roehling,

Dentschl. Flora p. 76. - Sphaeria cimhata Sowerby, Fungi Tab. 138.

C. ecllulis in eonceptaculo inclusis, liseo erumpente, nigreseente, cirrhis luteis. - Conceptaculum orbieulare, conicum, basi convexa, seutellari in cortice interiore immata et superne epidermide adnata inensum, rnare hac rupta laceratur et demudatur huic inclusum stroma olivaceo-cinerascens pulverulentum, humidum vero nigreseens, quod superne ermpit formatque discum exiguum, sordidum, rugosum, difformi-subrotundum, ostioli centrali, nigro, per quod protruditur gelatina eirrosa. Cellulae difficile discermuntur, oblonga, atra cera concolori farcta, sed humejacta gelatina flava turgent, ostiolis in collum centrale junctis. Fr. l. c. - Sprorae simplices, hyalinae, cylindricae vel cylindricosubfusiformes, utrinque obtuso-rotundatac, $4 \mathrm{~mm}$. long., $1.5 \mathrm{~mm}$. erass., numerosissimae.

In Vitis viniferae Lin. sarmentis emortuis. Belgium. (Westendorp.)

Auf der alogestorbonen Rinde verschiedener Populus-Arten, sowie auf Ailantlus glandulosa Desf. ist dieser Pilz sehr gemein und wohl iiberall zu tinden, auf Weinreben jedoch wird er, mit Ansnahme der citirten Stello bei Westendorp, von keinem einzigen Botaniker aufgezählt. Und doch kann man unmöglich annehmen, dass ein so genialer Mykologe wie Westendorp, dessen seharfer, 
sicherer Unterscheidungsgabe wir so viele gute nene Pilzspecies, namentich Mikromyceten verdanken, sich geint labe. Fis wird daher ainsserst wiinschenswerth sein, wem die Cytispore chysosperma recht eifrig auf Weinreben gesncht werde. Der Pilz bildet nieht sehr grosse, aber dicht beieinauder stehonde, zerstrente Perithecien, welehe die Rindenoberhant durchbrechen und dieselbe kegelförmig un das Centrum herum heben. Dic Farbe dor Perithecien ist für gewöhulich schwarz, matt mul ihre kaum sichtbare Scheibe ist schr klein. Tritt jerloch fenchte Witterung cin, so verïndert sich wie mit einem Zauberschlage das ganze Ansselsen des Pilzes. Dic kleinen und unscheinbaren, fast rersteckten und verdeckten Perithecien sehwellen an und aus dere num dentlich wahruehmbaren Scheibe treten tief goldgell gefirbte Sehleimmassen hervor. Dieselben ergiessen sich in spiralförmiger Rankengestalt rund um die Perithecien herum, rerfliessen hiantig und bilden daun, wenn sie an der I uft erhärtet sind, of Massen von :-5 Mn. in Halbmesser, welehe die verschiedensten Formen annehmen. In diesem goldgelloen Sehlein mun sind dic in ungezïhlten Massen vorhandenen Śporen eingebettet nind werden mit ilnen entleert. Die Sproren selbst sind cylindrisch oder eylindrischspindelföming, einfach, an beiden Enden stump,f-abgerundet, cutweder gerade oder renig gekrimmt, farblos und messen $4 \mathrm{~mm}$. in der Iänge und $1.5 \mathrm{~mm}$. in der Breite. - Vou Westendorp ward dieser Pilz auf todten Ranken von Titis viniferch Lin. in Belgien gefunden. (Tal. I. tig. 17.)

\section{Hormococens olirascens Sace.}

Saccardo, Michelia 1. p. 94, no. 91. - Id. fungi italici autogr. delineati no. 91.

H. peritheciis (spuris?) sparsis vel subcaespitulosis, inutoerumpentibus, e globoso-conoideis, vertice applanatis, astomatis, quandoque (eollabescendo?) disciformibus, atris; sporophoris dense fasciculatis, filiformibus, simplicibus, furcatis vel fasciculato-ramosis, 25-30 1mm. long., 1.7-2 $\mathrm{mm}$. crass., septulatis, liyalinis, apice in spermatia eylindracea, $3-6 \mathrm{~mm}$. longa, $15-2.5 \mathrm{~mm}$. crassa, utrinque obtusa, continua, olivacea abeuntibus. -- Sace. l. c.

In sarmentis corticatis putrescentibus ritis viniferae lin. Venetia. (Saceardo.) 
Die Mäufchen oder muechten Perithecien dieses Pilzes stehen zerstrent oder zu kleinen Colonien verbunden, sie sind wenig hervorragend, von rund-kegelförmiger Gestalt, am Scheitel etwas abgeplattet, manchmal dadurch fast scheibenförmig werdend, sehwarz und ohne Miundung; die sporentragenden Basidien oder Sporophoren sind fadenförmig, zu dichten Bündeln vereinigt und büschelfümig sich veräistelnd, $25-30 \mathrm{~mm}$. lang, 1.7-2 $\mathrm{mm}$. dick, vielfach und sehr kurz septirt, farblos, an ihren Sipitzen tragen sie die kurz cylindrisehen Sporen rou $3-6$ mm. Iänge und $1.5-2.5 \mathrm{~mm}$. Dicke, welche beiderseitig abgestumpft sind, keine Seheidewand besitzen und von olivenbrännlicher Farbe sind. - Saccardo fand diesen hübschen nenen Pilz auf faulenden, berindeten Ranken von Titis rinifera Lin. in Tenetien; ausserdem koumt el aber auch noch auf den Aestchen einer ganzen Reibe anderer Bäume und Sträucher vor. (Tab. IV. tig, 13.)

\section{Ifrothecium Vitis Bon.}

Bonorden, Handbuch der Mykologie p. 143 , Tab. X. fig. 215. - Schulzer in Verhandl. d. zool-botan. Gesellschaft zu Wien 187(1, p. 64:2. - Pirotta, funghi parassiti dei Vitigni p. 74 , Tal. XII. fig. 25-27.

II. receptaculis subpezizaeformibus, candidis, ca. 0.7-1 Mm. latis, hymenio viridescente rel nitente, disco dilutissime griseo; basidiis simplicibus, sterigmatibus quatuor, sporas magnas, ovales vel rotundas, hyalinas, pellucidas, 14 mm. long., $4 \mathrm{~mm}$. crass. gerentibus.

Ad samenta arida Vitis viniferce Lin. Guestphalia (Bomorden), Slavonia (Schulzer).

Dieser Pilz bildet sehr kleine, an eine Peaizu erinnernde, weissliche, $0 \cdot 7-1 \mathrm{Mm}$. breite Receptaculi oder Fruchtager, deren Iymenium glänzend griunlich und deren Scheibe sehr hellgran ist; die Basidien sind einfach, sie tragen auf ihren rier Sterigmen oder Trägern die grossen eiförmigen oder rundlichen Sporen von wasserheller Fairbung und $14 \mathrm{~mm}$. Lainge bei 4 mm. Breite. Anf diurren Ranken von Titis vinifera Lin. in Westphalen von Bonorden, in Slavonien von Schulzer gefunden. 


\section{Cryptosporium ampelinum Thüm.}

Thïmen in Oesterr. botan. Keitschr. 1877, P. 271. - ? Pirotta, funghi larassiti dei Vitigni p. 49.

(. peritheeis ninutis, primo tectis, demum epilermide perforantibus, sarpe seriatis, subplanis, compresso-globosis, nigris; sporis eylindraceis, rectis, continnis, utrinque minine obtusis, 10-14 mm. long., 1-15 $\mathrm{mm}$. crass., hyalinis. - I'otins Comptovalsae ampelinae Fuck. (Ialsa ampelina Nke.) Symb. myeol. p. 212, fumgrs spermatifferus, sed sporarum dimensio non quadrat.

In samentis subputrilis Vitis ciniferce Lin. Austria inferior. Hieme 1877. (Thümen.)

Die ungemein kleinen Peritheeien dieses P'ilzes stehen znmeist dieht gedrängt in den flachen Rillen der Reben, sie sind Anfings von der Oberhant bedeckt, durchbohren jedoch spaiter dieselbe und haben eine etwas zusammengedriickt-kugrolige restalt, die Farbe ist ein mattes Sichwarz. Die ziemlich zahlreichen sporen sind gerade-cylindrisch, einfach nud an beiden Enden cin wenig abgestumpft, die Farbe ist wasserhell, in rler Länge nessen sie 10-14 mm., in der Breite $1-1.5 \mathrm{~mm}$. - Wenn von den Maassen der Sporen abgeschen wird, so ist vorliegender Pilz illentisch mit demjenigen, welchen Fuekel auf Seite 212 seiner", $\mathrm{Sym}$ bolae mycologicae" als Spermogonienform zu seiner Cryptoralsa ampelina (Valsa ampelina Nke.), s. w. o. 1). 106, zieht. Fr beschreibt denselben a. a. O. folgendermassen: "(Peritheciis spermatiiteris seriatis peritheciis aseigeris plane aequalibus; spermatiis copiosis, cylindraceis, utrinqne obtusis, rectis, continnis, hyalinis, $16 \mathrm{~mm}$. long., $2.5 \mathrm{~mm}$. crass.). Perithecien reihenförmig angeordnet, denjenigen der Schlauchform ähnlich; Spermatien, d. l. Sporen, zahlreich, cylindriseh, beiderseits abgestumpft, gerade, einfach, wasselhell, $16 \mathrm{~mm}$. lang, $2.5 \mathrm{~mm}$. dick." - Man sieht, dass also dic Beschreibung von Perithecien sowohl, als auch von den Sporen vollkommen übereinstimmt, nu die Grösse gibt Fuckel anders an! Da nun aber ziemlich oft die Fuckel'sehen Dimensionen etwas nugenan angegeben sind und selbst bei Exemplaren, welche er selbst vertheilte, durchaus nicht immer genau stimmen, so glaube ich mit ziemlicher Sicherheit mein Cryptosporium mit seinem Spermatienpilz von Cryptovalsa ampelina identificiren zu 
können. - Auf halbfaulen oder wenigstens ziemlich lange im Freien gelegenen Reben des gemeinen Weinstockes, Vitis vinifera Lin., in Nieder-Oesterreich (Thïmen) und (wemn meine Vermuthungen sich bestätigen) in Nassau (Fuekel). (Tab. V. fig. 12.)

\section{Vermicularia compacta Cooke et Ell.}

Cooke et Ellis in Grevillea V. p. 54. - Pirotta, funghi parassiti dei Vitigni p. 64 .

V. peritheciis gregariis, hispidis, atris, distinctis, compactis; sporis fusiformibus, curvulis, utrinque acutis, nucleatis, demum septatis. - Cooke et Ell. 1. c.

Ad samenta Titis viniferce Lin. America septentr.: NewJersey. (J. B. Ellis.)

Ich besitze keine Exemplare dieser ganz neu aufgestellten Species, muss mich dennach in der Besehreibung an die kurzen Mittheilungen der Autoren halten. Barnach sind die Perithecien in ganz regelnässigen Zwischenriumen dicht nebeneinander stelienrl, sie sind schwarz, rauh, fest und umgeben auf cine Länge von mehreren Zollen die Reben vollständig, wodureh letztere ein ganz eigenthiumliehes, raulies Ausschen erhalten. Dic Sporen sind spindelfömign, gebogen, an beiden Enden zugespitzt, haben Anfangs Nuclei, aus welchen sich s] äterhin Scheidewände entwickeln und nossen $20 \mathrm{~mm}$. in der Lïnge. - Im nordamerikanischen Staate New-Jersey von J. B. Ellis an Ranken von Titis vinifera Lin. entdeckt.

\section{Cheilaria Vitis Sehlzr.}

Schulzer in Verhand1, des zool.-botan. Gesellschaft zu Wien XX. 1872, p. 645. - Pirotta, funghi parassiti dei Vitigni p. 67.

Ch. peritheciis induratis, nigris, crassis, verucosis, demum tunicatis; lryplis tenuibus, filiformibus, hyalinis; sporis oblongis, utrinque angustato-rotundatis, quinqueseptatis, minime constrictis, dilute fuscis, episporio erasso, 22-28 m1n. long., 6-8 mm. crass.

In Vitis riniferae Lin. sarmentis emortuis. Slavonia. (Schulzer.)

Nachstehende Beschreibung in deutscher Sprache gibt der Autor a. a. ().: "Perithecien dick, fest, schwarz, aussen höckerig, 
geöfhiet sehalenförmig, $1 / 5-1 / 5$ Linie breit, inwendig mit zarten Hyphen bekleidet, welche in der Gesammtheit braungelb sich darstellen, einzeln aber unter Wasser völlig durchsichtig sind. Jede trigt an der Spitze eine oblonge, beiderseits vertiinnt abgerundete, 22-28 $\mathrm{mm}$. lange, 6-8 mm. dicke, in der Mehrzahl fünfmal septirte, etwas gekerbte, lichtbrame Spore, deren Septa und Contouren auffallend stark sind, nur der Umriss der beiden Endzellen ist schwach. Ueber den Sporen, bis zum Rande der Schale ist diese mit einer völlig hyalinen, im Wasser mnlösbaren Masse ausgefüllt". - Diese Species, welche in Slavonien auf' alsgestorbenen Reben von Vitis vinifera Lin. aufgefunden wurde, ist mir vollkommen unbekannt.

\section{Polynema Vitis sehlzr.}

Schulzer in Verhandl. der zool.-botan. Gesellschaft zu Wien XX. 1872, 1. 647. - Pirotta, fungli parassiti dei V'itigni p. 91.

P. peritheciis ermpentibus, stromaticis, rotundis, flavo-fuseis, diseo ceraceo-flaveseente, pillosis, pilis tubato-flaridis, aequalibus, sursum setaceis; sporis dense gregariis, bacillacformibus, hyalinis, simplicibus, 5-7 $\mathrm{mm}$. long., $3 \mathrm{~mm}$. crass.

In sarmentis aridis Titis viniferce Lin. Slavonia. (Schulzer.)

Von dieser Art gibt Sehulzer a. a. O. nachfolgende dentsche Beschreibung: „Der Pilz scheint auf'gewachsen zu sein, aber beim Durchschneiden sieht man, dass er hervorbrach, und dass das die Fruchtscheibe tragende Receptaculum noch einer Art Stroma anfsitzt, wie es einigen Cenangiacei eigen ist. Dieses hat weit grössere Zellen als der obere 'Theil, ist gleich diesem wachsartig und sehr lichtgelb]ich, ferner bald stark ausgebildet, bald von geringer Maichtigkeit, jedoch immer vorhanden und stets im Standorte verborgen. Dem Stroma ist das zu 'lage stohende Receptaculum gleichsam eingefügt, aber wegen des auffullenden Grössenunterschiedes der beiderseitigen Zellen die Grenze dentlich sichtbar. Der vorstehende Theil des Pilzes ist anssen trübbramgelb, rundlich, bei trockenem Wetter am Scheitel vertieft, bei feuchtem schalenförmig geöffnet, mit wachsartiger, gelber S'cheibe, die in der Jugend eine körnige Decke hat, 1/6-1/5 Linie breit, und an der Aussenseite mit trübgelben, unter Wasser durehscheinenden, stellenweise Plasma führenden, jedoclı nicht septirten, 
iiberall gleich dicken Haaren dicht besetzt, welche an der Basis borstenförmig-straff abgehen, oben dagegen wirr durcheinander sich gegen den Scheitel wenden, wo sie dic Schalenöffnung, besonders bei trockenem Wetter röllig verschliessen. Das obere eigentliche, sich zur Schalenform iffnende Receptaculum besteht an der ganzen Innenwand aus kleinen Zellen, auf welchen dicht gedrängt die unter Wasser völlig farblosen, stabförmigen, 5 bis $7 \mathrm{~mm}$. langen und kaum $3 \mathrm{~mm}$. dicken, einfachen Sporen entstehen. - Zwischen Juli und August mit Myrothecium Vitis Bon. in gemischten Gruppen. Ansser diesem und Fusoma Titis Schlzr. waren noch ganz in der Nähe dieses Pilzes Cucurbitaria Vitis Schlzr., Leptosphaeria Titis Schlzr. и. a. m." - Diese Species, welche mir ebenfalls ganz umbekannt ist, ward an todten Reben ron Vitis vinifera I in. in Slaronien anfgefunden.

\section{Discosia Vitis Schlzx.}

Schulzer in Verhandl. der zool.botan. Gesellschaft zu Wien XX. 1872, p. 645. - Pirotta, funghi parassiti dei Vitigni p. 64.

D. peritheciis duris, nigris, globosis, opereulosis; hyphis simplicibns, hyalinis, sporas gerentibus; sporidiis ovato-fusiformibus, triseptatis, plerumque subeurvulatis, minime crenulatis, utrinque ciliatis, eiliis hyalinis, achrois vel subhyalinis, $22 \mathrm{~mm}$. long., $5 \mathrm{~mm}$. crass. (sine ciliis).

Ad sarmenta emortua Titis vinifercue Lin. Slavonia. (Schulzer.)

Die Beschreibung a. a. O. gibt der Autor wie folgt: „Ein schwarzes, hartes Perithecium ist blos oben als Decke vorhanden, die anderen Theile sind scheinbar nur von der Substanz der Wohnpflanze umschlossen. Dieser Raum ist fast kugelig, beiläufig $1 / 10$ Zoll breit, und hat zwar ringsherum eine zarte Bekleidung, jedoch nur an der Basis eine mächtige Zellenschicht, von welcher allein fruchtbare, einfache, hyaline Hyphen entspringen, deren jede einc Spore erzengt. Diese sind spindelförmig-oval, dreimal septirt, meist etwas gekrimmt, ein wenig gekerbt, an jedem Ende mit einem cilienförmigen Fortsatze verschen, welcher gleich den Endfüchern - hyalin ist, während die zwei übrigen Fächer eine lichte Färbung haben. Letztere besitzen starke Contouren, erstere nicht; auch die Septa sind schr stark. Ohne wimperartigen Fortsatz betrïgt die Länge der Sporen $22 \mathrm{~mm}$. 
und die Dicke $5 \mathrm{~mm}$. In Januar mit Gibbera Vitis Schlzr. und den dieselbe begleitenden Pilzen unternischt, meistens jedoch mit der Gibbera in demselben Rasen". - In Slavonien anf abgestorbenen Reben des gemeinen Weinstockes, Vitis vinifera Lin., von Schulzer gefunden. - Mir unbekamnt.

\section{Septoria falx Berk. et Curt.}

Berkeley, Notices of North Ameriean Fungi in Grevillea III. p. 11, no. $446 \mathrm{~b}$. Pirotta, fungli parassiti dei Vitigni p. 66.

S. ramnlicola; peritheciis erumpentibus, majoribus; sporis filiformibus, curvis, pedicellis aequilongis. - Berk. l. e.

Ad sarmenta Vitis species indeterminatae America septentr.: Carolina australis. (H. W. Ravenel.)

Diese, von den Autoren als "sichelförmige Septoria" bezeichnete Art liegt mir nicht vor', ich muss demzufolge mich damit begnügen, die weiteren, äusserst dürftigen Bemerkungen a. a. O. zu reproduciren. Die verhältnissmäissig grossen Perithecien brechen aus den Ranken hervor, die Sporen sind gebogen, kurz, sehr schmal, fadenfürmig und gleichen einer Sichel, indem sie an einem diunnen Stiel, einer Basidie, welche gerade nud mit der Spore von gleicher Liinge ist, befestigt sind. - An diurren Ranken einer nicht näher bezeichneten Vitis-Art vou H. IV. Ravenel im nordamerikanischen Staate süd-Carolina entdeckt.

\section{Septoria Mïggenburgii Pirotta.}

Pirotta, funghi parassiti dei Vitigni p. 66. - Septoric I'itis Schlzr. in Verhandl. der zool.-botu. Gesellschaft zu Wien XX. 1872, p. 617.

S. peritheciis globosis, minimis, atris, omnino immersis, dein vertice obtuso apertis; sporis absconditis, bacillo-fusiformibus, curvatis, vix coloratis, octiseptatis, septis indistinctis, novem nucleatis, $48-63 \mathrm{~mm}$. long., $3 \mathrm{~mm}$. crass.

In sarmentis emortuis Vitis viniferae Lin. Slavonia. (Schulzer.)

Des Autors Beschreibung lautet a. a. O.: "Das schwarze, kugelige, aus sehr locker verbundenen Zellehen bestehende säckchen ist ganz in die Rinde cingesenkt und offhet sich -- diese mit dem stumpfen Scheitel sprengend - schr weit. Ueberaus klein und nur zufällig durch Abschnitte zu finden. Das Säickehen 
geht nach imnen in eine braungelbliche Bekleidung iiber, von welcher an der Basis die karm etwas gefärbten, stab-spindelförmigen, 48-63 mm. langen, $3 \mathrm{~mm}$. dicken, gekrimmten Sporen entstehen, welche gewöhnlich neun Sporidiolen führen, was auf acht Septa deutet, ron welchen ich im Juli jedoch kam hier und da eine zweifelhatte spur beobachtete. Vergleicht man die Länge der Sporen mit der kamm die Hälfte davon betragenden Höhe des Säckchens, so muss man schliessen, dass sie ror dem Oeffnen desselben darin sehr verborgen gelagert sein mïssen. Beinahe anstossend mit Cucurtitaria Tritis Schlzr., doch anch in der Nachbarschaft der Leptosphaevia Vitis Schlzr. und ihren Nebenformen". - In Slavonien anf todten Ranken ron Vitis vinifera Lin. gefunden. - Mir rollkommen unbekannt. -- Der Name Septoria Vitis ward bereits im Jahre 1846 ron Leveillé vergeben, musste demnacl geändert werden. Uebrigens wieder ein eclatanter Fall mangellaftester Literaturkenntniss ron Seite des Herrn Schulzer.

\section{Sclerotium salmenticolum Thitm.}

Thümen in Oesterr. botan. Zeitschr. 1877, p. 27.3.

S. sparsum rel solitarim, oblongum, epidermide perforandum, demum elevatum, liberum, subconvexum, atrum, laeve, magnum, intus parum pallidius, granuloso-fibrosum. - Thïm. l. c.

In Titis viniferce Lin. samentis putridis. Austria inferior. Hieme.

Dieses Sclerotium, welches im Allgemeinen nicht gerade häufig ist, findet sich sowohl an alten Reben als auch an trockenen Wickelranken ron Titis vinifera Lin. Es bildet entweder rereinzelte oder zerstreut beisammen stehende, ziemlich grosse, erhabene, Anfangs ron der Oberhaut bedeckte, glatte, beinahe convexe Massen. Im Innern sind dieselben grauschwarz, von krümmelig-faseriger Structur. - Ob und eventuell zu welchem höheren Pilze diess Sclerotium als Danermycel zu ziehen sei, dariiber bin ich noeh rollstandig im Unklaren. Tch fand es bisher nur in Nieder-Oesterreich, im Winter, wie gesagt, ziemlich selten. 


\section{Ozonium anricomum Lk.}

Link, Ohservationes myeologicae I. p. 19. - Id. in Linné, Spee. plant. cura Willdenow VI. I. p. 138. - Fuckel, Symbolae mycologicae 1) 403. - Saccardo, Mycologia veneta p. 204. - Rabenhorst, Deutschl. Kryptogamen-Flora 1. 60, no. 581. - Wallroth, Fl. germ. cryptogam. p. 156. - Ozoniun fulvum Pers. Mycol. europ. I. 1. 87. - Byssns fulva Hunt. fl. I'riberg. 1. 02. - Byssus aresentiaca De C. Fl. franç. II. p. 6s.

0. thallo effuso, incumbente, floecis ramosissimis, vitellinis, extimis tenuissimis. - Strato valde expanso, ligmum sub cortice obtegit, tomentum efficit magis minusve densum, floccis magis minusve rigidis. Nudis oculis flocei crassiores a reliquis primo adspecta distinguuntur. Color magis minusve fulvus. Sub microscopio composito flocci in ramis majoribus deuse oppositi et paralleli sunt, septis nullis, in ramis minoribus solitarii ramosi, septis saepe creberrimis distineti. Nec vesiculas nee granta inspersa vidi. - L.k. I. e.

In sarmentis subputridis Vitis viniferce lin. Venetia, pr. Conegliano. (C. Spegazzini.)

Schon seit langer Zeit weiss man, dass die Arten von Ozonium, Dematium, Irypha n. s. w. keine selbstständigen Pilze, sondern höchst wahrscheinlich nur die sterilen Mycelien von einigen $\mathrm{Hy}$ menomyceten sind. Zu welchen Arten sie allerdings zu rechnen ist, das weiss man noch nicht, und so lange diese Unkemntniss danert, ist man fante de mieux gezwungen, diesen Gebilden ihren urspriinglichen Namen zu belassen! Die uns hier beschäftigende For'm bildet anf faulenden Reben, deren Rinde bereits abgefallen ist, ziemlich verbreitete, dicht an die Unterlage sich anschmiegende, zarte Rasen von einer, zwischen Dottergelb und Hochgelb die Mitte haltenden, Farbe. Die Fäden, woraus das Pilzgeflecht besteht, sind ausserordentlich zart und dïmn und selır stark verästelt. - C. Spegazzini fand diese Alt auf faulenden Ranken von Vitis rinifera Lin. bei Conegliano in Venetien. 
III. Die Pilze der Blätter.

\section{Die Pilze der Blätter.}

\section{A. Auf lebenden Blättern.}

\section{Peronospora viticola De By.}

De Bary, Ann. d. sc. natur. IV. Ser., Tom. XX. 1863, p. 125, no. 40. - Berkeley, Notices of North American Fungi in Grevilleit III. p. 109, no. 657. Farlow, Botanical articles in Bulletin of the Bussey Institution p. 415 sey. c, icon. 1876. - Ravenel, fungi Carol. exsice. V. no. 90. - De Thümen, Mycotheca universalis no. 617. - Botrytis canc Herb. Schwz. sec. Farlow 1. c.

P. caespitibus hypophyllis, effusis, densis, plus minus limitatis, saepe nervisequis, subcandidis vel sordido-albescentibus; hyphis erectis, diclo-vel trichotono ramosis, suberassis, hyalinis, 8-9 mm. crass., ramulis brevibus, apice brevi, tridenticulato, subaequali, hyalinis; conidiis paueis, ovoideis, utrinque rotundatis, laevibus, intus subgrumulosis, 12--15 mm. long., $8-10 \mathrm{~mm}$. crass., hyalinis vel pallidissime sublutescentibus.

Descriptio De Baryana 1. e.: P. mycelii tubi crassi, saepe constricti varicosique (hanstoria non vicli). Stipites conidifferi fasciculatin e stomatibus emergentes, graciles, elati, summo apice parum attemuto brevissime semel bisve dichotomi vel trifurcati; sub apice ramos plerumque, quadri vel sex, raro tri vel septem gerentes. Rami primarii plerumque alterni, distantes et exacte distichi, onmes pro stipitis altitudine breves; inferiores plerumque trifurcati dirisionibus iterum bis trifureatis vel quandoque bis dichotomis; rami ultimi (quanti) ordinis aerpe ac stipitis divisiones apicales, brevissiune conico-subulati recti, acuti. Rami primarii superiores minores, inferiorum secundariis vel tertiariis conformes. lami omnium ordinum angulis rectis patentes, primarii 
in $u$ o plano divaricati, planum ramificationum secundi orlinis in primario, tertiarorum in primario et secundario perpendieulare. (Rarius rami primarii 2 inferiores oppositi sunt, raro ramulis 2 alterius muniti nee trifureati, rarissime rami primarii iregulariter sparsi nee distichi sunt.) Conidia parvula, ovoidea, apice lato rotundata vel subtruncata, papilla destituta, membrana circumeirca aequali hyalina. Oogonia parva, membrana tenui, hyalina vel lutescente oosporam foventia subglobosam episporio tenui fuscente diaphano laevi munitam.

In foliis vivis Vitis Labruscae lin., Vitis aestimalis Mcchx., Vitis cordifolice Mchx, et Titis vulpinue Lin. in regionibus centralibus et atlanticis Americae septentrionalis, passim.

Dieser von den Amerikanern "Grape Vine Mildew" genannte Pilz hat sich in den mittleren und östlichen Staaten der nordamerikanisehen Union zu ciner wahren Pest des Weinbatues entwickelt und der durch ihn verursachte Schaden soll alljährlich ein bedentender sein. IIoffentlich wird er bei der, in den letzten Jahren lebhaften, Finfiihrung und Cultur amerikaniseher Rebsorten nicht anch nach Europa eingeschleppt. 1)enn die Angabe Frank's im dritten Bande der von ihm bearbeiteten "Synopsis der Pflanzenkunde" von lacunis, Hannover 1877, p. 1853, dass Peronosporr viticola anch in Ungarn bei Werschetz anfgetreten sei, berlarf noch der Bestätigung. - Die Peronospore bildet anf der unteren Blattseite nicht grosse, aber zumeist zahlreiche, manchmal zusammenfliessende Häufchen von sehmutzig-weisshicher Farbe, diese stehen zuweilen längs der Blattnerven geordnet, sind ziemlich fest ungrenzt und wie bei allen Arten der Gattung kriumelig-locker; auf der Unterseite bilden sic einen bräunlichen, ein klein wenig ins Violette schillemden Fleek, welchem oberseits ein meistens kleinerer hellstrohgelber entspricht. Die Hyphen stehen in verhältnissmässig dïmen, wenig zahheichen Bïndeh, sie sind ziemlich dick, $8-9$ nm., und haben eine zwei- oder dreitheilige Verzweigung, sie stehen aufrecht und sind von wasserheller Farbe. Die kurzen, dicklichen Zweige sind an den Spitzen kurz dreitheilig gespalten, saimmtliche Theile von nngefähr gleicher Länge. Die Conidien, welche sich an diesen Spitzen der Seitenästchen bilden, sind oval, oben und unten abgerundet, entweder farblos orler fast ummerklich hellgelb, anssen glatt, inwendig schwachkörnlig und ihre Grösse betrigt 12 bis 
$15 \mathrm{~mm}$. in der Länge, 8-10 mm. in der Dicke. - Nach Farlow a. a. O. finden sich Oosporen nur an Vitis aestivalis Mchx., dieselben sind sehr zahlreich, klein, haben ein glattes Episporium und sind hellgeblich. - Zu bemerken ist noch, dass der Parasit, wie es scheint, auf Titis Labrusca Lin. am schwächsten auftritt, wenigstens sind anf den in meinen Sammlungen befindlichen Exemplaren des Pilzes auf dieser Nälupflanze nur immer wenige, $3-t$ Räschen auf einem Platt, während ich andererseits Blätter von Titis aestivalis Mchx. besitze, deren Unterseite fast ganz mit Peronospora bedeckt ist. - Auf lebenden Blättern von Vitis Labrusca Lin., Vitis aestiralis Mahx., Titis cordifolia Mchx. und Vitis relpina Lin. in Norr-Amerika. (Tab. 1. fig. o.)

\section{Cladosporium Rösleri Cattan.}

Cattaneo in Bolletino Comiz. agrario Vogherese 1876. - Pirotta, funghi parassiti dei Vitigni p. s0). - Clarlosporimm pestis Thüm. in Oesterr. botan. Zeitschr. 1877, p. 12. - Id. Herbarium myeolog. oeconom. no. 419. - Id. Myeotheca universalis no. 671. - Id. Wiener Landwirthschaftl. Zeit. 1876, p. 541 c. icon.

Cl. maculis hypophyllis, gregaris, indeterminatis, irregularibus, dilute olivaceis, postremo fuseis, in foliorum pagina superiore maculam stramineam, demum fuscam formans; hyphis brevibus, simplicibus, interdum (sert ran) suluramosis, subfasciculatis, laevibus, septatis, pallide fuseis; sporis eylindraceis, utrinque angustato-rotundatis, non vel nui- vel biseptatis, ad septas non constrictis, 40-44 $\mathrm{mm}$. long., 6-8 mm. crass., coloris hypharum. - Thïmen 1. e.

In ritis riniferae Lin. foliis vivis. Anstria inferior ubique et vitienltorum vera pestis. Julio - autumno.

A. a. (3. in der "Wiener landwirthschaftlichen Zeitung" gab ich ron diesem Pilze die folgende Beschreibung: „Im August und September entstehen auf der Unterseite der Weinblätter unregelmässig zerstreute, kleine, später nur wenig sich vergrössernde Rasen von hellolivenbräunlicher Färbung. Die Zahl dieser Räschen wächst zusehends, ebenso werden sie dunkler; trotzdem ist auf der Blattoberfläche noch nichts zu sehen, was die Anwesenleit des Pilzes vermuthen lässt. Erst nach einigen Wochen, nachdem die Räschen eine dunkle Olivenfarbe angenommen laben, bemerkt man anch oberseits gelbe, bald brann werdende 
Flecken, welehe mit der fortschreitenden Entwickelung des Pilzes immer melı zunehmen und bald den grössten Theil des Blattes umfassen. Mitte Oetober sind die Pilzrasen fast seliwarz geworden und das Blatt zeigt auf seiner Oberfläehe zwischen grossen gelben eine ziemliche Anzalıl dunkelkastanienbranner Flecken. In diesem letzten Stadium ist jedoch rom Pilze selbst nicht mehr viel zu sehen; seme Vegetationszeit ist vorïber. - Unter dem Mikroskop zeigt der Pilz sehr kurze Hyphen oder Fïdeu, welehe zumeist ungetheilt, nur selten wenig istig sind und in liunnen Bïndeln zusammenstehen; sie sind äusserlich glatt, haben einzelne Qnerwände und eine hellbranne Farbe. An der Spitze dieser Hyphen werden nun die sehr zahlreichen Sporen abgeschnïrt; diese sind lang, eylindrisch, an beiden Enden etwas verschmälert und abgermudet, gerade, nur selten etwas gekrimmt, nicht septirt oder seltener mit einer, anch mit zwei Querwanden und von derselben Farbe wie die Hyphen. Thre I a inge beträgt $40-44 \mathrm{~mm}$., ihre Dicke $6-8 \mathrm{~mm}$.

Ueber diesen Pilz, weleher (mit mehreren anderen Pilzen, sowic durch Insecten remusachten Fleeken) den Namen des "schwarzen Brenners" führt und in den Weinbau treibenden Pezirken Nieder-Oesterreichs sehr gefürehtet ist, gingen und gehen, wenigstens zum Theil, dic Ansichten ganz ungehener auseinander. Von mehreren Seiten ward er früher als der Conidienpilz angesehen, welchen Fuckel in seinen "Symbolae mycologicae" p. 104 als Vorform seiner Spluerellre Titis beschreibt. Diesen Irrthum, welehen ich vor Jahren, als ich vorliegende Art nur nach diirftigen Exemplaren, welche mir eingesehickt worden, kannte, selbst zu theilen beinahe geneigt war, habe iclu dureh meinen ersehöpfenden Aufsatz a. a. O. definitiv beseitigt, ich stellte auch dort die Abbildungen beider Sporenformen emander gegenüber. Trotz diesen ansfïhrlichen Erklïrungen fand sich Herr Friedrich Haszlinsky veranlasst, in der "Oestereichischen botanischen Zeitschrift" 1877, p. 55, seiu licht anch ïber diesen Parasiten leuchten zu lassen. Er fuihrt an, dass er unter dem 'T'itel ya tröllö äbölye" ein eigenes Werk iiber Spleaerella Titis und deren Vorformen verfasst und dazu eine Tafel mit 23 Figuren gegeben habe, den ganzen Formenkreis des Pilzes darstellend. Nun bin ich nicht so gliicklich, die angezogene Arbeit zu kennen, da mir die magyarische Sprache völlig unbekannt ist (eine Unbekannt- 
schaft, welche ich wohl mit so ziemlich allen anderen ansserungarischen Gelehrten theile), aber nach der Probe zu schliessen, welche der Herr Verfasser hier von deren Inhalt gibt, werde ich mich darüber zu trösten wissen. Herr Haszlinsky wirft nämlich ohne weitere Unstände Cladosporium Roesleri, dann Septosporium curvatum Rabh. (Haszlinsky citirt ganz falsch als Autor A. Bramn) und die Fuckel'sche Conidienform, d. h. mein Septosporium Fuckelii in einen 'Topf zusammen und nemnt sie sämmtlich eine Vorform der Sphaerella! Wie es mit diesem neuesten Mixtum compositum steht, habe ich in derselben Zeitschrift p. 193 ausfiihrlich gezeigt, ich stellte dort die makround mikroskopischen Merkmale einander schematisch gegenüber und jeder einsichtsvolle Leser wird mir sicherlich Recht geben, dass diese drei Arten, wovon iibrigens Septosporium curvatum Rabh. iiberhaupt gar nicht auf Weinlaub vorkommt, streng auscinander gelialten werden mïssen. Wenn es iiber den Horizont mancher Iente geht, difficile, tabei aljer sichere und nnwandelbare Unterscheidungskennzeichen aufzufinden oder zu begreifen, so laisst sich dagegen eben nichts sagen, aber wenn dieselben Herren mit genialem Achselzucken auf Diejenigen herabsehen, die eine solche Unterscheidnngsgabe besitzen, und beispielsweise gleich in einem $\Lambda$ them diese und den hochverdienten, geistreichen Botaniker Jordan lächerlich zu machen versuchen, so verdient diess eine ganz energische /uriickweisung!

Bisher, wie es scheint, nur in Nieder-Oesterreich, dort aber sehr häufig und schädlich auf lebenden Blättern von Vitis vinifera Lin. - Diirfte sicherlich auch in anderen Ländern aufgefunden werden. (Tab. III. tig. 23.)

\section{Cladosporimm ampelinmm Pass.}

Passerini in Erbario erittogam. italiano Ser. II. no. 595. - Thümen, Herbarium mycologicum oeconom. no. 175 et 175 b. - ? Septoria Vitis Lév. in Annales des sciences naturelles 1846, V. p. 279. - Cercospore Vitis Sacc. Mycotheca veneta no. 284, 363. - Cladosporium viticolum Ces. in Klotzach, Herbar. mycolog. Ser. I. no. 1877. - Ilelminthosporium Titis Pirotta, funghi parassiti dei Vitigni p. 75.

Iyphae fasciculatae, simplices, strictae, apice plus minusve torulosae, e fumoso hyalinae; sporae terminales, fusiformes, fuscae, quincue- vel septemseptatae, basi saepe in articulum stipitiformem 
(an germinantis?) productae. - Pass. 1. c. -- Sporae $40 \mathrm{~mm}$. long., $10-11 \mathrm{~mm}$. crass.

Ad folia viva Vitis viniferce Lin. Italia (Passerini, Pirotta, Cesati, Saccardo), Gallia? (Leveillé), Austria inferior (Thïmen) et Titis Labruscae Lin. Gorizia (Bolle).

Einen sehr beträchtlichen Schaden kann dieser Parasit, wofern er in grosser Menge auftritt, in den Weingïrten verursachen. Zu Anfang zeigen sich auf der Oberfläche der Blätter mehr oder minder kreisförmige, hellbranne Flecken, welche schnell an Grösse und Zahl zunehmen und zuletzt einen dunkelrothbraunen Rand oder Hof haben, während die innere Fläche durch Austrocknumg zerrissen ist. Auf der unteren Blattfläche entwickelt sich zu goleicher Zeit der Pilz selbst, er bildet hier ganz :ihnliche Flecken wie auf der Oberseite, nur von einer etwas helleren Farbennuance. Im Centrum des Fleckes zu Anfang, dann auf der ganzen Flïche desselben erheben sich die ungemein zahlreichen, zu Bündeln vereinigten Hyphen, dieselben sind einfach, d. h. nicht verzweigt, steif aufrecht stehend, an den Spitzen ein wenig anfgetrieben und von einer hellen aschgrauen Färbung. An ihren Spitzen bilden sich die mehr oder minder spindelförniggen Sporen von hellbratner Farbe, welche fünf- bis siebenmal in der Qnere getheilt, an diesen Theilungsstellen jedoch nicht oder nur ganz unbedentend eingeschnitten, am Scheitel stumpf zugespitzt und an ihrem unteren Ende znweilen mit einem, an einen Stiel erinnernden Fortsatze versehen sind; ihre länge beträgt $40-42 \mathrm{~mm}$., ihre Breite 10-11 mm. - Die Form anf Vitis Labrusca Lin. zeigt im mikroskopischen Bam, nicht das geringste Abweichende, wohl aber ist sie makroskopisch anders gestaltet. Dic Flecken auf der Oberseite der Blitter sind viel dunkler als diejenigen auf Vitis vinifera, auch ist ihre Form keine kreisrunde, sondern eine ganz unregelmässige, die Farbe ist ein dunkles Braunroth, während der ringsherum lanfende Hof ein rïthliches Gelbbraun zeigt. Unterseits treten die Flecken, verursacht dureh die starke Behaarung, weit weniger deutlich hervor und sind verschwommen bräimlich. - Ob die von Pirotta a. a. O. anfgestellte Behauptung, dass dieser Pilz mit Leveillé's Septorict Vitis identisch sei, richtig ist, kann ich momentan wegen Fehlens von Leveillé'schen Original-Exemplaren nicht unterscheiden; die Versetzung der Art in die Gattung Helminthosporium war aber jedenfalls unrichtig. - 
Im Jahre 1876 im Spätsommer hatte ich bei Klosterneuburg in Nieder-Oesterreich Gelegenheit, eine Epidemie dieses Pilzes zu beobachten. Er trat sehr häufig mit Cladosporium Roesleri Catt. gemeinschaftlich auf demselben Blatte auf und verursachte ein friihzeitiges Abfallen der Blätter und naturgemäss ein darauf folgendes Kränkeln der befallenen Weinstöcke. - Ich kenne den Pilz bisher aus Italien, wo ihn Passerini, Pirotta und Saccardo, ans Frankreich, wo ihn (wenn Pirotta nämlich richtig eitirt) L_eveillé, und aus Nieder-Oesterreich, wo ich ihn selbst auf Vitis vinifera Lin. fand; bei Görz im österreichischen Küstenlande ward er von Bolle ebenfalls, und zwar in grosser Anzahl auf Blättern von Titis Lalnuscre Lin. entrleckt. (Tab. 1V. fig. 6.)

\section{Septosporimm Fuchelii Thüm.}

Thümen in Oesterr. botan. Zeitsehr. 1877, p. 137. - Thïmen in Wiener Landwirthschaftl. Zeitung 1876, p. 511. - Sphrevello Titis Fuck. Fungus conidiophorus in Symbolae mycologicae p. 104, Tab. II. fig. $\therefore$.

S. caespitibus explanatis, tenuissimis, velutinis, olivaceis, in maculis maximis exardis, pallide fuseis; hyphis fasciculatis, subsimplicibus, gracilibus; sporidiis elongato-subclavatis, sex- vel septemseptatis, olivaceis, variis, maximis, $72 \mathrm{~mm}$. long., $8 \mathrm{~mm}$. crass. - Fuck. 1. c.

Ad folia viva Titis viniferre Lin. Nassovia. (Fuckel.)

Ueber diesen Pilz bemerkt Fuckel a. a. O. ferner noch: "Besonders anf ,Klebroth' erscheint dieser Pilz im Angust bis September und verursacht eine allzufriihe Entblätterung desselben, wodurch er schädlich wird. Er bewohnt meistens die untere Blattfliche und gibt sich oberhalb durch hellbraune, diure Flecken, die schnell das ganze Blatt umfassen, zu erkennen". Ich selbst keme diesen Parasiten nu aus dem dürftigen Exemplare, welches Fuckel unter no. 2240 seiner "Fungi rhenani exsiccati" vertheilte. Whe ich mich eingehend mit dem Studium der Pilze des Weinstockes beschäftigte, glaubte ich ihn auch auf Weinblättern aus Nieder-Oesterreich zu erkennen, sah aber bald meinen Irrthum ein. Das Septosporium wrchert auf der unteren Fläche lebender Blätter, wo es ziemlich ausgebreitete, zarte, sammtartige Rasen von Olivenfarbe bildet, diese steben auf zuerst kleinen, dann aber sehr schnell grösser und immer grösser 
werdenden dïrren Flecken von hellgelblichbrauner Farbe, anf der oberen Blattfläche ist die Färbumg etwas heller, der land etwas verschwommener. Die llyphen erheben sich in biindehn vereinigt aus dem zarten Mycelium, sie sind olivengelblich, einfach, wenigstens nur ausnalmusweise eimmal rerëistelt, ziemlich schlank und gegliedert, anfrecht stehond, nul wenig gebogen. An ihren Spitzen entwickeln sich die ungemein grossen Sporen von umgekehrter Keulenform, sio sind ziemlich lang, der Quere nach füinf- bis siebenmal getheilt und an den meisten dieser Theihungsstellen etwas weniges eingeschnürt, in jedem Abschnitt haben sie einen oder zwei Nuclei, die Farbe ist die gleiche wie die der Hyphen. Ausserdem kommen aber auch noch andere unzweifelhaft jiingere sporen ror, welehe unten und oben sehwach zugespitzt, nur drei- oder viermal septirt sind. - Nach Fuckel a. a. O. gehört dieser Pilz zu seiner Splecerella litis als Conidienform, er begrindet diese Buhaptung jedoch ledighich anf Combination and anf Cohabitation, und da eine ganze lange Reihe von falsehen deratigen Fuckel'schen Combinationen anfgefuihrt werden kann, so sehe ich mich vorläutigg, bis nicht beweisende Culturversuche vorgenommen worden sind, gezwumgen, die Fuckel'sehe Annahme zu bezweifeln und dem Pilz obigen sellsststandigen Namen zu geben. Einen weiteren Grund foür diese Behauptung glaube ich auch darin zu finden, dass der Sehlauchpilz, die Splacerella Vitis Fuckel's, bereits an versehiedenen Orten aufgefunden ward, von mir beispielsweise im nördlichen Böhnen, an mehreren Punkten Nieder-Oesterrejehs, der angebliche Conidienpilz dazu aber bisher nu von Fuckel in Nassau beobachtet ward. Wer sich eingehender ïber diese Formen alle und ihr Verhältniss zu einander zu unterrichten wituseht, der möge den oben citirten Artikel der landwirthschaftlichen Zoitung nachlesen. - Auf lebenden Blättern von Vitis vinifera Lin. in der Provinz Nassau (Fuckel). ('Tab. 1. fig. 18.)

Spicularia Icterus Fuek.

Fuckel, Symb. mycolog. 1. 359, Tab. II. tig. 34. - Id. Fungi rhenani exsicuti no. 2212. - Pirotta, funghi parassiti dei Vitigni p. ss.

S. caespitibus laxis, in macula exarida; hyphis finctiferis erectis, lineam unam altis, septatis, fuscis, apice subdichotomo- 
ramosis, ramulis apice conidia eapitata gerentibus; eonidiis eandidis, oblongo-ovatis, breviter stipitatis, $14 \mathrm{~mm}$. long., $8 \mathrm{~mm}$. crass., simplicibus. - Fuck. l. c.

Ad folia viva Vitis viniferce Lin. Nassovia. (Fuckel.)

Fin hochinteressanter Pilz! - Auf ziemlich grossen, mehr oder minder kreispunden, gelb-ausgebleichten Flecken finden sich anf der Unterseite der Blätter die kleinen, lockeren Räschen des Pilzes. Die Hyphen erheben sich ungefüh 1//2 Mm. hoch iiber die Blattlläche, sie sind gerade anfgerichtet, mit Querwänden, brämnlich und tragen an ihrem Ende Aestehen, welche der Mehrzahl nach abermals verzweigt sind, an den Spitzen dieser Verzweigungen oder wenn dieselben fehlen, an der Spitze der Aestchen selbst bilden sich die Sporen, diese sind mehr oder weniger elliptisch oder breit oval and haben entweder in der Nitte ihres muteren Endes oder an einer Seite desselben einen kleinen Fortsatz, eine Art von ludimentären Stiel. Ihre Farbe ist weisslichwasserhell, oben sind sie breit abgestumpft, unten schwach verschmälert, in Innern mit zahhreichen Nucleis, meistens sitzen fiuf bis sechs Sporen regehnässig vertheilt an einem $\Lambda$ estchen; die länge der einzehnen Spore ist $14 \mathrm{~mm}$, die Breite $8 \mathrm{~mm}$. Auf lebenden Blättern von Vitis vinifera Lin. Nassan. (Fuckel.) Ueber den Schaden, welchen dieser Pilz in den WVeingärten verursacht, lasse ich, der ihn wohl nach Herbar-Exemplaren genau kennt, im Leben aber niemals Gelegenheit hatte, ihn zu beobachten, am Besten den Autor sprechen. Fuckel schreibt a. a. O.: "Ich halte diesen Pilz fü die Ursache jener Krankheit, die ich Gelbsucht genannt habe und welche besonders dieses Jahr an den Blättern aller Traubensorten, ausgenommen die Fleischtranbe (Malvasier) auf dem linksheinischen Ufer, von Mainz bis Guntersblum, so häufig und so schädlich war. Nach den Zeitungen zu selıliessen, ist es dieselbe Krankheit, die im siidlichen Frankreich seit kurzer Zeit so grossen Schaden bringt, und der man als Ursache kleine, blattlausähnliche Thiere, die sich an die Wurzeln setzten, zuschreibt". (Hier irrt der Verfasser, ohne /wreifel meint er mit den blattlausähnlichen Thieren die Plylloxera vastatrix Planch., die gerade dazumal [Fuekel schrieb seine "Symbolae mycologicae" vor dem Jahre 1869] in Frankreich aufzutreten begann, ibber deren Natur man aber zu jener Zeit noch völlig im Unklaren war.) 
„Die Krankheit gibt sich zuniehst durch ein Gelbwerden des ganzen Weinstockes, kurz nach der Blïthe, zu erkennen, allmälig bilden sich diurre Flecken an den Blättem, die schnell das ganze Blatt umfassen, wodureh die ganzen Reben entblïttert werden. An diesen diurren Flecken fehlt niemals die Spicularia. Die Folge davon ist, dass die kleinen Beerchen abfallen orler kaum schrotkorngross bleiben und, wie mir seheint, der ganze Stoek abstirbt. Die spicularia befällt ganze Weinberge und hält die kreisförmige Verbreitung, die so vielen P'ilzen eigenthiumlich ist, inne. Um einen wahrscheinlich im vorigen Jahre befallenen und abgestorbenen Stock werden die Nachbarstöcke im Kreise herum, der sich raseh vergrössert, befallen. Man benerkt schon von Weitem durch das landkarteniihnliche Colorit der Weinberge die Kraukheit. Im Rheingau beobachtete ich sie bis jetzt noch nicht. Sie scheint vorzugsweise die OesterreicherTrauben zu befallen und kommt in besagter Gegend in allen Bodenarten, besonders den Berglagen, vor." (Tab. I. tig. 11.)

\section{Septocylindrium dissiliens Sace.}

Saccardo, Mycotheca veneta no. 583. -.. Id. in Nuovo Giornale lotanico italiano VIII. p. 186. -- Id. Michelia I. p. 8!, no. 74. - Id. fungi italici antografice delineati no. 74. - Pirotta, funghi parassiti dei Vitigni 1. 8\%. - Torule dissiliens Duhy in Mem. d. I. soc. de Pliysique de Genève VII. - Rabenhorst, Fungi europaei no. 1874. - Thiimen, Iferbarium nyeolog. oeconom. no. 17\%. Erb. crittugam. italiano I. no. 1347 .

S. in pagina inferiore maculas gregarias, indeterminatas, plus minus confluentes, olivaceas, tenuissimas formans; sporis longis, cylindraceis, concatenatis, utrinque obtuso-subacutatis, rectis vel subarcuatis, uni- vel triseptatis, ad septas non constrictis, e olivaceo viridescentibus, $50-70 \mathrm{~mm}$. long., 5-6 mm. crass.

In pagina inferiore foliosm vivarm Titis viniferae Lin. Helvetia (Duby), Parma (Passerini), Venetia (Saceardo).

Auf' der Unterseite der Blätter bildet dieser Pilz dicht gedrängt stehende undeutliche Flecken, welche meistens nicht umgrenzt sind, sonderu nach dem Raude zu verschwimmen, sehr häutig laufen mehrere in einander iiber, sie sind sehr zart und diinn, kaum selwwach sammtig zu nemen und von olivenbrauner Farbe, im Alter werden sic deutlicher, graubräunlich mit einem bräinnlichen Hofe ringsum; die Sporen sind perlschnurförnigg verbunden, 
anfiecht sich erhebend, schr lang cylindrisch, an den beiden Enden stumptspitzlich, gerate oder etwas gebogen, ein-, zweioder meistens dreimal septirt, an den Theihngsstellen nicht eingeschniut, von olivengriunlicher Farbe und $50-70 \mathrm{~mm}$. lang bei 5-6 mm. Dicke. - In Ober-Italien, wo dieser Parasit auf der Unterseite lebender Blätter von Titis vinifer lin. gegen Ende des Sommers epidemisch anftritt, verursacht er duch friihzeitiges Entblättern der Weinstöcke einen bedentenden Schaden. Er ist bis jetzt in der Provinz Parma von Passerini, in Venetien von Saccardo beobachtet worden, Duby entideckte ihn znerst in der Ungebung von Genf. (T'ab. IV. tig. 1.)

\section{Dendryphinm Passerinianm Thüm. nor. spec.}

D. acervulis ampligenis, solitariis, minutissimis, subeleratis, applanatis, atris in partibus maximis, irregularibus, exsiccatis, pallide fuscis foliorum; hyphis plus minns rectis, brevibus, subcrassis, erectis, articulatis, articulis brevibus, fusco-olivaceis, ramosis, ramis subaequilongis, apicalibus; sporis ramorum globosoellipticis, catenulaeformibus, sporis apicalibus unaturis $6 \mathrm{~mm}$. long., $3 \cdot 5-4$ mm. crass., coloris hypharum.

Ad Titis viniferue Lin. folia languida, Italia superior: Gajone jer. Parma. Autumno. (G. Passerini.)

Ein merkwiudiger Pilz, welcher in seinem llabitus kaum dic Gattung verräth, zu welcher ihn zu stellen ich genöthigt war. Auf grossen Flecken, welche alle fünf Lappen des Blattes umfassen, lyellbräinlich und fast ganz diure sind, wuchert das Dendrolphium in ganz kleinen, dem blossen Auge kaum wahrnehmbaren Häufchen, zumeist auf der Unter-, seltener auch anf der Oberseite. Ausser diesen bramen Flecken zeigt das Blatt aber auch noch eine Anzahl von tiefpurpurothen, welche, am Rande der braumen beginnend, sich unregelmässig auf der Blattfläche verbreiten. Die Hyphen des Dendryphium sind aufrecht, fast gerale, ziemlich kurz und dicklich und bestehen aus sehr vielen kurzen Gliedern, an der Spitze entspringen einige, meist drei oder vier Aeste an derselben Stelle, diese bestehen aus Sporen von rundlich-elliptischer Gestalt, rosenkranzförmig aneinander hängend. Die letzte, die Endspore, löst sich nach erlangter Reife immer ab, sie ist regelmässig elliptisch geformt, $6 \mathrm{~mm}$. lang, 
3.5-4 mm. breit. Die Farbe von Hyphen und Sporen ist gleichmässig ein dunkles Olivenbraun. - Ich glaube kaum, dass es einem Zweifel nnterliegen kann, dass dieser Pilz die Ursache des Eintrocknens erst der Blattzipfel und dam wohl bald des ganzen Blattes ist, er wird dadurch also dem Weinstocke schädlich und dïrfte unter die directen Schädiger desselben anfzunelmen sein. Ich erhielt diesen neuen Parasiten dureh Herru Professor G. Passerini, welcher ihn auf welkenden Blïttern von Titis vinifera Lin. bei Gajone unweit Parma in October 1876 sammelte. (T'ab. I. fig. 4.)

\section{Graphium clarisporum Berk, et Cnrt.}

Berkeley et Curtis in Ravenel, Fungi Carol. exsice. III. no. 77. - Rerkeley, Notices of North American Fungi in Grevillea III. p. 100, no. 619.

G. ninutum, olivaeenm, e macnlis orbicularibus, brumeis oriundum; sporis linearibus clavatisve, pluriseptatis. - Berk. l. c.

Q. stipitibus erectis, hypoplyyllis, minutis, dense gregariis, atris in macula plus minusve orbiculata, dilute olivacea, snbdistineta, in pagina superiore rufescentia; hyphis continuis, simplicibus, brevibus, rectis vel subflexmosis, dilute olivaceis, tenuibus; sporis capitulas formans, cylindraceis vel subanguste-clavatis, utrinque subacutato-obtusis, triseptatis, rectis, $44 \mathrm{~mm}$. long., 4 $5 \mathrm{~mm}$. eráss., coloris hypharum.

In foliis vivis aridisve Vitis Labnuscae Lin. America septentr.: Carolina australis (Curtis), New-Jersey (J. B. Ellis).

Auf melır oder weniger runden, vereinzelten, hellolivenbrauneu, nicht fest abgegrenzten Flecken der Blattmnterseite, welchen oberseits rothbrame Flecken entsprechen, erheben sich dicht gedrängt stehend die kleinen, zierlichen Pilze. Die einzelnen Individnen bestehen ans kurzen, glänzend schwarzen, aufrechten Stielchen, die an ihrem oberen Ende ein ganz winziges Köpfehen tragen. Die Stielehen bestehen aus mehreren einzelnen, zusammenhängenden Hyphen von (unter dem Mikroskop) hellolivenbramer Farbe, welche zart, dünn, gerade oder zuweilen etwas hin und her gebogen, einfach und ohne Scheidewäinde sind. An der Spitze tragen sie die Sporen, von denen eine Anzahl köpfehenartig zusammenstehen, sie sind meistens cylindrisch, manchmal anch schmal keulenförmig, an beiden Enden stumpf- 
lich zugespitzt, haben drei Seheidewände, sind gerade und messen in der Länge $44 \mathrm{~mm}$., in der Dicke $4-5 \mathrm{~mm}$, ihre Farbe ist ebenfalls ein helles Olivenbramn. - Dieser niedliche Pilz vegetirt auf lebenden sowohl, als auch auf todten Blättern von Titis Labrusca Lin., er ward bisher nur in Nord-Amerika, und zwar von Curtis in Süd-Carolina und von J. B. Ellis in New-Jersey gefunden. (Tab. V. fig. 7.)

\section{Cicinnobolus Cesatii De By.}

De Bary, Beiträge zur Morphologie und Physiologie der Pilze p. 71 in Abhandl. d. Senkenberg. naturf. Ges. 1870. - Schulzer in Oesterr. botan. Zeitsehr. 1875, p. 298, - Cicinnobolus Oidii Tuckeri Mohl in Botan. Zeit. 1854, p. 143, Tab. 6, fig. 1-7. - Rabenhorst, Fungi europaei no. 2215. - Ampelomyees quisqualis Ces. in Klotzsch, Herb. mycol. no. 1669. - Nontagne, Note botan. s. 1. Hlane de la Vigne par Berkeley in Mem. d. 1. soc. centr. d'Agriculture 1856, fig. 5, 6 .

C. mycelio in Oidii Tuckeri Berk. lyphis parasitans; hyphis erectis, brevibus, multiarticulatis, articulis sublongis, cylindricis, achrois vel subfuscidis; sporangiis acrogenis vel cellulis penultimis gerentibus, clavatis vel ellipsoideis, $25-35 \mathrm{~mm}$. long., 9$15 \mathrm{~mm}$. crass., episporio subreticulato, impellueidis, dilute luteis vel fuscis; sporis numerosis, ellipticis vel subeylindricis vel fere ovato-globosis, rectis rel subeurvis, utrinque rotundatis, hyalinis, plerumqne uni- vel binncleatis, hyalinis, $2.5-3 \mathrm{~mm}$. long., $1 \mathrm{~mm}$. crass.

In Oidio Tuckeri Berk, ad folia viva Vitis viniferae Lin. parasitans. Aestate - autumno. Ubiqne.

Viel ist über diesen Pilz geschrieben, unzülnlige Versuche und Untersuchungen sind angestellt worden, erbitterte Controversen wurden durch ihn veranlasst, ehe seine wirkliche, wahre Eigenschaft erkannt ward. Mohl war der erste, welcher etwas Licht in die Sache brachte und a. a. (). eine ganz gute Beschreibung und anch Abbildungen des Pilzes gab, allerdings noch von der festen Ueberzeugung ansgehend, dass er es hier lediglich mit einer Fruetificationsform der sogenannten Enysiphe Tuckeri zu thun habe. Vor ihm hatte bereits der Italiener Amici die Sache einer eingehenden Untersuchung unterzogen und die Vermuthung einer Verwandtschaft mit der Ehrenbergschen Gattung Cicinnobolus ausgesprochen; ferner latte Cesati in no. 39 vom Jahre 1852 der "Gazzetta" von Vereelli sich iiber 
unseren Pilz gäinssert und bxemplare desselben unter dem Namen Ampelomyces quisqualis in Klotzsch, "Herbarium mycologicum" sub no. 1669 b vertheilt, und zwar lediglich Exemplare auf Weinbeeren. In der neuesten \%eit hat mu De Bary a. a. O. zur Evidenz die Selbstständigkeit des Cicinnobolus nachgewiesen und dargethan, dass er parasitiseh auf dem Oidium Tuckeri wuchere, diesen schädlichen Parasiten arg mitnehme und aussange, und endlich hat Passerini unter no. 2215 der Rabenhorstschen „Fungi europaei" Weinblätter" mit sehr reichlicher Cicimnobolus-Tegetation rertheilt und durch diese schönen Exemplare wesentlich das Studium des Pilzes erleichtert. - Das Mycel unseres Pilzes wuehert in und anf den Ilyphen des Oidium Tuckeri Berk. und ist im Stande, wemn es reichlich entwiekelt ist, diesen Pilz fast ganz zu vernichten, und so findet man hïutig Blïtter, anf denen mur noch Ueberreste des Oidium vorhanden sind, während der Cicinnobolus reichlich fruetificirt. Aus diesem Mycel num steigen sehr kurze, gerade aufgerichtete, viclfach gegliederte Iyphen oder Fruchtträger auf, deren einzehe Glieder eylindrisch, verhältnissmässig lang und wasserhell sind. Aus der obersten Kelle dieser Fruchthyphen, nach Mohl a. a. O. anch zuweilen aus der vorletzten, einen Vorgang, den ich selbst nicht beobachtet habe, entwickelt sich das Sporangium. Dieses ist entweder keulenförmig oder elliptisch, von hell- oder dunkelbräunlicher Farbe, undurchsichtig, mit einer kïrnig-netzartigen Membran und 25--35 mm. Täinge bei 9-15 mm. Breite. Aus dem Scheitcl dieses Sporangiums nun werden die zahlreichen Sporen entleert, sie sind elliptisch oder beinahe cylindriseh, auch kommen fast kngelig-eirunde vor', ganz durchsichtig, an beiden Enden abgerundet, entweder gerade oder seltener etwas gekriimmt, farblos und mit einem oder zwei kleinen Nuclei versehen, ihre Grösse beträgt $2.5-3 \mathrm{~mm}$. in der Läinge und $1 \mathrm{~mm}$. in der Breite. - Anf Blättern von Titis viniferce Lin., welehe mit Oidium Thekeri Berk. bedeckt sind. Wohl überall vorkommend. - Schulzer von Miiggenburg sagt a. a. O.: "Wir haben den ricimobolus, besonders an Reben, als einen sehr nuitzlichen Pilz zu begriissen, denn es ist klar, dass er die Erysiphe nicht blos an der Frnctification hindert, sondern förmlich anssottet." Mit dieser Ansicht bin ich vollkommen einverstanden und habe ich mich in der "Natu" von 1877, p. 484, in ganz demselben Sime 
ausgesprochen. Womit ich mich aber durchaus nicht einverstanden zu erklären vermag, das sind die anderen Ansichten, welche dieser Autor in dem angezogenen Artikel zum Besten gibt. Nicht nur, dass er, um seiner Manie zu fröhnen, das Oidium Tuckeri, diese doch ganz gut unterschiedene Form, mit dem Oidium auf Convolvulus und anf Cucurbita zusammenwirft (Formen, welche vorläutig noch zu der Collectiv-Species Oidium erysiphoides Fr. gezogen werden, deren genaue Untersuchung aber noch aussteht und welche eventuell ebenso gut eigene Species sein können, wie zahlreiche andere Oidia, welche von Passerini, Saccardo, mir und Audern als gute Arten erkannt wurden, worauf übrigens schon Fresenius in seinen "Beiträgen zur Mykologie" p. 76 hinweist), sondern er gibt für dieses Sammelsurium auch einen neuen Namen: Torula Albuginis, ein Name, der sicherlich anch nicht in ein eimziges wirklich wissenschaftliches Werk sich Eingang verschaffen dürfte. Anch mit den Maasangaben Schulzer's in dieser Mittheilung bin ich nicht einverstanden, sondern muss meine, anf sehr zahlreiche Messungen beruhenden Grössenangaben durchans aufrecht erhalten! (Tab. II. fig. 1.)

\section{Exosporium Badhami Awd.}

Auerswald in sehedulis et litteris, sed absque diagnosa. - Septoria Badhami Berk. et Br. in Berkeley, Outlines of fungology p. 320. - Cooke, Handb. of British Fungi p. 444, no. 1309.

E. peritheciis parvulis, hypophyllis, dense gregariis in maeula irregularia, subfusca, obsolete marginata, sparsa, in foliornm pagina superiore maculas magnas, late effusas, nou limitatas violaceo-fuscas formans, globosulis, prominulis, setis rigidis, pancis tectis, atris; sporis pancis, stipitatis, clavulatis, vertice rotundatis, basi angustatis, bi- vel triseptatis, ad septas non constrictis, dilute fuscescentibus, $16-18 \mathrm{~mm}$. long., $6-8 \mathrm{~mm}$. crass.

Ad folia subviva langnidave Titis viniferce Iin. Thuringia. (Fleischhak.) Anglia.

Diesen merkwürdigen Pilz kenne ich ganz allein nur aus einem Exemplar meines Herbariums, welches aus der Sammlung Auerswalds herstammt. Auerswald, der leider so frühzeitig der Wissensehaft und seinen Freunden Entrissene, hat, wie ich mit fast voller Gewissheit annelumen kann, eine Diagnose dieses Parasiten nicht publicirt, die hier mitgetheilte ward demzufolge von mir 
nach dem erwälnten (Higinal-Exemplar verfasst. - Merkwïrdig nannte ich den Pilz oben aus dem Grunde, weil er bisher nur aus Gegenden bekannt ist, wo kein eigentlicher Weinbau getrieben wird, sondern nur an Haus- und Gartenspalieren einzelne Weinstöcke cultivirt werden. Ob Exosporium Badlami nicht auch in Weingegenden auftritt, diese Frage vermag ich vorläufig nicht zu beantworten, mir ist es niemals vorgekommen; jedenfalls wäre es aber höchst wichtig, genau darauf zu fahnden, denn nach dem äissseren Ansehen der befallenen Blätter zu urtheilen, ist dieser Pilz ohme alle Frage den Weinstöeken schädlich. Um die weiteren Forschungen nach diesem Schädling möglichst zu erleichtern, gebe ich hier eine recht genaue Beschreibung von demselben.

Das befallene Weinblatt zeigt auf der Oberseite eine grosse Anzahl nicht genau abgegrenzter und vielfach ineinander ïbergehender Flecken von schmutzigviolett-bräunlicher Färbung; in der Mitte dieser mehr oder weniger die ganze Blattfläche bedeckender Flecken ist die Substanz des Blattes schon fast ganz ausgetrocknet und erscheint demzufolge viel heller gefärbt. Anf der Unterseite finden sich verhäItnissmässig weit weniger Flecken, diese stehen zerstreut, sind kleiner, von unregelmässiger Gestalt und hellbrauner Farbe, sie sind ziemlich deutlich begrenzt, aber mit einem helleren, allmälig verschwindenden Hofe rings umgeben. Auf diesen braunen Flecken nun, welche genau den oben erwähnten heller gefärbten und ganz ausgetrockneten Mittelpartien der oberseitigen Flecken entsprechen, finden sich die Perithecien. Diese stehen dicht gedrängt beieinander, sind nur wenig hervorragend, unbedeekt, fast kugelig von Gestalt, schwarz von Farbe und selır klein und haben am Scheitel wenige kurze stachelartige Erhöhungen. Im Innern enthalten sie einen bräunlichen Kern mit nur sehr wenigen Sporen von keulenförmiger Gestalt. Die Sporen sind gestielt, am Scheitel abgerundet, an der Basis in den kurzen Stiel verschmälert, zwei- bis dreimal in der Quere getheilt, an den Theilnngsstellen jedoch nicht eingeschniurt, die Farbe ist ein zartes, helles Braun, die Länge beträgt 16-18 mm., die Breite 6-8 mm. - Auf lebenden und welkenden Blättern des gemeinen Weinstockes, Vitis viniferc Lin. 'Tlülingen, bei Arnstadt, September 1869. (Fleischhak.) England. (Tab. III. fig. 4.) 


\section{Uredo Vitis Thüim. nor. spec.}

U. acervulis hypophyllis, dense gregariis, nonnunquam in maculis fuseis sed plerumque sine maculas, in foliorum pagina superiore maculas parvas, stramineas formans, hemisphaericis, solitariis, muquam eonfluentibus, duris, pallide amantiaco-flavis (tamen in speciminibus exsiccatis), minntis, solidis; sporis guttulaeformibus aut globosis, $15 \mathrm{~mm}$. diam., ant ovatis $20 \mathrm{~mm}$. long., $14 \mathrm{~mm}$. crass., ant ellipsoideis, 22 $\mathrm{mm}$. long., 12-15 mm. crass., subpedicellatis, basi propagullatis, dintissime Iutescentibus, episporio laevi, crasso, inaequali, Hlerumrue vertice crassissimo.

In foliis vivis rel sublanguescentibus Vitis viniferce I in. Rarissime. - America septrutr.: Aiken, Carolina anstralis. Nestate. (H. W. Ravenel.)

Wie es selreint, ist dieser lochinteressante Pilz sehr selten, ich sah ihn wenigstens noch in keinem ILerbar, las nirgends irgend eine Notiz iiber ihn und erhielt anch von dem Sammler, dem $\mathrm{nm}$ die botanische, speciell mykologische Erforschung der Südstaaten der Nordanerikanisehen Republik so hochverdienten H. W. Ravenel, nur eine geringe Anzahl Blaitter. Der Pilz tritt anf der unteren Blattläche in kleinen, lalbkugeligen, festen, gesellig stehenden, jedoch niemals znsammentliessenden Häufehen anf. Dieselben sind, wenigstens bei den getrockneten Exenplaren, hell ocherfarben oder hellgelblich-orange und stehen zuweilen auf einem sehr kleinen, braunen Fleck, welchen auf der oberen Blattseite ein ebenso kleiner, strohgelber entspricht. Die Śporen sind sämmtlich tröpfchenförmig, d. h. sie laben an der Basis einen kleinen xudimentären Stiel oder sind, besser gesagt, in einen solchen ausgezogen, die Form ist entweder kugelig, bei einem Durchmesser von $15 \mathrm{~mm}$, oder eiförmig, bei $20 \mathrm{~mm}$. Länge und $1 \pm$ mm. Dicke, oder endlich elliptiselı, bei $22 \mathrm{~mm}$. Länge und $12-15 \mathrm{~mm}$. Breite, ungemein hellgellich, oft fast wasserhell und haben ein glattes, aber dabei sehr dickes Episporium, dessen Dicke jedoch nicht an allen Stellen gleich, am Scheitel aber stets am grössten ist. Paraphysen sah ich nicht. - Sofern der Pilz nicht lı̈̈ufiger auftritt, als man nach den Mittheilungen Ravenels amnehmen kanu, diurfte der dureh ihn verursachte Schaden ein minimer orler wohl gar keiner sein. Da diese Art bisher in Europa nicht beobachtet wrele, in Nord-Amerika aber auf 
einer dort aus Europa erst eingeführten Art vegetirt, so entsteht die Frage, wo die eigentliche Heimath dieses Parasiten za suchen sei, ob diess- oder jenseits des Oceans. Es wäre jedenfalls wichtig, in den Südstaaten der Union nach unserem Uredo auf den indigenen Weinspecies zu suchen. - Bisher nur aus Aiken in Sïd-Carolina, Vereinigte Staaten von Nord-Amerika, auf lebenden und zu welken beginnenden Blättern des gemeinen Weinstockes, Vitis vinifere Lin., bekannt. (H. W. Ravenel.) (Tab. V. tig. 10.)

\section{Rhytisma monogramme Berk, et Curt.}

Berkeley, Notices of North American Fungi in Grevillea IV. P. 9, no. 782. 27. Report of the New Jork State Museum p. 108. - Pirotta, funghi parassiti dei Vitigni p. 20.

R. in maculam brumeam, nigro marginatam situm; peritheciis hysteriiformibus, solitariis. - Berk. 1. c.

Ad folia viva Vitis aestivalis Mchx. America septentrionalis.

Die Autoren äussern a. a. O. den dringenden Wunsch, dass eine nähere Kenntniss dieses eigenthümlichen und merkwürdigen Pilzes ermöglicht werde. Sic beschreiben ihn äusserst lakonisch als hysteriumförmig, die cinzelnen Perithecien auf braunen, schwarz umsäumten Flecken. Voilì tout! Da von Schläuchen keine Rede ist und die ganze Beschreibung durehaus nicht recht zu einer echten Rlyytisma passt, möchte ich die Vermuthung aussprechen, dass wir es hier wohl mit einer Melasmia oder Discosia, gewiss aber nicht mit einem Ascomyceten zu thun haben. - In Nord-Amerika auf lebenden Blättem von Vitis aestivalis Mchx.

\section{Uncinula spiralis Berk. et Curt.}

Berkeley and Curtis, Notices of North American Fungi in Grevillea IV. p. 159, no. 992. - Pirotta, fnnghi parassiti dei Vitigni p. 29. - 26. Report of the New York State Museum p. 80. - Uncinula americana Howe sec. Peck.

U. apendicibus longis, Hexuosis, apice spiralibus. - Berk. l. c. U. amphigena, mycelio eximie tenui, subarachnoideo, eito evanido; receptaculis sen peritheciis globosis, sparsis, minutis, nitido-atris, laevibus; apendieulis longis, flexuoso-subcurvatis, apice spirali; ascis late pyriformibus vel brevi oroideo-pyrifor- 
mibus, hyalinis, $80 \mathrm{~mm}$. in diam.; sporis sex, ellipticis, utrinque rotundatis, interdum medio subinflexis, hyalinis, $20 \mathrm{~mm}$. long., $8-10 \mathrm{~mm}$. crass.

Ad folia viva, languidave Titis cordifolice Mehx. Albany, Newrork (C. H. Peck), Vitis Labruscae Lin. Pennsylvania (Michener), America septentrionalis.

Diese Mehlthau-Art ist bisher nur aus den Vereinigten Staaten von Nord-Amerika bekannt, wo sie aber auch nur die indigenen Tritis-Arten zu befallen scheint, ein Vorkommen auf der eingeführten Vitis viniferc Lin, ward wenigstens bisher noch nirgends constatirt. Der Pilz regetirt anf beiden Blattflächen, er besitzt nur ein ungemein sehwaches, sehr bald verschwindendes, spimewebenartiges Mycelium, welches aus ziemlich geraden, steifen, wasserhellen Fäden gebildet ist. Die zerstrent stehenden, nur manchmal zu kleinen, 4-8 Individuen umfassenden T'rupps verbundenen Perithecien sind klein, kugelig, glatt und glänzend schwarz von Farbe. Sie enthalten nur zwei Schlänche von breit und kurz birnenförmiger Gestalt, diese sind wasserhell und ungefähr $80 \mathrm{~mm}$. im Durehmesser gross. Sechs Sporen sind darin enthalten, welche eine elliptische Form haben, beiderseitig an den Enden abgerundet sind und manchmal an der einen Laingsseite eine kleine Einbuchtung zeigen, die Farbe ist wasserhell, die Länge $20 \mathrm{~mm}$., die Breite $8-10 \mathrm{~mm}$. Die Anhängsel an den Perithecien sind sehr lang, an der Spitze, wie bei allen UncinulaArten nur einfach und, was der Art ihren specifischen Namen gegeben hat, spiralförmig gedreht oder gewunden. - Wie mir aus Nord-Amerika mitgetheilt wird, ist der durch diesen Schmarotzer verursachte Schaden nur ein geringer, selten werden die Blätter während der Vegetationszeit befallen, sondern in den meisten Fällen werden erst die schon halbwelken Blätter heimgesucht und selbst diesen kann er nicht viel anhaben, da erstens das Mycelium, wie oben angedeutet, ausserordentlich sehwach entwickelt und schnell verschwindend ist und dann anch die Zahl der Perithecien, zum Beispiel im Vergleiche zu vielen europäischen Mehlthau-Arten, eine äusserst geringe ist. - Auf Vitis cordifolia Mchx. ward diese Uncinula bei Albany, New-Tork, auf Titis Labrusca Lin. in Penmsylvanien von Michener aufgefunden. (Tab. II. fig. 19.) 


\section{Phoma Negrianum Thïm. nov. spec.}

Pl. peritheciis minutis, epiphyllis, dense gregariis, hemisphaerico-subprominulis, glaucis, nigris in foliorum partibus maximis, irregularibus, exaridis, griseo-albicantibus, subtus fuscis, sine ordine dispositis; sporis eylindrico-ellipticis, utrinque subrotundatis, plerumque anucleatis, raro cum nucleo in utroque polo, simplicibus, diaphanis, $5-7 \mathrm{~mm}$. long., $3-355 \mathrm{~mm}$. crass.

Ad folia viva, morbo "Gialluma" laborantis, Vitis viniferce Lin. prope Casale Monferrato in Pedemontio, ubi legit Advotat F. Negri, Octobri 1876, misit elar. G. Passerini.

Diese, bisher noch nicht wissenschaftlich bearbeitete Krankheit des Weinstockes ist in ihrem Vaterlande unter dem Namen "Gialluma" bekamnt und gefiurchtet. Es entstehen auf den lebenden Blättern im IIerbste erst kleinere und dam sich sehr bald weit und immer weiter ausbreitende dürre Flecken, welche häufig bis zu zwei Dritttheilen des ganzen Blattes umfassen, sie sind nicht scharf abgegrenzt, von einer weisslich-grauen Färbung mit vereinzelten, braunen Flecken, unterseits ist die Farbe des ausgetrockneten Blattheiles eine matt graubraune. Auf diesen Flecken num, und zwar auf der oberen Blattseite finden sich die ungemein zahlreichen Perithecien des Pilzes ohne alle Ordnung zerstreut, selre dicht zusammenstehend, sie sind von einer fast kugelfürmigen Gestalt, hervorragend, glinzend schwarz, klein. Sie beherbergen cylindrisch-elliptisehe Sporen, welche an beiden Enden kurz abgerundet sind, meistentheils haben sie keinen Nucleus, nur ausnalmmsweise tinden sich einzehe Sporen, welche an jeden Ende die Andentung eines solehen zeigen. Die Sporen sind einfach, ungetheilt, farblos, durchsichtig und messen $5-7 \mathrm{~mm}$., meistens $6.5 \mathrm{~mm}$. in der Länge, $3-3.5 \mathrm{~mm}$. in der Breite. - Bisher ist mir dieser Pilz nur in Exemplaren bekannt, welche im October 1876 an lebenden Blättern von Vitis viniferce Lin. vom Advocaten F. Negri (welchem zu Ehren ich die Art auch benamnte) bei Casale Monferrato in Piemont gesammelt wurden, und die mir mein Freund Professor Passerini zusandte. (Tab. I. fig. 13.) 
Phoma ustulatum Berk. et Curt.

Berkeley, Nutices of North American Fungi in Grevillea II. 1. 82, no. 384.Pirotta, funghi parassiti dei Vitigni p. 54.

Ph. maculis helvolis; peritheciis punctiformibus; sporis utrinque attematis. - Berk. l. c.

In foliis vivis Vitis aestivalis Mchx. America septentrionalis.

Nicht einmal der nähere Fundort dieser Art, welche, da sie auf den lebenden Blättern vorkommt, ganz besonders interessant ist, wird a. a. O. mitgetheilt. Zufolge der Beschreibung sind die durch den Pilz hervorgebrachten Flecken gross, röthlich gelb oder rothbram; die Perithecien sehr klein, punktförmig, die Sporen an dem einen knde etwas verschmälert, kurz, spindelförmig, 0.0003 englisehe Zoll lang. - In Nord-Amerika an den lebenden Blättern von Vitis aestivalis Mehx.

\section{Septoria ampelina Berk, et Curt.}

Berkeley, Notices of North American Fungi in Grevillea III. p. 9. no. 440. - Pirotta, funghi parassiti dei Vitigni p. 66.

S. maculas amphigenas, indistinctas, non limitatas, atro-purpureas vel purpureo-fuscas, magnas, saepe confluentes formans; peritheciis amphigenis, dense gregariis, minutissimis, epidermicte tectis, vix prominulis, nitido-atris, numerosis; sporis cylindricis, subarcuatis, utrinque obtuso-rotundatis, bi-vel triseptatis, multipunctatis vel vix nucleatis, subpellucidis, dilutissime flavidis, 20-22 mm. long., $4 \mathrm{~mm}$. crass.

Ad folia viva Vitis vulpinae Lin. America septentr.: Aiken, Carolina anstralis. (Ravenel.) - Texas ad folia Vitis species indeterminatae. (C. Wright.)

Da die Autoren a. a. O. blos die Diagnose: "Maculis rufulis, aliis brumneis stellatis intermixtis, sporis linearibus, eurvatis" geben, so zog ich es vor, nach dem reichlichen, in meinem Herbar befindlichen Materiale eine bessere zu entwerfen; ich lasse nunmehr derselben hier eine ausführliche Beschreibung des Parasiten folgen: Auf beiden Blattflächen finden sich zerstrent ziemlich grosse Flecken von ganz unregelmässiger Gestalt, welche keine scharfe Begrenzung zeigen, sondern am Rande gleichsam verwischt sind, ihre Farbe ist ober- und unterseits die gleiche, näm- 
lich eine schwarz-purpurfarbene oder purpubraune, in der Jugend eine.hellbraune. Die in nicht zu grosser Anzahl vorhandenen, beiderscitig nur wenig hervoragenden Perithecien stehen ziemlich dicht beieinander, sind ïusserst klein, von der Oberhant bedeckt und von mattsehwäzlicher Farbe. Dis darin enthaltencm sporen haben eine crlindrische Form, sind schwach gekriimmt, an beiden Enden stumpflich abgerundet, laben zwei oder drei Scheidewände und inmen cine Anzahl undenthicher Nuclei, besser gesagt, sind sic inmen punktirt. Sie sind wenig durchscheinend und von ganz hellem Gelb, ihre länge beträgt $20-2 \cdot 2 \mathrm{~mm}$, ilıe Breite \pm mm. - Berkeley a. a. O. führt an, dass er diesen Pilz von C. Wright aus 'Texas in Nord-Amerika erhielt, gibt aber die species, von welcher die Blïtter waren, leider nicht an, ich erhielt ihn in grosser Menge auf den lebenden Blättern von Titis vulpina I.in. aus Siid-Carolina, wo iln H. W. Ravenel gesammelt hat. (Tab. I. fig. 12.)

\section{Septoria Vitis Lév.}

Leveillé in Amnales d. sc. natur. Ser. III. 1846, V. p. 279. - Pirotta, funghi parassiti dei Vitigni 1. 65.

S. conceptaculis hypophyllis, gregaris, minutissimis, receptaculo effuso, nigro, maculaeformi insidentibus; sporis curvatis, fusiformibus, continuis. - Lév. l. c.

Ad folia adlue vira Vitis viniferce Lin. Gallia, Romainville pr. Paris. (Leveillé.)

Da ich nicht in der Latge war, Original-Exemplare dieses, wohl seltenen, Parasiten zu untersuchen, gebe ich hier die Anmerkungen des Antors wieder. Fr schreibt a. a. O.: "Im Herbste zeigen die Blätter des Weinstockes sehr häutig auf beiden Seiten sehwarze, mehr oder weniger ausgebreitete Flecken, auf welchen sich jedoch der hier beschriebene Pilz lediglich auf der Unterseite entwickelt. Scine Perithecien (Receptakeln) sind äusserst klein, dicht beieinander stehend und nu mit Hilfe der Loupe zu erkennen; sie entleeren zeitweise kleine, weisse Ranken, dic aus ungemein zarten, kleinen, etwas gebogenen, spindelförmigen, durchsichtigen und farblosen, an einc Libertella erinnernden Sporen bestehen". - So viel mir bekannt, bisher nur in 
Frankreich, und zwar in der Umgebung von Paris an lebenden Blättcrn von Vitis vinifera Lin. durch Leveillé beobachtet.

\section{Phyllosticta riticola Thïm. nor. spec.}

Septoria viticola Berk. et Curt. sec. Ravenel.

Ph. peritheciis amphigenis, sed praccipue hypophyllis, in pagiua superiore vix subimmersis, paucis, in pagina inferiore prominulis, in macula magna, exarida, plus minus orbiculata, interdum confluentia, subter fusca, superne fusco-purpurea, exacte limitata, densissime gregariis, minutis, globosis, epidermide tectis, postremo aliquando liberis, numerosissimis; sporis minutis, paucis, brevi-ellipsoideis, utrinque rotundatis, simplicibus, nucleatis, nucleo uno maximo in medio parte, 8 -9 mm. long., $4 \mathrm{~mm}$. crass., achrois.

Ad Vitis vulpinae Lin. folia viva. America septentr.: Aiken, Carolinae australis. (H. IV. Ravenel.)

Den Angaben des Sammlers, H. W. Ravenel, zufolge ward dieser Pilz von Berkeley und Curtis als Septoria viticola bestimmt, in der mir zugiinglichen, sehr reichen Literatur konnte ich jedoch diesen Namen nirgends auffinden, auch ist er nicht in der nenesten Publication Berkeley's ïber die Pilze Nord-Amerikas zu finden (Berkeley M. J., Notices of North American Fungi in Grevillea I-IV, wo im III. Bande ron Seite $8-12$ die SeptoriaArten abgehandelt werden). Die mikroskopische Untersuchung zeigte ïbrigens auch, dass vorliegender Pilz nicht zur Grattung Septoria, sondern zu Phyllosticta zu stellen sei, da die Sporen einfach und nicht, wie bei ersterem Genns, lang und vielfach septirt sind. - In mehr oder minder kreisrunden Flecken, welche auf den Blättern zerstreut sind, eine ansehnliche Grösse haben, bis zu $1.3 \mathrm{~cm}$. im Durchmesser, und zuweilen ineinander übergehen, stehen die ungemein zahlreichen, keine bestimmte Ordnung einhaltenden Perithecien. Die Flecken sind auf der Blattoberseite purpur-bräunlich, unterhalb schön hellbraun. Die Perithecien sind ziemlich klein, fast immer von der Oberhaut bedeckt und unterseits etwas, oberseits kaum merklich hervorragend, von kugeliger Gestalt und ziemlich fest. Die wenig zahlreichen Sporen sind ellipsoidisch, oben und unten abgerundet, 
einfach, furblos und führen in der Mitte einen sehr grossen, die ganze Breite der Spore eimehmenden, wasserhellen Nuclens. Die Läinge der Sporen beträgt 8-9 mm., die Breite $4 \mathrm{~mm}$., diese Grösse ist ganz constant. - Dass diese Ply llosticta den davon befallenen Wein'eben sehr schädlich ist, liegt auf der Hand, da durch die grossen, ausgetrockneten Stellen in den Bliittern deren Lebensfähigkeit sicherlich sehr stark beeinträchtigt wird. - Bisher nur auf lebenden Blätter'n von Vitis vulpina Lin. im nordamerikanisehen Staate Siid-Carolina von H. W. Ravenel gesammelt. (Tab. V. fig. 17.)

\section{Phyllosticta Labruscae 'Thiim. nov. spec.}

Ph. peritheciis mediis, dense gregariis, numerosis, sine ordine dispositis, epiphyllis, hemisphaericis, prominentibus, atris in macula suborbiculari, distincte linitata, lineam brunueam cincta, exarida, rufo-fusca, epiphylla, in pagina inferiore maculam pallidam fuscescentem, indistinctam formans; sporis numerosis, oblongis, regularibus, ntrinque rotundatis, diaphanis, episporio tenui, achrois, intus grumulosis, 9-11 mm. long., 6-7 mm. crass.

In foliis vivis Vitis Labruscae Lin. prope Newfield, NewJersey, America septentrionalis. Aestate 1877. (J. B. Ellis.)

Von der auf den Blättern von Vitis vulpina vorkommenden Phyllosticta viticola Thüm. (Septoria viticola Berk. et Curt.) unterscheidet diese Art sich schon anf den ersten Blick. Die, beiden Species gemeinschaftlichen, bramnen Flecken auf den Blättern sind bei vorliegender Art etwas grösser auf den ïlteren, wreit kleiner und zahlreicher auf den jüngeren Blättern. Die Farbe ist ein mehr oder minder mattes Rothbraun, auf der Blattunterseite ist der Fleck, wohl theilweise dureh den Filz derselben verursacht, kaum wahrnehmbar und erscheint eigentlich nur in einer zwischen Rosa und Gelborange die Mitte haltenden Färbung, begrenzt ist er hier gar nicht, während er oberseits dureh eine sehr feine, dunkelbraune Linie anf das Schärfste abgegrenzt erscheịnt. Die bei Phyllosticta viticola anf beiden Blattfläichen, jedoch vornehmlich unten erscheinenden Perithecien sind bei unserer Art ausschliesslich auf der oberen vertheilt, sie sind ohne jede Ordnung auf den braunen Flecken dicht stehend zerstreut, kaum manchmal sehwach an eine concentrische Anordnung 
erinnerud. Ihre Gestalt ist lalbkugelig, sie ragen ziemlich weit hervor und sind glinzend schwarz. Die im Imnern befindlichen zahlreichen Sporen sind oblong, regehmässig von Gestalt, oben und unten abgerundet; durchscheinend, inwendig körnig, haben ein feines, zartes Episporium, sind farblos und messen 9-11 $\mathrm{mm}$. in der Länge, 6-7 mm. in der Breite. - Auf jeden Fall ist der durch diesen Pilz den Weinstöcken rerursachte Schaden ein cbenso intensiver als der, welchen Phyllosticta viticola hervorbringt, die in grosser Menge auf den Blättern auftretenden dïrren Flecken miissen sicherlich ein friihzeitiges Abfallen derselben verursachen. - Im nordamerikanischen Staate New-Jersey bei Newfield ward dieser Pilz von Herrn J. B. Ellis anf den lebenden Blättern yon Vitis Labrusca Lin. entdeckt und mir cingesendet. ('Tab. III. fig. 10.)

\section{Ascochyta Ellisii Thiim. nor. spec.}

A. peritheciis hypophyllis, dense gregariis, sine ordine dispositis, distinctis, prominulis, conico-hemisphaericis, liberis, opaconigris in macula orbiculari, numerosa, subparva, limitata sed non cincta, dilute fusca, subexarida; sporis globosis vel oratis vel ellipsoideis, simplicibus, episporio crasso, laevi, hyalinis, utrinque rotundatis, numerosis, $6-8 \mathrm{~mm}$. long., $5-6 \mathrm{~mm}$. crass.

Ad folia viva Titis Labruscae Lin. America septentr.: NewJersey. Aug. $1877 \mathrm{leg}$. J. B. Ellis. - Saepe in pagina superiore etiam Phyllosticta Labruscae Thiim. occurrit.

Auf der Unterseite der lebenden Blätter einer Culturform von Titis Labrusca Lin. ohne allen Filz, finden sich zahlreiche, mehr oder minder runde Flecken von hellbrauner Farbe, sie sind scharf abgegrenzt, aber nicht dureh eine farbige Linie, ziemlich ausgetrocknet und klein; ohne jede bestimmte Anordnung finden sich daranf' zahlreiche, dicht stehende, kleine Peritheeien, welche fast halbkngelförmig herrorragen, von der Oberhant unbedeckt sind und eine mattschwarze Farbe haben. Diese Perithecien enthalten zahlreiche kleine Sporen, deren Form vom Kugeligen bis zum Eirunden und Elliptischen übergeht, sie sind farblos, haben ein ziemlich dickes Episporium oder, wenn man will, enthalten sie einen verhältnissmäissig sehr grossen, fast die ganze Spore ausfüllenden Nuclens, an beiden Polen sind sie 
abgerundet und messen $6-8 \mathrm{~mm}$. in der Länge und $5-6 \mathrm{~mm}$. in der Breite. Häutig tindet sich anf denselben Blättern, jedoch nur ober'seits die Plryllosticta Labruscae Thüm. ebenfalls vor. Die Flecken, welche dieser Pilz hier verursacht, sind von einem viel intensiveren Braumoth als die sterilen Flecken der Ascochyta, haben auch die unserem Pilze fehlende, charakteristische, feine, brame Grenzlinie, so dass beide Arten selbst mit blossem Auge leicht von einander zu tremnen sind. - J. B. Ellis fand diesen neuen Parasiten auf einer ganz unbehaarten Culturform der Vitis Labrusca im Staate New-Jersey bei Newfield in Nord-Amerika im August 1877. (Tab. V. fig. 18.)

Auf lebenden Blättern kommen ferner noch folgende schon abgehandelte Species vor:

Oidium Tuckeri Berk. - Seite 1,

Gloesponium ampelophagum Sace. - Seite 9,

Spliaceloma ampelimum De By. - Scite 18,

Crudosporium Funago Ik. - Seite 22.

\section{B. Auf abgestorbenen Blättern.}

\section{Ilucor stolonifer Ehrbg.}

Ehrenherg, Sylvae mycolog. berolin. p. 25. - Link in Linné, Spee. plant. cura Willdenow VI. 1. p. 92. - Wallroth, Fl. cryptog. germ. II. p. 323. - Fries, Systema mycol. III. p. 321. - Rabenhorst, Deutsehlands Kryptogamen-Flora I. 1. 131, no. 1194. - Nees ab Esenbeck, System der Pilze Tal. 5. - Zimmermann, das Genus Mrucor p. 49. - lihizopus nigricans Elrbg. in Nova Acta Acad. Leop. X. p. 198, Tab. 11.

II. byssinus, floccis fertilibus, simplicibus, basi stolones radicantes emittentibus, peridiolis olivaceo-nigris sporidiisque globosis. - Flocei fertiles magis fasciculatim juncti (quam in M. clavato lk.), breviores, sicci olivacei. Adoleseentibus peridiolis flocei fertiles basi enituntur flocenlos radicantes, quo transitus ad Thelactin evidens. - Fr. l. c. - Sporae 7 -12 mm., zygosporac $17-20 \mathrm{~mm}$. dianetro sec. clar. Zimmermann.

In foliis putridis Vitis viniferae Lin. - Fries 1. c.

Diese sehr häufige, an faulenden Pflanzenresten aller Art vorkommende Species kann ich nicht besser beschreiben, als 
wenn ich die Worte Zimmermann's aus seiner vortrefflichen Monografie hier wiederhole. "Mycelium in und auf dem Substrat verbreitet, ein bis drei Centimeter lange, bogig anfsteigende und sich wieder niedersenkende, mit Wurzelhaaren am Substrat haftende Stolonen treibend. Fruchttrïger meist zu zwei bis fünf, selten zu sechs bis zwölf, dicht neben einander auf dem Substrat entspringend und dam spitzwinkelig divergirend, stets straff anfrecht, bräunlich gefärbt und 2-3 Millimeter hoch. Sporangium tief schwarzblau, mdurchsichtig, grobkörnig-warzig, eirca 0.2 bis 0.35 Millimeter, sehr selten blos 0.03 Millimeter im Durchmesser, mit hochkuppelförmiger Columella, die sich nach dem Zerfallen des Sporangiums gewïhnlich schirmartig umstiilpt. Sporen kugelig oder breit oval, nach dem Austrocknen oft an beiden Enden genabelt und fein gestreift, durchschnittlich $12 \mathrm{~mm}$. im Durchmesser; der Durchmesser sinkt jedoch zuweilen, aber selten bis auf $7 \mathrm{~mm}$. herab. Zygosporen an den Berïhrungsstellen ordmungslos iiberemander liegender Hyphen, kugelig, circa $17-20 \mathrm{~mm}$. im Durchmesser, Anfangs schwarzblan, dann sehwarzbratn, mit stark hervortretenden, dicken, unregelmässigen, hohlen, warzenförmigen Vorsprüngen versehen. Suspensoren von verschiedener Grösse." - Nach Fries a. a. O. auf faulenden Blättern von Vitis vinifera Lin. (Tab. I, fig. 8.)

\section{Haplotrichum epiphyllum Rabh.}

Rabenlorst, Dentschlands Kryptogamen-Flora p. 101. no. 933. - Acludium epiphyllum Wallr. Fl. cryptogamica Germaniate II. ]1. 288, no. 1889.

H. hyphis erectis, productis, tenerrimis, fuseo-ferrugineis, effusis, parce fasciculatis, dein eflusis persistentibus, e vertice sporidia primum umbellata, ovalia, exigna, pellucida spargentibus. WVallr. 1. c.

Ad folia contabescentia Titis vinifercte Iin. Thuringia, autumno. (Wallroth.)

Die von Link aufgestellte Gattung Maplotrichum unterscheidet sich von der Gattung Acladium Nees ab Esenbeck's vornehmlich dadurch, dass die Sporen bei ihr an der Spitze der Hyphen dicht zusammengedrïngt eine Art von Kopf bilden, während sie bei dem anderen Genus sich eimzeln von der Spitze der Hyphen abschniiren. Rabenhorst hatte also vollkommen Recht, die Wall- 
roth'sche Art von Acladium abzutremen, wie wir sofort aus der Beschreibung des Pilzes schen werden, welehe ich allerdings lediglich nach den Angaben der beiden oben genannten Mykologen verfassen muss, da ich noel keine Gelegenheit hatte, gerade diese Art aus Autopsie kennen zu lernen, obzwar ieh in meinem Herbar mehrere Species der Gattung Haplotrichum besitze. Die Hyphen sind bei unserer Art alle aufreeht stehend, sehr zart und dïnn, röthlichbraun, zum Theil bündelförmig vereinigt, sie entspringen ans einem weit verbreiteten Mycelium und bilden ziemlich grosse Rasen. Am Scheitel der Hyphen entwickeln sich die kleinen, eiförmigen, mit einem Nabel versehenen, durchsichtigen Sporen, welehe zu Anfang doldig um das Hyphenende gruppirt, cin lockeres Köpfehen bilden. - Von Wallroth ward unser Pilz auf faulenden Blättern des gemeinen Weinstockes, Titis vinifera Lin. im Herbste in Thïringen entdeckt.

\section{Acrostalagmus cimmabarinus Cda.}

Corda, Icones fungorum, II. 1. 15, Tab. 10, fig. 66. - Willkomm, Wunder der Mikroskopie p. 92. fig. a-e. - Cooke, Handb. of British Fungi p. 635 c. icon. Berkeley, Ontlines of fungology p. 408. - Fuckel, Symbolae mycologicae p. 145. Id. Fungi rhenani exsiccati no. 155. - Thüimen, Fungi anstriaci exsiceati no. 990.

A. eaespitibus tenuibus, effusis, laxis, detergibilibus, cinnamomeis; hyphis primo repentis, denum erectis, septatis, ramosis, ramulis plus minus conico dispositis, verticillatis, apicibus globulis sporarum ornatis; globulis sporarum primo guttulis gelatinosis immersis, demum nudis; sporis parvulis, aerogenis, radiatim aggregatis, eontinuis, ellipticis, hyalinis vel pallidissime roseis, utrinque rotundatis, simplieibus, numerosissimis, $3-4 \mathrm{~mm}$. long., $1.5-2 \mathrm{~mm}$. erass.

Ad folia exsieea putrida Vitis vinifercue Lin. Bohemia. (Thümen.) Auf grïnen und dam plötzlich getödteten und sich zersetzenden Blättern bilden sich mehr oder minder ausgebreitete, zarte, dïnne, leicht wegwischbare Rasen von schön zimmtbratmer Farbe. Die, das Mycel bildenden Fiiden kriechen unter der zerbröckelnden Blattoberhant und senden, dieselbe durchbrechend, steif aufreeht stehende, mit Querwänden versehene Hyphen empor. Diese, von wasserheller Farbe, verzweigen sieh in ihrer oberen Hïlfte und bilden einen, mehr oder minder kegelfürmigen 
Fruchtstand. Die Zweige sind nur einfach und tragen an ihren Enden kleine Kügelchen, welche aus, dureh eine Art Schleim, verbundenen Sporen bestehen. Später, sowie unter Berïhrung mit Wasser lösen diese Sporenkügelchen sich auf und die einzelnen Sporen selbst werden frei, sie sind kurz elliptisch, einfach, oben und unten abgerundet, ohne Nuclei, wasserhell oder ganz schwach röthlich gefärbt und messen $3-4 \mathrm{~mm}$. in der Länge und 1.5-2 $\mathrm{mm}$. in der Breite. - Auf Blättern von Vitis vinifera Lin. in Böhmen von mir gefunden.

Fuckel bringt a. a. O., unbedingt ohne alle Berechtigung und nur seiner Combinationsmanie folgend, unseren Pilz mit seiner Trichosphaeria erythella in genetischen Zusammenhang, einem Pilze, welcher lediglich anf den faulenden Stengeln von Brassica-Arten anftritt! Acrostalagmus cinnabarimus hingegen ist ein ganz gemeiner Schimmelpilz, weleher auf den verschiedensten, in Zersetzung begriffenen Pflanzentheilen iiberall anzutreffen ist! (Tab. II. fig. 13.)

\section{Chaetostroma pedicellatum Preuss.}

Preuss in Limnaea 1851. XXIV. p. 148, no. 160. - Fnckel, Symbolae mycologicae p. 369. - Pirotta, Fungli parassiti dei Vitigni p. 70.

Ch. gregarium, perlicellatum, prinum album demum fuscescens; stromate pulvinato, subhemisphaerico, basi praesertim setoso; setis subulatis, septatis, albis; strato hymenii crasso tecto; floceis sporidiiferis filiformibus; sporis oblongis, minutis, hyalinis, allbis. Preuss 1. c.

Ad folia putrida Titis viniferce Lin. Rarissime. Vere. Nassovia. (Fuckel.)

Meine Exemplare dieser äusserst seltenen Speeies sind zwar nicht auf Weinblättern, sondern auf solehen einer unbestimmten Rosen-Art, da jedoch Fuckel a. a. O. anch Vitis als Substrat anfiihrt, so gebe ich einfach eine kurze Beschreibung des Pilzes. Die Häufchen sind ungemein klein und stehen dicht ancinander. gedrängt, sie sind scheinbar etwas gestielt, hellbraun (nach Preuss zu Anfang weiss!), an der unteren Seite sind sie mit wenigen, borstigen oder kurzpfriemenförmigen, nach dem Autor septirten, Härehen bekleidet. Die Hyphen sind sehr kurz, fadenförmig, farblos, die winzigen Sporen einfach, elliptisch oder oval, wasser- 
hell oder, Preuss zufolge, weiss, welche letztere Angabe ich jedoch entschieden für nicht richtig halte, ihre Tänge beträigt $2-2.5 \mathrm{~mm}$., ihre Breite 1 mm. - Auf faulenden Blättern von Vitis vinifera Lin. Sehr selten. Nassau. (Fuckel.)

\section{Botrytis cinerea Pers.}

Persoon, Synopsis fungorum p. 690. - Flora danica, Tom. XIII. no. 2278. 2. Fries, Syst. mycolog. III. p. 396. - Nhertini et Schweinitz, Fungi Niskiensis 1. 363. - Schmmacher, Flora Saellandica II. 1. 238. - Link in Linné species plantarum eura Willdenow I. p. 60. - Fuckel, Symbolae mycologicae 1. 330. De Bary, Morphologie und Physiologie der Pilze p. 30 et 201. - Polyactis sclerotiophila Rabh. in Klotzseh, Herbarium vivum myeologienm no. 1668.

B. thallo elevato, effuso, floccis fuligineo-cinereis, subramosis, sporidiiferis simplicibus, parum elevatis, sporidiis globosis, concoloribus. - Plagas non ita magnas ocerpat, floceis vix linean altis, simplieibus hine inde ramosis, articulis alternatim valde constrictis; sporidiferi reliquis non altiores; sporidia parva, globosa, vinosa. - Lk. l. e.

In Sclerotio echinato Fuck. ad Vitis viniferce Lin. folia subputrida, parasitans. Ubique. Hieme-vere.

Wenu man von einigen veralteten, nicht mehr gebräuchlichen "terminis technicis" absieht, ist die Diagnose Link's noch immer so gut, dass eine bessere sehwer zusammenzustellen wäie. Ich lasse daher dieselbe hier stehen und schicke nur noch einige Bemerkungen voraus, bevor ich den Pilz in dentscher Sprache beschreibe. Botrytis cinerea Pers. ist eine allgemein anf faulenden Stengehn und Blättern verbreitete Art, die Form auf dem Fuckelschen Sclerotium echinatum weicht in nichts ron der Norm-Art al, als in Substrate, und ich bin daher kamm zweifelhaft gewesen, ob ieh den, von Rabenhorst gegebenen Namen Polyactis sclerotiophila adoptiren sollte, und entschloss mich den alten Namen beizubehalten. Ein besonderes Interesse erlangt unser Pilz durch die Untersuchungen De Bary's a. a. O., wo er angibt, dass Sclerotium echinatum a uf fenchtem Boden gesäet die Butrytis, unter demselben Peziza Fuckeliana ergebe, im letzteren Falle ohne Conidienträger, d. h. Botrytis gebildet zu haben. Ob trotz dieses, eigentlich doch negativen Resultates, die Botrytis cinerea als Conidienform zu obiger Peziza gezogen werden könne, erscheint mir immerhin noch sehr 
zweifelhaft und bin ich eher geneigt, sie als einen ganz gewöhnliehen Schmarotzer des Sclerotiums anzusehen. De Bary schreibt a. a. O.: "Aus den Keimschläuchen der Ascosporen erhielt ich in manehen Culturen wiederum nur Sclerotien, ohne Conidienbildung. Die letztere kann daher völlig ïbersprungen werden, insofern die Selerotien direct wiederum die Aseusträger zu erzeugen vermögen. In anderen Fällen treibt das in dem Rebenblatte wuchernde Mycelium gleichzeitig mit der Selerotienbildung oder vor und nach derselben zahlreiche aufrechte, conidientragende Botrytis-Fäden. Aus den Keimschlänchen der Conidien sah ieh, sowohl anf Rebenblättern als auf anderen pflanzlichen Organen und Substanzen, zunächst immer reichlich Botrytis tragendes Mycelium hervorgehen. Dass dieses, wenigstens auf den Blättern der Rebe, anch Sclerotien zu erzeugen vermag, ist kaum zweifelhaft, obgleich sichere directe Beobachtungen darïber fehlen. Es ist bekannt, dass mehrere, ungemein häufige Sclerotium-Formen, wie die als S. durum, S. bullatum besehriebenen, gleichfalls sowohl BotrytisFäden austreiben, als von einem Botrytis tragenden Mycelium ihren Ursprung nehmen und diese Botrytis ist vou dem conidientragenden Apparate der Peziza Fuckeliana nicht zu unterscheiden. $\mathrm{Ob}$ letztgenannte Sclerotien dem Formenkreise dieser nämlichen Species oder anderen, nahe verwandten angehören, ist noch zu entscheiden. Auf den genetischen Zusammenhang der sogenannten Botrytis cinerea mit selerotienbildenden Pezizen hat Miunter auf der dentsehen Naturforscher-Versammlung zu Speyer zuerst in miindlichem Vortrage aufmerksam gemacht; nur hat er, irregeleitet durch die Aehnlichkeit, welehe die verschiedenen hierher gehörigen Sclerotien mit einauder zeigen, die Botrytis cinerea Pers. zu Peziza Sclerotiorm Lib. gezogen!" - Noeh sei hier bemerkt, dass Fuckel, welcher unseren Pilz auch unter no. 148 in seineu "Fungi rhenani exsiccati" edirte, zu den Worten "Fungus conidiophorus" ein Fragezeichen machte, nach ihm heisst uibrigens der oben von De Bary Peziza Fuckeliana genannte Schlauchpilz Sclerotinia Fuckeliana Fuck., unter welchem Namen er anch von mir auf Seite 197 besehrieben wird. - Zum Schlnss eine kurze Besehreibung des Pilzes, wie el sieh auf dem angegebenen Substrate zeigt. Auf den Sclerotien, welche sich auf den Nerven der Weinb]äter befinden, erheben sich kleine, nur wenig ausgebreitete Rasen, welehe aus Büseheln von aschgranen Färlen bestehen, welche sehr 
dicht bei einander wuchern. Diese Fäden sind in halber Höhe ungefähr, wirtelästig getheilt, sehr zart und in Glieder abgetheilt. An ihren Spitzen und zuweilen auch am Aste selbst tragen die sämmtlichen Wirteläste kleine, dicht gedrängte Sporenknäuel, deren Sporen wasserhell, kugelig oder kurz eiförmig sind und 1-1.8 mm. im Durchmesser haben. - Parasitisch auf dem, auf Weimblättern, Vitis vinifera Lin., wuchernden Sclerotium echinatum Fuck. Ueberall, im Winter. (Tab. III. fig. 15.)

\section{Phymatostroma fusarioides Cda.}

Corda, Icones fungorum I. p. 5, Tab. 1, fig. S2. - Rabenhorst, Deutschlands Kryptogamen-Flora p. 57. no. 557.

Pl. effusum, seriation confluens, pallide roseum, stromate diffuso; fruetulis magnis, angularibus, roseis; sporis fusiformibus, hyalinis, alteris. - Cda. 1. e.

Ad folia putrida Vitis vinifercte Lin. Bohemia, Prag. (Corda.)

Ich hatte bisher keine Gelegenheit, diesen, wie es scheint, sehr seltenen Pilz, (denn er wird von keinem anderen Autor als Corda angegeben) zu beobachten, muss mich daher damit begniigen, eine Beschreibung nach der lakonischen Diagnose und der auch nicht recht befriedigenden Zeichnung Corda's zu geben.' Der Pilz bildet weit verbreitete und in Reihen zusammenfliessende Räschen von blass rosenrother Fïrbung, das Mycelium ist weit verzweigt und verästelt, zellig fleischig, die 'T'rägersehicht ist gross, winkelig-ästig und ebenfalls rosenroth und schniirt die zahlreichen, farblosen, spindelförmigen, an beiden Enden scharf zugespitzten Sporen ab. - Von Corda bei Prag in Böhmen auf faulenden Blättern des gemeinen Weinstockes, Vitis viniferc Lin. gefunden. (Tab. II. tig. 18.)

\section{Selerotinia Fuckeliana Fuck.}

Fuckel, Symbolae mycologicae p. 330. - Perisa Fuckeliana De Bary, Morphol. u. Physiol. der Pilze p. 30, 39, 201.

S. individuis sparsis, minutis e Sclerotio excrescentibus; cupulis minutis, plus minusve infundibuliformibus, carnosis; asci, sporidiaque non vidi. 
E. Sclerotio echinato Fuck., in Vitis viniferce Lin. foliis parasitans, orto.

Alles, was mir bisher uiber diesen interessanten Discomyceten bekannt geworden ist, habe ich bereits bei Botrytis cinerea Pers. und Sclerotium echinatum Fuck. gesagt und kaun es dort nachgelesen werden. De Bary a. a. O. stellt wohl den Namen auf, gibt aber weder eine Diagnose, noch eine Beschreibung, noch eine Abbildung mit Ausnahme eines, zwanzig Mal vergrösserten Durchschnittes durch ein Exemplar des Pilzes. Weder Fuckel, wie er a. a. O. sagt, sah die Sclerotinia, noch ich, noch war es mir möglich, von einem meiner Correspondenten cin Exemplar zu erhalten. Auch gliiekte mir niemals eine Cultur der Selerotien.Der Pilz entsteht aus dem Sclerotium echinatum Fuck. auf faulenden Blättern von Vitis vinifera Lin.

\section{Excipula viticola $\mathrm{Sch} \mathrm{w}$.}

Schweinitz, Synopsis of North American Fungi p. 246, no. 2125.

E. minutissima, punctiformis, sparsa, aterrima, demum fere omnino aperto, disco candido. - Schwz. l. c.

In Vitis custivalis Mchx. foliorum pagina aversa. Raro. America septentr.: Pennsylvania. (Schweinitz.)

Von dieser Species habe ich keine Fxemplare zu Gesicht bekommen kömmen. Schweinitz beschreibt dieselbe kurz und bündig als sehr klein, punktförmig, zerstreut stehend, tiefschwarz, endlich fast ganz geöffnet und eine weisse Scheibe zeigend. El fand sie auf der unteren Seite (wohl abgestorbener?) Blätter von Vitis aestivalis Mchx. bei Bethlehem im nordamerikanischen Staate Pennsylvanien.

\section{Rhytisma Vitis Schwz.}

Schweinitz, Synopsis of North American Fungi p. 241, no. 2037. - Berkeley, Notices of North American Fungi in Grevillea IV. p. 8. - Pirotta, funghi parassiti dei Vitigni p. 20.

Rh. innatum, 1-2 lineam diametro, orbiculatum aut subquadratum, atrum; pagiua superiori demum dehiscens plicis flexuosis, irregularibus, pagina inferiori subeinerascens, ant cum foliam pruinosun, aequabile sed tamen punctatulum. - Schwz. l. c. 
In foliis putridis (nee in vigentibus observatum) Vitis aestivalis Mchx. America septentr.: Carolina australis et Pennsylvania. (Seliweinitz.)

Von der zweiten Art del Gattung Rhytisma, welche auf Weinblättern gefunden ward, der Rhytisma melogromme jedenfalls grumdversehieden, und zwar ist es wohl eine echte Rhytisma, ein Schlanchpilz (obzwar der Antor von den Ascis und Sporen nicht spricht), während die Berkeley'sche Art, wie ich bei derselben bemerkte, wohl eine Discosia oder Melasmia sein dürfte. Ich bin sogar eigentlich geneigt, natiirlich mit der grössten Reserve, diese beiden Pilze mit einander in Verbindung zu bringen und spreche die Vermuthung aus, dass Rhytisma melogramme die Spermogonienfor'm vorliegender Rhytisma sei. Die gleiche Nährpflanze beider Species unterstiitzt diese Annahme; Gewissheit kann man freilich erst dureh Untersuchung und Vergleichung von Original-Exemplaren erhalten. Der Autor diagnosirt unsere Form folgendermassen: die Perithecien sind eingewachsen, eine bis zwei Linien im Durchmesser haltend, kreisrund oder beinahe quadratisch, tief schwarz, sie bilden auf der oberen Blattfläche aufplatzende, hin und her gebogene, unregelmässige Falten, auf der unteren hingegen fast aschgraue Flecken, welche wie das Blatt selbst bereift sind, und zwar geglättet und gleichartig aber doch punktirt sind. - Von Schweinitz entdeckte diesen hochinteressanten Pilz auf den faulenden Blättern von Vitis aestivalis Mehx. (er bemerkt dabei ganz ausdrücklich, dass er ihn nicht auf noch lebenden Blättern fand) in Süd-Carolina und Pennsylvanien.

\section{Acrospermum Ravenelii Berk. et Curt.}

Berkeley, Notices of North American Fungi in Grevillea IV. p. 161, no. 999.

A. clavatum, breve; ascis elongatis, sporidiis filiformibus. Berk. l. e.

Ad folia arida Vitis Labruscae Lin. America septentr.: Carolina septentrionalis (Curtis.)

Ich habe diese Art nicht gesehen, kann also nicht angeben, in wiefern sie sich von Acrospermum compressum Tode unterscheidet, die Autoren begniigen sich damit, zu sagen, dass die Perithecien kurz keulenförmig sind und lange Schläuche mit fadenförmigen Sporen enthalten. - Sie wächst auf abgestorbenen 
Blättern von Vitis Labrusca Lin. im nordamerikanischen Staate Carolina, wo Curtis sie auffand.

\section{Acrospermum compressim Tode.}

Tode, Fungi Mecklenburgenses selecti, I. p. 8, Tab. 2, fig. 13 a-f. - Fries, Syst. mycol. II. p. 245. - Berkeley, Fungi exsiec. no. 270. - Bischoff, Cryptog. fig. 3406. - Engl. Flora, V. p. 221. - Lib. Crypt. arden. exsice. no. 32. Cooke, Handb. of British Fungi I. p. 430. - Fuckel, Symb. mye. p. 92. Fuckel, Fungi rhenani exsice. no. 776. - Karsten, Mycol. fennica p. 247. Clavaria compressa Purt. Brit. plants III. no. 1587, Tab. 19, fig. 3. - Clavaria herbasum Pers. Fungi clav. 1. 69, Tab. 3, fig. 4. - Pers. Syn. fung. p. 605. De Candolle, Flore française VI. p. 30. - Scleroglossum lenceolatum Pers. in Mougeot, erypt. voges. exsicc. no. 67. - Sclerotium herbarum N. a. Esenbeck, Syst. der Pilze II. p. 84. - Xyloglosum herbam Pers. in sched.

A. perpendiculare, orate elongatum, compressum, rigidissimum. Fungus perennans, linea aliquantulum, longior, Clavariam simulans, rigidissimus; cute laevi, membranacea, a carne inseparabili, olivacea, demum nigrescente, substantia glutinosa, cito indurescente, alba. Apicem versus e rugis, seu sulcis, quibusdam circularibus, parallelis, pollen erumpit candidum, quo mox acumen integrum obtegitur. Fructescentia peracta semina aurae afflata avehuntur, fungo demum complanato et longitudinaliter sulcato. - Tode 1. e.

Perithecia solitaria vel subcaespitosa, perpendicularia, libera, sessilia vel stipitata, elongata vel claviformia, apice attenuata, ut plurimum compressa, primitus pallida, tandem fuseo- vel olivaceonigrescentia vel nigricantia, nitidula, primo laevia, exolete longitudinaliter sulcata, altitudine, eireiter 1 millim. Asci filiformes, longissimi, $3-5 \mathrm{~mm}$. crass., sporae 8, parallelae stipatae, tiliformes, dilute luteolo-hyalinae, longitudine fere asci, crassitudine vix $1 \mathrm{~mm}$. - Karst l. c.

Ad folia semiputrida Vitis Labruscae Lin. - America septentr.: Poughkeepsie, New-York (IV. R. Gerard), Newfield, NewJersey (J. B. Ellis.) Aiken, South Carolina (Ravenel).

Auf allen möglichen faulenden Stengeln und Blättern findet man bei uns in Europa diesen Pilz, aber auf Weinblättern, soviel mil wenigstens bekannt, ist er noch nicht beobachtet worden. Ganz umgekehrt scheint sich dies in der neuen Welt zu verhalten, unter den vielen 'Tausenden von Pilzen, welche ich bereits 
aus Amerika erlielt, fand sich wohl öfters das Acrospermum compressum, jedoch immer nur auf faulenden Blättern von Vitis Labrusca Lin., niemals auf einem anderen Substrat, woraus jedoch noch lange nicht gesehlossen werden darf, dass er dort ausschliesslich auf Weinblätter besehränkt sei, er kann ebenso gut bisher nur ausserdem ïbersehèn worden sein. Der Pilz selbst bildet auf der oberen Seite von in Zersetzung begriffenen Labrusca-Blättern kleine, keulenförmige, gerade auflecht stehende, schwarze Peritheeien; diese sind ungefähr 1 Min. hoch und ungemein leicht abbrechbar. Von Fuckel und einigen neueren Mykologen wird er zu den Schlauchpilzen, und zwar zu der Familie der Perisporiaceen, wozu auch die Erysiphe, Mehlthau-Arten, gehören, gerechnet und in die Nähe von Ostropa Fr. und Lophium Fr. gestellt, während man ihn frïher, und selbst noch Cooke a. a. O., zu den Sphaeronemeen zog. Die Schläuche sind ungemein lang, fadenfürmig, wasserhell, bei nur 3-5 mm. Breite; die acht Sporen sind fadenförmig, gelblich-wasserhell, alle neben einander liegend, nur $1 \mathrm{~mm}$. breit und beinahe so lang als der Schlauch. - Auf faulenden Vitis Labrusca-Bliittern, wie es scheint, in ganz NordAmerika nicht selten.

\section{Sphaerella Vitis Fuek.}

Fuckel, Symbolae mycologicae p. 104. - Id. Fungi rhenani exsiccati no. Sz9. - Thïmen, Fungi anstriaci exsice. no. 658. - Pirotta, funghi parassiti dei Vitigni p. 30. - Sphaeria Vitis Rablı. in Klotzsch, Herbariun mycol. oeconom. Ser. I. no. 1047. - ? Splucieria maenliformis Pers. in Westdorp, Les cryptog. d'apres l. stat. natur. p. 106.

Sph. peritheciis dense gregariis vel confluentibus, hypophyllis, minutis, atris, vix hemisphacricis in maculis parvis, gregariis, irregularibus, nitido atris; nucleo compacto, durissimo, albido, pellucido, crispulo; aseis invisibilibus, non certe conspicuis, nidulantibus, sporis longe ellipsoideis, utrinque rotundatis, medio septatis et ad septum constrietis, fusco-cinereis, $20 \mathrm{~mm}$. long., $10-$ $12 \mathrm{~mm}$. crass.

Ad folia arida Vitis vinifercae Lin. Nassovia (Fuckel), Bohemia (T'hïmen), Austria inferior (Thümen).

Ein ganz eigenthüimlicher Pilz diese Sphaerella! - Sie bildet auf der Unterseite todter Blätter ziemlich kleine, unregelmässige, 
meist durch Nerven scharf abgegrenzte, schwärzlich-matte Flecken, welchen eben solche, nur etwas heller gefürbte auf der Oberseite entsprechen. Auf diesen Flecken stehen dicht zusammengedrängt, zuweilen ineinander verfliessend die kleinen, kaum halbkugelförmig hervorragenden, schwarzen Perithecien. In diesen aber ist es mir, gerade wie Fuckel auch von sich a. a. O. angibt, trotz zahlloser Versuche noch nicht ein einziges Mal gelungen, deutlich einen Schlauch zu erkenmen. Genau wie Fuckel sagt: "die Peritheeien schliessen einen weissen Nucleus ein, der unter dem Mikroskope sich als eine fest zusammenhïngende, runde, durchscheinende, gallertartige, gekräuselte Masse darstellt, in welcher ich keine deutlichen Schlänche, wohl aber einzelne ejförmige Sporen unterseheiden konnte. Auch mit dem stärksten Druek gelang es mir nicht, die Masse zu zertheilen", genau so erging es auch mir. Sporen sind auch mir, und zwar jedesmal in grösserer Anzahl vorgekommen, dieselben waren aber nicht, wie Fuckel sagt, eiförmig, sondern lang elliptisch, bräunlichgrau, oben und unten abgerundet, in der Mitte septirt, und an diesem Septum etwas eingeschniirt, $20 \mathrm{~mm}$. lang, 10-12 mm. breit. Diess wäre Alles, was bisher über den Bau dieses Pilzes erforscht wurde, hoffentlich gelingt es bald, einmal reife Schlänche mit Sporen aufzufinden, ob aber dann die Art noch bei Sphaerella verbleiben oder zu einem anderen Genus versetzt werden wird, dariiber ist jetzt nichts zu sagen, vorläufig muss der Name auf jeden Fall erhaltein bleiben.

Fuckel brachte unseren Pilz mit einer Conidienform, dem von mir Septosporium Fuckelii genannten Pilze, in genetischen Zusammenhang, von Andern ward Cladosporium Roesleri als Vorform dazugezogen. Ob und welehe Form überhaupt dazu zu rechnen sei, dariber ist noch keine Gewissheit vorlianden, dass Cladosporium Roesleri Catt. dazu nieht gehört, habe ich bei der Beschreibung dieses Pilzes sowohl, als auch in der "Wiener landwirthschaftlichen Zeitung" 1876, p. 541, ausführlich nachgewiesen. - Bisher ist unsere Sphaerella aus Nassau (Fuekel), Böhmen (Thümen) und aus Nieder-Oesterreich (Thümen) anf Blätter'n des gemeinen Weinstockes, Vitis vinifera Lin., nachgewiesen, doch dürfte wohl mit Sicherheit angenommen werden, dass sie uiberall dort, wo iiberhaupt Wein gebaut wird, auch vorkommt. (Tab. I. fig. 14.) 


\section{Sphaterellat sentina Fuck.}

Fuckel, Symbolae myeologicae p. 104. - Splaceria sentinc Fr. Systema nycolog. II. p. 580. - Rabenhorst, Dentsehl. Kryptogamen-Flora p. 171, no. 1538. - Walloth, Flora german. cryptog. II. p. 775 . - Fries, Summa veg. Scand. 1. 391. - Schweinit\%, Synopsis of North American Fungi p. 224, no. 1771. Sphaerella Pyri Awd. in Rabh. et Gonnerm. Mycologia emolraea V. 1) 11, Tab. III. fig. 34 .

Spl. gregaria, peritheciis immersis, latentibus, globosis, nigris, intus albis, ostiolo erumpente subgloboso. Perithecia in foliae parenchymate latent, tecta, sed non prominent, minima, opaca, plerumque fareta. Ostiola in pagina inferiore nuda, nudo oculo S. punctiformi non alsimilia, valde opaca, multo magis distincta quam in sequentibus. - Fr. I. e.

Sph. pyreniis hypophyllis, nigris, sub summa epidermidis pellicula delitescentibus, illamque vertice hemisphaerico prominulo, subelevantibus et semiperforantibus, dense gregariis, globulosis, poro simplici pertusis, $120-140 \mathrm{~mm}$. latis; ascis clavatis, subsessilibus, octisporis, $70 \mathrm{~mm}$. long., $9 \mathrm{~mm}$. crass.; sporis fusiformibus, subcurvatis vel subsigmoideis, utrinque obtusis, uniseptatis, ad sepimentum non constrictis, biserialibus, hyalinis, 27-31 mm. long., $4 \mathrm{~mm}$. crass. - Avd. l. c.

Ad Vitis Labruscae Lin. folia, non raro. America septentr.: Pennsylvania. (Schweinitz.)

Mit Absicht habe ich bei dieser Art sowohl die Diagnose von Fries als jene von Auerswald angeführt; da es durchaus nicht gewiss ist, ob beide dieselbe species meinen. Sagt doch Anerswald selbst a. a. O.: "Ich kam mich nicht entschliessen, diese häufig auf der Unterseite von Birnenblättern vorkommende Art für die fragliche Sphaeria sentina Fr. zu erklären, da mir weder seine Diagnose (peritheciis intus albis etc.), noch der von ihm angegebene Standort (ad folia dejecta v. c. Pyri Mali) zu passen scheint". Fuckel führt a. a. O. ausser Pyrus commnnis, wenigstens für seine Pyenidienform, auch noch Pyrus Malus und Prumus domestica als Substrate an. So viel steht jedenfalls fest, auf Weinblättern füihrt kein einziger Autor die Sphaerella sentina an, mit Ausnahme von Schweinitz, und da drängt sich die Vermuthung auf, dass dieser darunter jenen Pilz gemeint hat, welchen wir Splucrella Vitis Fuck. nemnen, denn auch dieser hat einen weissen Nucleus, so dass die Bezeichnung von Fries, "peri- 
theeiis intus albis" ganz darauf passt, und ausserdem kann man sehr leicht die Fries'sche Diagnose, welche weder von Ascis noch von Sporen spricht, auf Sphaerella Vitis Fuck. anwenden. Wenn auch demnach nicht mit absoluter Sicherheit, doch ziemlich gewiss kann man also die Schweinitz'sche Sphaeria sentina als Sphaerella Vitis Fuck. ansprechen. Um den nordamerikanischen Mykologen aber Gelegenheit zu geben, dieser sehr wichtigen Untersuchung sich unterziehen zu können, reproducire ich a. a. O. die Zeichnung der Schläuche und Sporen der Sphatella Pyri Awd. Die Beschreibung dieses Pilzes, welcher positiv identisch mit der Fuckel'schen Sphaerella sentina ist, würde folgendermassen lauten: Die Perithecien sitzen schr dicht gedrängt auf der Blattunterseite, sie sind schwarz, kugelig und unter der Epidermis gelagert, welche sie mit dem etwas hervorragenden, halbkugelförmigen Scheitel emporheben und dam durchbohren, ihre Grösse beträgt 120-140 mm. Die keulenförmigen Schläuche sind ungestielt, achtsporig, $70 \mathrm{~mm}$. lang und $9 \mathrm{~mm}$. breit, sie enthalten Sporen von fast spindelförmiger oder Sigma-ähnlicher Gestalt, diese sind an beiden Enden abgestumpft, einmal getheilt, jedoch an dieser Stelle nicht eingeschnürt, wasserhell, zweireihig angeordnet und messen $27-31 \mathrm{~mm}$. in der Länge und $4 \mathrm{~mm}$. in der Breite. -- Auf Blättern (jedenfalls diurren) von Vitis Labrusca Lin. in Pennsylvanien von Schweinitz gefunden. (Tab. II. fig. 6.)

\section{Sphaeria pruina Schwz.}

Schweinitz, Synopsis of North American Fungi 1. 22:3, 10. 1770.

Sph. sparsa, minutissima, primum immersa, demum ener gens, aterrima, globosa, elongata in ostiolum subsetaceum, atrun, rleciduum. Extus pruina alba cum folia tecta. - Schwz. l. c.

In aversa pagina foliorum Vitis aestivalis Mchx. - America septentrionalis: Pennsylvania. (Schweinitz.)

Eine blattbewohnende Sphaeria, also wahrscheinlich, den in der Nähe stehenden Species nach zu urtheilen, eine Sphaerella, aber jedenfalls von unserer europäischen Sphaerella Vitis Fuck. ganz und gar verschieden, wie ans der kurzen, lediglich die äusseren, makroskopischen Merkmale berücksichtigenden Diagnose hervorgeht. Dieser zufolge stehen die Perithecien zerstreut, sind 
äusserst klein, zu Anfang eingesenkt und später hervortretend, tiefschwarz, kugelig und haben ein verlängertes, fast borstenförmiges Ostiolum (oder Mündung), welches schwarz und hinfällig ist. Auswendig sind sie mit einem weisslichen Reif iiberzogen. - Es wäre auch denkbar, dass die lange, borstenförmige Miindung vielleicht auf eine Art der Gattung Gnomonia oder wenigstens eine Ceratostomee hinwiese! - Auf der Ruickseite von (jedenfalls abgestorbenen) Blättern der Vitis aestivalis Mchx. Schweinitz entdeckte diese Art bei Bethlehem in Pennsylvanien, Nord-Amerika.

\section{Sclerotium echinatum Fuck.}

Fuckel, Enumeratio fungorum Nassoviae 1. 32, no. 215. - Id. Symbolae mycologicae p. 330. - Id. I'ungi rhenani exsiceati no. 215.

S. semiteres, elongatum, in foliorum nervis primariis adnatum, longitudinaliter striatum, atrum, cum aculeis sparsis, patentissimis, longis, concoloribus, intus sordide-album, 1/2 unciam longum et $1 / 4-1$ lineam latam. Quasi Sclerotium nervale est, eujus massa fungosa foliorum pilos obducit. - Fuckel 1. e.

Ad folia subputrida Vitis viniferce Lin. Nassovia (Fuckel), Austria inferior (Thümen) et fortasse ubique. Hieme.

Der uns hier beschäftigende Pilz bildet auf den Nerven der Blattuntcrseite, und zwar nicht nur, wie a. a. O. Fuckel angibt, auf denen erster Ordnung, sondern auf allen Nerven, sowohl den dicksten als den allerschwächsten, lange, ergossene, fast krustenartig zu nennende Massen. Sie liegen oben auf dem Nerv auf, umsehliessen ihn an beiden Seiten bis zur Blattfläche, sind ziemlich hoch, der Länge nach etwas undentlich gestreift und mit zerstreuten, sehr weit abstehenden, langen Stachehn oder besser Stachelhaaren bedeckt. Die Farbe ist aussen schwarz, matt, im Innern schmutzig-weiss; die Grösse schwankt zwischen 1-5 Mm. in der Länge, 0·3-1 Mm. in der Höhe. Zuweilen wachsen mehrere Individuen in einer Reihe eng aneinander und so entstehen fortlaufende Ketten. Ueber das Verhalten dieses Pilzes, welcher nach De Bary, "Morphologie und Physiologie der Pilze" p. 30 und 201, das Dauermyeelium seiner Peziza Fuckelianr orler Sclerotinia Fuctieliana Fuck. ist, liabe ich mich bereits 1. 195 bei Botrytis cinerea Pers. ausgesprochen. Dieser letzt- 
genamnte Pilz wird als Conidienform zu unserem Sclerotium gezogen. Dass die Sclerotinia entsteht, wem man unseren Pilz ca. $1 \mathrm{~cm}$. tief unter feuchte Erde bringt, unterliegt keinem Zweifel. Weiteres ïber diesen Punkt ist unter Sclerotinia Fuckeliana zu finden. - Anf faulenden Blättern des gemeinen Weinstockes, Vitis viniferc Lin., in Nassan (Fuckel), Nieder-Oesterreich (Thümen.)

\section{Sclerotium Semen Tode.}

Tode, Fungi Mecklenburgenses II. p. 4, Tab. 4, fig. 6. - Fnckel, Symbolae mycologicae p. 32. - Kïhn, Krankh. d. Culturgewächse p. 130. - Fries, Systema mycologicum II. p. 249. - Walloth, Flora germ. eryptog. II. p. 141. - Nees al Esenheck, System der Pilze fig. 138. - Persoon, Synopsis fungorm 1) 123. - De Candolle, Flore francaise VI. 1. 113. - Greville, Flora erylıtog. Seotiae Tal). 144, fig. 2. - De Bary, Morphologie und Physiologie der Pilze p. 30.

S. sphaericum, nigrescens, corrugandum, sparsum. - Sphaerula magnitudine seminis Sinapis, sed saepe lineari sesquilinearique diametro, glaberrima, initio nivea, mox flavescens, tum fulva, post fusca, demum nigra, cute tum in rugulas contracta. Substantia solida, rigidula, attamen succulenta, alba. Primo vere, quin durante adhuc lieme in omnis generis plantarum foliis caulibusque, hieme jacentibus et putredine correptis, ubique fere locorum in conspectum venit fungus, jam sparsim, jam vero densiore agmine proveniens, firmiterque plantis ope rudimenti styli adhaerens, rugas antem mutus sponte decidit. - Tode l. c.

Arl Titis viniferae Lin. folia putrida. Hieme. Austria inferior. (Thümen.)

Auf allen nur erdenklichen Pflanzenspecies kommt dieses Sclerotium vor, wenn dieselben faulend auf dem feuchten Erdboden liegen, namentlich wemn Bliitter eine dichte Schicht bilden, entwickelt es sich massenhaft zwischen denselben. Der Pilz hat die Grösse eines Senfkornes, manchmal hat er auch noch grössere Dimensionen, bis zu $2.5 \mathrm{Mm}$. im Durchmesser, er ist aussen glatt, zu Anfang weisslich, wird dann gelblich, später kastanienbraun und endlich tief mattsehwarz. Am Substrate ist er nur vermittelst eines schwachen, zarten Mycelfadens befestigt, welcher bei der geringsten Veranlassung abreisst, so dass man ihn in den meisten Fällen, nur lose auffindet. Nach den Untersuchungen Bail's ïber die Natur der Selerotien p. 75 ist unser Pilz das 
Danermycel von Typhula variabitis Riess. - An und zwisehen fanlenden Blättern von Vitis vinifera Lin. in Nieder-Oestemeich häufig, im Winter und Frülıjahr. (Thümen.)

Auf abgestorbenen Blättern kommen ferner noch folgende, bereits friiher abgehandelte Species vor:

Cladosporium herbarum Lk. - Seite 33, Septocylindrium virens Sacc. - Seite 48, Trichothecium roseum Lk. - Seite 45, Sporocybe byssoides Fr. - Seite 48, Eurotium herbarion Lk. - Seite 138. 


\section{Die Pilze der Wurzeln.}

\section{Agaricus Armillaria mellens Vahl.}

Vahl, Flora Danica Tab. 1013. - Grev. Cryptog. Seot. Tah. 332. - Krombholz, Schwämme Tab. 43, fig. 2-6. - Vittadini, Fungi manger. Tab. 3. - Fr. Atlas Swamper Tab. 36. - Id. Epicrisis p. 22, no. 73. - Id. Hymenomycetes emopaei p. 44, no. 101. - Cooke, Handb. of British Fungi p. 19. - Saccardo, Mycoth. veneta 1. 13. - Briganti, Histor. fung. Neapol. p. 47, Tab. XX. fig. 1-3. Afaricus suaveolens Briganti, Fungi litogr. Tab. 4. - Agaricus Vitis Brig. sec. Pirotta, funghi parassiti dei Vitigni p. 12.

A. pileo carnoso, tenui, explanato, squamoso-piloso, margine expanso, striato; stipite spongioso-fareto, anmulo floceso patente; lamellis adnatis, dente decurrentibus, subdistantibus, pallidis, demum subrufescenti-maculatis, farinosis. - Solitarius, maximus inter folia decidua sylvarum; dense caespitosus ad bases truncorum; color vulgo mellens, pili pilei vulgo nigricantes, junior sacpe olivaceo-tomentosus. - Fr. l. c.

Ad radices truncorum vivorum Vitis vinifercle Lin. et arborum aliarum. Aut. Italia: Napoli. (Briganti.)

Ein durch ganz Europa verbreiteter, änsserst gemeiner Pilz, welchen man im Herbst nach fenchten Tagen in Menge auf den Wurzeln lebender Waldbäume, sowie, wenn auch seltener, auf Wiesen finden kann, und der unter dem Namen "Hallimasch" "auch vielfach genossen wird. Sein Ifut ist mehr oder weniger verflacht, hat in der Mitte einen oder zwei Buekel, ist gelblich, honigfarben oder schmutzig-bräunlich, 5-12 cm. breit, schmierig oder trocken, mit vielen haarigen, schwarz werdenden Schiippehen 
bekleidet, am Raude dïm, anfangs ringerollt, späiter ausgebreitet, und gestreift, der Stiel ist bis $15 \mathrm{~cm}$. hoch, $2-4 \mathrm{~cm}$. dick, walzenförnig, hin und her gebogen, an der Basis etwas, verdickt, fest, voll, faserig-schuppig, zuerst blass fleischfarben, später schmutziggell, bis olivenbraun, mit cinem hängenden, abstehenden, weisslichen, flockigen Ringe; die Lamellen stehen sehr weit auscinander, sind blass-weisslich, werden aber später durch die Sporen bräunlich-grefleckt; der Geruch und Geschmack ist angenehm, siiss-sïnerlich. - ()b der Pilz, welchen Briganti anf den Wuzeln von Rebstïcken fand, die typische Form des Agrvicus melleus ist, kann ich, da (Originale mir nicht zu Gebote standen, mit Sicherheit nicht angeben, da aber die Art ungemein variabel ist, so ist es wahrscheinlich nur eine eigene Form, die wohl nur dieses Substrat bewohnt, die gegebenen Namen Agaricus suaveoleus and Agaricus Titis sind daher unniitz und rerdienen keine Aufnahme. - Auf Wurzeln alter Stïcke von Vitis inifera Lin. in der Umgebung von Neapel dureh Briganti aufgefunden.

\section{Agaricus Mycena hiemalis Osb.}

Osbeck in Retz, Observationes botanicae II. 1. 19. - Fries, Epicrisis system. mycologici 1) 119, no. 442. - Id. Hymenonycetes europaei 1) 153, no. 517. Ayericus conticalis Bull. Champignons Tab. 519, fig. $1 \mathrm{a}, \mathrm{b}$. - Fries, Systema mycologieum I. 1. 159, var. b. - Berk. et Broome, Fungi exsiccati no. 993. Lyaricus adscendens Lasch. in Linnaea IV. p. 536.

A. pileo tenui, campanulato, obsolete umbonato, margine striato, stipite tenui adscendente deorsum puberulo, lamellis adnatis uncinatisque, angustis, linearibus, albidis. A. corticola Sclum. vulgo longior, nimis affuis, pileus pruinatus etiam in hoc, sed color lactior, vix cinereofuscus. - Fr. 1. c.

In radicibus subemortuis Titis vimiferae Lin., adhuc humatis. - Austria inferior: Klosterneuburg. Aestate 1877. (Rïsler.)

Einmal ward dieser Pilz erst auf den Wrureln des Weinstockes angetroffen, und zwar auf solchen, welche stark durch die Reblaus, Plyylloxera vastatix Planch., angegriffen waren, 20 cm. unter der Erdoberfliche war er vollkommen entwiekelt mit ganz ausgebildeten Sporen. In friiherer Zeit vielmals mit Agaricus crnticola Schum. verwechselt, trennte erst Fries in der "Epicrisis" a. a. O. die beiden Species. Der Hut ist bei vorlie- 
gender Art schr klein und zart, glockenförmig, kaum etwas genabelt, in der Mitte, gegen den Rand hin gestreift nder morleutlich schwach gefurcht, hellgelbbräunlich, weit heller als bei Ay. corticola. Der Stiel hat eine Länge von ungefähr $2-3$ Millimeter, ist diinn, schwach behaart, grau und wächst nach unten ziemlich lang an und in das Substrat, gleichsam eine Ant Wurzel bildend; die äusserst dicht stehenden Lamellen sind sehr sehmal, hakenartig gekrümmt, weisslich, linealisch. - In Nieder-Oesterreich bei Klosterneuburg auf Vitis viniferc Lin. von Prof. Rösler gefunden und mir mitgetleilt.

Roesleria hypogaea Thüm. et Pass.

Thïmen in "Nesterreichische botanische Zeitschrift" 1877. p. "270. - Id. in "Wiener Landwirthschaftliche Zeitung" 1877.

Roesleriø Thüm, et Pass.*) nov. genus Helvellacearum. Genus Tibrisseam Fr. accedit, sed paraphysarum defectu et sporis globosis, generis novi typum forsan sistit.

R. hypogaed Thüm. et Pass. - R. individuis gregariis, erectis, plus minusve rigidis, receptaculis capitatis, stipite aequali, opaco-albirlo, $1.5-2.5$ millim. longo fultis, capitulis globosis vel subcompresso-globosis, opacis, argenteo-griseis; ascis numerosissimis, octisporis, cito evanidis et sporas globosas, hyalinas, $5 \mathrm{~mm}$. in diam. in stratum tomentosum liberantibus; paraphysibus nullis. Thuim. 1. c.

In Vitis viniferce lin. radicibus adhue humatis, subterreis. Badenia (Roesler), Austria inferior (Thiimen).

Der Repräsentant einer neuen, hochinteressanten Giattung aus der Ordnung der Helvellaceen! Der Gattung Vibrissea Fr. steht dieser newe Pilz sehr nahe, unterscheidet sich aber vollkommen genügend davon durch den Mangel von Paraphysen und durch die runden Sporen, welch letztere bei Vibrissea lang cylindrisch sind. Den Namen der Gattung wählten wir zu Ehren des Professor's Dr. Leonhard Rösler, Vorstand der k. k. chemischphysiologischen Versuchsstation zu Klosterneuburg, welcher den Pilz vor neun Jahren zuerst anfgefunden hat. Bei Niillheim im

*) In honorem elarissimi, amicissimi Leonardi Roesleri, Phil. Dr., Klosterneuburgensis, venologi scientissimi! 
Breisgau (Grossherzogthum Baden) wurde derselhe nämlich im Jahre 1868 anf ziemlich grosse, beinahe kreistunde Stellen in deu Weingärten aufmerksam, in welchen die Stöcke fast entblättert und im höchsten Grade rkrankt arschienen. Bei einer sofort vorgenommenen Aufgrabung einiger Reben, da man ein eventuelles Auftreten der Phylloxera vastatrix Planel. befürchtete, bemerkte er an den Wurzeln kleine Pilze in grosser Anzahl und ansserdem ein dichtes, chokoladenfarbiges Mycelium. Die Pilze waren diesellen, welche jetzt als Roesteria hypogaea beschrieben wurden, das braune Mycelium jeloeh stand wahrscheinlich in keinem K/asammenhange damit, denn es ward an anderen Orten nieht wieder anfgefunden. Sehr feuchter Boden oder wenigstens fenchter Untergrund scheinen unbedingt nothweudig zur Entwickelung des Pilzes. Bei Klosterneuburg ward or das ganze Jalı hindurch sowohl an lebenden als an abgestorbenen Wurzeln, von einem Schuh tief unter der Erdoberfäche an bis zu anderthalb Meter und mehr 'Tiefe gefunden, und zwar zumeist an Wurzeh von ungeführ Bleistiftstäke, nur selten nud ausnahmsweise an Thauwurzeln oder' entgegengesetzt an dicken Hauptwurzelstöcken. Auch an alten, durch zwei bis drei Jahre in Gläsern eingeschlossenen Wurzeh entwickelte sich der Pilz plïtzlich ganz iippig; was für eine enorme Lebenskraft des Mycelimms spricht. - Sehr gern scheint dic Roeslevia auf den Wurzeln solcher Stöcke aufzutreten, welche durch die Plyglloxera vastatrix gelitten haben, offenbar sagt die feuchte oberfläche der Wurzeln, hervorgerufen durch ihre Beschädigung, dem Credeihen des Pilzes zu. Irgend eine Weehselwirkung zwischen diesen beiden Schädigern anzunehmen, ist jedoch mnstatthaft, wohl aber ist, was die äusseren Merkmale anbelangt, die Wirknng. beider auf die Weinstöke eine fast gleiche, indem die Bliitter ohne eine äussere Beschädigung zu zeigen, verwelken und abfallen, und so ist vielleicht die Annahme nicht ganz ungerechtfertigt, dass beide Schädiger schon öfter's mit einander verwechselt wurden.

Das äussere Ansehen des Pilzes und die mikroskopischen Merkmale will ieh hier versuchen, recht genau darzulegen, um die Oenologen aufmerksam zu machen auf diesen nenen Schädiger der Reben. - Mehr oder minder dicht beisammen erheben sich von der Rinden-Oberhaut 1 bis $2 \frac{1}{2} \mathrm{Mm}$. hohe Stielchen ron 
fast borstenförmiger Gestalt, sie sind meist steif und gerade aufrecht, nur selten etwas geneigt, gleichmässig dick, kaum nach oben etwas angeschwollen und von einem matten, dabei aber reinen Weiss, an ihrer Spitze tragen sie cin Köpfehen von matt silbergraner Färbung, welches entweder vollkommen kugelig oder wenig zusammengedrückt ist und bei den grössten mir vorliegenden Exemplaren knapp einen halben Millimeter im Durchmesser hält. Die Stielchen entspringen einem äusserst zarten. auf der Oberfläche der Wurzel gar nicht oder kamm sichtbaren Mycelium. Zerdrückt man ein Köpfchen auf dem Objecträiger, so sieht man eine grosse Anzahl von Schläuchen, welchc alle an ihrer Basis bindelförmig zusammenstehen und sich nach oben ausbreiten, sie haben eine fast cylindrische Gestalt, sind am Scheitel etwas abgerundet, nach der Basis ein wenig verschmälert und haben jeder acht Sporen. Diese sind kugelrtud, farblos und haben einen Durchmesser von $5 \mathrm{~mm}$. Geht man beim Zerdricken oder bei der Anfertigung feiner mikroskopischer Schnitte nicht mit äusserster Vorsicht zu Wege, so bemerkt man gar nicht, dass die Sporen in Schläuchen gebildet werden und ist in Folge dessen der Tänschming ansgesetzt, den Pilz für eine Art der Gattung Stilbum zu halten; die Membran der Schläuche ist nämlich so ausserordentlich dïnn und zart, dass sie fast unmittelbar, nachdem man sie blossgelegt hat, zerfliesst and eben nichts weiter als eine Unzahl von kugeligen Sporen, eingebettet in eine schleimige Masse zuriekbleiben. Paraphysen sind nicht vorhanden. - Auf lebenden und todten Wurzelu von Titis vinifere Lin. bei Müllheim und Durlach in Barden (Rösler), bei Klosterneuburg in Nicder-(Testerreich (Thümen); von Titis aestivalis Mchx. bei Klosterneuburg (Rösler). (Tab. IV. tig. 9.)

\section{Lycoperion giganteum Batsch.}

Batsch, Fungi fig. 165. - Fries, Syst. myenl. III. p. 29. - Persoon, Synopsis fungorum p. 140. - Cooke, Handb. of Brit. Fungi p. 37:. - De Candolle, Flore franę. II. p. 264. - Lycoperdon Borista Lin. Spee. plant. II. p. 1652. - Fuckel, Symbolae mycologicae p. 36. - Saccardo, Mycologia veneta p. 71. - Bovista gigantea N. a. Esenbeck, System der l'ilge fig. 124. -- Lengermannic gigantea Rostkov in Sturm, Dentsel. Flora p. 23, fig. 10.

L. peridio superne fragillimo, obtusissimo, areolatim dehiscente, evanescente, latissime aperto, cortice floceoso subdiscreto, 
capillitio raro, cum sporidis olivaceofuligincis evanescente. Fr. l.

In truncis radicibusque vetustis sed adhue vivis Vitis viniferce Lin. Antummo. Anstria inferior. (Rösler.)

Mit Ausnahme der Gegend von Klosternenburg in NiederOesterreich ist mir das Vorkommen dieses, "Strenling" oder anch wohl ..Bovist" genannten, Pilzes auf Stöcken und Wureln von Reben, von nirgenther bekannt. - Der allgemein gekannte P’ilz erreicht einen Durehmesser bis zu 55 Centimeter, er ist an seiner Oberfläche gelblieh, ganz glatt, bald aber zerreisst dieselbe, zuerst am Scheitel, dann sehnell anch weiter nach unten hin in eine grosse Menge stumpfe, mregehnässige Lappen. Diese lösen sich bald von der Substanz des Innern ab und legen diese bloss, und umschliessen nur noch den untersten, meistentheils etwas zusammen gezogenen Kegel, gleichsam mit einer gelblichgrauen, papierartigen Hiille. Nachden die sporen, durch Verschwinden und Abreissen der Hiille, der Luft exponirt, schuell gereift sind und eine ockergelbe Färbung angenommen haben, verschwinden auch diese bald und zuletzt bleibt im Spätherbst nichts weiter ïbrig als ein kurzer, napffïmiger Theil rer Basis. - Professor Rösler in Klosterneuburg beobachtete nuseren Pilz in sehr alten Weingärten, deren cinzelne Atïcke violleicht siebenzig bis hundert Jahre alt sein mochten, im Angust und September ungemein häutig, er wuchs sowohl auf der Errle als anch rlirect auf den Stöcken und alten Trüzeln von T'itis vinifera-Reben, und zwar in solcher Anzahl, dass zu sciner. Vernichtung durch Fener eigene Arbeiter entsendet werden mussten!

\section{Ceratostoma Vitis Fuck.}

Fuckel, Symbolae mycologicae p. 129. - Pirotta, funghi parassiti dei Vitigni p. 37.

(. peritheciis gregaris, in corticis tissuris niclulantibus, globosis, media magnitudine, nigris, extus pilosis, pilis pallidioribus, rostro longissimo, perithecio sexies longioribus, strictis, nigris; asci nondum inveni; sporidiis ovatis, continuis, fuscis, $6 \mathrm{~mm}$. long., 4 mm. crass., uniguttulatis. - Fuck. 1. c.

In fissuris corticatis, subputridis radicum Titis rinifene Lin. Rarissime in hieme. Nassovia (Fuckel). 
Wie aus den näheren Angaben des Autors zu entnehmen ist, tritt dieser Pilz nu sehr selten auf, er hat denselben wenigstens nicht in seinen "Fungi rhenawi exsiccati" vertheilt und spricht dieser Umstand wohl dafür, dass er ihn uberhaupt un ein einziges Mal gefunden hat. Ausser Fuckel selbst dürfte wohl iiberhaupt kein Mykologe im Besitz ron Exemplaren sein! - Die Perithecien sitzen gedrängt zusammen, gleichsam nistend in den Rissen der Rinde, sie sind kugelig, von mittlerer Grösse, schwarz und auswendig mit helleren Borstchen bedeckt; der Schnabel des Peritheciums ist sehr lang, wohl sechsmal die Länge desselben iiberragend, steif aufgerichtet und schwar\%. Schlüuche hat der Autor gar uicht gesehen, so dass die Stellung der Sipecies zur Gattung Ceratostome nu anf die äusseren Merkmale des Peritheciums begründet ist, Merkmale allerdings, welche so charakteristisch für dieses Genus sind, wie insbesondere der lange, hervorragende Schnabel, rlas Rostrum, dass man der Ansicht Fuckel's beipflichten muss, natürlich aber immer mit Vorbehalt, bis Schläuche aufgefunden sein werden. Die Sporen sind eiförmig, einfach, bratu, haben einen Nucleus und messen in der Länge $6 \mathrm{~mm}$., in der Breite $4 \mathrm{~mm}$. - In den Rissen fauler, berindeter Wurzeln von Vitis viniferc Lin. Nassau, bei Oestrich (Fuckel). 


\section{REGISTER.}

(Die mit Cursiv-Lettern gedruckten Namen sind Synonyme.)

Seite

Acladium epiphyllum Wallr. . . . . . . . . . . . 192

herbarum Lk. . . . . . . . . . . . . . 33

Acrospermum compressum Tude. . . . . . . . . . 200

Ravenelii Berk. et Curt. . . . . . . . 199

Acrostalagmus cinnabarinus Cda. . . . . . . . . . 193

Agaricus adscendens Lasch. . . . . . . . . . . . . 209

albus Secret. . . . . . . . . . . . . 62

calopus Fr. . . . . . . . . . . . . . . 61

condidus Bolt. . . . . . . . . . . . . . 62

corticalis Bull. . . . . . . . . . . . . . 209

epiplugllus Pers. . . . . . . . . . . . 63

hiemalis Osb. . . . . . . . . . . . 209

melleus Vahl. . . . . . . . . . . 208

protens Kalchb. . . . . . . . . . . . . 61

ramealis Pers. var. . . . . . . . . . 62

suaveolens Brig. . . . . . . . . . . . . 208

Vitis Brig. . . . . . . . . . . . . 208

Ampelomyces quisqualis Ces. . . . . . . . . . . 178

Amphisphaeria sylvana Sacc. et Spegaz. . . . . . . 26

Anthostomella limitata Sacc. . . . . . . . . . . . 123

Arthrobotryum atrum Berk. et Br. . . . . . . . 35

Ascobolus Vitis Wallr. . . . . . . . . . . . . 76

Ascochyta Ellisii Thüm. . . . . . . . . . 190

Aspergillus glaucus Lk. . . . . . . . . . . . . . 4

Asteroma viniperda Thüm. . . . . . . . . . . . 18 
Seite

Atractium citiatum Lk.

Auricularia mesenterica Pers.

Bertia Vitis Schlzr.

Boletus papyraceus Schwz.

Botryosphaeria cyanogena Niessl.

Botrytis acinolum Pers.

" cana Schwz. .

" cinerea Pers.

$"$ rosea De C.

Borista yigantea N. a. Es.

Calloria vinosa Fr.

Calosphaeria minima Tul.

Cenangium viticolum Fuck.

Cercospora Vitis Sace.

Chaetostroma pedicellatum Preuss. 
Seite

Cacaria compressa Purt.

herbarum Pers. . . . . . . . . . . 200

Corticium albido-carneum Thüm. . . . . . . . 70

armeniacum Thü̈. . . . . . . . . . . . 72

calceum Fr. . . . . . . . . . . . 68

erocicreas Berk. et Curt. . . . . . . . . 68

hypopyrrhinum Berk, et Curt. . . . . . . . 67

lactescens Berk. . . . . . . . . . 71

Leveilléamum Berk. et Curt. . . . . . . . . 72

molle Berk. et Curt. . . . . . . . . . . 72

viticola Fr. . . . . . . . . . . . . 70

Coryneum microstictum Berk. et Br. . . . . . . . . 144

Cryptosporium ampelinum Thüm. . . . . . . . . . 159

Cryptostictis hysterioides Fnck. . . . . . . . . . . 148

Cryptovalsa ampelina Fuck. . . . . . . . . . . . 106

protracta De Not. . . . . . . . . . 106

Rabenhorstii Śace. . . . . . . . 105

Cucurbitaria Vitis Schlzr. . . . . . . . . . . 111

Cyphella albo-violascens Karst. . . . . . . . . 76

Curregi Berk. et Br. . . . . . . . . 76

villosa Karst. . . . . . . . . . 75

Cytispora chrysosperma Fr. . . . . . . . . . . . 156

coryneoides Berk. et Curt. . . . . . . . . 156

incerta Thüm. . . . . . . . . . 154

Vitis Montg. . . . . . . . . . . . 155

Vitis Schlzr. . . . . . . . . 154

Dacryomyces viticola sichwz. . . . . . . . . . 60

Dactylium roseum Berk. . . . . . . . . . . . . 45

Dematium graminum Lib. . . . . . . . . . . . . 42

herbarum Pers. . . . . . . . . . . . 33

Dendryphinm Passerinianum Thüm. . . . . . . . 176

Dermater tumida Fr. . . . . . . . . . . . . 80

Diaporthe viticola Nke. . . . . . . . . . 103

Diatrype insitiva Fr. . . . . . . . . . . . . . . 126

ritionla Berk. et ('urt. . . . . . . . . 136

Titis Berk. . . . . . . . . . . . . 109

Didymosphaeria bacchans Pass, . . . . . . . . . 134 
Diplodia Bacchi Pass. et Thüm.

fabaeformis Pass. et Thiim. . . . . . . . . 141 interrogativa Thüm. et Pass. . . . . . . . 139 viticola Desm.

Discosia Vitis Schlzr.

Ditiola ciliata $\mathrm{Fr}$.

162

Dothidea myriococea Mntg.

picea Berk. et Curt.

Enchusias Vitis Haszl.

Eurotium herbariorum Lk.

Eutypa ludibunda Thiim.

Fumago vagans Pers.

Fusariam Biasulettianum Cda. pampini Thüm.

Fusisporium Biasolettianum Sace.

Gibbera Saubinetii Fuck.

Gloeosporium ampetophagum Sace. . . . . . . . . 9 
Seite

Graphium cinerellum Spegaz. . . . . . . . . . 55

" clavisporum Berk, et Curt. . . . . . . . 176

Gyrocerus Ammonis Cda. . . . . . . . . . . . . 39

Haplotrichum epiphyllum Rabh. . . . . . . . . . 192

Helminthosporium decacuminatum Thüm, et Pass. . . . 40

siliquosum Berk. et Curt. . . . . 40

Vitis Pirotta . . . . . . . . 170

Helotium hyalopes Euck. . . . . . . . . . . 88

puilatum Ger. . . . . . . . . . . . . . . 89

sarmentorum De Not. . . . . . . . . . 86

vitigenum De Not. . . . . . . . . . . . 87

Helrella mesenterica Dicks. . . . . . . . . . . . . 73

Hendersonia ampelina Thüm. . . . . . . . . . . . 147

hysterioides Fuck. . . . . . . . . . 148

longipes Berk, et Curt. . . . . . . 14 כ

nodorum I acr. . . . . . . . . . . 146

sarmentortum Westd. . . . . . . . . 146

viticola Thïm. . . . . . . . . . 145

Vitis sylvaticae Pirotta . . . . . . . . 145

Hormococcus olivascens Sacc. . . . . . . . . . . 157

Hypoderma commune Duby . . . . . . . . . 96

Rubi De Not. . . . . . . . . . . . 98

virgultorum De C. . . . . . . . . . 98

virgultorum De C. var. . . . . . . . . . 98

Hysterium australe Duby . . . . . . . . . . . 93

commune Fr. . . . . . . . . . . . 96

Curtisii Duby . . . . . . . . . . . . 92

flexuosum Schwz. . . . . . . . . . . 95

Rubi Pers. . . . . . . . . . . . . 98

viticolum Cooke et Ell. . . . . . . . . 94

Hysterographium flexuosum Rehm . . . . . . . . 95

viticolum Rehm . . . . . . . . 94

Lachella albo-violascens Fr. . . . . . . . . . . . 76

macrochaeta Spegaz. . . . . . . . . 78

Langermamia gigantaea Rostk. . . . . . . . . . . 212

Lenzites atropurpurea Sacc. . . . . . . . . . . 64 
Leptosphaeria appendiculata Pirotta

Cookei Pirotta. . . . . . . . . 29

Gibelliana Pirotta . . . . . . . . 132

vinealis Pass. . . . . . . . . . . 133

Vitis Pirotta. . . . . . . . . . 133

Titis Schlzr. . . . . . . . . . . 130

Leptostroma sphaeroides Fr. . . . . . . . . . . . 54

Leptothyrium longisporum Thüm. et Pass. . . . . . . 153

Passerinii Thïm. . . . . . . . . . 152

perpusillum Pass. et 'Thüm. . . . . . . 152

Lophiostoma angustatum Fuck. . . . . . . . . . . 121

Hederae Fuck. . . . . . . . . . . 118

sexnucleatum Cooko . . . . . . . . 122

Thïmenianum 今pegaz. . . . . . . . . 119

Lophium angustatum Fr. . . . . . . . . . . . . . 121

Lycoperdon Bovista Lin. . . . . . . . . . . . . . 212

giganteum Batsch. . . . . . . . . . . 212

Nacrosporium uvarum Thim. . . . . . . . . 3

Marasmins calopus Fr. . . . . . . . . . . 61

candidus Fr. . . . . . . . . . . 62

" epiphyllus Fr. var. sarmentorum Thüm. . . 63

viticola Berk. ct Curt. . . . . . . . . 62

Merulins corium Fr.

Momitia fructigena Schum.

Mucor glaucus Lin.

herbarionum Pers. . . . . . . . . . . 138

stolonifer Ehrbg. . . . . . . . . . . . . 191

Hymaecium mbricosum Fuck. . . . . . . . . . . . 120

Myrothecium convexum Berk. et Curt. . . . . . . 17

Vitis Bon... . . . . . . . . . 158

Myxotrychum caesium Fr. . . . . . . . . . . . 38

Naemaspora chrysosperma Pers. . . . . . . . . . 156

Nectria cinnabarina Fr. . . . . . . . . . . . 116

viticola Bcrk, et Curt. . . . . . . . . 115 
Seite

()idium Tuckeri Berk.

Uibitia vinosa Karst

()zonimm aturicommum Is.

Patellaria atro-fusea Berk. et Curt.

I'ericonia byssoides L'ers.

P'eromospora viticula De By.

Pestalozzia prezizoides t)e Not.

Thiimeniana Spegaz. . . . . . . . . . . 14

uvicola Spegaz.

Peziza albo-violascens Alb. Sohwz.

villosa Pers.

rinusa Alb. Sichwz.

viticola Pers.

viticola Pers.

85

viticola Sehwz.

Vitis Schwz.

Vitis viniferce Kirchn.

Phlebia mesenterica $\mathrm{Fr}$.

Phoma ampelinum Berk. et Curt. 
Seite

Hhoma micola Arcang. . . . . . . . . . . . . . 9

Vitis Bon. . . . . . . . . . . . . 32

Vitis Berk, et Br. . . . . . . . . . . . . 151

Phyllosticta labruscae Thium. . . . . . . . . . 189

viticola Thiim. . . . . . . . . . . 188

Pliymatostroma fusarioides Cola. . . . . . . . . . 197

Pleospora coronata Niessl . . . . . . . . . . . 129

phaeocomes (ies. et l)e Not. . . . . . . 129

Polyactis sclerotionthela Riabl. . . . . . . . . . . . 195

Polyporus coritum Pers. . . . . . . . . . . . . . 67

vaporarius Fr. var. papyracens Schwz. . . 05

viticola Fr. . . . . . . . . . . . 65

Polynema Vitis Schlzr. . . . . . . . . . . . 161

Propolis prominula Thüm. . . . . . . . . . . 78

Psitonia maculaeformis Fr. . . . . . . . . . . . . 37

Precinia rosea Cda. . . . . . . . . . . . . 45

Pyrenopeziza Titis Rehm. . . . . . . . . . . . 85

Pyrenotrichum Vitis Schlzr. . . . . . . . . . . 81

Liamelaria ampelophaga Pass. . . . . . . . . . . . 9

Rebentischia appendiculosa Race. . . . . . . . . . 124

Rhaphidospora samenti Pass. . . . . . . . . . 128

Rhizopus nigricans Ehrbg. . . . . . . . . . . . . 191

Rlytisma monogramme Berk. ef ('urt. . . . . . . . 183

Vitis Schwz. . . . . . . . . . 198

Roesleria hypogaea Thim. et Pass. . . . . . . . . 210

Rosellinia horrida Haszl. . . . . . . . . . . . 125

Scleroglossum lanceolatum Pers. . . . . . . . . . . 200

Sclerotinia Fuckeliana Fuck. . . . . . . . . . . 197

Sclerotium echinatum Fuck. . . . . . . . . . 205

herbarum N. a. Es. . . . . . . . 200

sarmenticolum Thüm. . . . . . . . 164

Semen Tode. . . . . . . . . . . 206

uvae Desm. . . . . . . . . . . . 20

Vitis Peyl. . . . . . . . . . . . 21

Septocylindrium dissiliens sace. . . . . . . . . . 175

virens Sace. . . . . . . . . . 48 
Seite

Septomema Vitis Sace. . . . . . . . . . . . . 48

Cieptoria ampelina Berk, et Curt. . . . . . . . . . 186

falx Berk, et curt. . . . . . . . . . . . 163

Miiiggenturgii Pirotta . . . . . . . . . . 163

viticula Berk. et Cirt. . . . . . . . . . 188

Vitis Lév. . . . . . . . . . . . 187

Vitis Schlzr. . . . . . . . . . . . . . 163

Vitis Lév. . . . . . . . . . . . 170

Septosporium Fuckelii Thüm. . . . . . . . . . . 172

sphaceloma ampelinum De By. . . . . . . . . . . 18

Splarerella fumaginia Catt. . . . . . . . . . . . . 28

pampini Thüm. . . . . . . . . . . 27

Pyri Awd. . . . . . . . . . . . . . 203

sarmentorum Pirotia . . . . . . . . . . 135

sentina Fuck. . . . . . . . . . . . . 203

Titis Fuck. . . . . . . . . . . . 201

Titis Fuck. . . . . . . . . . . . . . 173

Titis Schlzr. . . . . . . . . . . . . . 130

Sphaeria ampelos Sehwz. . . . . . . . . . . . 137

angustata Pers.. . . . . . . . . . . . . 121

appendiculosa Berk, et br. . . . . . . . . 124

cinnabarina Tode. . . . . . . . . 116

cimlute Sow. . . . . . . . . . . $156^{\circ}$

cyanogena Desm. . . . . . . . . . . 112

insitiva Tode . . . . . . . . . . . . 126

maculiformis Pers. . . . . . . . . . 201

Mesascium De Not. . . . . . . . . . 117

phreocomes Berk, et Br. . . . . . . . . . 129

pruina Schrz. . . . . . . . . . . . 201

sentina Fr. . . . . . . . . . . . . 203

subfasciculata Schwz. . . . . . . . . . 137

uberrimu Cast. . . . . . . . . . . 91

viticola Schwz. . . . . . . . 136

Vitis Rabb. . . . . . . . . . . 201

Vitis Cast. . . . . . . . . . . . 133

Vitis Schwz. . . . . . . . . . . 101

$\begin{array}{rr}\text { "Vitis sylvaticae Cast. . . . . . . . . . . . } & 145 \\ & 149\end{array}$

Sphaeronaema viticolum Berk, et C'urt. . . . . . . 149 
Sphaeropsis Peckiana Thüm.

splenerotheca Castagnei Lév. . monilioides spr. verticillatum sin.

Stereum cristatum Berk, et ('urt.

Stictis prominula Schwz.

Thelephore albide-camea schwz.

T'ubercularia ampelophila Sace. 
Seite

Tubercularia subdiaphana Schwz. . . . . . . . . . 57 sulcata Tode . . . . . . . . . . . . 59

vulgaris Tode. var. sarmentorum Wallr. . . 56

Tympanis viticola Fr. . . . . . . . . . . . . . 30

Uncinula americana Howe . . . . . . . . . . . . 183 spiralis Berk. et Curt. . . . . . . . . . . 183

" " var. lacemorum 'Thüm. . . . . . . 12

Uredo Vitis Thiim. . . . . . . . . . . 182

Valsa ampelina Nke. . . . . . . . . . . . . 106 cerviculata Erb. critt. non Fr. . . . . . . . . 104 lata Sace. . . . . . . . . . . . . 104 ludibunda Sace. . . . . . . . . . . . . 104 Rabenhorstii Nke. . . . . . . . . . . . 105 referciens Sace. . . . . . . . . . . . . . 104 vitigena Cooke . . . . . . . . . . . . . . . . 99 Vitis Berk. et Curt. . . . . . . . . . 101 Vitis Fuck. . . . . . . . . . . . . . . 99

Valsaria insitiva Ces. et De Not. . . . . . . . 126

Vermicularia compacta Cooke et Ell. . . . . . . . 160

Volutella ciliata Fr. . . . . . . . . . . . . . . 58

Xerotus lateritius Rav.. . . . . . . . . . . . . 65 viticola Berk. et Curt. . . . . . . . . . 65 Xyloglossum herbarum Pers. . . . . . . . . . . 200 Xyloma nitens Schwz. . . . . . . . . . . . . . 54 

TAFEL I. 


\section{Tafel I.}

Fig. 1. Sphaceloma ampelinum De By.

"2. Macrosporium uvarum Thïm.

"3. Iysterium Curtisii Duby.

"4. Dendryphium Passerinianum Thiüm.

„5. Peronospora viticola De By.

"6. Lophiostoma angustatum Fuck.

"7. Cryptovalsa Rabenhorstii Sace.

"8. Mucor stolonifer Lhrog.

" 9. Fusarium Cesatii Thüm.

"10. Lophiostoma Hederae Fuek.

"11. Spicularia Icterus Fuck.

"12. Septoria ampelina Berk. et Curt.

"13. Phoma Negrianum Thïm.

"14. Sphaerella Vitis Fuck.

"15. Botrytis acinorum Pers.

"16. Hypoderma commune Duby.

"17. Cytispora chrysosperma Fr.

"18. Septosporium Fuckelii Thüm.

"19. Lophiostoma Thümenianum spegaz. 
Taf I.

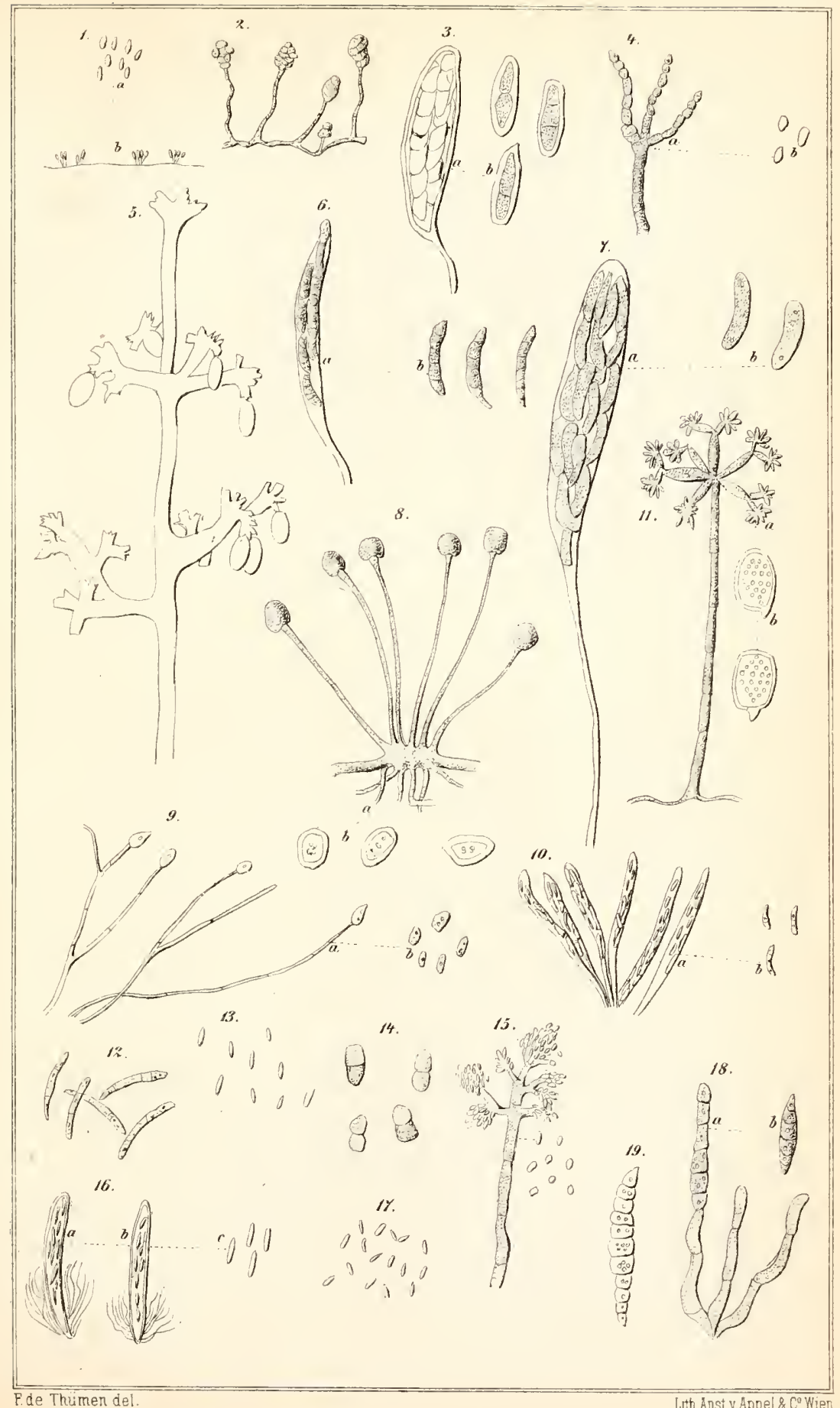



TAFEL II. 


\section{Tafel II.}

Fig. 1. Cicimnobolus Cesatii De By.

"2. Gyrocerus Ammonis Cda.

"3. Tubercularia sarmentorum Fs.

„4. Cenangium viticolum Fuck.

"5. Gonytrichum caesium N. a. E.

"6. Sphaerella sentina Fuck.

"7. Hysterographium flexuosum Rehm.

" 8. Aspergillus glaueus Lk.

. 9. Trichothecium candidum Wallr.

"10. Leptothyrium perpusillum Pass. et Thüm.

"11. Epochnium monilioides Lk.

"12. Phoma Cookei Pirotta.

"13. Acrostalagmus cimnabarinus Cda.

"14. Cryptostictis hysterioides Fuck.

"15. Leptostroma sphaeroides Fr.

"16. Coryneum microstictum Berk. et Br.

"17. Hendersonia sarmentorum Westd.

"18. Phymatostroma fusarioides Cda.

"19. Uncinula spiralis Berk. et Curt.

"20. Diplodia Bacehi Pass. et Thüm.

"21. Pestalozzia Thümeniana Spegaz. 


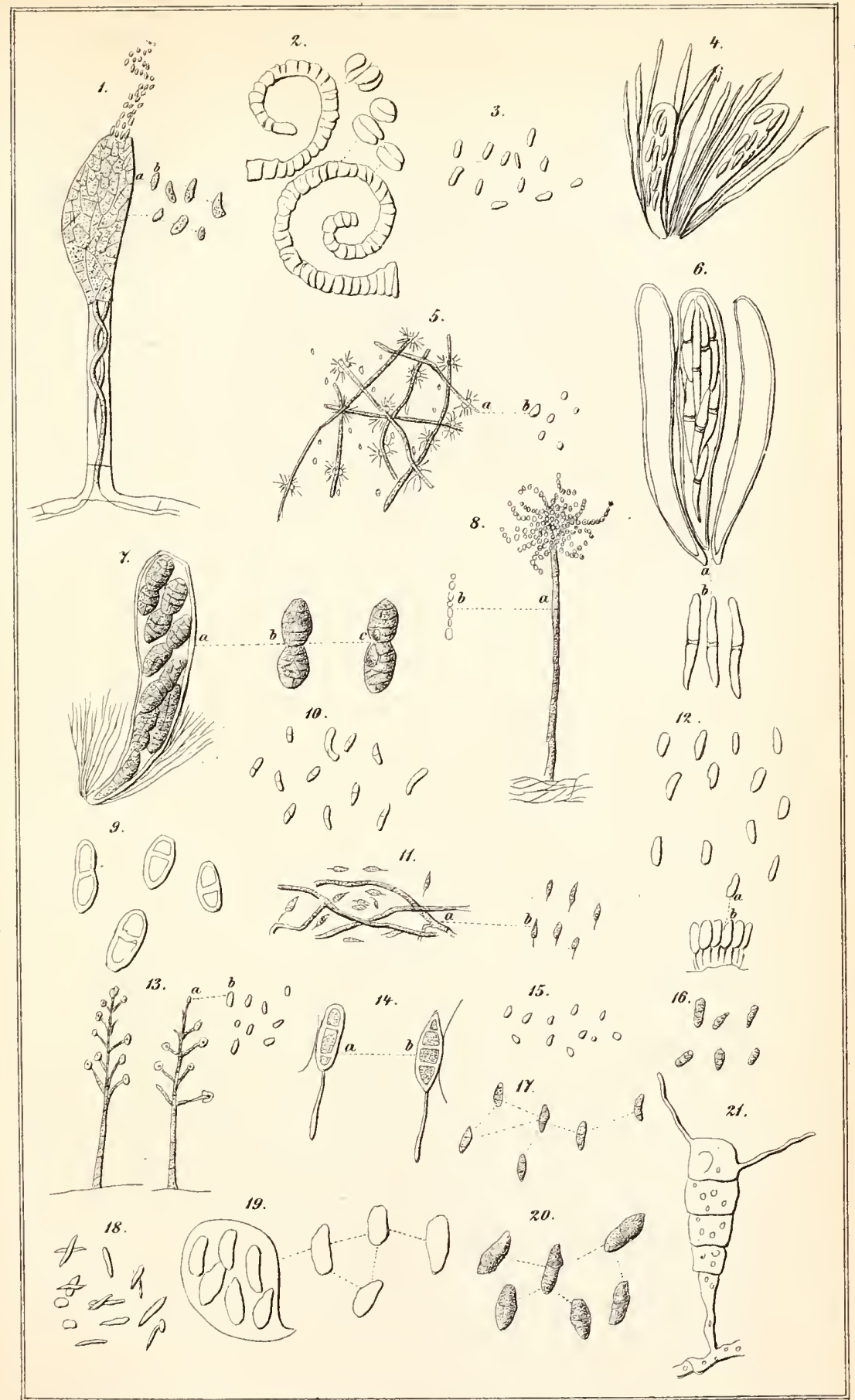



TAFEL III. 


\section{Tafel III.}

Fig. 1. Oidium Tuckeri Berk.

"2. Trichothecinm roseum Lk.

"3. Fusarium viticolum 'Thüim.

"4. Exosporium Badhami Awd.

"5. Leptothyrium Passerinii Thium.

"6. Eurotium herbariorum Lk.

"7. Fusarium Roesleri Thüm.

" 8. Valsa vitigena Cooke.

"9. Fusarium pampini Thium. et Pass.

"10. Phyllosticta Labruscae 'Thim.

"11. Phoma uvicola Berk. et Curt.

"12. Leptothyrium longisporum Thiim. et Pass.

"13. Phoma Vitis Bon.

"14. Phoma ampelinum Berk. et Curt.

"15. Botrytis cinerea Pers.

"16. Cladosporium Fumago Lk.

"17. Valsaria insitiva Ces. et De Not.

"18. Helotium hyalopes Fuck.

"19. Pleospora coronata Niessl.

"20. Sporocybe byssoides Fr.

"21. Leptosphaeria vinealis Pass.

.22. Sphacrella pampini Thïm.

"23. Cladosporium Roesteri Cattan.

"24. Gloeosporium ampelophagum Sace.

"25. Pyrenopeziza Vitis Rehm.

"26. Pestalozzia uvicola Pass. 


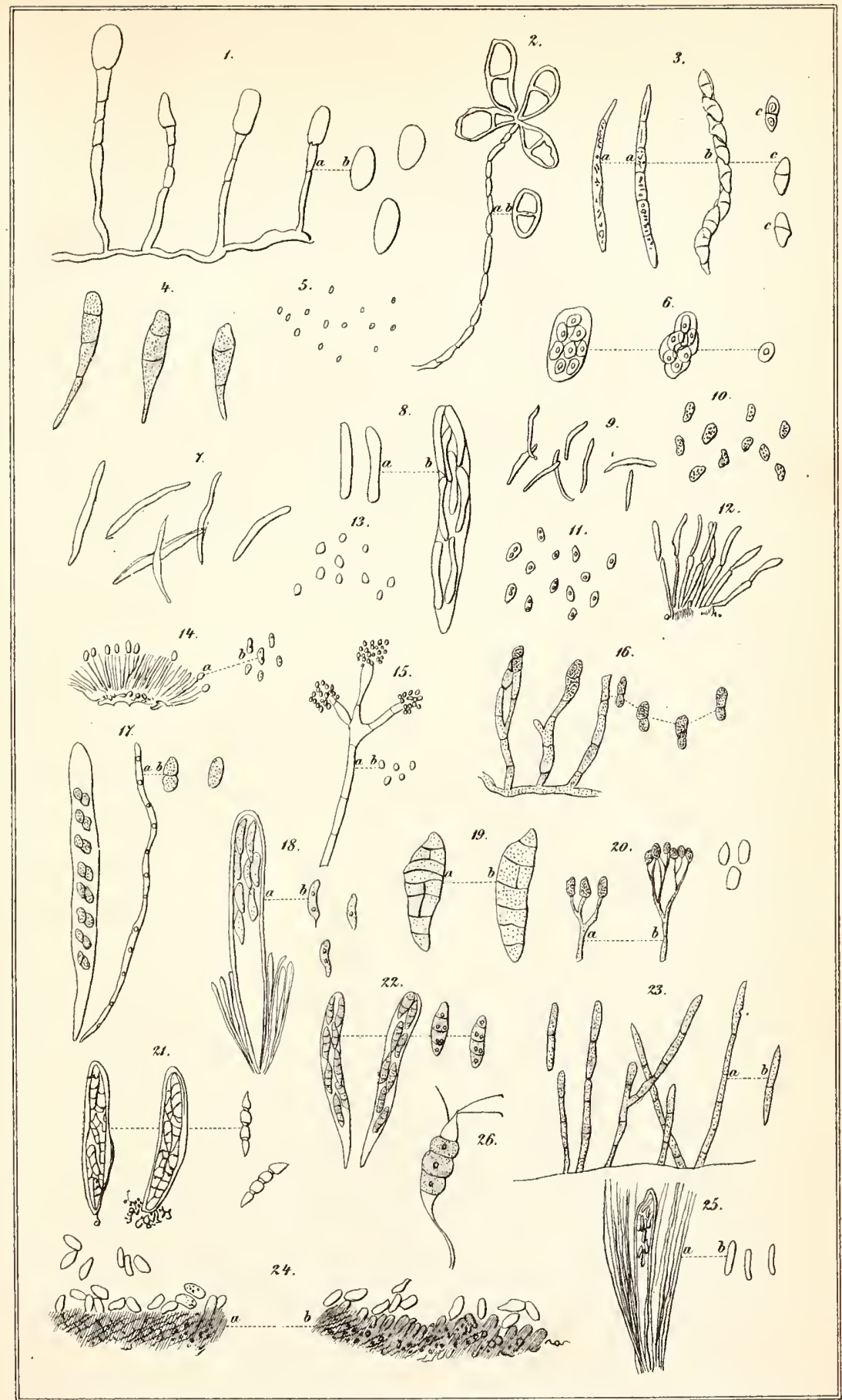





\section{TAFEL IV.}




\section{Tafel IV.}

Fig. 1. Septocylindrium dissiliens Sace.

„2. Septocylindrium virens Sace.

.3. Fusisporinm Biasolettianum Sace.

"4. Fusisporium Zavianum Sace.

"5. Lophiostoma sexnncleatum Cooke.

"6. Cladosporium ampelinum Pass.

"7. Rhaphidospora sarmenti Pass.

" 8. Didymosphaeria bacehans Pass.

"9. Roesleria hypogaea Thüm. et Pass.

"10. Chalara fusidioides Cda.

"11. Helotium sarmentorum De Not.

"12. Sporotrichum ampelinum Thüm. et Pass.

"13. Hormococeus olivaceus Sace. 
Taf. IV.
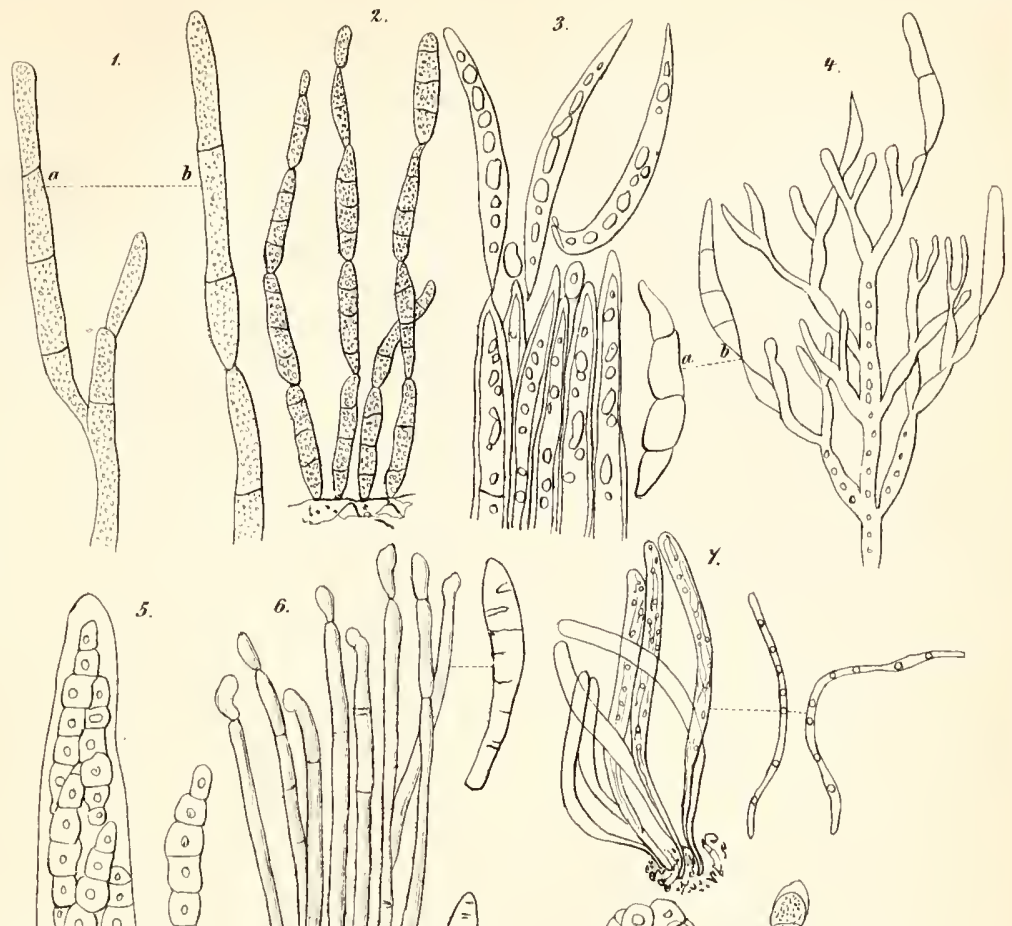

00000

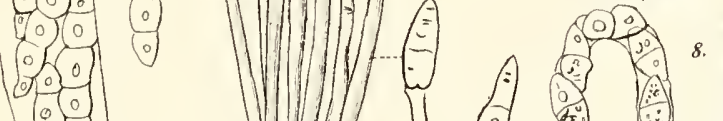

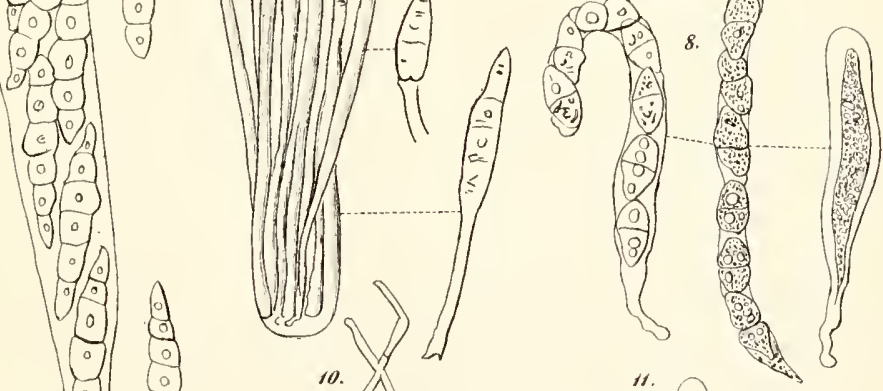

잉
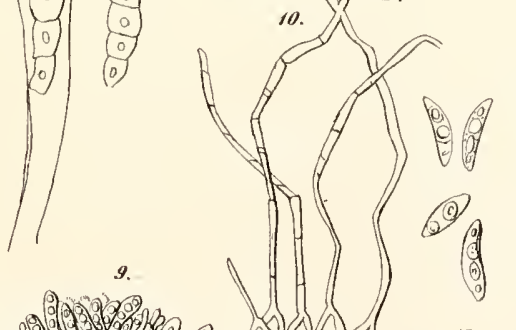

(a)

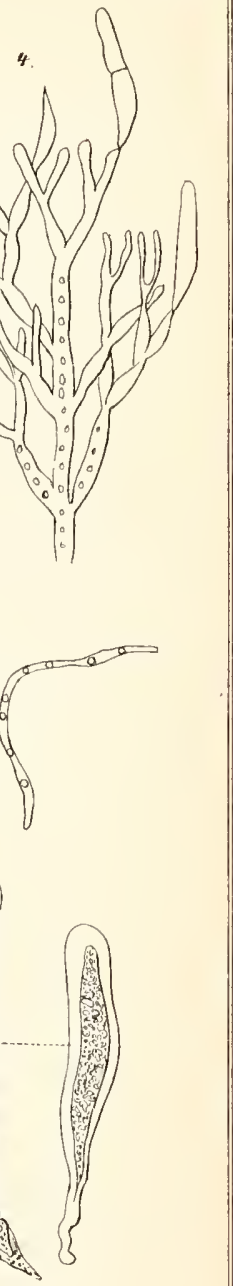



TAFEL $V$. 


\section{Tafel V.}

Fig. 1. Pestalozzia pezizoides De Not.

"2. Hysterographium viticolum Rehm.

"3. Hypoderma Rubi De Not.

"4. Teichospora Mesascinm Sacc.

"5. Cladosporium herbarum Lk.

"6. Helminthosporium decacuminatum Thüm. et Pass.

"7. Graphium clavisporum Berk. et Curt.

" 8. Cryptovalsa ampelina Fuck.

"9. Calloria vinosa Fr.

"10. Uredo Vitis Thüm.

"11. Diplodia interrogativa Thüm. et Pass.

"12. Cryptosporinm ampelinum Thiim.

"13. Sphaeropsis Peckiana Thüm.

"14. Hendersonia ampelina Thiim.

"15. Diplodia fabaeformis Pass. et Thüm.

"16. Diplodia viticula Desm.

"17. Phyllosticta viticola Berk. et Curt.

"18. Ascochyta Ellisii Thüm. 


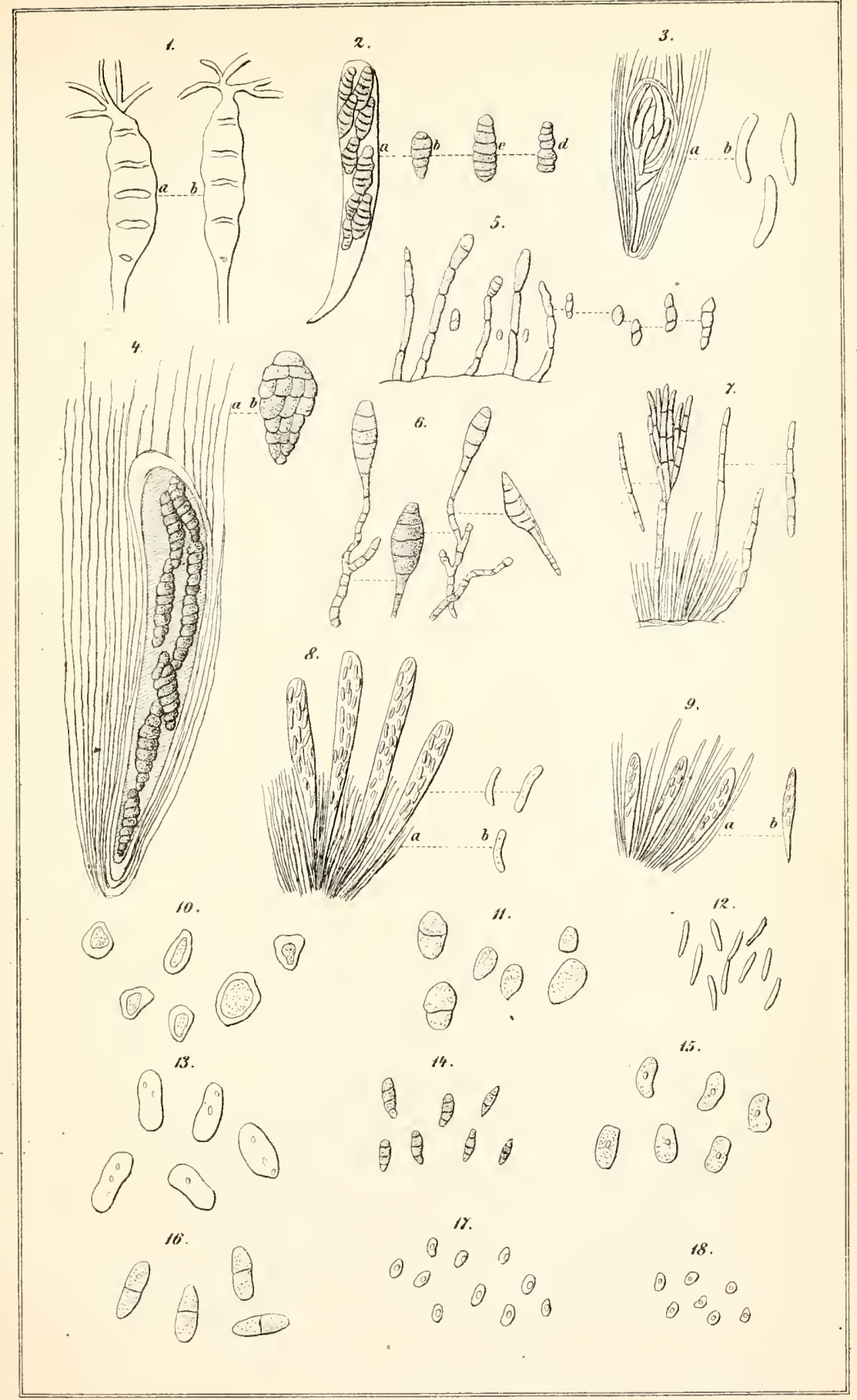




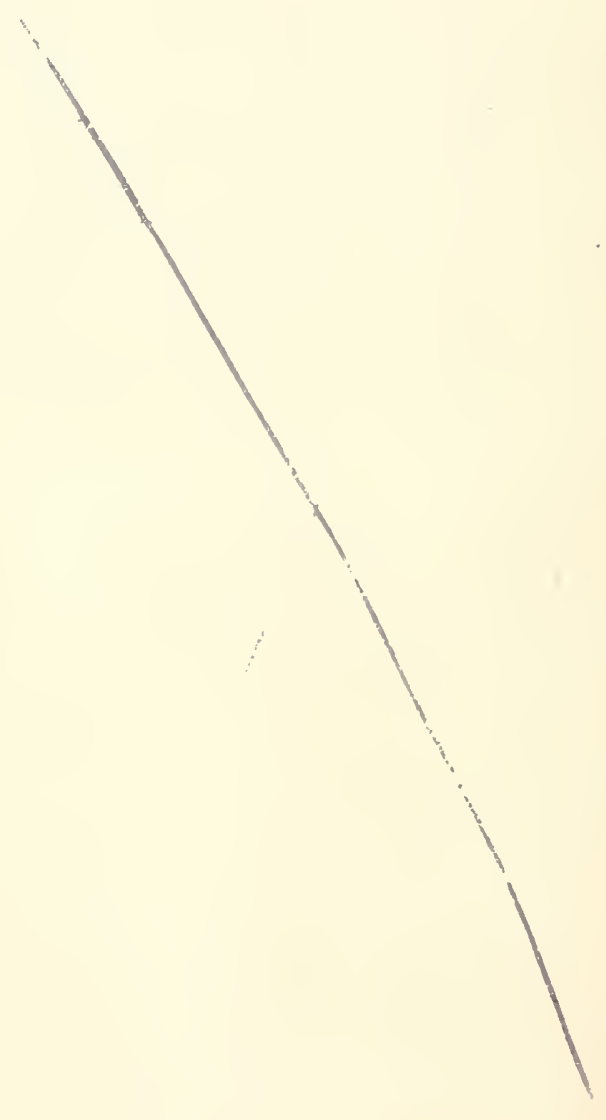






QL 196 N5m rork tolanical Garden Lidrary

Thumen Felix von/Die Pilze des Weinstoc

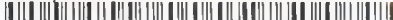

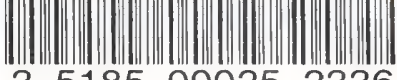

35185000252336 
